Thy National Library

of Canada

Canadian Theses Service

Ottawa, Canada

KIA ON4

\section{Bibliothèque nationale}

du Canada

Service des thèses canadiennes

\section{INOTICE}

The quality of this microtorm is heavily dependent upon the quality of the original thesis submitted for microfilming. Every elfort has been made to ensure the highest quality of reproduction possible.

If pages are missing, contact the university which granted the degree.

Some pages may have indistinct print especially if the original pages were typed with a poor typewriter ribbon or if the university sent us an inferior photocopy.

Reproduction in full or in part of this microform is governed by the Canadian Copyright Act, R.S.C. 1970, C. C-30, and subsequent amendments.

\begin{abstract}
AVIS
La qualité de cette microforme dépend grandement de la qualité de la thèse soumise au microlilmage. Nous avons tout fait pour assurer une qualité supérieure de reproduc. tion.
\end{abstract}

S'il manque des page's, veuillez communiquer avec l'université qui a contéré le grade.

La qualité d'impression de sertaines pages peut laisser à désirer, surtout si les pages originales ont été dactylogra. phicées à l'aide d'un nuban usé ou si l'université nous a fait parvenir une photocopie de qualité inlérieure.

La reproduction, méme partielle, de ceite microforme est soumise à la Loi canadienne sur le droit d'auteur, SRC 1970, c. C.30, et ses amendements subséquents. 


\title{
TREATMENT OF OILY WATERS USING PEAT
}

\author{
A Thesis \\ Submitted to the Faculty of Graduate Studies and Research \\ In Partial Fulfillment of the Requirements \\ for the Degree of \\ Doctor of Philosophy \\ in Civil Engineering \\ University of Regina \\ By \\ G. N. Mathavan \\ Regina, Saskatchewan \\ July 1990 \\ (C) Copyright 1990: G. N. Mathavan
}


The author has granted an irrevocable nonexclusive licence allowing the National Library of Canada to reproduce, loan, distribute or sell copies of his/her thesis by any means and in any form or format, making this thesis available to interested persons.

The author retains ownership of the copyright in his/her thesis. Neither the thesis nor substantial extracts from it may be printed or otherwise reproduced without his/her permission.
L'auteur a accordé une licence irrévocable et non exclusive permettant à la Bibliothèque nationale du Canada te reproduire, prêter. distribuer ou vendre des copies de sa thèse de quelque manière et sous quelque forme que ce soit pour meitre des exemplaires de cette thèse à la disposition des personnes intéressées.

L'auteur conserve la proprièté du droit d'auteur qui protège sa thèse. Ni la thèse ni des extraits substantiels de celle-ci ne doivent être imprimés ou autrement reproduits sans son autorisation.

\section{ISBN $\quad 0-315-70330-x$}

\section{Canad'ä}




\section{EACULTY OE GRADUATE STUDIES AND RASEARCH}

\section{CERTIEICATION OF THESIS WORK}

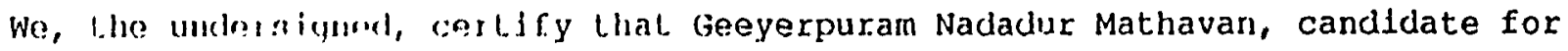
the Degree of leriour of Philosophy has presented a thesis on treatment of oily watch ming poat, that the thesis is acceptable in form and content, and that the stoudent demonstrated a satisfactory knowledge of the fleld covered by the thesis in an oral examination held on september 25, 1990.

Fixternal Fixamines:

Inlernal Examinns:
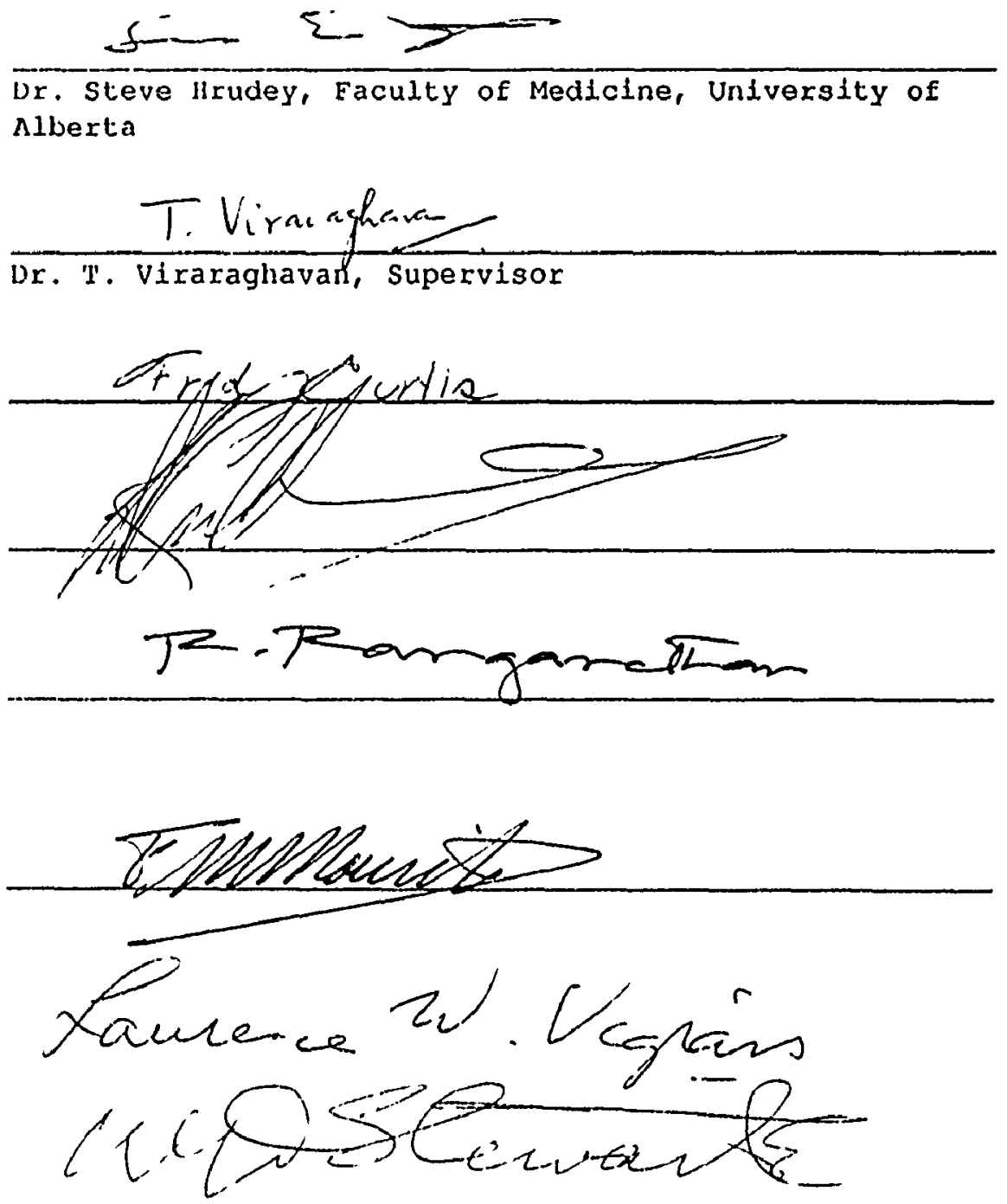
UNIVERSITX OF REGINA

EACUITY OF GRADUA:IE STUDIES AND RESEARCH

PERAISSION TO USE POSTGRADUATE THESES

TITLE OE THESIS: Treatment of oily waters using peat

NAME OF AUTHOR: Geeyerpuram Nadadur Mathavan

EACULTY: $\quad$ Faculty of Graduate Studies and Research

DEGREE: $\quad$ Doctor of Philosophy

In presenting this thesis in partial fulfillment of the requirements for a postgraduate degree from the University of Regina, I agree that the Libraries of this University shall make it freely available for inspection. I further agree that permission for extensive copying of this thesis for scholarly purposes may be granted by the professor or professors who supervised my thesis work, or in their absence, by the Head of the Department or the Dean of the Faculty in which my thesis work was done. It is understood that any copying, publication or use of this thesis or parts thereof for financial gain shall not be allowed without my written permission. It is also understood that due recognition shall be given tc me and to the university of Regina in any scholarly use which may be made of my material in my thesis.

SIGNATURE :

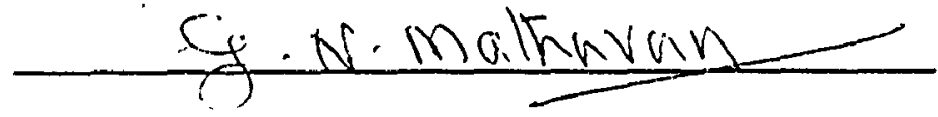

DATE :

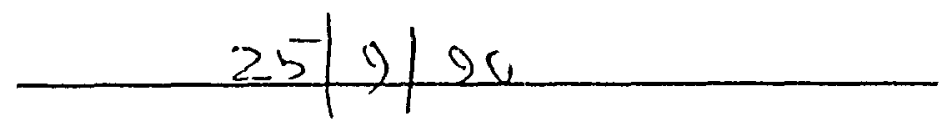


To my

Parents and Teachers

Reproduced with permission of the copyright owner. Further reproduction prohibited without permission. 


\section{Abstract}

This study attempts to identify the potential and limitations of using horticultural peat produced in Saskatchewan in treating five representative oil-in-water emulsions through a series of batch and continuous column studies. The adsorption of oil was described by the well-known BET, Langmuir and Freundlich adsorption isotherms. In the column studies, the efficiency of oil removed depended on the type of oil-in-water emulsion and the flow rate. While mechanically prepared emulsions showed higher removal efficiencies (up to 99 percent), it was difficult to treat chemically stabilized emulsions (greater than 40 percent removal).

Methods to enhance the oil-binding and oil-adsorption capacities of the horticultural peat were studied along with their relative oil removal efficiencies in comparison to other commercial media. Generally, acid treatment, wet heating and oven drying, and pyrolysis at different temperatures were found to be effective pretreatment options for enhancing the oil-adsorption capacity of the horticultural peat.

While identifying the breakdown mechanisms of oil-in-water emulsions in a peat bed, a sequential action of filtration and coalescence was observed. The fibrous peat induced coalescence up to a maximum of 14 percent at initial depths. Ilowever, it dropped down to 3 percent at greater depths due to the capture of oil drops in the bed. The characteristics of two-phase flow were identified and the headloss across the 
peat bed was predicted using the well-established Carman-Kozeny filtration equation. The batch and column tests results showed that adsorption to be one of important mechanisms involved in oil removal in a peat bed.

Preliminary studies on bacterial growth in a peat bed and its effect on oil removal are not conclusive as the studies were of a short duration. Long-tern. studies are needed to assess the potential of biological activity in a peat bed and its effect on oil removal.

The options available for environmentally acceptable disposal of oil-sorbed peat and their relative merits and demerits were identified. Due to the increased calorific value of oil-sorbed peat, it can be used as a secondary fuel. The oil-sorbed peat can also he squeezed to recover waste oil and it will be environmentally more acceptable to dispose of oil-squeezed peat in a landfill or use it for land cultivation. 


\section{Acknowledgements}

I am greatly indebted to Professor Dr. T. Viraraghavan, for his guidance and encouragement extended throughout the course of this work. I wish to express my gratitude to the dissertation committee members Dr. W. B. H. Cooke, Dr. D. R. Cullimore, Professor F. A. Curtis, Dr. F. Mourits, Dr. R. Ranganathan, Dr. D. Stewart and Dr. L. W. Vigrass for the scrutiny and valuable suggestions towards the completion of the thesis.

I acknowledge the Calgon Carbon Inc., Canada, Fiberglas Canada Inc., Filterfab Inc., Canada, Rohm and Hass Canada Inc., and Prairie Coal Ltd., Saskatchewan for the free supply of their products used in the experiments. I also thank the Saskatchewan Research Council (Petroleum Division), for providing Midale crude oil and produced water samples used in the investigation.

I wish to specially thank the Saskatchewan Research Council (Petroleum Division), Regina; Mr. D. R. Andrews, Technical Services and Research, SaskPower, Regina; Dr. B. Kybett, Director, Energy Research, University of Regina; Dr. Cullimorc, Director, Regina Water Institute, University of Regina; Dr. D. Chandler, Ilead Department of Chemistry, University of Regina, for permitling the liberal use of their laboratory facilities.

I als , thank the Department of Chemical Engineering, Department of Biology, 
University of Saskatoon, for the analyses of peat samples carried out. I wish to acknowledge the help and appreciate the understanding of Mr. D. Milton, in carrying out the experiments. I also wish to thank Mr. Harald Berwald, for the timely and meticulons work of fatricating the experimental columns and other apparatus used in the experiments.

I sincerely thank the Province of Saskatchewan, for the financial support extended through summer scholarships. I also wish to thank the Graduate Studies and Research, University of Regina, for the liberal financial support through teaching assistantships. I appreciate and thank the Petroleurn Society of CIM (South Saskatchewan Section) for the financial support.

I acknowledge the help received from Dr. Vasu Nambudiri, Mr. Awadesh Kumar Singh and Mr. Abimbola Abiola. I thank Dr. Spyros Pavlostathis and Mr. Zhuang, Pinz, Clarkson University, New York, U.S.A. for the support and help extended towards the completion of the thesis. Finally, I appreciate the patience and understanding of my wife Vaidehi, which deserves a very special mention. 


\section{Contents}

Abstract $\quad$ i

Acknowledgements $\quad$ iii

Table of Contents $\quad v$

List of Tables $\quad$ ix

List of Figures xiii

Notation $\quad$ xviii

1. INTRODUCTION 1

1.1 Rationale for Selecting Peat as a Medium for Treating Oily Wastes . 1

1.2 Objectives and Scope of the Study . . . . . . . . . . . . . 2

1.3 Treatment of Oily Wastes .................. 4

1.3.1 Terminology and classification of oily wastes ......... 4

1.3.2 Sources and quantity of waste generated ........... 6

1.3.3 Pollution effects of oily wastes and the need for treatment . . 10

1.3.4 Environmental legislation and existing treatment practices . . 11 
2.1 Classification and Properties of Emulsions . . . . . . . 19

2.2 Characteristics of Peat and its Use in Oil Removal . . . . . . . 27

2.2.1 Characteristics of peat $\ldots \ldots \ldots \ldots \ldots \ldots$

2.2 .2 Use of peat in oil removal $\ldots \ldots \ldots \ldots \ldots \ldots$

2.3 Batch Adsorption and Desorption Isotherms . . . . . . . . . 42

2.4 Breakdown Mechanisms $\ldots \ldots \ldots \ldots \ldots \ldots$

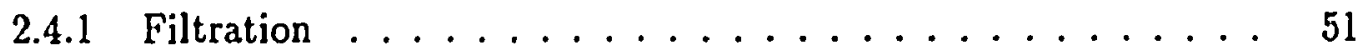

2.4 .2 Coalescence $\ldots \ldots \ldots \ldots \ldots \ldots \ldots \ldots$

2.4 .3 Adsorption $\ldots \ldots \ldots \ldots \ldots \ldots \ldots \ldots \ldots \ldots \ldots \ldots \ldots \ldots$

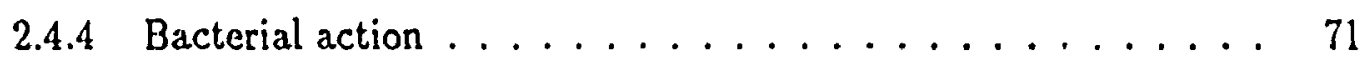

2.5 Reuse and Disposal of Oil-sorbed Peat $\ldots \ldots \ldots \ldots 75$

3. MATERIALS AND METHODS 82

3.1 Materials ...................... 82

3.1.1 Selection and preparation of oil-in-water emulsions . . . . 82

3.1.2 Peat, pretreated peat and other media considered . . . . 85

3.1.3 Characterization of oil-in-water emulsions and peat samples . 88

3.2 Methods . . . . . . . . . . . . . . . . . . 95

3.2.1 Analytical procedure for oil measurement . . . . . . . . 95

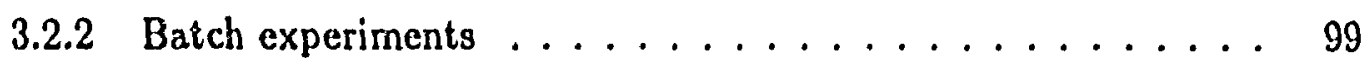

3.2.3 Adsorption and desorption $\ldots \ldots \ldots \ldots \ldots 102$

3.2.4 Column experiments $\ldots \ldots \ldots \ldots \ldots$

3.2.5 Breakdown mechanisms ............. 106

3.2 .6 Bacterial activity . . . . . . . . . . 108

$\mathrm{vi}$ 
4.1 Characteristics of Materials Used . . . . . . . . . . . . . 113

4.1.1 Peat, pretreated peat and other media . . . . . . . 113

4.1 .2 Oil-in-water emulnions $\ldots \ldots \ldots \ldots \ldots$

4.1.3 Analytical methods for oil measurement $\ldots \ldots \ldots \ldots 128$

4.2 Batch Tests . . . . . . . . . . . . . . . . . 128

4.2 .1 Horticultural peat . . . . . . . . . . . . 128

4.2 .2 Pretreated peat . . . . . . . . . . . 152

4.3 Column Tests . . . . . . . . . . . . . 165

4.3.1 Eight-hour tests with peat $\ldots \ldots \ldots \ldots \ldots$

4.3.2 Eight-hour tests with other media . . . . . . . . 174

4.3.3 Breakthrough studies with horticultural peat . . . . . . 180

4.3.4 Reuse and disposal of oil-sorbed peat . . . . . . . . . 202

4.4 Breakdown Mechanisms . . . . . . . . . . . . 212

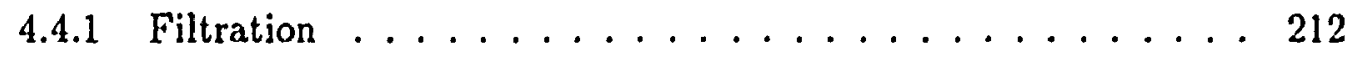

4.4 .2 Coalescence . . . . . . . . . . . . . . . 221

4.4 .3 Adsorption $\ldots \ldots \ldots \ldots \ldots \ldots \ldots \ldots \ldots$

4.4.4 Bacterial activity . . . . . . . . . . . 231

4.5 General Discussion . . . . . . . . . . . . . . . . . . 241

5. SUMMARY AND CONCLUSION 245

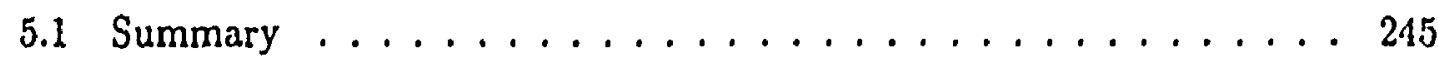

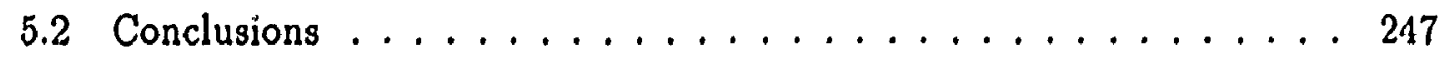

5.3 Practical Application of the Research . . . . . . . . . 250

5.4 Recommendations for Further Study . . . . . . . . . 25:5 
Appendix A. Concentrations of oily materials in industrial wastewaters 280

Appendix B. Photographs of peat samples and oil-in-water $\epsilon$ ¿nulsions $\mathbf{2 8 2}$

Appendix C. Design of batch adsorber system

Appendix D. Design of column adsoriver system

Appendix E. Cost of reuse and replacing options for the oil-sorbed peat and bacterial degradation of oil

Appendix F. Raw data 


\section{List of Tables}

1.1 Industrial sources and concentrations of oily wastes (Patterson 1975 and 1985$) \ldots \ldots \ldots \ldots \ldots \ldots \ldots \ldots \ldots \ldots \ldots \ldots \ldots \ldots \ldots \ldots \ldots$

1.2 Maximum allowable oil and grease discharge from Canadian refineries (Environment Canada 1987). . . . . . . . . . . . . . . 13

1.3 Allowable oil concentration for discharge into a water body in different countries (Blokker 1971 and Forster et al. 1973). . . . . . . . 14

1.4 Influent oil concentration limits for different treatment processes (Pereda

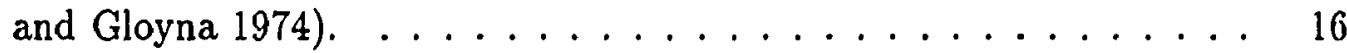

1.5 Effluent oil concentrations after treatment of municipal wastewater by different treatment processes (Gray 1975) . . . . . . . . 18

2.1 Classification of emulsion types (Tadros and Vincent 1983). . . . . 20

2.2 Six major classes of emulsions (Lissant 1977). . . . . . . . . . 21

2.3 Zeta potential as an indicator of dispersion stability (Hrudey and Kok

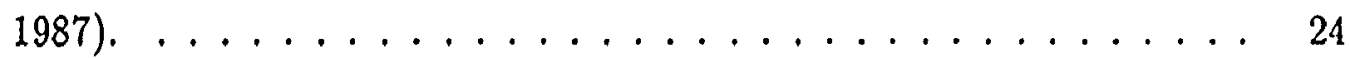

2.4 Classification of emulsions based on drop diameter . . . . . . . . . . 26

2.5 Elemental composition of peat (weight percent of dry matter) (Fuchs$\operatorname{man} 1980) \ldots \ldots \ldots \ldots \ldots \ldots$ 
2.6 Classification of peat according to generic origin and fiber content

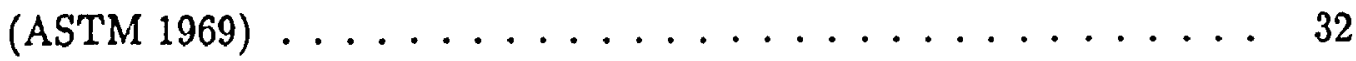

2.7 Salient features of physical and chemical adsorption (Ruthven 1984) . 48

2.8 Advantages and disadvantages of landfilling (US EPA 1980) $\ldots$. . . 77

3.1 Details of test methods for comparing the measurement of oil . . . 100

4.1 Characteristics of horticultural peat .............. 114

4.2 Characteristics of pretreated peat ............... 115

4.3 Characteristics of pretreated peat ............... 116

4.4 Comparison of oil-binding capacities of Finnish and Saskatchewan peats under different pyrolysis temperatures . . . . . . . . . . 118

4.5 Surface area, CEC and oil-binding capacities of different peats . . . 120

4.6 Surface area of peat samples . . . . . . . . . . . . . . 121

4.7 Characteristics of the media used in the experiments for comparison

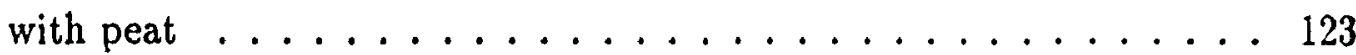

4.8 Characteristics of oils used in the experiments . . . . . . . . . 124

4.9 Characteristics of two solvents used for extracting oil from oil-in-water

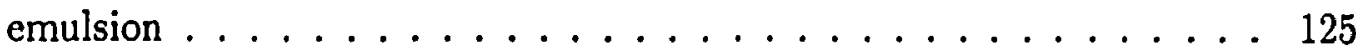

4.10 Characteristics of two produced water samples used in the experiments 126

4.11 Results of emulsion classification based on a typical analysis of diameter of oil droplets ......................... 127

4.12 Observed oil concentration for different methods using SMO . . . . 129

4.13 Observed oil concentration for different methods using MCO . . . 130

4.14 Statistical parameters for the differences in oil concentration from stan-

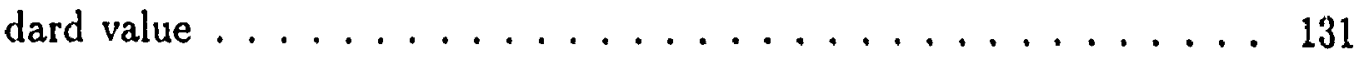


4.15 Oil removal efficiencies using horticultural peat from batch kinetic studies 140

4.16 Regression equations for the Langmuir and Freundlich isotherms . . 142

4.17 Statistical analyses for the BET isotherm . . . . . . . . . . 143

4.18 Number of molecular layers for the BET adsorption of oil by herticultural peat . . . . . . . . . . . . . . . . . 149

4.19 Statistical analyses for the Langmuir and the Freundlich isotherm equations $\ldots \ldots \ldots \ldots \ldots \ldots \ldots \ldots \ldots \ldots \ldots$

4.20 Isotherm constants for horticultural peat and emulsions . . . . . . 154

4.21 Results of the regression analysis for the adsorption of SMO onto pretreated peat samples $\ldots \ldots \ldots \ldots \ldots \ldots \ldots$

4.22 Adsorption isotherms for pretreated peat with SMO . . . . . . 156

4.23 Predicted Oil adsorption capacity of peat sample with SMO $\ldots \ldots 160$

4.24 Results of the regression equations for the adsorption of $\mathrm{CO}$ onto peat sample . . . . . . . . . . . . . . . . . . 161

4.25 Adsorption isotherms for the pretreated peat and $\mathrm{CO} \ldots \ldots . \ldots 162$

4.26 Predicted Oil adsorption capacity for peat samples with CO . . . 166

4.27 Results of eight-hour column studies $\ldots \ldots \ldots \ldots$. . . . . 173

4.28 Statistical parameters for Thomas equation . . . . . . . . . . . 191

4.29 Values of Thomas constants . . . . . . . . . . . . . . . . 192

4.30 Comparison of $\frac{x}{m}$ values from column breakthrough studies . . . . . 194

4.31 Statistical details for the linearized plots for the uptake of oil by horticultural peat . . . . . . . . . . . . . . 201

4.32 Summary of column test results for backwashing . . . . . . . . . . 203

4.33 Calorific values of different peat samples and other materials . . . . 204

$x i$ 


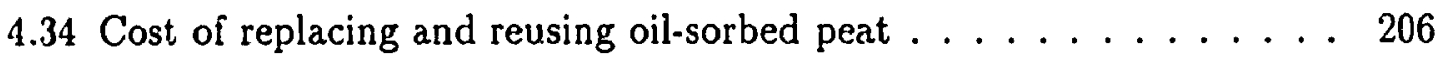

4.35 Values of Shape factor $\left(k_{o}\right)$ for different shapes (Carman 1956) . . . 219

4.36 Specific surface $\left(S_{\circ}\right)$ for different fibrous materials (Carman 1956) . 220

4.37 Measured and predicted head-losses across peat bed for a two-phase flow (oil-in-water emulsion) . . . . . . . . . . . . . 222

4.38 Results of coalescence experiments $\ldots \ldots \ldots \ldots \ldots \ldots$

4.38 Contd.... . . . . . . . . . . . . . . . . . . 227

4.39 Batch adsorption results for SMO (chemically emulsified) and peat . . 232

4.40 Total Bacterial Counts (One reactor, two media) . . . . . . . 233

4.41 Total bacterial colonies (three reactors) $\ldots \ldots \ldots \ldots . \ldots 237$

5.1 Peat required to treat $150 \mathrm{~m}^{3} / \mathrm{d}(39700 \mathrm{gpd})$ in batch adsorption system 252

5.2 Results of the scale-up and kinetic design of a continuous column adsorber for treating $150 \mathrm{~m}^{3}(39700 \mathrm{gpd})$ of wastewater flow $\ldots \ldots 254$

A.1 Concentrations of oily materials in various industrial wastewaters (Pat-

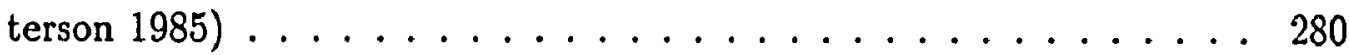

xii 


\section{List of Figures}

1.1 Treatment options based on the diameter of oil droplets in the influent (Rhee et al. 1987). . . . . . . . . . . . . . 17

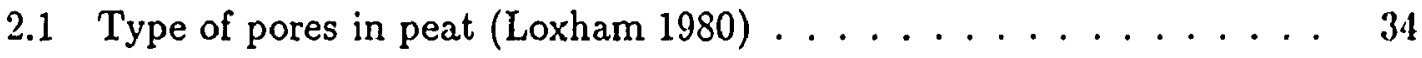

2.2 Shapes of isotherms (Weber and Chakravorti 1974) . . . . . . 46

3.1 Apparatus for pressing the oil-sorbed peat samples . . . . . . . . 94

3.2 Column arrangement . . . . . . . . . . . . . . . . . . 104

3.3 Column arrangements for a study of the breakdown mechanisms . . 107

3.4 Column arrangement for the bacterial studies $\ldots \ldots \ldots \ldots$

3.5 Column arrangements for comparative bacterial studies . . . . . . 111

4.1 Calibration for the measurement of oil using SMO . . . . . . 132

4.2 Calibration for the measurement of oil using MCO . . . . . . 133

4.3 Equilibrium time for the adsorption of SMO by horticultural peat . . 134

4.4 Equilibrium time for the adsorption of MCO by horticultural peat . . 135

4.5 Equilibrium time for the adsorption of $\mathrm{CO}$ by horticultural peat . . 136

4.6 Equilibrium time for the adsorption of $\mathrm{RE}$ by horticultural peat . . 137

4.7 Equilibrium time for the adsorption of PW by horticultural peat . . 138

4.8 Interference of drained-peat with carbon tetrachloride solution . . . 141

4.9 BET isotherm for the adsorption of SMO by horticultural peat . . . 145

xiii 
4.10 BET isotherm for the adsorption of $\mathrm{MCO}$ by horticultural peat . . 146

4.11 BET isotherm for the adsorption of $\mathrm{CO}$ by horticultural peat . . . . 147

4.12 BET isotherm for the adsorption of RE by horticultural peat . . . 148

4.13 Langmuir isotherm for the adsorption of oil from PW by horticultural

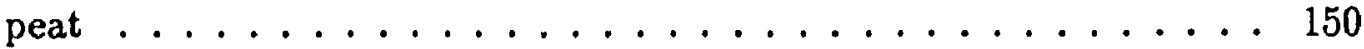

4.14 Freundlich isotherm for the adsorftion of oil from PW by horticultural

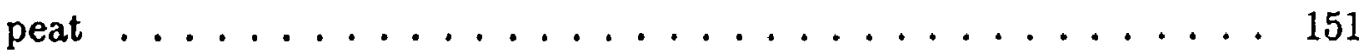

4.15 Predicted Langmuir and Freundlich adsorption of SMO by peat samples 157

4.16 Predicted BET adsorption of SMO by peal samples . . . . . . . 158

4.17 Predicted Langmuir and Freundlich adsorption of $\mathrm{CO}$ by pretreated

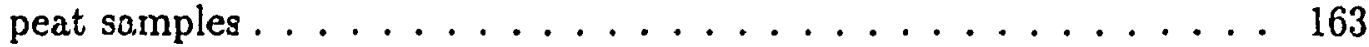

4.18 Predicted BET adsorption of $\mathrm{CO}$ by pretreated peat samples . . . . 164

4.19 Effluent oil concentrations from eight-hour run using SMO . . . . 168

4.20 Effluent oil concentrations from eight-hour run using MCO . . . . 169

4.21 Effluent oil concentrations from eight-hour run using $\mathrm{CO} \ldots 170$

4.22 Effluent oil concentrations from eight-hour run using RE . . . . . 171

4.23 Effluent oil concentrations from eight-hour run using PW . . . . . . . 172

4.24 Effluent oil concentrations from eight-hour column tests using SMO emulsion ............................... 175

4.25 Average percentage of oil removed from eight-hour column tests using SMO emulsion . . . . . . . . . . . . . . . 176

4.26 Effluent oil concentrations from eight-hour column tests using $\mathrm{CO}$

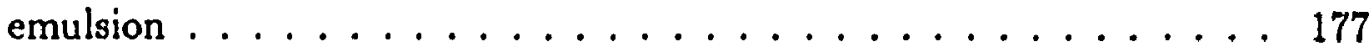

xiv 
4.27 Average percentage of oil removed from eight-hour column tests using $\mathrm{CO}$ emulsion . . . . . . . . . . . . . . . . 178

4.28 Comparative oil removal efficiencies for SMO and CO emulsions . . . 179

4.29 Breakthrough curve for SMO and horticultural peat . . . . . . 181

4.30 Breaktl rough curve for $\mathrm{MCO}$ and horticultural peat . . . . . . . 182

4.31 Breakthrough curve for $\mathrm{CO}$ and horticultural peat . . . . . . . 183

4.32 Breakthrough curve for $\mathrm{RE}$ and horticultural peat . . . . . . . 184

4.33 Breakthrough curve for $\mathrm{PW}$ and horticultural peat $\ldots \ldots \ldots \ldots$

4.34 Linearized Thomas plot for SMO . . . . . . . . . . . . 186

4.35 Linearized Thomas plot for MCO . . . . . . . . . . . . . . 187

4.36 Linearized Thomas plot for $\mathrm{CO} \ldots \ldots \ldots \ldots$

4.37 Linearized Thomas plot for $\mathrm{RE} \ldots \ldots \ldots \ldots$

4.38 Linearized Thomas plot for PW . . . . . . . . . . . . 190

4.39 Shapes of breakthrough curves (Weber and Chakravorti 1974) . . 195

4.40 Uptake of SMO by horticultural peat . . . . . . . . . . . 196

4.41 Uptake of MCO by horticultural peat . . . . . . . . . . 197

4.42 Uptake of $\mathrm{CO}$ by horticultural peat . . . . . . . . . . . 198

4.43 Uptake of oil from RE by horticultural peat . . . . . . . . . 199

4.44 Uptake of oil from PW by horticultural peat . . . . . . . . . . 200

4.45 Applied pressure vs SMO released . . . . . . . . . . . . . 208

4.46 Applied pressure vs $\mathrm{MCO}$ released . . . . . . . . . . . . . . 209

4.47 Applied pressure vs $\mathrm{CO}$ released . . . . . . . . . . . . 210

4.48 Applied pressure vs amount of oil released for three oil samples at 30 minutes duration $\ldots \ldots \ldots \ldots \ldots \ldots \ldots \ldots \ldots$ 
4.49 Plot of single-phase pressure drop . . . . . . . . . . . 213

4.50 Linearized plot of single-phase pressure drop . . . . . . . . . . 214

4.51 Variation of $k_{1}$ with void fraction for various shapes (Aker3 and Ward 1977) . . . . . . . . . . . . . . . . 215

4.52 Experimental variation of Kozeny constant with total porosity for assemblies of fibers and cylinders (Rushton and Griffiths 1977) . . . 216

4.53 Friction factor plot . . . . . . . . . . . . . . . . . . 224

4.54 Coalescence efficiency versus Reynolds number . . . . . . . . . 228

4.55 Coalescence efficiency vs Reynolds number (Sherony et al. 1978) . . 230

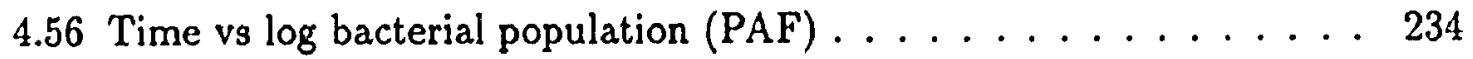

4.57 Time vs $\log$ bacterial population $\left(\mathrm{BH}_{4}\right) \ldots \ldots \ldots \ldots \ldots$

4.58 Time vs $\log$ bacterial population for reactor $\mathrm{R} 1$ and $\mathrm{R} 2 \ldots \ldots 238$

4.59 Time vs $\log$ bacterial population for reactor $\mathrm{R} 1$ and $\mathrm{R} 3 \ldots \ldots . . .239$

4.60 Time vs $\log$ bacterial population for teactor $\mathrm{R} 2$ and $\mathrm{R3} \ldots \ldots . . .240$

B.1 Typical pore structure of a Sphagnum peat moss . . . . . . . . . . 282

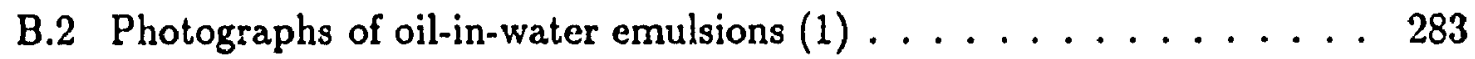

B.3 Photographs of oil-in-water emulsions (2) . . . . . . . . 284

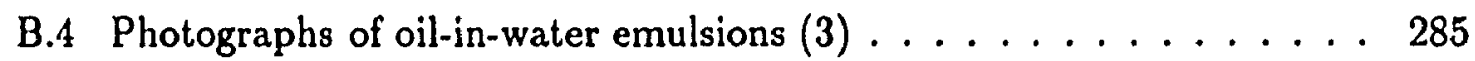

B.5 Photographs of contact angle between horticultutal peat and oils . . 286

B.6 Photographs of pretreated peat samples (1) . . . . . . . . 287

B.7 Photographs of pretreated peat samples (2) $\ldots \ldots \ldots \ldots$

B.8 Photographs of pretreated peat samples (3) . . . . . . . . . . . 289

B.9 Photographs of pretreated peat samples (4) . . . . . . . . . 290

B.10 Photographs of pretreated peat samples (5) . . . . . . . . 291

xvi 
B.11 Photographs of pretreated peat samples $(6) \ldots \ldots . \ldots 292$

B.12 Photographs of pretreated peat samples $(7) \ldots \ldots . \ldots 293$

B.13 Photograph of the apparatus used for sqeezing oil-sorbed peat . . . . 294

xvii 


\title{
Notation
}

\author{
A \\ a constant in equation 2.5 \\ abs \\ absolute unit \\ $\mathrm{AC}$ \\ activated carbon \\ ACID \\ acid (sulfuric) treated peat \\ AEEP \\ Association of Environmental Engineering Professors \\ ALKALI \\ alkali (sodium hydroxide) treated peat \\ APHA \\ American Public Health Association \\ A.PI \\ American Petroleum Institute \\ ASTM \\ American Society for Testing and Materials \\ $A_{0} A_{1} A_{2} A_{3}$ and $A_{4}$ constants in equations 2.18 and 2.25 \\ a \\ a constant in equation 2.2 \\ $a_{p}$ \\ a constant in equation 2.1 \\ $B_{i}$ \\ Biot number \\ $B_{0}$ \\ specific permeability coefficient \\ BDST \\ bed depth service time \\ BET \\ Brunauer, Emmett and Teller isotherm \\ BOD \\ biochemical oxygen demand, $5 \mathrm{~d}, 20^{\circ} \mathrm{C}$ \\ $\mathrm{BH}_{4}$ \\ a medium used in bacterialogical study \\ BTU \\ British thermal unit \\ b \\ a constant in equation 2.2 \\ barrels \\ a volumetric unit for crude oil production \\ $\mathrm{C}$ \\ concentration of solute in solution in equilibrium
}

xviii 


$\begin{array}{ll}\mathrm{C}_{0} & \text { initial concentration of solute } \\ \mathrm{C}_{e} & \text { concentration of solute in solution in equilibrium } \\ \mathrm{C}_{0} & \text { saturation concentration of solute } \\ { }^{\circ} \mathrm{C} & \text { degree centigrade } \\ \mathrm{CEC} & \text { cation exchange capacity } \\ \mathrm{CO} & \text { cutting oil } \\ \mathrm{CPI} & \text { central plate interceptor } \\ D & \text { diameter of the adsorbent } \\ \mathrm{DAF} & \text { dissolved air flotation } \\ D_{g} & \text { solute distribution parameter or partition cocficient } \\ D_{l} & \text { liquid-phase diffusivity } \\ D_{s} & \text { surface diffusion coefficient } \\ d_{f} & \text { fiber diameter } \\ d_{i} & \text { average particle size distribution } \\ E B C T_{\text {actual }} & \text { actual empty bed contact time } \\ E B C T_{\text {min }} & \text { minimum empty bed contact time } \\ \mathrm{FG} & \text { fiber glass } \\ g_{c} & \text { acceleration due to gravity } \\ \mathrm{gPd} & \text { gallons per day } \\ \mathrm{h} & \text { hour } \\ \text { ha } & \text { hectare } \\ \mathrm{HORT} & \text { horticultural peat } \\ \mathrm{HSDM} & \text { homogeneous surface diffusion model } \\ \mathrm{IPR} & \text { internal phase ratio } \\ \mathrm{IR} & \text { infra-red } \\ \mathrm{J} / \mathrm{mol} & \text { Joule per mole } \\ k & \text { a constant in equations } 2.4,2.7,2.16 \text { and } 2.17 \\ \mathrm{kPa} & \text { kiloPascal, a unit of pressure } \\ k_{0} & \text { shape factor } \\ \end{array}$


$k_{1} \quad$ Carman-Kozeny constant in single-phase flow

$k_{2} \quad$ Carman-Kozeny constant in two-phase flow

$k_{e} \quad$ mean reaction rate coefficient (biological)

$k$ saturation constant

$k_{d} \quad$ a constant in equation 2.6

$k_{f}$ film transfer coefficient

$k_{r} \quad$ a constant in equation 2.8

$k_{y} \quad$ a constant in equation 2.1

L a unit of length, volume and thickness of filtering layer

$M$ molarity, mass

$\mathrm{m}$ weight of adsorbent

$\mathrm{mPa}$ Pascal, a unit of pressure

MCO Midale crude oil

MW molecular weight

$N$ normality

$N_{R_{\text {a }}} \quad$ Reynolds number

$n \quad$ a constant in equation 2.4

$n_{d} \quad$ a constant in equation 2.6

OD-1 oven dried $\left(103^{\circ} \mathrm{C}\right.$ for one day) peat

OD-3 oven dried $\left(103^{\circ} \mathrm{C}\right.$ for three days) peat

$\circ / w$ oil-in-water emulsion

$\mathrm{Pa} \quad$ Pascal, a unit of pressure

PAF a medium used in bacteriological study

PP polypropylene

ppm parts per million

psig pounds per square inch (gauge pressure)

PW produced water

P150 pyrolyzed $\left(150^{\circ} \mathrm{C}\right)$ peat

P175 pyrolyzed $\left(175^{\circ} \mathrm{C}\right)$ peat 
P200 pyrolyzed $\left(200^{\circ} \mathrm{C}\right)$ peat

F.225 pyrolyzed $\left(225^{\circ} \mathrm{C}\right)$ peat

P250 pyrolyzed $\left(250^{\circ} \mathrm{C}\right)$ peat

P275 pyrolyzed $\left(275^{\circ} \mathrm{C}\right)$ peat

$\Delta P_{a} \quad$ pressure reduction in the layer containing sorbate

$\Delta P_{m}$ pressure reduction when starting filtration

$\Delta P_{1} \quad$ pressure drop in the bed for a single-phase flow

$\Delta P_{2} \quad$ pressure drop in the bed for a two-phase flow

$\mathrm{pH}$ hydrogen ion concentration

$Q \quad$ liquid flow rate

$q_{0} \quad$ maximum solid-phase concentration of the solute

$\mathrm{q}$ substrate utilization rate

$q_{m} \quad$ maximum specific substrate removal rate

$R \quad$ separation factor or equilibrium parameter in equation 2.3

$R \quad$ radius of the adsorbent

$R E$ refinery effluent

$R R C$ relative retention capacity

$r \quad$ compressibility constant in equation 2.8

$S$ Siemens, a unit of conductivity, and substrate concentration

$S_{c} \quad$ Schmidt number

SEM scanning electron microscope

SMO standard mineral oil

$S_{t} \quad$ Stanton number

$\bar{S}_{d} \quad$ average saturation

$\mathrm{T}$ single solute mass throughput

$T$ tortuosity factor in equation 4.2

$t$ a unit of time

TPI tilted plate interceptor

$t \quad$ elapsed time 


\begin{tabular}{|c|c|}
\hline$t_{\min }$ & minimum contact time \\
\hline $\bar{t}$ & dimensionless time \\
\hline$U_{t}$ & amount of sorbed substance \\
\hline V & volumetric flow rate \\
\hline $\mathrm{v}$ & flow-through volume, superficial velocity \\
\hline WH\&A & wet heated and air dried peat \\
\hline WH\&O & wet heated and oven dried $\left(103^{\circ} \mathrm{C}\right.$ for three days) peat \\
\hline$w / o$ & water-in-oil emulsion \\
\hline$X_{n i}$ & a constant in equation 2.5 \\
\hline $\mathrm{XAD}-2$ & a synthetic polystyrene macrorecticular resin adsorbent \\
\hline$x$ & mass of solute adsorbed \\
\hline$x_{d}$ & mass of solute desorbed \\
\hline $\mathrm{Y}$ & ratio of drop densities \\
\hline y & sorbate concentration of the filtrate \\
\hline Yo & sorbate concentration of the liquid to be filtered \\
\hline $\mathrm{y}_{\boldsymbol{x}}$ & sorbate concentration of water at equilibrium \\
\hline$\eta_{c}$ & the overall coalescence efficiency \\
\hline$\epsilon$ & porosity of fibrous bed in single-phase flow \\
\hline$\epsilon_{t}$ & porosity of fibrous bed in two-phase flow \\
\hline$\gamma$ & dynamic viscosity of the fluid \\
\hline$\phi$ & sphericity \\
\hline$\rho$ & bulk density of adsorbent in the fixed bed \\
\hline$\mu$ & kinematic viscosity of the fluid \\
\hline$\tau$ & empty bed contact time \\
\hline
\end{tabular}

xxii 


\section{INTRODUCTION}

\subsection{Rationale for Selecting Peat as a Medium for Treating Oily Wastes}

Several natural and synthetic media have been used for treating oily wastes. Depending upon the unit operation they can be classified as filtering media, coalescing media and adsorption media. Sand, coal, and diatomaceous earth have been studied as materials in filtration pro-esses. Fiberglass, amberlite XAD-2, polyesterfelt, and polypropylene have been studied for their effectiveness in coalescing oil from oily waters. Activated carbon has been studied extensively for its capacity to adsorb a variety of hydrocarbons from different oily waters. Peat is a potential medium for treating oily wastes due to its physical structure, chemical composition and known capacity to adsorb oil.

Peat may be gerie:ally defined as the product resulting from slow and partial decay of dead vegetation. It is usually formed in areas where water saturates or completcly covers the dead plant material that has accumulated on the ground. The water blocks the action of aerobic bacteria and greatly inhibits the rate of decay of the plant debris (Smith et al. 1980). Approximately 1.5 percent of the earth's surface is covered with peat while the largest deposits occur in the northern part of the northern hemisphere.

Canada and the U.S.S. R. account for approximately 80 percent of the world's total. Due to its abundant availability, peat is a relatively inexpensive medium to obtain. The application of peat in environmental pollution control has been reviewed by McLellan and Rock (1986), and Viraraghavan and Ayyaswami (1987). Only limited 
studies have been undertaken in the past related to its use in the treatment of oily wastes. Its use, however, for controlling marine oil spills has been patented as FINSORB in Europe (Belanger et al. 1988); and as OCLANSORB in Canada (Nicholson 1984). A systematic evaluation of peat's ability to treat different oily wastes, its limitations, and an explanation for the breakdown of oil-in-water emulsions in peat beds have not been attempted so far. Therefore, the present study was undertaken to determine the feasibility of using Saskatchewan's horticultural peat as a medium for treating different oily wastewaters normally encountered in industrial streams.

\subsection{Objectives and Scope of the Study}

The primary objectives of the study were as follows:

1. To assess the potential of Saskatchewan's horticultural peat as a medium for treating different oil-in-water emulsions under varying experimental conditions;

2. To examine the various physical and chemical pretreatment alternatives for the horticultural peat to increase its oil adsorption capacity;

3. To compare the oil removal capacities of the horticultural peat and pretreated peat with other commercially available materials;

4. To identify the various breakdown mechanisms involved in the removal of oil in the peat bed treating oil-in-water emulsions; and

5. To identify methods for reuse or disposal of the oil-sorbed peat.

The scope of the study included the following tasks: 
1. Literature review on the characteristics of peat, its use in oil removal, properties and classification of emılsions and various breakclown mechanisms involved in the oil removal processes;

2. Characterization of horticultural peat, pretreated peat and various oily wastewaters;

3. Batch kinetic and adsorption studies;

4. Eight-hour column studies at different flow rates;

5. Continuous column breakthrough studies;

6. Column experiments to identify various breakdown mechanisms such as filtration, coalescence, and adsorption that may occur in the peat bed in the breakdown of oil from oil-in-water emulsion;

7. Column studies to quantify the bacterial growth involved in the peat bed;

8. Physical and/or chemical pretreatment for the horticultural peat;

9. Batch and eight-hour column tests for evaluating the pretreatment alternatives and to compare the performances of peat with other media; and

10. Backwashing experiments and studies on the disposal options for the oil-sorbedpeat. 


\subsection{Treatment of Oily Wastes}

\subsubsection{Terminology and classification of oily wastes}

From the stage of its production, transportation, refining and use, oil can enter the environment and cause pollution. With burning of fuel, the resulting gases including unburnt hydrocarbons are discharged into the air and these can be washed back to the land through precipitation.

Oils can be crude, lubricating, petroleum or food fats. Oils also include light hydrocarbons such as gasoline and jet fuel, heavy hydrocarbon fuels and tars such as crude oils, diesel oils and asphalt, lubricants, and cutting fluids.

Crude oils are complex mixtures of hydrocarbons comprising three main chemical groups namely: paraffinic, naphthenic and aromatic. Crude oils range from simple volatile to complex waxes and asphalt with molecular weights ranging from 16 to over 20,000. Lubricating and petroleum oils vary in chemical and physical character depending on their origin and the refining processes.

Fats are found in both plants and animals and are one of the most important components of the human diet. Fats are mixtures of various triglycerides and have low and generally nonspecific melting points. A triglyceride at room temperature may be referred to as an oil (Waier Pollution Control Federation 1981).

Waxes are monohydroxylic alcohol esters of fatty acids. Waxes differ from fats and oils in being esters of long-chain normal primary alcohols. At room temperature, waxes are much harder than fats. When fat is boiled with sodium hydroxide, glycerine and sodium salts sucn as sodium palmitate, sodium stearate, sodium oleate and several other fatty acids in lesser proportions are formed. These sodium salts of fatty acids are called soap. Soaps are included in the analysis performed for oil and grease 
as they are extracted and measured as oil in the analytical procedure. Cutting oils are blends of fatty oils, mineral oils and tar.

Oil and grease may be present in water as an emulsion or as a light petroleum fraction in solution. Most heavy oils and greasy materials are insoluble in water, but may have been emulsified by contact with detergents, alkalies and other surfartant chemicals. Grease is not a name for a specific substance, but a general classification for grouping such materials as fats, oils, waxes and soaps. The term oil and grease includes materials from animal tissue, petroleum or compounds of petroleum as hydrocarbons and other materials extracted by specific solvents.

Oil and grease can be broadly characterized in three ways: (1) by polarity; (2) by biodegradability; and (3) by physical characteristics (Young 1979). Polar oils and greases are normaily derived from animal and vegetable materials typically found in food-processing wastewaters. Non-polar oils and greases are derived from petroleum or mineral sources. Most petroleum or mineral oils are biodegradable under circumstances of adequate nutrient supply and adequate physical access to the oil. Generally, polar oils are biodegradable while non-polar forms are considered bioresistant.

The American Petroleum Institute classified oily wastes into the following four groups (Patterson 1975):

(i) Light hydrocarbons: Include light fuels such as gasoline, kerosene and jet fuel and miscellaneous solvents used for industrial processing, degreasing or cleaning purposes.

(ii) Heavy hydrocarbon fuels and tars: Include heavy crude oils, diesei oils, No. 6 fuel oil, residual oils, slop oil, asphalt and road tar. 
(iii) Lubricants and cutting fluids: Oil lubricants generally fall into two classes: nonemulsifiable oils such as lubricating oils and greases and emulsifiable oils such as "water soluble" oils, rolling oils, cutting oils and drawing compounds. Emulsifiable oils may contain fat, soap, or various other additives.

(iv) Fats and fatty oils: Fats result from processing foods, natural products and animal flesh. Fatty oils for the most part originate from plant products. Quantities of fatty oils result from processing soyabeans, cottonseed, linseed, and corn.

\subsubsection{Sources and quantity of waste generated}

Oil continues to be one of the major sources of energy. Crude oil production in the world increased from 3.85 million barrels/year (200 million tonnes/year) in 1930 to 59.66 million barrels/year (3194 million tonnes/year) in 1989 (Oil and Gas 1990). Therefore, the potential for oil pollution has also increased substantially. Due to large scale transportation of oil by sea, there is considerable pollution on the marine environment due to oil spills. The total amount of oil which gets into the sea from all sources has been estimated as 3.7 million tonnes per year (Smith 1976b). The Ocean Affairs Board (1975) estimated the world-wide annual input of petroleum in to the marine environment to be 6.11 million tonnes. About 34 percent of this input was attributed to marine transportation. Other sources include: river and urban runoff 31 percent; coastal refineries, municipal and industrial waste 13 percent; natural seepage 10 percent; atmospheric input 10 percent and off-shore production 1.3 percent. In the Canadian marine environment, during 1978, over 1500 spills have been reported representing a total of about 20,000 tonnes of oil.

Oil pollution that occurs on land is mainly due to point source discharges from 
municipal and industrial units. The average concentration of oil in weak, medium and strong wastewater is reported to be 50,100 , and $150 \mathrm{mg} / \mathrm{L}$ respectively (Metcalf and Eddy 1979). The oil and grease may constitute about 20 percent of the organic matter measured as biochemical oxygen demand $\left(5 \mathrm{~d}, 20^{\circ} \mathrm{C}\right)(\mathrm{BOD})$ and may average 30 to $50 \mathrm{mg} / \mathrm{I}$ ( (Water Pollution Control Federation 1981). In a domestic wastewater sample containing $45 \mathrm{mg} / \mathrm{L}$ of oil and grease, over half the oil and grease was found to be colloidal and most of it was in the form of food fats and oil (Heukelekian and Balmat 1959).

Oil and grease in industrial wastewater may be derived from either mineral or food sources. Mineral oils may be derived from a varieiy of sources including service stations, car washes, laundries, oil refineries, machine shops, leaking underground storage tanks, steel mills, tanneries, drop forge plants and stormwater runoff.

Food fats and oils are discharged from commercial establishments and industries including meat packing plants, bakeries, rendering plants, focd manufacturers and restaurants.

Wastewater from industrial sources such as petroleum refineries, petroleum field operations, petrochemical plants, service stations, laundries and machine shops contain large quantities of free and/or emulsified oil. Of these, petroleum refincries discharge relatively large quantities of oily wastewaters. The average North American refinery discharges about 800 to 900 litres of wastewater per cubic metre of crude oil processed (US EPA 1974a). In 1983, there were 36 petroleum refineries in Canada with a total crude throughput of approximately 1.62 million barrels/day ( 0.23 million tonnes/day) (Environment Canada 1987)

Concentrations of oily materials in industrial wastewaters vary widely with the 
type of the industry. The ratio of the maximum to minimum concentration varied from 5 to 1 (Cavagnaro and Easzubowski 1988). Typical oil concentrations from various industrial sources are presented in Table A.1 (Patterson 1985; vide Appendix A); these oil concentrations show a wide variation. In the petroleum industry, the oily waste concentrations in the American Petroleum Institute (API) oil separator effluent may range from 10 to $7200 \mathrm{mg} / \mathrm{L}$. In the metal industry, two major sources of oily wastes are steel manufacturing and metal working. Rinse and coolant waters from cold rolling mills may contain several thousand $\mathrm{mg} / \mathrm{L}$ of oil, of which 25 percent or more may be emulsified and thus difficult to separate. Oily wastewaters from metalworking processes contain grinding oils, cutting oils and lubricating fluids; soluble and emulsified oil content of these wastewaters may vary from 100 to $5000 \mathrm{mg} / \mathrm{L}$.

Processing of meat, fish and poultry produces oil and fatty materials primarily during slaughtering, cleaning, rendering and by-product processing. The oil and grease content of these food processing industries generally range from 14 to 13,000 $\mathrm{mg} / \mathrm{L}$.

The total plant effluent oil concentrations reported (Table A.1) include both free and emulsified oil; these are not always indicative of the contaminant problem, because of dilution by other plant waste streams or intermittant discharges such as batch dumps leading to high values of oil and grease. The five major industrial sources of oily wastes classified by the American Petroleum Institute together with the typical oil concentrations are presented in Table 1.1. 
Table 1.1. Industrial sources and concentrations of oily wastes (Patterson 1975 and 1985).

\begin{tabular}{|c|c|c|}
\hline Industry & Waste character & $\begin{array}{l}\text { Typical oil } \\
\text { concentration } \\
\text { range }(\mathrm{mg} / \mathrm{L})\end{array}$ \\
\hline Petroleum & $\begin{array}{l}\text { Light and heavy oils resulting from producing, } \\
\text { refining, storage, transporting and retailing of } \\
\text { petroleum and petroleum products. }\end{array}$ & $10-7200 \dagger$ \\
\hline Metals & $\begin{array}{l}\text { Grinding, lubricating and cutting oils employed } \\
\text { in metal-working operations and rinsed from } \\
\text { metal parts in clean-up processes. }\end{array}$ & 100.5000 \\
\hline $\begin{array}{l}\text { Food } \\
\text { processing }\end{array}$ & $\begin{array}{l}\text { Natural fats and oils resulting from animal } \\
\text { and plant processing, including slaughtering, } \\
\text { cleaning and by-product processing }\end{array}$ & $14 \cdot 13700$ \\
\hline Textiles & $\begin{array}{l}\text { Oils and grease resulting from scouring of natural } \\
\text { fibers (wool, cotton etc.) }\end{array}$ & $21-12260$ \\
\hline $\begin{array}{l}\text { Cooling and } \\
\text { heating }\end{array}$ & $\begin{array}{l}\text { Dilute oil-containing cooling water, oil having leaked } \\
\text { from pumps, condensers, heat exchangers, etc. }\end{array}$ & 7.1200 \\
\hline
\end{tabular}

$\dagger$ API oil separator effluent 


\subsubsection{Pollution effects of oily wastes and the need for treat- ment}

The pollution aspects of oil-containing wastewater are complex because of the number of different types of oils involved and their diversity in physical-chemical composition and characteristics. In general, oil pollution impacts depend on the type of industry, the type of oil, the point of its formation in the process stream, its solubility in water, concentration, quantity, toxicity to a particular species, and the environmental significance of the discharge area. The presence of hydrocarbons even in the form of a monomolecular layer would partially cut off light and affect the normal oxygen transfer mechanisms. Depending upon the viscosity of the oil, approximately 150 to $2000 \mathrm{~kg}$ of hydrocarbons are sufficient to cover a lake of about one square kilometre in area (Yves 1982). Even a trace amount $(0.0008 \mathrm{mg} / \mathrm{L})$ of fuel oil in water can impart taste and odour problems.

Depending upon the environmental conditions, the presence of oil may causes toxicity to the soil and aquatic organisms. All oils and oil prolucts differ in toxicity to a particular species. Of the chemical compounds in oil, the water-soluble aromatics are generally considered to be more toxic as they are easily incorporated by aquatic organisms. The solubility of oil in water varies significantly with the type of oil and mixing conditions. For crude oils in a marine environment, the maximum solubility occurs in 2.5 to 9 days depending upon the type of oil (Environment Canada 1976a). The effect of toxicity may be lethal following a short-term damage or sublethal causing a long-term damage. Percy (1982) emphasized that the sublethal effects had more ecological significance than lethal effects. In general, light oils such as diesel fuel and gasoline cause more short-term damage, while some heavy crude oils may cause 
chronic toxic damage. In addition to this, cold climatic conditions in Canada pose problems because the behaviour of oil is interacted and complexed by the presence of ice in many forms (Environment Canada 1982). In general, oil-containing wastewaters may give rise to the following environmental problems and therefore require treatment for the removal of oil:

i. Formation of a thin layer on the top of the water body;

ii. Taste and odour problems;

iii. High chemical oxygen demand;

iv. Interference with biological activity; and

v. Toxicity to soil and aquatic organisms.

\subsubsection{Environmental legislation and existing treatment prac- tices}

In the marine environment (international waters), the authority for regulating oily discharges is vested with the Inter-government Maritime Consultative Organization. Under its regulations, oil may only be discharged at a rate of not more than about $33 \mathrm{l} \cdots, \mathrm{er} \mathrm{km}$ of travel. The discharge takes place while the ship is in motion and more than $80 \mathrm{~km}$ away from the shore (Smith 1983). In Canada, the oil pollution of the Canadian marine environment is regulated according to the Canadian Shipping Act 1971. The Act prohibits any discharge and makes the reporting of oil spills mandatory. The maximum fine for an oil discharge regardless of size is $\$ 100,000$. The Canada Shipping Act is administered by Transport Canada through the Canadian Coast Guard (Transport Canada 1980). 
There are numerous pretreatment standards and regulatory requirements for the discharge of oily wastewaters from industrial point sources located in land environments. These site-specific eiluent discharge regulations depend on the type of the industry, the quantity of waste generated and the environmental significance of the discharge area. Environment Canada (1976b) has established a discharge limit for oil and grease of $15 \mathrm{mg} / \mathrm{L}$ at federal establishments. At the provincial level, some provinces such as Ontario and Alberta have more stringent discharge requirements of $10 \mathrm{mg} / \mathrm{L}$ (Environment Canada 1987).

The Canadian Petroleum Refinery Effluent Regulations and Guidelines enforce a uniform national standard for oily discharges from petroleum refineries across Canada (Environment Canada 1987). The maximum allowable discharge of oil and grease, based on the crude oil process capacity, are presented in Table 1.2.

In the U.S. A., there are pretreatment limits for the discharge of oily waters from petroleum refineries. Accordingly, these refineries are required to pretreat their efluents to limit oil and grease concentration to $100 \mathrm{mg} / \mathrm{L}$ (US EPA 1982).

The discharge requirements for oily wastes into a water body in different countrics are summarized in Table 1.3. Apart from these pretreatment and discharge regulations, many industries are urged to recycle once-through process water for reuse in the plant. In petroleum field operations, very large quantities of water are produced during primary production as well as during enhanced production. Thesc produced water can be recycled if the water can be economically treated in-situ for oil removal. For steam flooding, an oil and grease concentration of less than $7 \mathrm{mg} / \mathrm{L}$ is allowed for use in the boilers to produce steam for injection. (Department of Energy, Mincs and Resources 1985). The primary treatment for the removal of oil involves the separation 
Table 1.2. Maximum allowable oil and grease discharge from Canadian refineries (Environment Canada 1987).

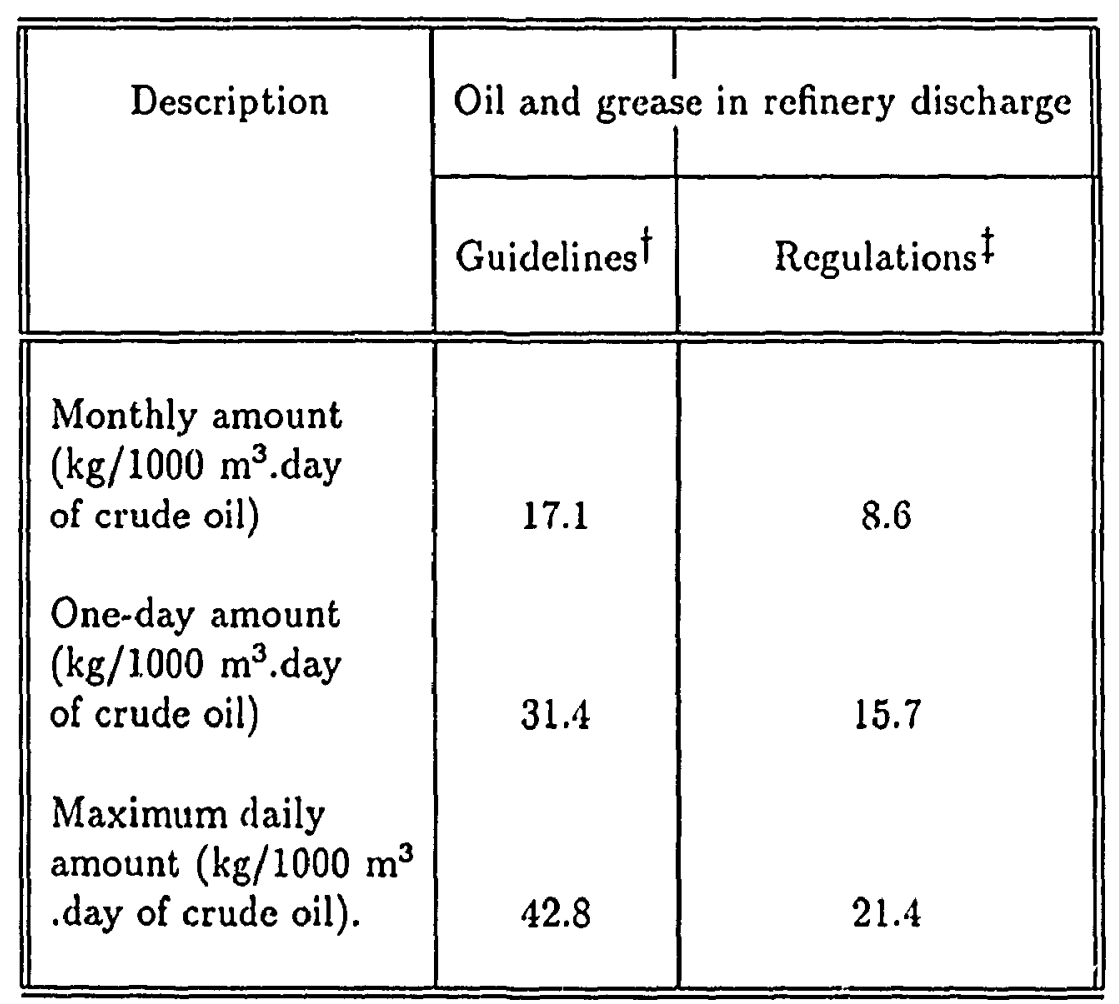

$\dagger$ Applicable to existing units

$\ddagger$ Applicable to new units 
Table 1.3. Allowable oil concentration for discharge into a water body in different countries (Blokker 1971 and Forster et al. 1973).

\begin{tabular}{||l|l|c||}
\hline \hline \multicolumn{1}{|c|}{ Waterbody } & Country & $\begin{array}{c}\text { Allowable oil concentration } \\
\text { (mg/L) }\end{array}$ \\
\hline Lake Ontario & Canada & 15 \\
River Rhone & Switzerland & 5 \\
River Rhine & Germany & $5-10$ \\
River Danube & Germany & $2-3$ \\
Galveston Bay & U.S. A. & 20 \\
Mississipi River & U.S. A. & 15 \\
Lake Erie & U.S. A. & 10 \\
New York harbour & U.S. A. & 1 \\
\hline \hline
\end{tabular}


of the floating (free and non-emulsified) oils and secondary treatment is then required to break the oil-in-water emulsion to separate the remaining oil and water. Conventionally, gravity separation, dissolved air flotation (DAF), multimedia filtration and chemical cnagulation are used for the removal of oil and grease. Induced coalescence through the use of porous/fibrous media has gained more attention recently as a potential treatment for oil removal. Carbon adsorption is very effective as a tertiary polishing technique for removing soluble oil. However, excessive oil tends to exhaust the adsorptive capacity of activated carbon rapidly. Therefore, the high operational cost makes this technique less attractive, unless adequate pretreatment is employed to reduce the dispersed oil content. Apart from activated carbon, several other natural and synthetic media can be used to remove oil by filtration, coalescence or adsorption. The selection of a particular treatment method depends on the type of oil-in-water emulsion, the influent oil concentration, and the required effluent oil concentration after treatment. Application limits for the selection of treatment processes based on the influent oil concentrations are presented in Table 1.4. Similar treatment options based on the diameter of oil droplets present in the influent are shown in Figure 1.1.

The typical effluent oil concentrations after treatment of municipal wastewater by different treatment processes are presented in Table 1.5. 
Table 1.4. Influent oil concentration limits for different treatment processes (Pereda and Gloyna 1974).

\begin{tabular}{||l|c||}
\hline \multicolumn{1}{|c|}{ Process } & $\begin{array}{c}\text { Application limit based on influent } \\
\text { oil conceritration (mg/L) }\end{array}$ \\
\hline \hline Gravity separators & $>150^{\dagger}$ \\
American petroleum institute (API) & $>150$ \\
Central plate interceptor (CPI) & $>73$ \\
Tilted plate interceptor (TPI) & \\
Dissolved air flotation & 200 to 90 \\
Full or partial pressurization & 200 to 15 \\
Chemical treatment recycle flow & 200 to 10 \\
Chemical treatment multi cell & \\
Coalescers & 150 to 10 \\
Granular media & 130 to 5 \\
Granular media with chemicals & 100 to 5 \\
Vacuum precoat filtration & 100 to 5 \\
Biological treatment & $<5$ \\
Activated carbon adsorption & \\
\hline \hline
\end{tabular}

$\dagger$ Oil concentrations $>80 \mathrm{mg} / \mathrm{L}$ are considered to be free oil and less than $80 \mathrm{mg} / \mathrm{L}$ are emulsified or soluble oil. 


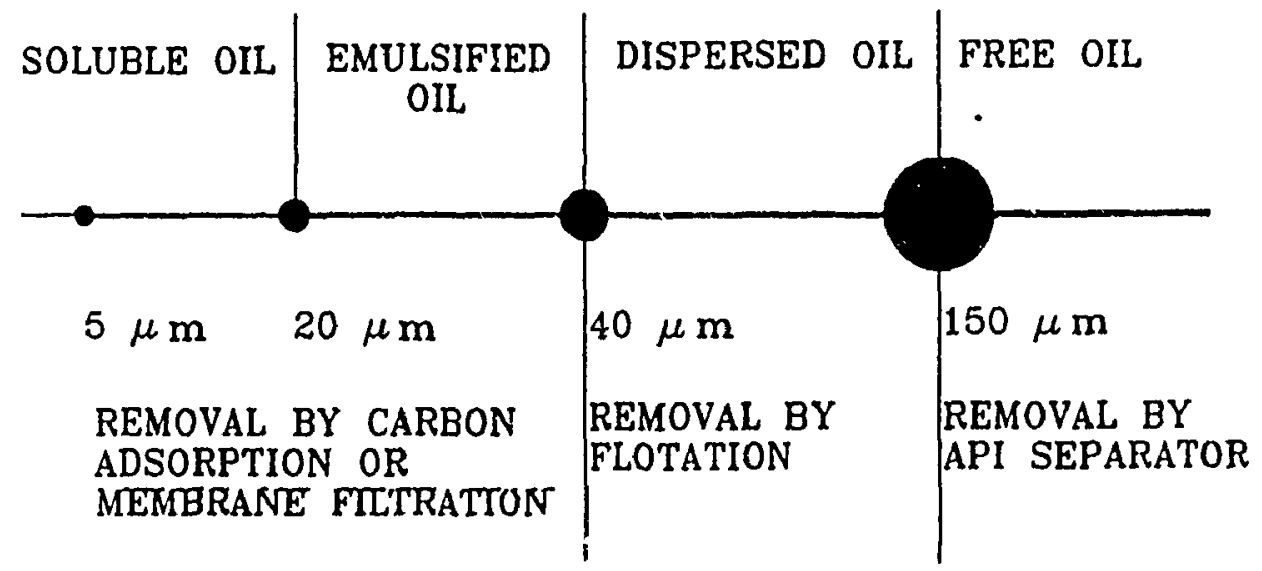

Figure 1.1. Treatment options based on the diameter of oil droplets in the influent (Rhee et al. 1987). 
Table 1.5. Effluent oil concentrations after treatment of municipal wastewater by different treatment processes (Gray 1975).

\begin{tabular}{|c|c|}
\hline Process & $\begin{array}{c}\text { Effluent oil } \\
\text { concentration }(\mathrm{mg} / \mathrm{L})\end{array}$ \\
\hline Aerated lagoon & 5 to 60 \\
\hline Stabilization pond & 5 to 50 \\
\hline Filtration & 5 to 50 \\
\hline Activated sludge & 5 to 40 \\
\hline Chemical coagulation and DAF & 5 to 30 \\
\hline $\begin{array}{l}\text { Filtration with activated } \\
\text { carbon adsorption }\end{array}$ & 2 to 30 \\
\hline $\begin{array}{l}\text { Chemical coagulation and } \\
\text { activated carbon adsorption }\end{array}$ & 2 to 20 \\
\hline $\begin{array}{l}\text { Chemical coagulation, dissolved air } \\
\text { flotation and activated sludge }\end{array}$ & 2 to 20 \\
\hline Ultra filtration & $<10$ \\
\hline
\end{tabular}




\section{REVIEW OF LITERATURE}

\subsection{Classification and Properties of Emulsions}

A wide variability exists in the definition of the term emulsion. For the purpose of this study, the following definition is adopted (Becher 1977):

An emulsion is a heterogeneous system, consisting of at least one immiscible liquid intimately dispersed in another in the form of droplets, whose diameters in general exceed $0.1 \mu \mathrm{m}$. Such systems possess minimal stability, which may be accentuated by such additives as surface-active agents, finely divided solids etc.

Tadros and Vincent (1983) attempted to subdivide the different types of emuisions into two major groups based on (i) the nature of "stabilizing moieties," and (ii) the basic "structure" of the system. The list representing the hierarchy of increasing complexity for the two subdivisions is presented in Table 2.1 .

By one distinguishing the inteinal and external phases, an emulsion involving oil and water can be classified into two large groups as: oil-in-water $(\mathrm{o} / \mathrm{w})$ or water-in-oil (w/o) emulsions. Depending upon the volume percentage of the internal phase or the internal-phase ratio (IPR), these emulsions can be further categorized (Table 2.2).

The volume percentage of the internal phase has a profound influence on the properties of the emulsion. When the internal phase constitutes less than approximately 30 percent of the total volume, the individual droplets do not interfere with each other appreciably and the physical properties of the whole system are determined primarily 
Table 2.1. Classification of emulsion types (Tadros and Vincent 1983).

\begin{tabular}{|c|c|}
\hline Nature of stabilizing moiety & Structure of the system \\
\hline $\begin{array}{l}\text { None (i.e. two pure immiscible } \\
\text { liquid }\end{array}$ & $\begin{array}{l}\text { Nature of the internal/external } \\
\text { phases }(\text { e.g. } \mathrm{o} / \mathrm{w} \text { or } \mathrm{w} / \mathrm{o})\end{array}$ \\
\hline Simple molecules and ions & Micellar emulsions/micro emulsions \\
\hline Noniunic surfactants & Macroemulsions \\
\hline Ionic surfactants & Bilayer droplets \\
\hline Surfactant mixtures & Double and multiple emulsions \\
\hline Nonionic polymers & Mixed emulsions \\
\hline Polyelectrolytes & \\
\hline Biopolymers & \\
\hline Mixed polymers and surfactants & \\
\hline Liquid crystalline "phases" & \\
\hline Solid particles & \\
\hline
\end{tabular}


Table 2.2. Six major classes of emulsions (Lissant 1977).

\begin{tabular}{||c|c|c|c||}
\hline \multirow{3}{*}{ Group } & \multicolumn{3}{|c||}{ Internal-phase ratio(IPR) } \\
\cline { 2 - 4 } & $<30 \%$ & 30 to $74 \%$ & $>74 \%$ \\
\hline \hline Water-in-oil (w/o) & Low-IPR w/o & Medium-IPR w/o & High-IPR w/o \\
\hline Oil-in-water(o/w) & Low-IPR o/w & Medium-IPR o/w & High-IPR o/w \\
\hline \hline
\end{tabular}


by the nature of the external continuous phase. When the internal phase ratio increases, the droplets begin to collide more frequently and cause an apparent increase in the viscosity of the system. At ratios higher than 50 to 52 volume percent (this is the volume ratio of uniform spheres stacked in a cubic array), the internal phases are forced into close contact and unless the emulsion is polydisperse, the formation shows quite high viscosity and non-newtonian flow behavior. At an internal volume ratio of about 68 percent, emulsions are not usually stable unless special emulsifier systems are used. Most of the conventional and traditional emulsifier systems lose effectiveness at or above this range, and the emulsions invert, with the greater phase becoming external. Gopal (1968) indicated that when the concentration of the dispersed phase is increased, other factors remaining favorable, inversion occurs when the concentration reaches about 75 percent. Becher(1977) reported that inversion, although a concentration effect, may occur at other values of phase volume. When the systems contain more than 75 percent internal phase, the droplets are so closely crowded that they can no longer be spheres unless the emulsion is polydisperse. Lissant (1977) indicated that at this point, the apparent viscosity of the system increases rapidly and non-Newtonian behavior becomes marked.

Based on the droplet size of the internal phase, Treybal (1963) classified an emulsion as (i) primary emulsion and (ii) secondary emulsion. Primary emulsion is characterized by a drop size of the order of $100 \mu \mathrm{m}$ and will separate readily by simple settling. If one or both of the two liquids involved contains polar compounds, one or both of the two layers which result from the settling operation will be clouded with a fine mist or fog of extremely fine droplets of the opposite phase. Such fogged layers are called secondary emulsions and consist of billions of droplets of submicron size 
suspended in a field of the opposite phase. Sareen et al. (1966) found that these secondary emulsions cannot be settled clear for many hours and coalescence of these tiny droplets into large ones is necessary if the emulsion is to be broken for separation. Sherony et al. (1978) reported that the distinction between primary and secondary emulsion is not clearly defined.

Generally, stability of an emulsion is determined by the performance of the dispersed phase in the continuous phase. Stability usually involves the maintenance of fluidity of the dispersed phase in the continuous phase in addition to resistance to creaming and coalescence. Jordan (1955) suggested two important factors which determine the performance of an emulsion: (i) the presence of an electrical charge on the surface of dispersed droplets or (ii) a capsulating film around the droplets, which is both protective and resistant but not adhesive. Becher (1977) and Adamson (1977) grouped emulsion stability theories as: (i) those dealing with the geometry and physical properties of the interfacial layer and (ii) those dealing with electrical effects. Hrudey and Kok (1987) presented a classification of stability based on zeta potential (Table 2.3). For the puipose of this study, the following definition is adopted for the term stability (Hrudey and Kok 1987):

This property (stability) represents the ability of an emulsion to maintain, over time, the dispersed phase in dispersed form with a constant size distribution.

Thus the stability of an emulsion can be described with reference to the drop size distribution of the dispersed phase. Since oil can be present in water in many forms, it is necessary to categorize them. Tabakin et al.(1978a and b) proposed five categories to describe the physical forms of oil in wastewater: 
Table 2.3. Zeta potential as an indicator of dispersion stability (Hrudey anci Kok 1987).

\begin{tabular}{||l|c||}
\hline \hline \multicolumn{1}{|c|}{ Stability } & Zeta potential (mV) \\
\hline \hline $\begin{array}{l}\text { Strong coagulation } \\
\text { flocculation } \\
\text { Incipient instability }\end{array}$ & +5 to -5 \\
Moderate stability & -30 to -40 \\
Good stability & -41 to -60 \\
Excellent stability & -61 and up \\
\hline \hline
\end{tabular}


1. Free oil. Oil which rises rapidly to the surface under quiescent conditions.

2. Mechanical dispersions. Fine droplets, ranging in size from microns to a few millimetres in diameter, which are stabilized by electrical charges and other forces but not through the influence of surface active agents.

3. Chemically stabilized emulsions. Oil droplets similar to mechanical dispersion but with enhanced stability resulting from surface active agents at the oil/water interface.

4. Dissolved oil. Truly soluble species in the chemical sense plus very fincly sus. pended oil droplets (typically less than $5 \mu \mathrm{m}$ in diameter). This form generally defies removal by normal physical means such as gravity separation, dissolved air flotation and filtration.

5. Oil-wet solids. Oil adhered to the surface of particulate material in wastewater.

The American Petroleum Institute (1969) characterized free oil as having a dispersed drop diameter greater than or equal to $150 \mu \mathrm{m}$ in size and an emulsified oil mixture as havin drop sizes smaller than $20 \mu \mathrm{m}$. The general classification of o/w emulsions based on the drop diameter of oil adopted in the present study is presented in Table 2.4 . 
Table 2.4. Classification of emulsions based on drop diameter

\begin{tabular}{||l|c|l|l||}
\hline $\begin{array}{l}\text { o/w emulsion } \\
\text { classification }\end{array}$ & $\begin{array}{c}\text { Diameter of } \\
\text { drops }(\mu \mathrm{m})\end{array}$ & \multicolumn{1}{|c||}{ Remarks } & \multicolumn{1}{|c||}{ Reference } \\
\hline \hline Primary & $>100$ & Visible to naked eye & Sareen et al. (1966) \\
Secondary & $<20$ & Milky in appearance & Sareen et al. (1966) \\
\hline $\begin{array}{l}\text { Free oil } \\
\text { Dispersed oil }\end{array}$ & $\begin{array}{c}150-20 \\
\text { Emulsified oil }\end{array}$ & $<20$ & API (1969) \\
Sciuble oil & $<5$ & API (1969) \\
Microemulsions & $<0.14$ & $\begin{array}{l}\text { Optically transparent } \\
\text { and have negative } \\
\text { interfacial tension }\end{array}$ & $\begin{array}{l}\text { Manning and } \\
\text { Snider (1983) } \\
\text { Tabakin et al. (1978a and b) }\end{array}$ \\
\hline \hline
\end{tabular}




\subsection{Characteristics of Peat and its Use in Oil Removal}

\subsubsection{Characteristics of peat}

\subsubsection{Definition and composition}

The term peat, according to ASTM 2607 (1969), refers only to organic matter of geological origin, excluding coal, formed from dead plant remains in water and in the absence of oxygen. Peat occurs in a bog, swamp-land or marsh and it has an ash content not exceeding 25 percent by dry weight. In geological terms, peat is coal at its primary stage and the mean rate of accumulation is $1 \mathrm{~m} / 1000$ years (Belanger et al. 1988).

Peat is defined as (i) a fibrous mass of organic matter in various stages of decomposition, generally dark brown in colour, and of spongy cunsistency; and (ii) as unconsolidated, carbonaceous sediment formed by the accumulation of partially fragmented, decomposed and commonly heterogeneous plant remains which retain more than 75 percent inherent moisture, and less than 12 percent mineral matter in saturated natural deposits. The peat deposits preserved by persistent moisture relationships may be buried and may form coal (Collins 1982).

Peat can be described as partially fossilized plant mattix that occurs in wet areas where there is a lack of oxygen; the accumulation is inerefore more rapid than its decomposition. Peat is a rather complex material containing lignin and cellulose as major constituents. These constituents, especially lignin, bear polar functional groups such as alcohols, aldehydes, ketones, acids, phenolic hydroxides and ethers that can be involved in chemical bonding. Because of the very polar character of these materials, specific adsorption of dissolved solids such as transition metals and 
polar organic molecules was reported to be high (Coupal and Lalancette 1976). Smith et al. (1980) reported that peat consists of the following:

1. Organic matter in an crganized state of preservation and therefore identifiable;

2. Organic matter which has undergone considerable breakdown but in which cell structure is still visible;

3. Organic matter which has degraded below the cellular level and is often forming peat matrix; and

4. Inorganic matter derived either from dust or from the cells of some plants.

The proportions of thess compounds were reported to vary from one peat sample to another lepending on the nature of the peat-forming material and the rate of decomposition.

Lishtvan et al. (1980) suggested that peat should be regarded as a class of multicomponent, polyfractional, semi-colloidal and high-molecular weight compounds featuring polyelectrolyte and micromosaic heterogeneity. The degree of heterogeneity and the compact state of peat aggregates would depend on the composition of the medium, the extent to which functional groups were associated and on the character of interactions between the aggregates. The authors have further postulated that the physical and chemical properties of peat are influenced by the nature of the plants from which it has originated, by the moisture conditions during and following its formation and accumulation and by geomorphological and climatic factors.

"Peat moss" generally refers to (i) the peat sold for horticultural uses and (ii) the peat generally consisting of little decomposed Sphagnum species. Sphagnum is a generic name having very distinctive leaf structure. The external surface contains 
hydrocytes which are maintained at their maximal volume by a spiral frame and are connected to the exterior through a large number of pores. On the internal surface, a grid of narrow cells called celes are seen. This distinctive structure gives peat the capacity to hold water (Belanger et al. 1988). Stanek and Worely (1983) showed that Sphagnum peat can hold water up to 10 times its dry weight and occupy over 95 percent of the total volume. Generally, the organic content and carbon content of pe:at moss is about 30 and 17 percent by dry weight respectively. The major components of Sphagnum peat are as follows (Belanger et al. 1988):

1. Carbohydrates (hemicellulose and cellulose);

2. Polyphenols (lignin, humic acids); and

3. Lipids (waxes, resins, steroids, terpenes).

The elemental composition of peat for different humification stages reported by Fuchsman (1980) is presented in Table 2.5.

\subsubsection{Classification, structure and surface area}

Peat samples are classified with respect to their degree of decomposition or humification. This is indicated by the fiber content or by the von Post humification scale. In 1922, von Post of Sweden introduced a scale starting with $\mathrm{H}_{1}$ for a fully undecomposed peat and ending with $\mathrm{H}_{10}$ for a completely decomposed peat. The location on the scale for a particular peat was determined by visual inspection of the colour of the water and the action of the peat substance as a result of pressing the substance in the hand (Tibbetts 1976). In view of the subjective nature of this method, attempts have been made to classify peat samples based on the fiber content. Farnham and 
Table 2.5. Elemental composition of peat (weight percent of dry matter) (Fuchsman 1980)

\begin{tabular}{||l|l|l|l||}
\hline $\begin{array}{l}\text { Organic } \\
\text { element }\end{array}$ & $\begin{array}{l}\mathrm{H}_{1}-\mathrm{H}_{10} \\
\text { Slightly humified } \\
\text { Sphagnum peat }\end{array}$ & $\begin{array}{l}\mathrm{H}_{6}-\mathrm{H}_{10} \\
\text { Highly humified } \\
\text { Sphagnum peat }\end{array}$ & $\begin{array}{l}\mathrm{H}_{9}-\mathrm{H}_{10} \\
\text { Highly humified } \\
\text { low-moor peat }\end{array}$ \\
\hline \hline Carbon & $48-53$ & $56-58$ & $59-63$ \\
Hydrogen & $5-6$ & $5.5-6.1$ & $5.1-6.1$ \\
Oxygen & $40-46$ & $34-39$ & $31-34$ \\
Nitrogen & $0.5-1$ & $0.8-1.1$ & $0.9-1.9$ \\
Sulfur & $0.1-0.2$ & $0.1-0.3$ & $0.2-0.5$ \\
\hline
\end{tabular}


Finney (1965) used the fiber content as a criterion for classifying peat and its degree of decomposition. Stanek and Silc (1977) compared the von Post method with rubbed and unrubbed fiber methods of determining the degree of decomposition of peat. Kong et al. (1980) were of the opinion that a more quantitative method might be necessary for estimating the changes in the decomposition of peat. Johnson (1987) presented a macrostructure analysis of Sphagnum peat as a tool to assess differences in decay and to compare different peat samples.

Day et al. (1979), Riley (1986) and Cohen (1987) have established procedures for determining the fiber content of rubbed and unrubbed peat samples. Malterer $c t$ al. (1987) and Hanninen (1987) have established correlations between different methods of measuring fiber content of rubbed and unrubbed samples. ASTM (1969) defined peat fiber as plant material of grain size greater than $0.15 \mathrm{~mm}$ or large, consisting of stems, leaves or fragments of bog plants but containing no particles larger than 12.7 $\mathrm{mm}$. The five classifications of peat as per ASTM (1969) based on generic origin and fiber content are presented in Table 2.6. ASTM (1971d) separated the peat materials into arbitrary fractions based on particle size. Accordingly, particles greater than $2.36 \mathrm{~mm}$ were termed coarse fiber, between 2.36 and $0.85 \mathrm{~mm}$ as medium fiber and smaller than $0.85 \mathrm{~mm}$ as fines.

In view of its fibrous nature, peat exhibits a wide variation in its pore structure. Loxham (1980) classified the peat pores into six different types as:

I. Large well connected open pores;

II. Simply connected slit type pores;

III. Closed end pores; 
Table 2.6. Classification of peat according to generic origin and fiber content (ASTM 1969)

\begin{tabular}{||l|l||}
\hline \hline Classification & \multicolumn{1}{|c||}{ Description } \\
\hline \hline 1. Sphagnum moss & $\begin{array}{l}\text { The oven }\left(150^{\circ} \mathrm{C}\right) \text { peat shall contain a minimum } \\
\text { of } 66 \frac{2}{3} \text { percent Sphagnum fiber by weight. } \\
\text { These fiber shall be stems and leaves of Sphagnum } \\
\text { that have recognizable fibrous and cellular structure. }\end{array}$ \\
2. Hypnum moss & $\begin{array}{l}\text { The oven dried peat sample shall contain a minimum of } \\
33 \frac{1}{3} \text { percent Hypnum moss fiber by weight. } \\
\text { These fibers shall be stems and leaves of Hypnum } \\
\text { that have recognizable fibrous and cellular } \\
\text { structure. }\end{array}$ \\
3. Reed-sedge & $\begin{array}{l}\text { The oven dried peat sample shall contain a minimum of } \\
33 \frac{1}{3} \text { percent fiber by weight of which Reed-sedge } \\
\text { and other non-moss fiber shall comprise } \\
\text { over } 50 \text { percent. }\end{array}$ \\
4he oven dried peat shall contain less than \\
5. Other peat
\end{tabular}


IV. Cornpletely isolated pores;

V. Remains of cells with ihe walls more or less intact; and

VI. Pores in the massive wood structures and roots.

These are schematically presented in Figure 2.1. Loxham (1980) showed that an increase in humification would lead to an increase in types II and III and a decrease in types I and V.

The surface area of peat reported in the literature varies widely from 0.3 to 300 $\mathrm{m}^{2} / \mathrm{g}$ depending upon the type of peat samples and the procedure employed for its measurement. Tinh et al. (1971) measured the surface area of a Quebec peat (von Post scale $\mathrm{H}_{1}$ ) as $220 \mathrm{~m}^{2} / \mathrm{g}$, using the Iodine Number method. Poots and Mckay (1979) measured the surface area of a Northern Ireland Sphagnum peat moss using three methods namely: (i) methylene blue (ii) telon blue and (iii) BET nitrogen adsorption. The surface area measured using the BET adsorption method ranged from 19 to $28.7 \mathrm{~m}^{2} / \mathrm{g}$ depending upon the particle size ( 150 to $\left.1000 \mu \mathrm{m}\right)$. For the other two methods (methylene blue and telon blue), the surface areas were reported to range from $77-122$ and $5-12 \mathrm{~m}^{2} / \mathrm{g}$ respectively. Thun and Leena (1982) observed that the surface area of peat could be increased to $50-60 \mathrm{~m}^{2} / \mathrm{g}$ by mechanical treatment; however the authors have not quoted the surface area of peat before mechanical treatment and pretreatment. Allen (1987) measured the surface area of Northern Ireland Sphagnum peat moss using mercury porosimetry and reported values ranging from 2.33 to $2.62 \mathrm{~m}^{2} / \mathrm{g}$ depending upon the particle size (150 to $\left.1000 \mu \mathrm{m}\right)$. From the findings of Poots and McKay (1979) and Allen (1987), it is observed that there was no appreciable increase in the surface areas of peat samples due to a decrease in 


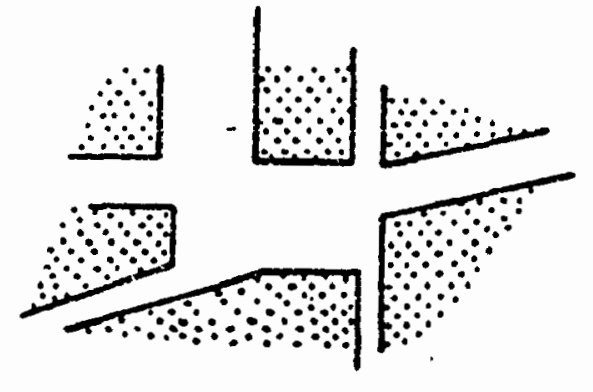

type. I.

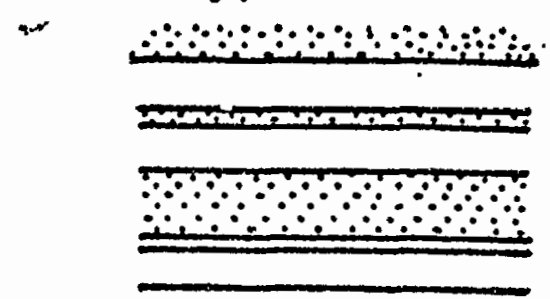

type II

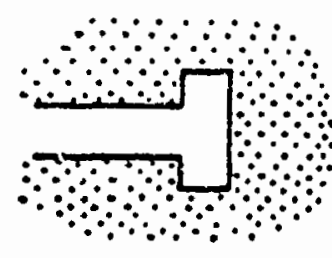

type III
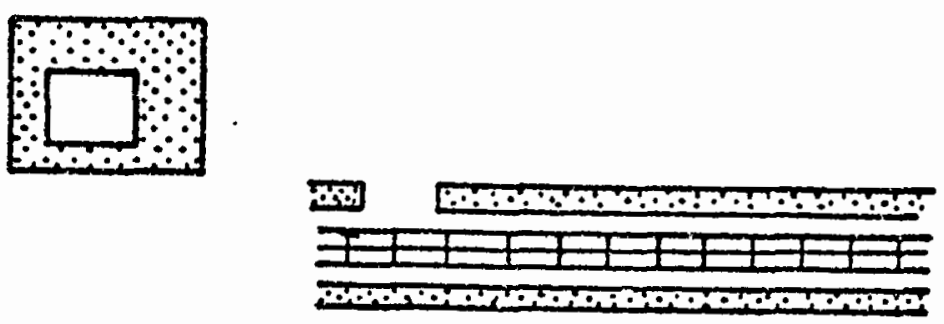

type II

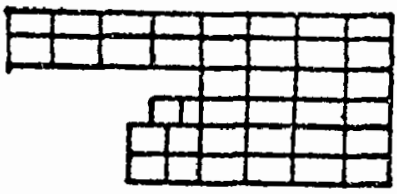

type $\bar{I}$ type III

Figure 2.1. Type of pores in peat (Loxham 1980) 
particle size. This possibly indicates that the surface area was influenced by smaller particles which were not measured or were difficult to measure accurately.

Sapek and Sapek (1987) attempted to correlate the transitional stages of peat to its surface areas, sorption and exchange capacities. They showed that the cation exchange capacity (CEC) increased with the degree of humification of peat. On the basis of the average values, the authors observed a general decrease in sorption values when there was an increase in surface area of peat. This observation according to the authors contradicts the general hypothesis that there would be an increase in sorption values due to an increase in surface areas.

Later, Sapek et al. (1988) measured the surface area of peat as $340 \mathrm{~m}^{2} / \mathrm{g}$, using the water sorption method. They also measured the average external surface area as $1 \mathrm{~m}^{2} / \mathrm{g}$. Again, the authors observed a negative correlation between surface arca and sorption properties and concluded that it was difficult to interpret the results. However, they have postulated that the enlargement of the area was not equal to the increase in humic substances which were responsible for CEC properties. Fuchsman (1987) emphasized the need to develop a comprehensive model to take into account the physical, chemical and biological aspects of peat for a better understanding of peat structure, its chemical composition and humification stages.

\subsubsection{Flow characteristics}

The flow characteristics of peat in in-situ and experimental conditions have been studied in the past using pure water and wastewater containing oil. The specific permeability $\left(\mathrm{L}^{2}\right)$ of in-situ peat reported by Bear et al. (1968) ranged from $10^{-13}$ to $10^{-11} \mathrm{~m}^{2}$. Korpijaakko and Radforth (1974) reported that the hydraulic conductivity 
$(L / t)$ of peat decreased with an increase in the degree of humification. For a von Post degree of humification of 5 to 6 (moderately humified peat), the authors have obtained a value of $0.008 \mathrm{~m} / \mathrm{min}$ (the corresponting value of specific permeability would be $1.36 \times 10^{-11} \mathrm{~m}^{2}$ ). Poots and McKay (1979) investigated the flow characteristics of a $0.2 \mathrm{~m}$ peat bed using water. The specific permeability coefficient reported by them ranged from $5.5 \times 10^{-11}$ to $5.5 \times 10^{-10} \mathrm{~m}^{2}$, depending upon the particle size. Ground and sieved Northern Ireland Sphagnum peat was used in their investigation. Ekman and Asplund (1975) studied the permeability coefficient in a 0.5 to $1 \mathrm{~m}$ thick peat bed having particle diameter of 0.84 to $2.62 \mathrm{~mm}$ using wastewater containing about 1000 $\mathrm{mg} / \mathrm{L}$ of diesel fuel oil (of which $900 \mathrm{mg} / \mathrm{L}$ was free oil and $100 \mathrm{mg} / \mathrm{L}$ was emulsified oil). The values reported by them ranged from 1.5 to $17.3 \times 10^{-10} \mathrm{~m}^{2}$, depending upon the bulk density of the peat.

Kong et al. (1980) showed that the hydraulic conductivity of in-situ peat decreased with depth due to the increase in decomposition of the peat at greater depths. For a fibric peat (in Mildred Lake area, Alberta), the authors have reported the hydraulic conductivity as 200,81 and $32 \mathrm{~mm} / \mathrm{h}$ (with corresponding permeabilities of $7.0 \mathrm{x}$ $10^{-11}, 2.3 \times 10^{-i^{2}}$ and $9.1 \times 10^{-13} \mathrm{~m}^{2}$ respectively) at $0.55,0.80$ and $1.15 \mathrm{~m}$ depth, respectively. For a fibric peat in a different site (Evansburg site), the authors have reported the hydraulic conductivity as 41,19 and $7 \mathrm{~mm} / \mathrm{h}$ (with corresponding permeabilities of $1.16 \times 10^{-12}, 5.38 \times 10^{-13}$ and $1.98 \times 10^{-13} \mathrm{~m}^{2}$, respectively) at 0.35 , 0.63 and $0.90 \mathrm{~m}$ depth, respectively. 


\subsubsection{Drying/Heat treatment of peat}

Peat is a chemically heterogeneous and complex material. The reduction in moisture content itself can alter the physical and chemical properties of the peat. Several methods can therefore be considered to alter the structure of peat to enhance its potential for pollutant removal. They may be physical, chemical or a combination of both. Sharp (1982) discussed twelve different methods of reducing the moisture content in peat and showed that freeze-thaw cycles were effective in reducing the moisture content by breaking the colloidal structure of peat. Alden and Forsberg (1987) showed that the addition of cationic and anionic polyelectrolytes improved the dewatering rate substantially. Brown and Farnham (1980) indicated that oxidation of fibric, hemic and sapric peats would begin at $155^{\circ} \mathrm{C}, 130^{\circ} \mathrm{C}$ and $115^{\circ} \mathrm{C}$ respectively. Maximum water removal was reported to have occurred at $88^{\circ} \mathrm{C}$ and further water removal continued up to $100^{\circ} \mathrm{C}$. Spedding (1988) showed that rapid drying of peat increased its porosity and promoted the formation of a coke-like structure. Belenger et al. (1988) indicated that the moisture content in peat could not be reduced below 70 percent without altering the structure of the peat. Thun et al. (1983b) showed that the poor mechanical strength, the high affinity for water, the tendency to swell and the poor chemical stability of peat can be improved by heat treatment (thermolysis). Poly-condensation reactions and the introduction of new sulphonic acids and carboxyl groups were reported to have increased the mechanical strength and ion exchange values of peat.

Thermal pretreatment methods that facilitate dewatering of peat are generally referred to as carbonization or pyrolysis. Pyrolysis or destructive distillation is a process in which organic material is decomposed at an elevated temperature in either 
oxygen-free or low-oxygen atmosphere. The end products of carbonization and pyrolysis are gases, liquids and char. One such thermal treatment method that facilitates dewatering of peat is called wet-carbonization. Wet-carbonization consists of heating wet peat at temperatures between $149^{\circ} \mathrm{C}$ and $538^{\circ} \mathrm{C}$ and pressures between $2.1 \mathrm{MPa}$ (300 psi) and $13.8 \mathrm{MPa}(2000 \mathrm{psi})$ at residence times up to one hour. During wetcarbonization, decarboxylation and dehydratization reactions occur and the colloidal fraction of peat gets disrupted (Mensinger 1980). Even though these processes in the past wcre aimed at increasing the fuel value of peat, considerable interest is shown at present in the end product for environmental applications.

Thun et al. (1983a) studied the wet-pyrolysis of a slightly decomposed Finnish peat for enhancing its oil adsorption capacity. The end product was referred to as Berthinate. The peat was reported to have been pyrolyzed at six different temperatures ranging from $150^{\circ} \mathrm{C}$ to $600^{\circ} \mathrm{C}$ for a time period of 60 to 430 minutes. They have concluded that a carbonization temperature of 225 to $275^{\circ} \mathrm{C}$ and a carbonization period of 10 to 20 minutes were the optimum conditions for use in the treatment of oily wastes. The authors also showed that liberation of water, decarboxylation and polymerization reactions occurred in the peat during pyrolysis. According to them, this resulted in a pore structure favoring oil binding (oleophilic) and water repellent (hydrophobic) chrracteristics. The hardening of the outer surface was reported to have increased the mechanical strength of peat. Lishtvan et al. (1980) observed the coexistence of hydrophilic and hydrophobic peat components within the peat structure. Belanger et al.(1988) summarized the structural changes in peat under different pyrolysis temperatures. It was found that at 125 to $150^{\circ} \mathrm{C}$ a major part of the water was eliminated from the pores and a partial alteration in structure and chemical 
composition of the peat occurred. At $150^{\circ} \mathrm{C}$, the waxes and resins started to melt. It was indicated that this fusion of waxes modified certain properties of the peat and made it hydrophobic resulting in a capacity to adsorb oil. Between 150 and $250^{\circ} \mathrm{C}$, the water that was chemically bonded to peat molecules was reported to have been elıminated resulting in major structural changes. Further in this temperature range, the formation and degradation of components such as alcohols, acids and aldehydes occurred. Between 200 and $300^{\circ} \mathrm{C}$, there was decomposition of cellulose, hemi cellulose, sugar and lignin. It was reported that between 200 and $400^{\circ} \mathrm{C}$, all molecules present in the raw peat underwent a transformation.

\subsubsection{Use of peat in oil removal}

D'Hennezel and Coupal (1972) showed that a commercial peat moss absorbed oil about 8 times its dry weight and found that the absorption of oil by peat moss increased with decreasing oil viscosity. They also investigated the effect of oil absorption by peat using a Bunker-C cil-in-water emulsion and found that the absorption increased from 7.7 ( $\mathrm{kg}$ of oil per $\mathrm{kg}$ of peat) at 0 percent water content to a maximum of 15.8 ( $\mathrm{kg}$ of oil per $\mathrm{kg}$ of peat) at 40 percent water content. The authors postulated that the addition of water up to a certain extent enlarged the pore diameter of the peat. The authors have also demonstrated that peat can clean up to 95 percent of oil from oil spills.

Mueller (1972) showed that the sand filtration of an oil-containing industrial waste (added with 3000 to $4000 \mathrm{mg}$ of peat per litre of oil-containing wastewater) achieved oil removals greater than 95 percent. This removal efficiency was reported to be higher than the 94 percent achieved for the same industrial waste in a flotation unit. 
Ekman and Asplund (1975) reported that the oil adsorption capacity of a heattreated peat was $6.35 \mathrm{~kg}$ of oil per $\mathrm{kg}$ of dry peat, as compared to $16.2,7.85,7.55$ and $5.25 \mathrm{~kg}$ of oil per kg of such oil-sorbing agents as foamed plastic, mineral wool, hydrolysis waste and volcanic glass, respectively. The authors further demonstrated that a $0.50 \mathrm{~m}$ peat bed removed up to 99 percent of the oil from a wastewater containing $1000 \mathrm{mg} / \mathrm{L}$ of diesel fuel oil-in-water emulsion emulsified with alkylarylsulphonate. They reported that the oil removal efficiency increased with the flow rate initially and concluded that the peat bed acted as a "kind of coalescer" bed by separating the oil phase from the water phase.

Ekman and Asplund(1975) developed the following equation to predict the material transfer in a peat bed:

$$
\frac{y_{0}-y_{x}}{y-y_{x}}=\exp \left\{\frac{k_{y} a_{p} L}{V}\right\}
$$

where:

$$
\begin{aligned}
& y_{0}=\text { sorbate concentration of the liquid to be filtered }\left(\mathrm{M} / \mathrm{L}^{3}\right) ; \\
& y_{x}=\text { sorbate concentration of water at equilibrium }\left(\mathrm{M} / \mathrm{L}^{3}\right) ; \\
& y=\text { sorbate roncentration of the filtrate }\left(\mathrm{M} / \mathrm{L}^{3}\right) ; \\
& V=\text { flowthrough volume }\left(\mathrm{L}^{3}\right) ; \\
& L=\text { thickness of the filtering layer }(L) ; \text { and } \\
& k_{y}, a_{p}=\text { material transfer constants based on surface area of sorbate } \\
& \text { granules }\left(L^{2}\right) .
\end{aligned}
$$

Using the above equation, the authors have calculated the amount of oil adsorbed per $\mathrm{kg}$ of peat in a $0.15 \mathrm{~m}$ thick peal bed as $2.89,1.45$ and $0.95 \mathrm{~kg}$ for average peat particle 
sizes of $2.62,1.39$ and $0.84 \mathrm{~mm}$, respectively. The authors have also pointed out that the compression of the peat bed affected the efficiency of the filtration process.

The application of chemically modified forms of peat as a cation exchanger, anion exchanger and oil coalescer was reported by Smith (1976a). Phosphoric acid treatment of Irish wet peat under varied temperature conditions $\left(150\right.$ to $\left.200^{\circ} \mathrm{C}\right)$ increased the cation exchange capacity of dried, sieved and untreated peat from $0.4 \mathrm{meq} / \mathrm{g}$ to $0.76 \mathrm{meq} / \mathrm{g}$ (Smith et al.1976). Smith and Mark (1976) showed that dried Irish peat and sulfuric acid-treated Michigan peat were capable of removing 90 percent of the oil from an oily water with an oil concentration of $250 \mathrm{mg} / \mathrm{L}$ at a flow velocity of 25 $\mathrm{mL} / \mathrm{min}$. The study also indicated that the coalescence capacity of the peat samples was comparable to that of XAD-2, a synthetic coalescing medium and an adsorbent. The average oil removal by XAD-2 was reported to range from 89 to 97 percent compared to 96 percent for dried Irish peat and acid-treated Michigan peat. Smith ct al. (1977) further investigated the effect of sulfuric acid treatment on peat and reported that the cation exchange capacity of peat increased from $0.35 \mathrm{meq} / \mathrm{g}$ for untreated dried and sieved Irish peat to $1.40 \mathrm{meq} / \mathrm{g}$ for an acid-treated Irish peat. The authors concluded that the application of modified peat on an industrial scale appeared to be feasible.

Asplund et al. (1978) designed a fixed bed peat filter for treating a wastewater containing $1000 \mathrm{mg} / \mathrm{L}$ of oil. The emulsified oil concentration varied from 80 to $350 \mathrm{mg} / \mathrm{L}$ depending upon the concentration of detergent added $(0.25$ to 25 volume ppm) to promote emulsification. The oil removal efficiency decreased from 98 to 57 percent when the emulsified oil concentration increased from 100 to $355 \mathrm{mg} / \mathrm{L}$. They concluded that peat can be an effective medium for treatment of oily wastewaters 
having low emulsion stability. The authors reported further that a peat filter bed was constructed to treat wastewater from a car wash plant. Asplund et al (1978) have further investigated the oil removal efficiency in a continuous countercurrent peat filter and showed that an oil concentration of $1000 \mathrm{mg} / \mathrm{L}$ (containing $190 \mathrm{mg} / \mathrm{L}$ of emulsified oil), at the inlet was reduced to 1 to $10 \mathrm{mg} / \mathrm{L}$ at the outiet. The authors concluded that a longer column or a longer contact time was needed for achieving higher plsification levels and that the purification capacity could be improved by the right choice of peat.

\subsection{Batch Adsorption and Desorption Isotherms}

The term adsorption in chemical engineering practice refers to condensation of vapors on surfaces or interior pores of a solid by physical ur chemical bonding forces. The molucules of vapor that penetrate into the pores of the solid by some process of diffusion are called absorption, and that remain attached to the surface are termed adsorption. Often the two occur simultaneously. Physical adsorption is caused by molecular interactior, forces while chemisorption involves transfer of electron between the solid and gas (Brunauer 1943, and Young and Crowell 1962).

The term adsorption has been used in environmental engineerirg $p_{1}$ actice without distinguishing the mechanisms involved in the process, although some choose to call the phenomena sorption (Reynolds 1982). For the purpose of this study, adsorption refers to the uptake of oil by peat regardless of the mechanism, and it is the same as sorption. In oil-binding capacity determinations, the word absorption is used to characterize the penetration of oil into peat. The term desorption refers to the release stage. 
In a solid-liquid system, positive adsorption results in the removal of solutes from solution and their concentration at the surface of the solid, until the concentration of the solute remaining in solution is in dynamic equilibrium with that at the surface. At this equilibrium, there is a defined distribution of solute between liquid and solid phases. This distribution ratio is expressed as $\left(\frac{x}{m}\right)$ or $q_{0}$, where $x$ is the amount of solute adsorbed and $m$ is the mass of the adsorbent. Since adsorption is temperature dependent, at a given temperature, the equation describing the adsorption is called an isotherm. The adsorption equation is a functional expression for the variation of adsorption with concentration of adsorbate in bulk solution at constant temperature. Most isotherms describing adsorption attempt to correlate the rate of adsorption to various other parameters such as concentration, contact time, flow, and mass transfer coefficients (film-diffusion and pore-diffusion) involved in the proress. Several such mathematical relationships aid in the interpretation of adsorption data. Adsorption data can be described in many forms; the most common forms of adsorption isotherms used in environmental engineering are the Laugmuir, the Froundlich and the Brunauer, Emmett and Teller (BET) (Weber 1972, Metcalf and Eddy 1979, Eckenfelder 1981, Benefield et al. 1982, and Reynolds 1982). The Langmuir and BET models were derived from first principles in chemical engineering process to describe: the adsorption of gases onto solids. The Freundlich is an empirical equation. Nevertheless, these models have been extensively used in wastewater treatment to design the adsorptio: of soluble as well as insoluble substances. In this study the choice and applicability of these three adsorption equations are restricted to an empirical approach to describe the process of adsorption of oil by peat.

The Langmuir equation describing adsorption is of the form: 


$$
\left(\frac{x}{m}\right)=\frac{a b C_{e}}{\left(1+b C_{e}\right)}
$$

where:

$$
\begin{aligned}
& x=\text { mass of solute adsorbed to the solid }(\mathrm{M}) ; \\
& m=\text { mass of adsorbent used }(\mathrm{M}) ; \\
& C_{e}=\text { concentration of solute in solution in equilibrium }\left(\mathrm{M} / \mathrm{L}^{3}\right) ; \\
& a=\text { Langmuir constant; the number of moles adsorbed per unit weight of } \\
& \text { an adsorbent in forming a complete monolayer; and } \\
& b=\text { Langmuir constant. }
\end{aligned}
$$

The Langmuir model is based on the following assumptions (Weber 1972):

i. the maximum adsorption corresponds to a saturated monolayer of solute molecules on the adsorbent surface;

ii. the energy of adsorption is constant;

iii. there is no transmigration of adsorbate in the plane of the surface; and iv. the adsorption is reversible.

Hall et al. (1966) noted that essential characteristics of a Langmuir isotherm can be expressed in terms of a dimensionless constant, separation factor or equilibrium parameter $R$, which is defined as follows:

$$
R=\frac{1}{\left(1+b C_{0}\right)}
$$

Where: 


$$
\begin{aligned}
& C_{0}=\text { initial concentration }\left(\mathrm{M} / \mathrm{L}^{3}\right) ; \text { and } \\
& b=\text { Langmuir constant. }
\end{aligned}
$$

This parameter indicates the shape of the adsorption isotherm as follows:

Value of $R$ Types of isotherm

$$
\begin{aligned}
R>1 & \text { Unfavorable } \\
R=1 & \text { Linear } \\
0<\mathrm{R}<1 & \text { Favorable } \\
\mathrm{R}=0 & \text { Irreversible }
\end{aligned}
$$

The shapes of the isotherms for the above four sets of conditions defined by Weber and Chakravorti (1974) are shown in Figure 2.2.

The Freundlich adsorption equation is of the form:

$$
\left(\frac{x}{m}\right)=k C_{e}^{\frac{1}{n}}
$$

where:

$k=$ Freundlich equilibrium constant indicative of adsorptive capacity; and $n=$ Freundlich constant indicative of adsorption intensity.

Weber (1972) theorized that the Freundlich equation is a special case for heterogeneous surface energies in which the energy term $a$ in Langmuir's equation (2.1) varies as a function of surface coverage $\left(\frac{x}{m}\right)$, strictly due to variations in heat of adsorption.

The BET equation is of the form: 


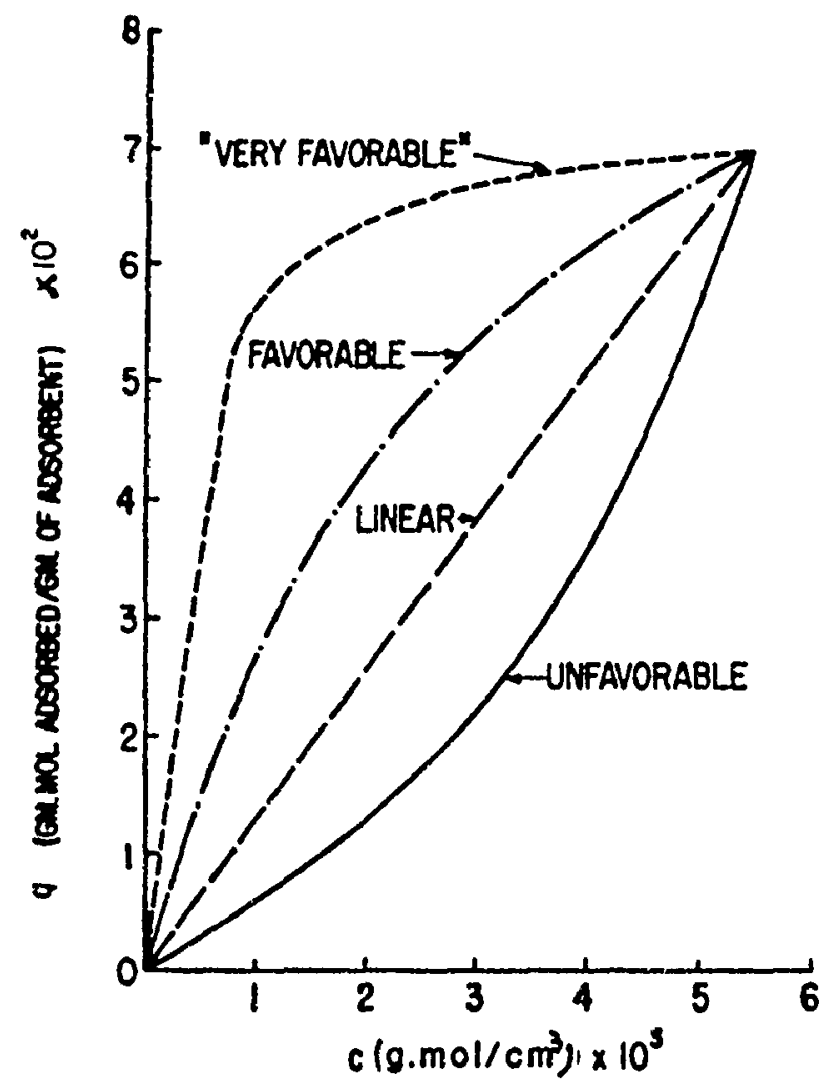

Figure 2.2. Shapes of isotherms (Weber and Chakravorti 1974) 


$$
\left(\frac{x}{m}\right)=\frac{A C X_{m}}{\left(C_{s}-C\right)\left[1+(A-1) \frac{C}{C_{1}}\right]}
$$

where:

$A=\mathrm{a}$ constant describing energy interaction between the solute and the adsorbent surface;

$X_{m}=$ amount of solute adsorbed in forming a complete monolayer $(\mathrm{M} / \mathrm{M})$;

$C=$ concentration of solute in solution in equilibrium $\left(\mathrm{M} / \mathrm{L}^{3}\right)$; and

$C_{s}=$ saturation concentration of solute in solution $\left(\mathrm{M} / \mathrm{L}^{3}\right)$.

Weber(1972) summarized that:

i. the BET model represents an isotherm reflecting apparent multi layer adsorption;

ii. the BET isotherm reduces to the Langmuir model when the limit of adsorption is a monolayer; that is: (when $\mathrm{A}=\mathrm{bC}_{s}, \mathrm{C}$ is negligibly small and $\mathrm{A}>\mathrm{I}$ );

iii. that a given layer need not complete formation prior to initiation of subsequent layers; the equilibrium condition will therefore involve several types of surfaces in the sense of number of layers of molecules on each surface site;

iv. for adsorption from solution, the BET model assumes that layers beyond but not including the first have equal energies of adsorption; and

v. both the Langmuir and BET isotherms may be deduced either from kinetic considerations or thermodynamic considerations.

The salient features of physical adsorption and chemisorption are distinguished by Rulhven (1984) (Table 2.7). 
Table 2.7. Salient features of physical and chemical adsorption (Ruthven 1984)

\begin{tabular}{|c|c|}
\hline Physical ad orption & Chemical adsorption \\
\hline Non specific & Highly specific \\
\hline Monolayer or multilayer & Monolayer only \\
\hline $\begin{array}{l}\text { No dissociation of } \\
\text { desorbed species }\end{array}$ & May involve dissociation \\
\hline $\begin{array}{l}\text { Only significant at } \\
\text { relatively low temperatures }\end{array}$ & $\begin{array}{l}\text { Possible over a wide range of } \\
\text { temperatures }\end{array}$ \\
\hline $\begin{array}{l}\text { Rapid, non-activated, } \\
\text { reversible }\end{array}$ & $\begin{array}{l}\text { Activated, may be slow and } \\
\text { irreversible }\end{array}$ \\
\hline
\end{tabular}


Bell and Tsezos (1988) calculated the number of molecular layers involved in the adsorption process based on the uptake monolayer coverage. Assuming adsorption to occur only at the surface, the surface area covered by each molecule was estimated using molecular weight of the adsorbate and surface area of the adsorbent.

Pushkarev et al. (1983) noted that there is little information in the literature on the sorption of oil as compared with the data on the sorption of low-molecular substances. The authors concluded that the isotherm describing adsorption of oil was generally complicated by extremal points due to the complex process of adsorption and therefore difficult to model.

Desorption, the reverse process of adsorption is usually measured to assess the rate at which the adsorbed solute will be released from the adsorbent back to the liquid phase under a given condition. The desorption isotherm will become an adsorption isotherm, if the process is truly reversible. When the adsorption is irreversible, both the rates (adsorption and desorption) will differ depicting different rate reactions. Desorption is an important measure especially when oil-sorbed peat has to be disposed of on land. Zytner et al (1989) showed that the desorption isotherm can be determined by modifying the Freundlich adsorption equation (2.3) by replacing the adsorption constants with desorption constants as:

$$
\left(\frac{x_{d}}{m}\right)=k_{d} C_{e}^{\frac{1}{n_{d}}}
$$

where:

$\left(\frac{x_{d}}{m}\right)=$ mass desorbed per unit mass of adsorbent $(\mathrm{M} / \mathrm{M})$;

$k_{d}=$ Freundlich equilibrium constant indicative of desorption capacity; and 


$$
n_{d}=\text { Freundlich constant indicative of desorption intensity. }
$$

Zytner et al. (1989) further stated that it is possible to determine the relative retention capacity from the adsorption and desorption isotherm constants by using the following expression:

$$
R R C=\frac{k}{k_{d}}
$$

where:

$$
\begin{aligned}
& R R C=\text { relative retention capacity (dimensionless); } \\
& k=\text { Freundlich adsorption equilibrium constant and } \\
& k_{d}=\text { Freundlich desorption equilibrium constant. }
\end{aligned}
$$

As this ratio increases, the retention capacity of the adsorbent also increases. When the ratio approaches 1 , the adsorbent in question has reversible adsorption indicating no retention capacity (Zytner et al. 1989).

\subsection{Breakdown Mechanisms}

The aim of treating the oily waters is to separate the undesirable oil present in the water. Depending upon the stability of an emulsion, the separation process may be one or a combination of the following:
i. flotation;
ii. filtration;
iii. coalescence;
iv. adsorption; and 
v. biological.

In a peat bed, the possible breakdown mechanisms can be filtration, coalescence, adsorption and biological action. Of these, filtration, coalescence and adsorption are physical processes. The physical structure and chemical properties of peat can aid in filtering the oil drops, coalesce smaller drops and adsorb part of them due to forces of attraction. Biological action is a possibility in the peat bed, as peat is a very good support medium for biological growth. The data generated in the present study are to be analyzed using available models from the literature to examine the relative contribution of these mechanisms in the breakdown of oil from oil-in-water emulsions.

\subsubsection{Filtration}

The filtration mechanisms can be broadly grouped under: (i) transport and (ii) attachment mechanisms. The transport mechanism encompasses the physical forces involved in the liquid and include: straining, settling, Brownian motion, diffusion, inertial forces, hydrodynamic action, and flocculation. When the transported particle approaches the surface of the medium, an attachment mechanism is required to retain the particle. This attachment mechunirm encompasses the surface properties of the medium and include: electrokinetic iffict, van der Walls force, adsorption, and biological activity.

Filtration models have been extensively analyzed on the basis of the following general classifications (Bear 1972, Scheidegger 1974, and Akers and Ward 1977):

i. Capillaric models;

ii. Hydraulic radius theory; 


\section{iii. Drag theory; and}

iv. Statistical theory.

The earliest and simple capillary models relied on a simplified structure for the bed and as such the equations produced are very sensitive to the assumed capillary diameter distribution (Akers and Ward 1977).

The hydraulic radius theory developed by Kozeny is based upon the assumption that a porous medium is equivalent to a series of channels which are assumed to be somewhat more elaborate than in capillaric models. Since permeability has the dimension of $L^{2}$, a length unit called hydraulic radius of the medium was linked with the hypothetical channels of the porous medium (Scheidegger 1974). The assumptions basic to hydraulic radius theories are given below:

i. no pores are sealed off;

ii. the pores are distributed at random and reasonably uniform in size;

iii. the porosity is not too high;

iv. diffusion is absent; and

v. fluid motion occurs like motion through a batch of capillaries.

Drag theory is an approach to the physical explanation of permeability different from Kozeny. In this, the walls of the pores are treated as obstacles to an otherwise straight flow of the viscous fluid. The drag of the fluid on each portion oil the walls is estimated and the sum equated to the resistance of the porous medium to flow.

In statistical theory, it is assumed that the porous medium is homogeneous and isotropic. Methods for cbtaining a statistical description of a porous medium have 
been based on the introduction of a linear random function of the porous medium (Scheidegger 1974).

The theories of filtration though formulated for single-phase flow (involving flow of water only) were extended and applied to two-phase flow (simultaneous flow of oil and water for example) and even multi-phase flow (oil-water-gas systems for example). This has led to more complications in the validity of the assumptions.

When one or more liquids occupy a medium, two types of flow are possible (Bear 1972).

a. Type 1, miscible displacement: In this case, the two fluids are completely soluble in each other. The interfacial tension between the two fluids is zero and the two fluids dissolve in each other. A distinct fluid-fluid interface does not exist. This is commonly known as hydrodynamic dispersion.

b. Type 2, immiscible displacement: In this, a simultaneous now of two or more immiscible fluids or phases (oil, water and gases for example) occur within the medium. The interfacial tension between the liquids is nonzero and a distinct fluid-fluid interface separates the fluids within each pore. A capillary pressure difference exists across the interface at each point. Even though there is a transition zone between the two phases, for all practical purposes, an abrupt interface is assumed for the two-phase problem for simplicity.

In the present study involving water and oil, Type 2 immiscible displacement flow would occur in the peat medium. In such situations, the extension of general theory of filtration (involving single-phase flow) to these two-phase flows has been attempted on the basis of average saturation and relative permeability (Bear 1972, Scheiclegger 1974, Sherony et al. 1978). The relative permeability has been shown to depend not 
only on its saturation (fraction of accessible pore space occupied by the fluid) but also on the saturation history, wettability of the solid, local velocity and interfacial tension between the two fluids (Richardson 1961, Owens and Archer 1971 and Tabor 1969). It has been reported in the literature that for all practical purposes, it is reasonable to assume that the relative permeability depends only on saturation (Bear 1972; Scheidegger 1974). While summarizing the limitation of filtration theories to two phase flow, Scheidegger (1974) pointed out that the limitations are partly due to the sam causes as in the single-phase flow.

Wallace and Brown (1972) examined the deep bed filtration of oil field waters using sand and sand-anthracite media. Though oil removal efficiencies (77 percent average) have been reported, no explanation for the breakdown of oil or predictions for the head loss were reported. Murkes and Stockholm (1986) reported on the crossflow filtration of emulsions combined with coalescence, a new filter- coalescer concept. The author concluded that Acropores (AN200 and 450), a porous ( 0.2 to $0.45 \mu \mathrm{m}$ ) media, was effective in removing 90 percent of oil from a mechanically dispersed oilin-water emulsion. However no filtration or coalescence models were attempted to explain the process. The separation of oil from oil-in-water mixtures was presented by Heidenreich et al. (1982) using particulate beds and by Gloyna and Preda (1971) using crushed graphite ore. The filtration models for the flow of dilute stable oil-inwater emulsions in porous media have been studied in petroleum reservoir engineering applications (Alvarado and Marsden 1979, Soo and Radke (1986) and Soo et al. 1986). The pressure drop due to two-phase flows was investigated by Chieu et al. (1975), Spielman and Goren (1970), Sherony and Kintner (1971a and b) and Ekman and Asplund (1975) using Carman-Kozeny filtration equations for different media. 
Ekman and Asplund (1975) studied oil-in-water emulsion filtration in a peat bed and presented the following equation to predict the head loss across the peat bed by taking into account the compressibility of the peat bed:

$$
\left(\Delta P_{a}-\Delta P_{m}\right)^{(1-r)}=k_{r} U_{t}
$$

where:

$$
\begin{aligned}
& \Delta P_{a}=\text { pressure reduction in the layer containing sorbate: } \\
& \Delta P_{m}=\text { pressure reduction when starting filtration; } \\
& r=\text { compressibility constant of sorbing layer; } \\
& U_{t}=\text { amount of sorbed substance and } \\
& k_{r}=\text { a constant }
\end{aligned}
$$

The Carman-Kozeny filtration equation of hydraulic radius theory has been used very widely in the field of environmental engineering for predicting the head loss across a filter bed. The data generated in the present study was analyzed using the well-known Carman-Kozeny filtration equation for predicting the head-loss across the peat bed.

In the case of fibrous materials having high porosities, the specific permeability coefficient given by Kozeny is (Carman 10,5):

$$
B_{0}=\frac{d_{f}^{2} \epsilon^{3}}{16 k_{1}(1-\epsilon)^{2}}
$$

where:

$$
\begin{aligned}
& B_{0}=\text { permeability coefficient },\left(\mathrm{L}^{2}\right) \\
& d_{f}=\text { fiber diameter },(\mathrm{L})
\end{aligned}
$$




$$
\begin{aligned}
& \epsilon=\text { porosity } ; \text { and } \\
& k_{1}=\text { Kozeny constant. }
\end{aligned}
$$

The Kozeny equation for permeability has been used with much success for flows in the laminar region. The condition for laminar flow given by Sherony et al. (1978) is :

$$
\frac{N_{R_{e}}}{(1-\epsilon)}<10
$$

where:

$$
N_{R_{e}}=\text { the Reynolds number. }
$$

Combining Darcy and Carman-Kozeny equations, Sherony and Kintner (1971b) presented equations to predict the head-loss across a fibrous bed involving single and two-phase flows as:

$$
\begin{aligned}
& \Delta P_{1}=\frac{16 L U \gamma_{c} k_{1}(1-\epsilon)^{2}}{d_{f}^{2} g_{c} \epsilon^{3}} \\
& \Delta P_{2}=\frac{16 L U \gamma_{c} k_{2}\left(1-\epsilon_{t}\right)^{2}}{d_{f}^{2} g_{c} \epsilon_{t}^{3}}
\end{aligned}
$$

where:

$$
\begin{aligned}
& \Delta P_{1}=\text { pressure drop across the bed for single-phase flow }\left(\mathrm{M} / \mathrm{L}^{2}\right) ; \\
& \Delta P_{2}=\text { pressure drop across the bed for two-phase flow }\left(\mathrm{M} / \mathrm{L}^{2}\right) ; \\
& \gamma_{c}=\text { dynamic viscosity of continuous phase; (M/L.T); } \\
& k_{1}=\text { Carman-Kozeny constant for single-phase flow (dimensionless); } \\
& k_{2}=\text { Carman-Kozeny constant for two-phase flow (dimensionless); } \\
& \xi_{c}=\text { acceleration due to gravity, }\left(9.80 \mathrm{~m} / \mathrm{sec}^{2}\right) ;
\end{aligned}
$$




$$
\begin{aligned}
& \epsilon=\text { porosity of fibrous bed in single-phase flow; } \\
& \epsilon_{t}=\text { porosity of fibrous bed in two-phase flow; } \\
& d_{f}=\text { diameter of fiber }(\mathrm{L}) \\
& L=\text { bed length }(\mathrm{L}) ; \text { and } \\
& U=\text { superficial velocity }(\mathrm{L} / \mathrm{T})
\end{aligned}
$$

Sherony and Kintner (1971 $\mathrm{a}$ and $\mathrm{b}$ ) have used these equations for predicting the pressure drop across a fibrous bed. The average saturation $\left(\bar{S}_{d}\right)$, of the dispersed phase is related to $\epsilon_{t}$ by:

$$
\overline{S_{d}}=\left(1-\frac{\epsilon_{t}}{\epsilon}\right)
$$

Equation (2.9) plotted on $\log$-log paper is a straight line and can be used to evaluate the Carman-Kozeny constant $k_{1}$. Sherony et al. (1978) calculated the change in porosity $\epsilon_{t}$ caused by the accumulation of the oil droplets using the following equation:

$$
\frac{\Delta P_{1}}{\Delta P_{2}} \frac{k_{1}}{k_{2}} \frac{\epsilon^{3}}{(1-\epsilon)^{2}}=\xi=\frac{\epsilon_{t}^{3}}{\left(1-\epsilon_{t}^{2}\right)}
$$

where $\xi$ is a constant dependent on the above ratio. The value of $\xi$ has been , ported to vary from 1 to 500 for the corresponding $\epsilon_{t}$ values of 0.6 to 1.0 (Sherony et al. 1978). The authors have used a generalized plot showing the variation of $k_{1}$ with $\epsilon$ consolidated from the literature. Using these two plots, it is possible to predict $\xi$ and $\epsilon_{t}$ and thus $\bar{S}_{d}$, the average saturation. The average saturation values were used by Sherony et al. (1978) to calculate the friction factor in the head loss predictions of a fibrous bed coalescer using Carman-Kozeny equation. The authors have finally indicated that this technique of measuring the average saturation is, at best, an approximation, and postulated that, owing to the lack of a suitable law relating the 
phenomena in a general way to the pertinent variables, some approximation must be used for the purpose of design.

\subsubsection{Coalescence}

Coalescence is the phenomenon whereby the droplets of the discontinuous dispersed phase merge to produce successively large droplets until, eventually, a separate phase may be created (Hrudey and Kok 1987). The process is usually initiated by a collision between the droplets which is of sufficient force to rupture the interfacial film. Once the droplets are in physical contact, the process is completed by surface forces (Chieu et al. 1975).

A wide variety of materials have been used as coalescing media: natural fiber (cotton and wool), synthetic materials (fiberglass, viscose, nylon, polypropylene and feit), reticulated (open-pore) foams, membranes (hydrolyzed and cellulose acetate), screens, mats and granular materials (pebbles, sand and diatomaceous earth)(US EPA 1978). Since peat is a fibrous material having high porosity, it may induce coalescence when oil-in-water emulsions are passed through it. This phenomenon had also been observed in a peat bed treating oily wastes in the earlier studies by Ekman and Asplund (1975) and Smith (1976). It is therefore necessary in this study to quantify the coalescence that might occur in the bed.

The mechanisms involved in the process of coalescence in a fibrous bed are grouped under three major steps by Hazlett (1969) as: (i) approach (ii) attachment and (iii) release.

The principal forces in approach mechanisms are direct interception, diffusion, inertial impaction, electrostatic attraction, van der Waals force and sedimentation. Ilazlett (1969) showed that the difiusion mechanism would dominate if the ratio 
of drop diameter to fiber diameter was less than $1 \mu \mathrm{m}$. Generally, the diffusion efficiency decreased with increased flow velocity, particle size and fiber size (Vinson 1965). Inertial impaction contributed very little to the coalescence (Hazlett 1969). If the dispersed phase density was less than that of the continuous phase, the inertial impaction would act to prevent drops from approaching the fiber (Chieu et al. 1975). The existence of electrical charge on the fiber influenced the approach of the drop to the fiber considerably (Chieu et al. 1975).

Once the dispersed drop has arrived at the fiber by one or more of the approach mechanisms, the next step is to attach the drop onto the fiber for further coalescence. For attachment to be eflective, the oil drop must displace the water film from the fiber and preferentially wet the fiber. This process is enhanced if the surface energy of the fiber increases. It is further stated that this could be confirmed by contact angle (i.e the angle made by the dispersed phase with the solid phase). A contact angle of zero implies complete wetting of the solid by the liquid, a value of $180^{\circ}$ corresponds to absolute non-wetting and intermediate values to varying degrees of incomplete wetting. Chieu et al. (1975) concluded that for practical purposes, if the contact angle is $>90^{\circ}$, the liquid is considered to wet the solid. Adamson (1977) pointed out that roughness of a surface tends to alter the contact angle. In a fibrous bed coalescer, the smaller the contact angle between the fiber and a drop, the larger the area of contact and gre or the probability that the drop will encounter and coalesce with another drop.

Hazlett (1969) suggested that the hydrodynamic force acting on a drop must overcome the adhesive force between the droplet and fiber before detachment (release) could occur and assumed that the coalesced drop became large enough to bridge to 
the next downstream fiber. After attachment to the next fiber, it is believed that threads of coalesced oil snake through the bed and lose their identity as a discrete drop.

\subsubsection{Mathematical models for coalescence efficiency}

Several mathematical models have been developed to describe the process of coalescence. These models predict the filter coefficient (in turn the efficiency of coalescence), oil saturation and pressure drop as a function of system variables.

Sherony et al. (1978) mentioned that one of the first attempts to describe the operation of a fibrous-bed coalescer was made by Jeffreys and Davies (1971). In this model, direct interception was considered to be the mechanism of approach and it was assumed that above a maximum velocity, the drops do not adhere to the fiber surface to be long enough to allow for interdrop coalescence. Sherony et al. (1978) observed that the length of time a drop remains on a fiber is not the critical point, since at the time the drop detaches it has attained a specific size and therefore size is critical.

Hazlett (1969) presented a model based on the assumption that interception is the principal mechanism $c \hat{i}$ approach. This model's predicted that coalescence would increase with an increase in velocity. This prediction was found contrary to experimental observations (Sherony ct al. 1978).

Vinson and Churchill (1970) presented a model's based on the assumption that drops collide with fibers and have a probability of being retained. The drops are captured by interception and the thinning of the continuous phase film results from the normal stresses due to the flow and the van der Waals attraction. 
Spielman and Goren (1970 and 1972) presented a model which assumes that when a dispersion flows through a fibrous bed, the suspended drops are transported to the fibers and entrapped liquid interfaces where they are captured and coalesced into the bulk of previously captured liquid. This model's predictions are based on capillary pressures (pressure difference between interface), Darcy's law, relative permeability and average saturation.

Sherony and Kintner (1971 a and b) developed a collision model which relates the collision frequency between particles and fibers to the overall coalescence efficiency. The model predicts the ratio of outlet to inlet particle number densities ( $\left.Y^{\prime}\right)$ and takes into account the mean inlet particle size, mean fiber size, void fraction of the bed, degree of bed saturation and bed length. The ratio of outlet to inlet particle number density $(\mathrm{Y})$ in terms of these parameters is given by:

$$
Y=\exp \left\{-\frac{3}{4} \frac{\bar{S}_{d}}{\left(1-\bar{S}_{d}\right)} \frac{(1-\epsilon)\left(1+\frac{d_{d}}{d_{f}}\right)}{d_{f}} \eta_{c} L\right\}
$$

where:

$\epsilon=$ porosity or void fraction of the fibrous bed;

$\bar{S}_{d}=$ average saturation (the fraction of void volume occupied

by the dispersed phase adhering to the solid) (dimensionless);

$d_{i}=$ average partic's size of the distribution (L);

$d_{f}=$ fiber diameler $(L)$;

$\eta_{c}=$ the overall coalescence efficiency (fraction); and

$L=$ bed length $(L)$.

The model is based on the following assumptions: 
1. The model is confined to emulsion concentrations of $1000 \mathrm{mg} / \mathrm{L}$ or less, flowing in to the bed.

2. The bea is a randomly packed fiber with a resident population of adhering drops (hold-up) and size distribution of the held drops is constant with time.

3. The particles from the liquid interact with the hold-up by collisicn.

4. The velocity is independent of particle mass.

5. In the velocity region of interest, the impaction mechanism is predominant.

6. The number density of particles attached to the fiber is dependent upon the degree of saturation of the bed.

7. Emulsion flowing through the bed does not form a continuum.

8. The probability of a collision between two drops is independent of drop diameter.

Rosenfeld and Wasan (1974) presented a model to measure the overall coalescence efficiency based on an interception mechanism. Sherony et al. (1978) found that results from this model were similar to those obtained by Sherony and Kintner (1971 $a$ and $b)$.

\subsubsection{Adsorption}

Successful design of an adsorption column requires prediction of either the concentration time profile for the effluent or the rate of accumulation of the adsorbate onto the adsorbent surface. Both these predictions involve mathematical models to accurately describe the kinetics of the mass transfer from the bulk of the solution to the bulk of the solid phase. 
A number of mathematical models have been developed for use in the design of adsorbers for wastewater treatment. The earliest models are (1)the kinetic approach developed by Thomas (1948), Weber and Morris (1963) and the scale up approach presented by Fornwalt and Hutchins(1966). The expression by Thomas for an adsorption column is given by:

$$
\frac{C}{C_{0}} \approx \frac{1}{1+\exp \left[\frac{k}{Q}\left(q_{0} M-C_{0} V\right)\right]}
$$

where:

$$
\begin{aligned}
& C=\text { effluent solute concentration }\left(\mathrm{M} / \mathrm{L}^{3}\right) ; \\
& C_{0}=\text { influent solute concentration; } \\
& k=\text { Thomas rate constant }\left(\mathrm{L}^{3} / \mathrm{t} \cdot \mathrm{M}\right) ; \\
& q_{0}=\text { maximum solid-phase concentration of the solute }(\mathrm{M} / \mathrm{M}) ; \\
& M=\text { mass of the adsorbent }(\mathrm{M}) ; \\
& V=\text { throughput volume }\left(\mathrm{L}^{3}\right) ; \text { and } \\
& Q=\text { volumetric flow rate }\left(\mathrm{L}^{3} / t\right) .
\end{aligned}
$$

Thomas equation constants $k$ and $q_{0}$ values can be evaluated using breakthrough data for use in the design of a full-scale adsorption bed. The scale-up approach developed by Fornwalt and Hutchins can be applied to data generated in a column experiment which has been operated at the same liquid flow rate in terms of bed volumes per unit time, as the design column. Since the contact times are the same, it is assumed that the volume of liquid treated per unit mass of adsorbent for a given breakthrough in the test column is the same as for the design column. These two equations have been used in the past for the design of fixed-bed adsorbers (Reynolds 1982; Benefield et al. 1982). 
A functional relationship common to adsorption is that the uptake varies as a function of time for reactions controlled by rates of intraparticle diffusion. Weber and Morris (1963) proposed one such relationship as follows:

$$
\frac{x}{m}=k \sqrt{t}
$$

where:

$k=\mathrm{a}$ constant describing the rate of adsorption; and

$t=$ elapsed time.

It has been shown by Weber and Morris (1963) that this linear relationship existed for many adsorbate-adsorbent system. Although $k$ values obtained have dimensions as solute molarity per weight of adsorbent square root time, the relative values of $k$ should be significant as rate parameters in the adsorption processes.

Keinath and Weber (1968) presented predictive models for the design of fluid-bed adsorbers. It has been demonstrated that the diffusion equations for mass transfer were related closely to Thomas kinetic equation. This model was based on the Langmuir equilibrium condition and the rate limiting step could be either film or internal diffusion.

The bed depth-service time (BDST) method of analyzing adsorption column is based on the model first proposed by Bohart and Adams (1920) for the adsorption of gaseous chlorine on carbon. Later Hutchins (1973) extended its application to wastewater treatment. This BDST model presents a linear empirical equation to predict the breakthrough time as a function of bed depth, flow rate, inlet and outlet solute concentrations.

Roth and Kodavasal(1981) reviewed the BDST model and showed that: 
i. the axial dispersion adversely influences adsorption particularly at low velocities;

ii. the equilibrium is usually well described by the Freundlich equation, but rarely is n equal to unity; and

iii. the pore structure of the adsorbent and the physical properties of the solute determine the diffusion rates within the pores.

Adams and Eckenfelder (1974), Poots et al. (1976) and Saatchi and Oulman (1980) have used the BDST model for adsorption and filtration involved in wastewater treatment. Poots et al.(1976) concluded that this model was not applicable for the adsorption of basic blue dye onto peat even though peat adsorbed the dye upto 50 percent of its weight. Saatchi and Oulman (1980) showed that the BDST model described the filtration of iron by sand in a continuous sand filter. Thus attempts have been made in the past to extend the classical adsorption models to describe the removal of soluble and insoluble pollutants in wastewater treatment. The experimental and theoretical basis for using adsorption model (BDST) for filtration has been presented exhaustively by Saatchi (1979).

Loxham (1980) presented a model to describe the adsorption of pollutants by peat and concluded that the complicated pore geometry of peat made modelling very difficult. The following classifications were made by the author for the adsorption zone in the peai bed:

i. a dead zone with pore spaces smaller than $1 \mu \mathrm{m}$;

ii. a homogeneous zone (type II pore) (Figure 2.1) with pore spaces between 1 and $150 \mu \mathrm{m} ;$ and 
iii. a small zone (type I pore) (Figure 2.1).

Further, the author had also observed that pollutants acting as substrate for bacteria caused more complications in modelling the movement of pollutants in a peat bed. Hammer and Kadlec (1980) presented a model to describe the adsorption of orthophosphate by peat and concluded that bacterial growth did not increase the adsorption rate.

A mong the adsorption mudels describing the kinetics of adsorbate removal in fixedbed granular activated carbon, the homogenecus surface diffusion model (HSDM) developed by C Cittenden and Weber (1978 a,b), Hand et al.(1983) and Crittenden et al.(1987) is more widely used in the environmental engineering practice (Association of Environmental Engineering Professors (AEEP) manual 1988; Clark and Lykins 1989). This model was reported to have successfully predicted the fixed-bed adsorber dyramics of over 100 adsorbate-adsorbent systems (Hand et al. 1984). HSDM was used in the present study to analyze the fixed-bed data to evaluate the performance of peat in adsorbing oil.

The assumptions involved in the HSDM are as follows:

1. the hydraulic loading and influent concentration are constant;

2. there is no radial disfersion or channeling;

3. surface diffusion is much greater than pore diffusion;

4. intraparticle mass transfer mechanism is not a function of concentration;

5. the liquid phase diflusion flux can be described by the linear driving force approximation, using estimates of the film transfer coeflicients; 
6. the adsorber is assumed to be spherical and is in a fixed position;

7. the adsorption equilibrium is described by the Freundlich isotherm; and

8. plug flow exists within the bed.

A detailed procedure for the application of this model in predicting the breakthrough profiles of an acsorption column and parameter estimation ( film transfer coefficient, surface diffusion coefficient and liquid diffusion coefficient) is available in the literature (Liu and Weber 1981; Hand et al. 1984; Crittenden et al. 1987; AEEP 1988; Clark and Lykins 1989).

The dimensionless time of mass throughput $\mathrm{T}$ is defined as:

$$
T=\frac{\text { rate of mass adsorbate fed }}{\text { total mass of adsorbent at equilibrium }}
$$

Hand et al. (1984) presented the following empirical equation for the time dependent throughput volume as a function of $S t_{\min }, B_{i}$ and $\frac{1}{n}$ :

$$
T\left(B_{i}, \frac{1}{n}, S t_{\min }\right)=A_{0}+A_{1}\left(\frac{C}{C_{0}}\right)^{A_{2}}+\frac{A_{3}}{1.01-\left(\frac{C}{C_{0}}\right)^{A_{4}}}
$$

where:

$T=$ single solute mass throughput (dimensionless);

$B_{i}=$ Biot number based on surface diffusion coefficient(dimensionless);

$\frac{1}{n}=$ Freundlich constant;

$S t_{\min }=$ minimum Stanton number required to establish a constant

pattern (dimensionless);

$A_{0}, A_{1}, A_{2}, A_{3}$, and $A_{4}=$ constants in the HSDM equation; and

$\frac{C}{C_{0}}=$ time dependent effluent to influent concentration ratio. 
The valuez of $A_{0}, A_{1}, A_{2}, A_{3}$ and $A_{4}$ were presented by Hand et al. (1984) for different $\frac{1}{n}$ and Biot numbers.

The dimensionless Biot number is defined as:

$$
B_{i}=\frac{\text { rate of liquid phase mass trans fer }}{\text { rate of solid phase mass transfer }}
$$

As $B_{1}$ increases, the liquid-phase mass transfer rate becomes faster as compared to the intraparticle mass transfer rate. The Biot number is given by;

$$
\begin{gathered}
B_{i}=\frac{k_{f} R(1-\epsilon)}{D_{S} D_{g} \epsilon \phi} \\
D_{s}=\frac{\rho_{b} q_{e}}{\epsilon C_{0}}
\end{gathered}
$$

where:

$B_{i}=$ Biot number (dimensionless);

$k_{f}=$ film transfer coefficient $(L / t)$;

$R=$ radius of the adsorbent particle $(L)$;

$\epsilon=$ bed void fraction (dimensionless);

$D_{s}=$ surface diffusion coefficient $(\mathrm{L} / \mathrm{t})$;

$D_{g}=$ solute distribution parameter or partition coefficient (dimensionless);

$\phi=$ sphericity (dimensionless);

$\rho_{b}=$ bulk density of adsorbent in the fixed bed $\left(\mathrm{M} / \mathrm{L}^{3}\right)$;

$q_{e}=$ adsorbate phase concentration in equilibrium with influent phase concentration $(\mathrm{M} / \mathrm{M})$; and

$C_{0}=$ influent fluid-phase concentration $\left(\mathrm{M} / \mathrm{L}^{3}\right)$. 
The dimensionless solute distribution parameter $D_{g}$ is defined as:

$$
D_{g}=\frac{\text { mass of adsorbcte in solid phase in equilibrium }}{\text { mass of adsorbate in liquid phase in equilibrium }}
$$

The adsorbate affinity for the adsorbent increases with an increase in $D_{g}$ values and normally range from 2000 to 5000 (Hand et al. 1984; Crittenden et al. 1987).

There are several methods to calculate the film transfer coefficient $\left(k_{f}\right)$ (Crittenden et al. (1987). The correlation developed by Williamson et al. (1963) is as follows:

$$
\begin{gathered}
k_{f}=\frac{2.4 V_{s}}{S_{c}^{0.58} N_{R_{e}}^{0.66}} \\
S_{c}=\frac{\mu}{\rho_{l} D_{l}}
\end{gathered}
$$

where:

$$
\begin{aligned}
& k_{\jmath}=\text { film transfer coefficient }(\mathrm{L} / \mathrm{t}) ; \\
& V_{s}=\text { superficial fluid velocity }(\mathrm{L} / \mathrm{t}) ; \\
& S_{c}=\text { Schmidt number; } \\
& N_{R_{e}}=\text { Reynolds number; } \\
& \mu=\text { kinematic viscosity of the fluid (M/L.t); } \\
& \rho_{l}=\text { fluid density }\left(\mathrm{M} / L^{3}\right) ; \text { and } \\
& D_{l}=\text { liquid-phase diffusivity }\left(L^{2} / \mathrm{t}\right) .
\end{aligned}
$$

Crittenden et a! (1987) showed that if the molecules are nearly spherical, and molecular weights (MW) are greater than 1000 , the following cori elation developed by Polson (1950) can be used for calculating the liquid diffusion coefficient $D_{l}$;

$$
D_{l}=2.74 \times 10^{-5}(M W)^{-\frac{1}{3}}
$$


Hand et al. (1083) showed that the surface diffusion coefficient $\left(D_{s}\right)$ is dependent on $\bar{t}$, a dimensionless time, and a function of $\bar{C}$, a dimensionless fluid-phase concentration as shown below:

$$
\begin{gathered}
D_{s}=\frac{\bar{t} R^{2}}{t} \\
\ln \bar{t}=A_{0}+A_{1} \bar{C}+A_{2} \bar{C}^{2}+A_{3} \bar{C}^{3}
\end{gathered}
$$

where:

$\bar{t}=$ dimensionless time ;

$A_{0}, A_{1}, A_{2}$, and $A_{3}$ are constants dependent on $\frac{1}{n}$ and Biot number; and $\bar{C}=$ dimensionless fluid-phase concentration as a function of dimensionless time.

Hand et al. (1984) showed that for Freundlich constant $\frac{1}{n}$ less than 1.0, the mass transfer zone remained constant in shape as it moved through the fixed bed (that is, after it was established). Under this condition, known as constant pattern, the Stanton number $(S t)$ given below describes the length of the mass transfer zone:

$$
S t=\frac{k_{\jmath} \tau(1-\epsilon)}{R \epsilon \phi}
$$

where:

$$
\begin{aligned}
& R=\text { radius of the adsorbent }(\mathrm{L}) \\
& \phi=\text { sphericity; and } \\
& \tau=\text { empty bed contact time (EBCT) or fluid residence time in packed } \\
& \text { bed }(\mathrm{t}) .
\end{aligned}
$$


IIand et al. (1984) and AEEP (1988) demonstrated that actual time for the prediction of the concentration profiles dependent on the contact times as:

$$
\begin{gathered}
t=t_{\min }+\left[E B C T_{\text {actual }}-E B C T_{\min }\right]\left(D_{g}+1\right) \\
t_{\min }=E B C T_{\min } \epsilon\left(D_{g}+1\right) T \\
E B C T_{\min }=\frac{S t_{\min } R}{k_{f}(1-\epsilon)} \\
E B C T_{\text {actual }}=\frac{\pi D^{2} L}{4 Q}
\end{gathered}
$$

where:

$$
\begin{aligned}
& E B C T_{\text {actual }}=\text { actual empty bed contact time }(\mathrm{t}) ; \\
& E B C T_{\min }=\text { minimum empty bed contact time required; } \\
& \mathrm{L}=\text { depth of adsorbent in the bed }(\mathrm{L}) ; \\
& \mathrm{D}=\text { diameter of the adsorbent column }(\mathrm{L}) ; \text { and } \\
& \mathrm{Q}=\text { liquid flow rate }(\mathrm{L} / \mathrm{t})
\end{aligned}
$$

\subsubsection{Bacterial action}

Apart from physical chemical forces, biological action can also bring about partial or complete oil removal depending upon the environmental conditions for the microorganisms to act. Information about the biodegradation of hydrocarbons in marine, freshwater and soil environments are available in the literature (Atlas 1988; Leahy and Colwell 1990). The biodegradation of oil in the marine environment has 
been studied extensively. These results summarized below indicate the interactions of microorganisms and oil:

1. In the presence of oil, the population density of hydrocarbon utilizing bacteria always increase (Atlas 1981).

2. Bacteria have the ability to degrade oil and at least 22 genera are known to possess this capacity (Bartha and Atlas 1977).

3. Fresh crude oil inhibits nitrogen fixation whereas weathered oil has no effect (Griffiths et al.1982).

4. Effects of oil on carbon source have been shown to last at least 18 months and have been predicted to last 2 to 3 years. (Griffiths et al.1981 and Griffiths et al. 1982).

5. The readily metabolizable compounds are utilized by the greater part of the bacterial community during a relatively short incubation period (Baker and Griffiths 1984).

Foght and Westlake (1987) and Leahy and Colwell (1990) indicated that while biodegradation of hydrocarbons in marine systems has been the subject of much research due to large scale oil spills, there was relatively little research into the cor* responding freshwater processes. The following are summarized regarding biodegradation of oil in the freshwater systems:

1. The physical state of the hydrocarbon ( solid, liquid or dissolved) determines the ease of bacterial attack (Foght and Westlake 1987). 
2. More than 100 strains of oil-degrading bacteria have been reported. Some of them are; Pseudomonas, Acromobacter, Arthrobacter, Micrococus, Nocordia, Vibrio, Brevibacterium, Corynebacterium and Flavobacterium (Gunkel and Grossmann 1980).

3. In favourable environment, bacteria are responsible for the majority of oil degradation. They usually outnumber the yeasts and fungi population although the biomass of the two groups may be equivalent. Fungi and yeasts would appear to have a significant effect on oil degradation only in conditions which are unfavorable for bacterial growth (Cooney and Summers 1976).

4. Oil-degrading bacteria may be free-living or attached to detrital particles and these attached ones, though fewer in number than the free-living bacteria, show disproportionately greater heterotrophic activity (Kirchman and Mitchell 1982).

5. Some microbes are killed or inhibited by oil, some are unaffected and some will be able to utilize the oil as a carbon source. Generally n- alkanes are degraded quickly (Atlas 1981) and the aromatics are more resistant to biodegradation. Some low molecular weight aromatics (benzene, toluene etc.) are toxic to some microbes due to their solvent action on cell membranes.

6. In both marine and freshwater systems, nutrients such as nitrogen and phosphorus have been shown to be nutrients capable of limiting the degradation of oil (Leahy and Colwell 1990).

7. Oil degradation is favored under slightly alkaline condition (Hambrick et al. 1980). 
8. There are sinnilarities observed between freshwater and marine microbial oil degradation events though experimental evidence is lacking (Foght and Westlake 1981).

Peat is a good support medium for bacterial growth. Population of psychrophilic bacteria have been reported as $2 \times 10^{6}$ cells/g peat (Christensen and Cook 197C). Kong et al. (1980) showed that the bacterial population in peat was higher than fungi and reported to range from 28 to $1600 \times 10^{6}$ per gram of dry peat. The variations in bacterial population were indicated to be due to unfavorable soil $\mathrm{pH}$ (4.0 or less). The authors have also postulated, quoting Waksman and Purvis (1932), that the cellulose and lignin existing in the Sphagnum peat was highly resistant to the action of bacteria. In general, the rate of biological oxidation of carbon has been reported to be slow (per unit of carbon) in peat compared to other plant materials. This was attributed to the presence of inhibiting substances which are pnenolic in nature (Given and Dickenson 1975; Ivarson 1977 ). Kuster (1963)reported peat components to be both stirnulatory and inhibitory to microbial activity.

Wheatley et al. (1976) concluded that bacterial activity in a bog was maximum at the top $1.5 \mathrm{~m}$ depth with counts of $23,000 \times 10^{6} / \mathrm{gram}$ of wet peat. Martin et al. (1982) reported that the bacterial population was $3.4 \times 10^{5}$ to $55 \times 10^{6}$ bacteria per gram of dry peat in a peat bog. Among the bacterial population, the dominant species were reported to be aerobic Gram-negative, mostly of the Pseudomonas (Given and Dickenson 1975, Martin et al. 1982). Williams and Crawford (1983) showed that the bacterial activity in the peat bog was slow and limited due to deficiencies in phosphorus and nitrogen. 
Brooks (1989) studied the treatment of a domestic wastewater in a Sphagnum peat moss and showed that the fungal population dominated over the bacterial population. It was reported that the ratio of fungal to bacterial activity was $8: 1$ in the winter months and 6:2.5 in the summer. The fungal population reported ranged from $1.9 \times$ $10^{6}$ to $1.2 \times 10^{9}$ colony forming units/gram of dry peat.

Kong et al. (1980) were of the opinion that the microbial activity in peat had not been studied extensively. Information on the bacterial activity in peat treating oily wastes are not available in the published literature.

\subsection{Reuse and Disposal of Oil-sorbed Peat}

When an oily wastewater is passed through a medium like peat, the oil moves from the liquid phase and attaches onto a solid phase. As the treatment progresses, eventually the medium loses its capacity to remove oil any further. At this point of exhaustion, usually the medium will be replaced with the fresh one or backwashed and reused.

Backwashing is an option if the medium can release the held oil in a liquid used for backwashing. Pushkarev et al. (1983) indicated that hot water $\left(70\right.$ to $\left.80^{\circ} \mathrm{C}\right)$ was used for backwashing oil-sorbed filters. The higher temperature would cause release and movement of oil by decreasing the viscosity of oil.

Since peat is an inexpensive medium ( $\$ 0.30 \mathrm{per} \mathrm{kg})$, the possibility of replacing the oil-sorbed peat with fresh one appears to be a more promising alternative than backwashing. In that event, land disposal options are to be found for the oil-sorbed peat. It has already been documented that the following options are generally available for the oil-sorbed debris (US EPA 1972; 1974b; 1977a and b). 
i. landfilling with municipal solid waste at sanitary landfills and/or dumps located near the treatment unit site;

ii. burial at specially selected sites;

iii. deposition on vacant land with little or no soil cover;

iv. use in construction projects as a road base; and

v. land cultivation (also called land spreading, land forming and soil incorporation).

The advantages and disadvantages of landfilling, land cultivation and burial are presented in Table 2.8. The priorities for the disposal of oil spill debris recommended by US EPA (1980) are:

i. reclaim as much oil from the waste and reuse as waste oil;

ii. burn, incinerate, pyrolyze the remaining oily debris if air pollution standards can be met;

iii. aerobic microbial decomposition; and

iv. long term anaerobic decomposition in sanitary landfills or direct burial.

In recent years, oil water mixtures, oil and grease and organic and cil residues have been considered as hazardous wastes in Canada (Bird and Rapport 1986). Therefore, it is unlikely that oily debris would be allowed to be land-filled in a municipal solid waste disposal facility.

In the U.S.A., several amendments have already been issued and oil refinerics are facing more stringent regulations for the storage, treatment and disposal of oily wastes 
Table 2.8. Advantages and disadvantages of landfilling (US EPA 1980)

\begin{tabular}{|c|c|c|}
\hline Description & Advantages & Disadvantages \\
\hline $\begin{array}{l}\text { Land } \\
\text { cultivation }\end{array}$ & $\begin{array}{l}\text { * Oil is degraded, minimizing } \\
\text { long-term environmental threat } \\
\text { * Land surface reversible for } \\
\text { debris or other purpose } \\
\text { * Soil properties may be } \\
\text { improved }\end{array}$ & $\begin{array}{l}\text { * Opportunity for oil } \\
\text { volatilization and thus } \\
\text { air pollution is increased } \\
\text { * Periodic soil mixing is required } \\
\text { * Relatively costly } \\
\text { * Stacking at the disposal } \\
\text { site may be necessary } \\
\text { * May be impractical to } \\
\text { implement during inclement } \\
\text { weather condition }\end{array}$ \\
\hline $\begin{array}{l}\text { Landfilling } \\
\text { with reuse }\end{array}$ & $\begin{array}{l}\text { * Minimal equipment } \\
\text { * Relatively low initial cost } \\
\text { * Minimal site preparation } \\
\text { * Availability of sites }\end{array}$ & $\begin{array}{l}\text { * Land is not available } \\
\text { immediately for use } \\
\text { * Long-term pollutional } \\
\text { effects requiring monitoring }\end{array}$ \\
\hline Burial & $\begin{array}{l}\text { * Covering minimizes volatilization } \\
\text { * Relatively quick in completion }\end{array}$ & $\begin{array}{l}\text { * Land is not available } \\
\text { immediately for use } \\
\text { * Long-term pollutional } \\
\text { effects requiring monitoring }\end{array}$ \\
\hline
\end{tabular}


classified as hazardous materials. Long-term disposal methods such as land forming are phased out and refineries are changing their waste management practice to suit the ame.:ded regulation (Olschewsky and Megna 1988). The US EPA has imposed current hazardous waste performance standards on existing solid waste facilities (Spracker 1985). Trunick (1987) was of the opinion that due to clean-up liability provision under new hazardous waste classification, landfill operators were hesitant to accept hazardous wastes. Special sites with double synthetic liners are required to dispose oily drilling wastes (Haight 1987).

The classification of oily wastes under hazardous material restricts the disposal in a solid waste landfill sites; therefore, the cost of disposing oily wastes are increasing considerably. Material recovery and on-site incineration options are gaining attention as promising treatment methods for the final disposal of hazardou's oily materials (Hertzberg 1986; Witherspoon and Swiss 1986; Yates 1987; Rotman 1988 and De Young 1988). The oil-sorbed peat can be squeezed to recover waste oil consistent with the current trends in the disposal of solid and hazardous wastes.

Oil and peat are used as fuel for burning. Thus a mixture of peat and oil may increase the calorific value to some extent. The calorific value of Saskatchewan's fucl peat had been reported as 19665 - $21338 \mathrm{~J} /$ mole (8470 - $9170 \mathrm{BTU} / \mathrm{lb}$ )(Saskatchewan Mineral Resources 1981). For heavy fuel oil, the calorific value has been reported as $41422-41840 \mathrm{~J} / \mathrm{mole}(17000-18000 \mathrm{BTU} / \mathrm{lb})$. If the oil-sorbed peat has to be used as a fuel material, moisture reduction will have to be considered for increased calorific values.

In an evaluation of the effects of land application of oil and gas drilling wastc on soils and crops in the Kindersley and Esteven regions of Sa katchewan, Abouguendia 
et al. (1987) showed that freshwater based drilling wastes applied to agricultural land at a rate of 247 barrels/ha. (100 barrels/acre) had little or no effect on soil characteristics or plant growth. The oil concentrations of the waste samples applied on land have not been mentioned in the report. However, the study recommended that the present off-lease maximum application rate of 247 barrels/ha. (100 barrels/acre) indicated in the Saskatchewan Approval Guidelines (Saskatchewan Energy and Mines 1986) be retained. Peat as such is being used extensively in horticulture as a soil conditioner for plant growth. Thus oil-sorbed peat possesses several advantages for its application on land.

Biederbeck and Jacques (1988) studied the application of oily wastes from heavy oil operations on a sandy cultivated soil at Maidstone near Saskatchewan to determine the optimum conditions for utilizing oily wastes to improve soil quality and yield, and to minimize contamination of crops and soil by polynuclear aromatic hydrocarbons. The major positive effects based on this study were as follows:

i. reduction in soil erosion;

ii. increase in soil respiration due to increased microbial activity;

iii. higher populations of soil microorganisms, particularly hetrotrophic bacteria and hydrocarbon degraders;

iv. extensive uptake of mineral nutrients by the microorganisms prevented the loss of nutrient from top soil due to leaching;

v. strong herbicidal action of oily residues as weed growth $\ldots .$. inhibited much more than the growth of cereal crops and there was a now li,r weed control tillage in summer fallow; 
vi. neither grain nor straw of wheat grown on sludge-treated soil was contaminated with any potentially harmful (carcinogenic) and persistent polyaromatic hydrocarbons compounds.

The major negative effects were as follows:

i. extensive reduction in hydraulic conductivity of soil due to hydrocarbon coating of sand grains, however the hydraulic conductivity never fell below $0.09 \mathrm{~m} / \mathrm{h}$;

ii. with sludge incorporation, the salt content in the top soil ircreased 10 to 20 fold and decreased due to natural leaching (rain and snow melt);

iii. rapid and extensive immobilization of plant-available nutrients;

iv. breakdown of incorporated oily wastes was rather slow due to the decrease in soil aeration zone, this increased the anaerobic zone near the top of the soil where the oil contents were less than 1 percent; and

v. the reductions in wheat yield increased (from 25 to 99 percent) when the top soil oil concentration was greater than about 0.6 percent.

Further Biederbeck (1989) concluded that extensive improvements in structure and biological activity of sandy soil could be achieved without excessive reduction in grain production by reducing the toxicity of unmetabolized hydrocarbon residue, by maintaining the oil content in the surface soil below 0.5 to 0.7 percent.

Holmes (1980) was of the opinion that treatment of oily debris required a unique solution for the satisfactory disposal at each location. Knowlton and Ricker (1980) and Wahbeh (1980) concluded that land farming offered the most economical and environmentally safe option for the treatment and disposal of oil-spill debris. 
The results of these studies generally indicate that several options are available for the disposal of oil-sorbed peat. However, site specific and pollutant specific studies are needed to determine the short- and long-term effecis of oil-sorbed peat on soil, water, crop and air (in case of burning). 


\section{MATERIALS AND METHODS}

\subsection{Materials}

\subsubsection{Selection and preparation of oil-in-water emulsions}

Crude oil has been described as probably the most complicated natural mixturc on earth (Carlberg 1980). It consists mainly of hydrocarbons (50 to 98 percent) with variable amounts of oxygen, sulfur and nitrogen. The composition of oil varies from field to field, between wells within a field and even between samples from the same well. It is therefore not possible to give a precise constitution for crude and no concise system has been developed for adequately classifying different crudes (Clark and Brown 1977). The American Petroleum Institute provides four reference oils, two crudes (Louisiana and Kuwait) and two refined oils (No.2 fucl and Bunker-C fuel) for comparison (Clark and Brown 1977). In the present study, the following oil-in-water emulsions (two refined oils, one crude oil, two industrial wastes and one treated industrial effluent) have been used:

1. Medium viscous ( $130 \mathrm{mPa} . \mathrm{s})$ standard (light) mineral oil (SMO) markeled by Fisher Scientific Company, U.S.A.;

2. Low viscous ( $50 \mathrm{mPa} . \mathrm{s}$ ) Midale crude oil (MCO) from Midale oil field in Saskratchewan, Canada, collected through Saskatchewan Research Council, Petroleum Division, Regina, Saskatchewan; 
3. Cutting Oil (CO) collected from a lathe at Saskatchewan Institute for Applied Science and Technology (SIAST), Wascana Campus, Regina (marketed by Castrol Canada Inc; Castrol Clearedge EP 284);

4. Refinery effluent (RE) collected from the wastewater treatment lagoon effluent of the Co-operative Oil Refinery, Regina, Saskatchewan;

5. Produced water (PW) (water discharged from production wells at Swift Current, Saskatchewan, after enhanced oil recovery using in-situ combustion); collected through Saskatchewan Research Council, Petroleum Division, Regina, Saskatchewan, Canada; and

6. Standard mineral oil stabilized with oleic acid and triethanolamine for controlled experiments to study breakdown mechanisms.

In the case of SMO and MCO, synthetic emulsions were prepared by adding a known amount of oil to tap water and mixing these fluids in a high speed ( $3450 \mathrm{rpm}, \frac{1}{4} \mathrm{hp}$ motor) blender (Reliance Electric Company, U.S.A, Model L48C) for two hours. The blend was then allowed to stand for 30 minutes. The floating oil was decanted and the dispersed sample was used in the experiments. The use of deionized water was not considered as it is not common in oily wastewater discharges. The oily discharges from the food processing industry, workshops and car wash plants mostly use tap water and therefore tap water was used in the experiments to prepare oil-in-water emulsions. Grab samples were used in the case of $\mathrm{CO}$ and RE. For some column and batch experiments, synthetic $\mathrm{CO}$ enulsions were prepared in the laboratory (instead of arab samples from SIAST, Wascana Campus) by dissolving a known amount of EP 284 cutting oil in tap water. Since this oil is a soluble oil, no blenders were used for 
mixing and there was also no need to decant the floating oil. Two PW samples (one with high salinity and low oil concentration and the other with low salinity and high oil concentration) were used in the batch and 8- hour column studies. A third sample was used in the column breakthrough studies. These PW samples were characterized for salinity, conductivity, total solids, total carbon and $\mathrm{pH}$ as per "Standard Methods" (American Public Health Association, (APHA 1985).

For controlled emulsions used in studies related to breakdown mechanisms, a known amount of SMO with oleic acid and triethanolamine was mixed with tap water using a $\frac{1}{100} \mathrm{hp}, 5000 \mathrm{rpm}$ (Greiner Scientific Corporation, U.S.A., Model 77912-02) motor as per the phase-inversion method presented by Lissant (1977). The phase-inversion method is useful for producing oil-in-water emulsions with small drop sizes. In this procedure, a fatty arid (oleic acid) is added to the known weight of SMO and heated to just below the boiling point of water $\left(90^{\circ} \mathrm{C}\right)$. An amine salt emulsifier (triethanolamine) is added to the water phase and heated just below the boiling point. The water is then added to the oil with vigorous mixing using a $\frac{1}{100}$ hp, 5000 rpm motor (Greiner Scientific Corporation, U.S.A., Model 77-912-02) and, at first, a water-in-oil emulsion results. Since the emulsifier used is not suitable for producing high-internal-phase-ratio emulsions, the thick water-in-oil emulsion inverts suddenly, resulting in an oil-in-water emulsion with very small droplet sizes. 


\subsubsection{Peat, pretreated peat and other media considered}

\subsubsection{Peat.}

Horticultural peat (HORT) produced at the Carrot River plant of Premier Peat Company (formerly Saskatchewan Minerals) of Saskatchewan was used in the experiments. The Sphagnum peat moss was processed at the plant after harvesting from a bog. The processing at the plant involves essentially dewatering and sieving. This horticultural peat was hand cleaned in the laboratory to remove large pieces of wood, stems etc., washed in running tap water for 15 minutes and air dried for 24 hours before its use in the experiments. This peat was characterized for particle size, moisture, $\mathrm{pH}$, organic matter, sand, ash content, fiber content, cation exchange capacity (CEC), porosity, surface area and oil-binding capacities as per the procedures presented later in 3.1.3.

\subsubsection{Pretreated peat.}

The horticultural peat was subjected to the following physical and/or chemical pretreatment procedures to enhance its oil-adsorption capacity.

1. Oven drying at $103^{\circ} \mathrm{C}$ for one day (OD-1): The washed and air-dried horticultural peat was oven dried at $103^{\circ} \mathrm{C}$ for one day.

2. Oven drying at $103^{\circ} \mathrm{C}$ for three days (OD-3): The washed and air-dried horticultural peat was oven dried at $103^{\circ} \mathrm{C}$ for three days.

3. Wet heating and air drying (WH\&A): The washed and air-dried horticultural peat was mixed with tap water and the slurry was boiled in an open beaker for 
15 minutes. The cooled slurry was filtered and air dried at room temperature for 48 hours with periodical overturnings.

4. Wet heating and oven drying (WH\&O): The wet heating was carried out as per the procedure explained in the third scheme; but instead of ait drying, the peat was oven dried at $103^{\circ} \mathrm{C}$ for 24 hours.

5. Acid treatment (ACID): Sulfuric acid (IN) was mixed with a washed and airdried horticultural peat sample and allowed to stand for 15 minutes. The slurry was filtered, washed in running tap water for 15 minutes and air dried at room temperature for 48 hours with periodical overturnings.

6. Alkali treatment (ALKALI): Sodium hydroxide (IN) was mixed with a washed and air-dried horticultural peat and allowed to stand for 15 minutes. The slurry was filtered, washed in running tap water for 15 minutes and air dried at room temperature for 48 hours with periodical overturnings.

7. Wet pyrolysis at $150^{\circ} \mathrm{C}(\mathrm{P} 150)$ : (Procedure under item 12 below:)

8. Wet pyrolysis at $175^{\circ} \mathrm{C}(\mathrm{P} 175)$ : (Pocedure under item 12 below:)

9. Wet pyrolysis at $200^{\circ} \mathrm{C}(\mathrm{P} 200)$ : (Pocedure under item 12 below:)

10. Wet pyrolysis at $225^{\circ} \mathrm{C}(\mathrm{P} 225)$ : (Pocedure under item 12 below:)

11. Wet pyrolysis at $250^{\circ} \mathrm{C}(\mathrm{P} 250)$ : (Pocedure under item 12 below:)

12. Wet pyrolysis at $275^{\circ} \mathrm{C}(\mathrm{P} 275)$ : Wet pyrolysis of washed and air-dried horticultural peat was carried out in a PARR laboratory reactor of $600 \mathrm{~mL}$ capacity for all the samples (item 7 to 12$)$. The peat $(24 \mathrm{~g}$ ) and $150 \mathrm{~mL}$ of tap water 
was heated to six different temperatures $\left(150,175,200,225,250,275^{\circ} \mathrm{C}\right)$ under pressures ranging from $577.37 \mathrm{kPa}$ to $6386.26 \mathrm{kPa}$ (83.74 psig to 926.25 psig). After reaching the required temperature and pressure, the slurry was maintained at the same condition for 15 minutes. Then the reactor was turned off and allowed to cool fur 24 hours before collecting the pyrolyzed samples. On an average, the temperature rise was 6 to $7^{\circ} \mathrm{C} / \mathrm{min}$. The collected samples were washed in running tap water for 15 minutes and air dried for 48 hours with periodical overturnings.

These pretreated samples were characterized for moisture, ash, organic matter,pH, oil binding capacity, and cation exchange capacity as per the procedures presented in 3.1.3.

\subsubsection{Other media considered.}

The oil removal efficiencies of horticultural and pretreated peat samples were compared with the oil removal efficiencies of the following media:

1. Ottawa sand (SAND): cleaned, sieved using US sieve No. 12 (particle size $<$ $1.2 \mathrm{~mm}$ ), washed and air dried.

2. Estevan coal (COAL): Estevan Souris (shallow coal zone) coal supplied by Prairie Coal Limited, Estevan, Saskatchewan. The coal was cleaned, sieved (particle size $<1.2 \mathrm{~mm}$ ) and air dried.

3. Pink fiberglass (FG): Supplied by Fiberglass Canada, Inc., Regina, Saskatchewan;

4. Amberlite (XAD-2): A synthetic resin supplied by Rohm and Haas Canada,Inc., Toronto, Ontario; 
5. Polypropylene (PP): Reinforced needle felt. 100 percent polypropylene, supplied by Filterfab Inc., Toronto, Ontario; and

6. Activated carbon (AC): Filtrasorb 400, supplied by Calgon, Toronto, Ontario.

\subsubsection{Characterization of oil-in-water emulsions and peat samples}

\subsubsection{Oil-in-water emulsions}

The viscosities of the oils were measured using a Brookfield Synchro-Electric viscosity meter (Brookfield Engineering Lab, Inc., U. S. A., Model RVF).

The interfacial tension between the oils and tap water (SMO, MCO and SMO stabilized with chemical emulsifiers) was measured at the Saskatchewan Research Council laboratory (Petroleum Division), Regina, according to the spinning drop technique in a spinning drop interfacial tensiometer (EOR Inc., U. S. A., Model LP. 10).

The contact angles between peat and two oils (SMO and MCO) were measured using photographs to identify the wetting property. For this, the peat medium was pressed into pellets using a thermopress (AB speed presses, Buehler Ltd., U. S. A., Model 20-1331). These pellets were glued onto a small plate and set horizontally in a glass beaker filled with water. A drup of oil was released beneath the film through a squeezer on to the top of the peat pellet. A picture was taken and the contact angle was measured (Chieu et al. 1975).

The diameter of the oil droplets were measured using a Spectrex laser particle counter (Spectrex Corporation, U.S.A., Model SPC-510). Photographs of the emulsions were taken using a Nikon microflex (Nipon Kogaku, U. S. A., Model PFM) 
microscope.

\subsubsection{Peat samples}

A sieve analysis of the peat samples was carried out according to the procedure suggested by ASTM (1963) (D422-63) and ASTM (1958) (D421-58). Oven-dried $\left(103^{\circ} \mathrm{C}\right.$ for 12 hours) peat $(45 \mathrm{~g})$ was sieved through a stack of sieves ranging in size from 4 mesh to 200 mesh. After shaking the stack of sieves, the peat remaining on each sieve was weighed. The amount retained in percent on each sieve was then calculated. The amont of fines (in percent) was then computed by subtracting the amount retained on each sieve from 100 percent as a cumulative procedure. A semilog plot of grain size versus percent fines was used to determine the coefficient of uniformity, the coefficient of concavity and the effective size.

The particle size range of the peat sample was determined as per the ASTM (1971d) (D2977-71) procedure. The air-dried peat sample (20 g) was passea through 8 and 20 mesh sieves and shaken for 10 minutes with a bottom pan to collect the samples finer than the two meshes. The fractions retained on 8 and 20 mesh sieves were weighed and reported as coarse and medium fibers respectively. The fraction collected on the pan was weighed and reported as fines.

The porosity of the peat sample was determined by the flooding technique. In this method; a known volume of peat sample was placed in a measuring cylinder and flooded with water up to the top. The mouth of the measuring cylinder was sealed with para film to prevent peat particles from floating on top of water. The amount of water required to fill the voids in the peat sample was measured and the porosity was determined. 
The moisture content of the peat sample was determined as per the ASTM (1971a) (D2974-71) procedure. The peat samples were mixed thoroughly and a representative quantity of the sample was placed in a pre-weighed porcelain dish. The peat sample was then oven dried at $105^{\circ} \mathrm{C}$ for 16 hours and then cooled and weighed. The loss in weight was used to calculate the moisture content. Another method (Method II) was also specified by ASTM (1971a) (D2974-71). In this method, the equilibrium moisture was determined by air-drying peat sample at room temperature to an equilibrium (constant weight) value. The sample was over turned periodically for maximum air exposure. The air-dried sample was then ground and a representative quantity of the air-dried sample was dried in an oven at $105^{\circ} \mathrm{C}$ for 24 hours. The peat sample was weighed and the moisture content was determined.

The $\mathrm{pH}$ of the peat samples was determined by electrometric measurement as per the ASTM (1971c) (D2976-71) procedure. A known weight fraction (3 g) of air-dried peat was placed in $350 \mathrm{~mL}$ of deionized water and allowed to soak for 30 minutes with occasional stirring. The $\mathrm{pH}$ was then read using a Accumet Selective Ion Analyzcr (Fisher Scientific Ltd., Model 750). A similar $\mathrm{pH}$ determination was also made for peat samples soaked in calcium chloride. The sand content of the peat samples was determined as per ASTM (1971b) (D2975-71).

Surface area measurements were carried out at the Department of Chemical Engineering, University of Saskatchewan, Saskatoon, by adsorption measurements in the Micrometrics apparatus (Instrument Corporation, Noroross, Georgia, U. S. A., Model 2100D). The adsorption measurement was carried out using nitrogen (supplied by Linde, purity 99.99 perceni) at liquid nitrogen temperature. The sampie size was approximately $2 \mathrm{~g}$. Prior to adsorption, the sample was degassed at $100^{\circ} \mathrm{C}$ under 
vacuum $(0.0015$ Torr $)$ for 16 hours and then cooled to liquid nitrogen temperature for adsorption. The pressure range for the adsorption measurement was $33.25 \mathrm{~Pa}$. The equilibrium pressure was attained within 15 minutes. Dead volume measurement was done with He. The amount of nitrogen adsorbed per gram was calculated using the BET isotherm. Based on the number of molecules involved in the adsorption and using the cross-sictional area of each nitrogen molecule, the surface area was calculated.

Scanning electron microscope (SEM) pictures of peat samples were taken at the Department of Biology, University of Saskatchewan, Saskatoon, to examine the peat structure.

The fiber content of the peat samples was determined as per the procedure outlined by Riley (1986). About $20 \mathrm{~g}$ of peat sample was mixed with $200 \mathrm{~mL}$ of deionized water, in a $300 \mathrm{~mL}$ plasticized paper tub, covered and allowed to stand overnight. The sample was then mixed at $240 \mathrm{rpm}$ for 10 minutes and allowed to stand for about 6 hours. Then the sample was poured into a 100 mesh $(0.15 \mathrm{~mm})$ sieve and washed with tap water using shower arrangements at a rate of about $5 \mathrm{~L} / \mathrm{min}$. Midway through washing, the sieve was covered and immersed in a 2 percent $\mathrm{HCl}$ solution to dissolve any carbonates that were present. The washing was continued until the rinse water was clear (approximately 10 minutes). The fibers retained on the mesh were carefully collected, oven dried $\left(90^{\circ} \mathrm{C}\right)$ for 24 hours, cooled and weighed. The results were expressed as percentage fiber $>0.15 \mathrm{~mm}$.

The cation exchange capacity (CEC) was cietermined using the method suggested by Riley (1986). The total amount of exchangeable cations in the peat sample was determined using $25 \mathrm{~g}$ of peat mixed with $200 \mathrm{~mL}$ of $1 \mathrm{M}$ neutral ammonium acetate 
and allowed to stand for 10 minutes. The mix was filtered through No.44 Whatman filter paper into a dry filter flask. The peat samples were rinsed four times with $50 \mathrm{~mL}$ of isoprof $:$ alcohol. The washings were rejected. The residue on the filter was leached with 30 to $50 \mathrm{~mL}$ portions of $\mathrm{KCl}$ solution to disperse adsorbed $\mathrm{NH}_{1}^{+}$ nitrogen. Allowing sufficient time between two filtration operations, the leaching was continued until about $250 \mathrm{~mL}$ was collected in a clean conical flask. The total volume was made up to $250 \mathrm{~mL}$ by adding deionized water.

A $25 \mathrm{~mL}$ aliquot wis transferred into a Kjeldahl nitrogen apparatus (Kjeltec system, Model 1002) and the nitrogen content was determined. Using the percentage nitrogen, the dry weight of the peat sample and the moisture content, the CFC; was calculated and expressed as $\mathrm{CEC} / 100 \mathrm{~g}$ of dry peat.

The average pore sizes of the peat samples were determined using a microscope (Nikon Microflex, Nipon Kogaku, U.S. A., Model PFM). Over 40 measurements were taken and the average fiber size was reported as a mean with standard deviation.

The degree of humification (von Post scale) was determined by visual inspection of the peat substance and the water released by pressing the peat sample by hand (Tibbetts 1976).

The calorific values of the peat samples were measured at Sask Power, Technical Services and Research Laboratories, Regina, using an adiabatic bomb calorimeter (Parr Instruments, U. S. A.,Model 1241). Calorific values for horticultural peat and oil-sorbed (SMO, MCO and $\mathrm{CO}$ ) horticultural peat sample were measured. The amount of oil added was determined from the breakthrough studies. For a breakthrough oil concentration of $15 \mathrm{mg} / \mathrm{L}$ (effluent discharge requirements for oil and grease), the amount of oil adsorbed per unit weight of peat $\left(\frac{x}{m}\right)$ was computed using 
a mass balance approach. Accordingly, $0.83,0.75$ and $0.04 \mathrm{~kg}$ of SMO, MCO and $\mathrm{CO}$ respectively were thoroughly mixed per $\mathrm{kg}$ of peat. Calorific values for air-dried, water-saturated, and oven dried $\left(103^{\circ} \mathrm{C}\right)$ peat samples were determined for comparison.

About 1000 to $2000 \mathrm{mg}$ of peat was pressed and made into a pellet and the rise in temperature in the calorimeter was noted to the nearest third decimal place. During the process of pressing, some amount of $\mathrm{MCO}$ was released from the peat sample. This was not noticed with the other two oils (SMO and $\mathrm{CO}$ ). Corrections were applied for the nitrogen and sulfur present in the peat, and also for the unburnt fuse left in the calorimeter. The final heat values were reported as $\mathrm{J} / \mathrm{mol}(\mathrm{btu} / \mathrm{lb})$.

Experiments to quantify the amount of oil (SMO, MCO and $\mathrm{CO}$ ) released by pressing the oil-sorbed peat were conducted in an apparatus shown in Figure 3.1. Oil was added to air-dried horticultural peat at a $\frac{x}{\mathrm{~m}}$ value of $2(2 \mathrm{~kg}$ of oil per $\mathrm{kg}$ of peat). The samples were mixed thoroughly and about 2000 to $3000 \mathrm{mg}$ of oil-sorbed peat was placed in the aluminium container and the aluminium piston placed on top of the samples. A pressure ranging from 689 to $13,788 \mathrm{kPa}$ (100 to $2000 \mathrm{psig}$ ) was applied to the aluminium piston using a hydraulic jack. The weight of the peat samples was determined after applying pressure over a period of $0,5,10,1.5$ and 30 minutes. The amount of oil released was calculated using the difference in weight between the initial sample weight (of oil-sorbed peat before pressing) and the weight of the sample after application of the pressure for a given time. Experiments were conducted with SMO, MCO and CO samples.

The oil-binding (or oil-absorption) capacity was measured as per the procedure suggested by ASTM (1960) (1483-60), modified by D'Hennezel and Coupal (1972). 


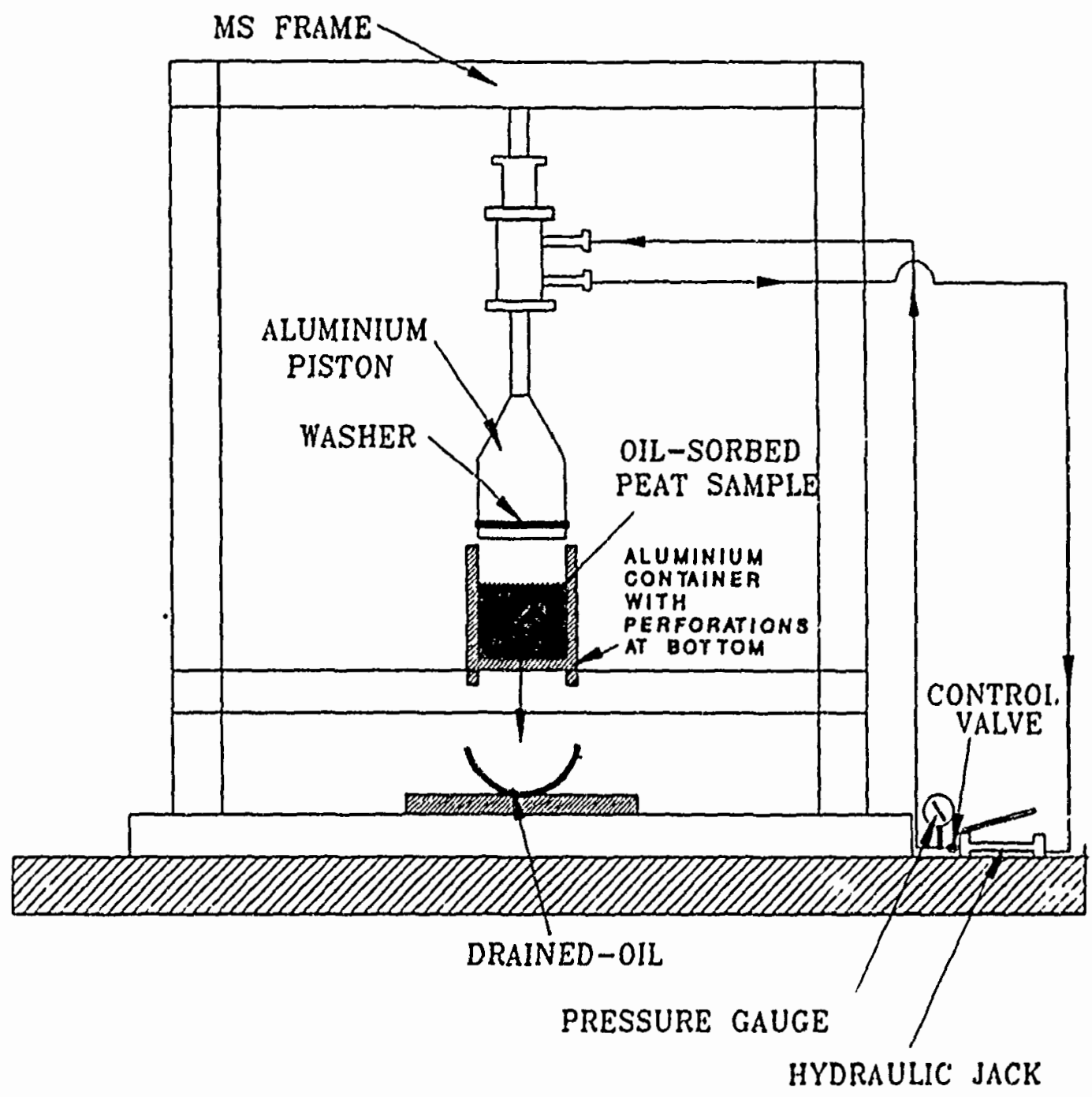

Not to Scale

Figure 3.1. Apparatus for pressing the oil-sorbed peat samples 
In the ASTM procedure, a given amount of peat moss $(5 \mathrm{~g})$ was placed in a stainless steel cup and while stirring constantly oil was added at a very slow rate until the peat moss agglomerated into a single lump. In the modified procedure $5 \mathrm{~g}$ of peat was immersed into the oil, slowly mixed, and was allowed to stand for 30 minutes. The oil was then allowed to drain for 6 hours until the dripping stopped. The oil-sorbed peat was weighed and the oil-binding capacity was calculated.

\subsection{Methods}

\subsubsection{Analytical procedure for oil measurement}

Unlike some constituents that represent distinct chemical elements (ions, compounds or groups of compounds), oils and greases are defined by the method used for their determination (American Public Health Association 1985). Several procedures, instruments and solvents are available for the extraction and measurement of oil. The choice of a method and solvent is still an open issue.

For liquid samples, four methods are mentioned in the "Standard Methods (APHA 1985) for the determination of oil and grease, with their significance and limitations. The partition-infrared method (503 B) uses a known standard reference oil (37.5 percent iso-octane, 37.5 percent hexadecane and 25 percent benezene) against which trichlorotrifluoroethane (1,1,2-trichloro-1,2,2-trifluoroethane or Freon equivalent) extractables are measured as oil and grease. This standard reference oil can be used only when the oil present in the water is not known. This "unknown oil" is defined as one for which a representative sample of oil and grease is not available for the preparation of a standard. However, in some of the industria! wastewater discharges, the source oil is known (e.g. crude oil, cutting oil, vegetable oil etc.). This known oil 
is defined as a sample of oil and/or grease that represents the only material of that type used or manufactured in the processes represented by a wastewater. Therefore, in such circumstances the "known oil" is used as a standard reference oil so that the variability that can arise due to comparison with unknown reference oil can be eliminated. The American Petroleum Institute (1958) indicated this variability to be \pm 20 percent with the use of synthetic calibration oil as against \pm 10 percent with the use of a representative calibration oil. In the present study, MCO has been used as a reference oil for unknown oils encountered with refinery effluent discharges and produced waters. For other known oils such as SMO, and $\mathrm{CO}$, the respective oils have been used for preparing a standard calibration chart.

Anomalies in oil and grease analyses of petroleum wastewaters and their implications were discussed by Sun et al.(1987). The study showed that in certain cases the variation in oil concentration from a refinery wastewater varied by 200 percent due to interference of soluble organics which were not extracted fully in the method (503A) specified in "Standard Methods". A review of various methods and solvents used for extracting oil from water was summarized by Stenstrom et al. (1986). It was indicated that the use of spectrophotometry overcomes two major shortcomings of gravimetric techniques namely:

i. it extends the nominal limit of detection of oil and grease to levels below 10 $\mathrm{mg} / \mathrm{L} ;$ and

ii. the evaporation of the solvent is less in the IR spectrophotometry technique which reduces the loss of low molecular weight compounds.

Therefore, in the present study IR spectrophotometric detection of oil and grease as outlined in 503B of "Standard Methods" was followed. Instead of Freon 113 as 
a solvent, carbon tetrachloride $\left(\mathrm{CCL}_{4}\right)$ has been used in view of its high extraction efficiency and sensitivity. Its use for extracting oily wastes has been well reported in the literature (American Petroleum Institute 1958; Simard et al. 1951; Beckman 1968; UOP 1972; Gruenfeld 1973; Horiba 1983). Carbon tetrachloride has been identified as a suspected carcinogen. Therefore, the use and handling of this solvent needs extreme precaution to avoid health risks.

The procedure for the extraction and measurement of oily material from oil-inwater emulsions involved acidifying the sample $(200 \mathrm{~mL})$ to $\mathrm{pH} 5$ using hydrochloric acid. The sample was then transferred into a conical extraction fiask and $10 \mathrm{~mL}$ of hydrochloric acid was added. The mixture was thoroughly shaken for 10 to $15 \mathrm{~min}$ utes to extract the oily materials. When it was allowed to settle for 5 to 10 minutes, the $\mathrm{CCl}_{4}$ separated from the water and settled to the bottom. The $\mathrm{CCl}_{4}$ layer was carefully drained through filter paper (Whatman No.5) and a sodium sulphate bed into a volumetric flask and stoppered. Three such extractions of each $10 \mathrm{~mL}$ were collected for each measurement. Infrared scanning was done using this extracted $\mathrm{CCl}_{4}$ in a $1 \mathrm{~cm}$ cell from wavenumbers $2700-3100 / \mathrm{cm}$. The sum of the absorbances at two peaks $(2860 / \mathrm{cm}$ or $3.50 \mu \mathrm{m}$ and $2830 / \mathrm{cm}$ or $3.42 \mu \mathrm{m})$ was calculated. The concentration of oil for the calculated absorbance was obtained from a standard calibration chart prepared using known weights of oil in $\mathrm{CCl}_{4}$. If the absorbance exceeded 0.8 for any sample, dilutions were performed.

In the first year of this research (1986-87), a Beckman IR-4 spectrophotometer was used. Later a Beckman IR-4 and a Perkin Elmer FT-IR spectrophotometer model 1600 were used. During 1988, a Horiba OCMA-220 oil content analyzer with an integral extractor (which can automatically extract oily substances using a preset 
time) was procured and used in the measurement of oil. All these instruments are basically IR spectrophotometers capable of measw. ' $\mathrm{g}$ hydrocarbon concentrations at wavenumbers 2700 to $3100 / \mathrm{cm}$.

Due to the change in procedures with the use of the Horiba oil-content analyzer, it is reasonable to expect some variability in the measurements of oil. An experiment was conducted to statistically compare variations in the performance of the two solvents (Freon 113 and $\mathrm{CCl}_{4}$ ) in extracting oily materials from water, using two different instruments (Perkin Elmer with manual extraction and Horiba oil-content analyzer with automatic extraction). The combinations were grouped into four different methods as follows:

1. Method 1 (M1): Procedure as specified in 503B of "Standard Methods" involving manual extractions using Freon 113 and analyzing the extractions using the Perkin Elmer, FTIR spectrophotometer. The samples were acidified to pII 2 prior to extraction.

2. Method 2(M2): Same as M1; instead of Freon 113, carbontetrachloride was used for extracting oily materials. The samples were acidified to pHI 5 prior to extraction.

3. Method 3 (M3): Acidification ( $\mathrm{pH} \mathrm{2)} \mathrm{and} \mathrm{solvent} \mathrm{(Freon} \mathrm{113)} \mathrm{are} \mathrm{similar} \mathrm{to}$ M1. Instead of Perkin Elmer FTIR, the Horiba OCMA 220 NDIR oil content analyzer with automatic extraction was used.

4. Method 4 (M4): Acidification ( $\mathrm{pH} 5)$ and solvent $\left(\mathrm{CCl}_{4}\right)$ are similar to M2. Instead of the Perkin Elmer FTIR, the Horiba OCMA 220 NDIR oil content analyzer with automatic extraction was used. 
These four methods were compared using two different oils namely SMO and MCO.

The oil-in-water emulsions (standards) used in the experiments were synthetically prepared by mechanical agitation of tap water with known amount of the oils. Oleic acid and triethanolamine were used as emulsifiers in the phase-inversion method presented by Lissant (1974). The standard oil concentrations used for the experiments ranged from 10 to $500 \mathrm{mg} / \mathrm{L}$. Sixteen such standards were prepared for measuring oil concentration using the above four methods. Details of the four test methods used are presented in Table 3.1.

\subsubsection{Batch experiments}

\subsubsection{Equilibrium time}

Batch kinetic studies were conducted using a jar test apparatus at room temperature $\left(21 \pm 0.5^{\circ} \mathrm{C}\right)$. When peat particles are placed in an oil dispersion and agitated or mixed to give adequate contact time, the adsorption of oil occurs. The oil concentration will decrease from an initial value to an equilibrium value if the contact time is sufficient. The time needed to reach equilibrium is defined as the equilibrium time. Peat samples, in amounts of $1.0,0.5$, and $0.1 \mathrm{~g}$ per $200 \mathrm{~mL}$ oil containing wastewater were mixed at $60 \mathrm{rpm}$ to determine the equilibrium time. Samples were withdrawn at $0.25,0.50,1,2,3$ and 4 hours intervals. The slurry was filtered using a glass wool bed to separate peat and oil-containing waste. The filtrate was extracted and analyzed for oil concentration. Experiments were duplicated and the average values were used in the calculations. Equilibrium time plots were drawn for each of the three quantities of peat used, by plotting oil concentration vs time. From these plots, the equilibrium time was identified for all five representative oil-in-water emulsions investigated in 
Table 3.1. Details of test methods for comparing the measurement of oil

\begin{tabular}{|c|c|c|c|c|}
\hline Description & Method 1 & Method 2 & Method 3 & Method 4 \\
\hline Solvent & Freon 113 & $\mathrm{CCl}_{4}$ & Freon 113 & $\mathrm{CCl}_{4}$ \\
\hline $\begin{array}{l}\text { Method of } \\
\text { extraction }\end{array}$ & Manual & Manual & $\begin{array}{l}\text { Horiba } \\
\text { extractor }\end{array}$ & $\begin{array}{c}\text { Horiba } \\
\text { extractor }\end{array}$ \\
\hline Sample volume $(\mathrm{mL})$ & 200 & 200 & 5 to 15 & 5 to 15 \\
\hline Acidification $(\mathrm{pH})$ & 2 & 5 & 2 & 5 \\
\hline No. of extractions & 3 & 3 & 1 & 1 \\
\hline $\begin{array}{l}\text { Volume of each } \\
\text { extraction (mL) }\end{array}$ & 10 & 10 & 5 to 15 & 5 to 15 \\
\hline $\begin{array}{l}\text { Time for each } \\
\text { extraction ( } \mathrm{min} \text { ) }\end{array}$ & 15 & 15 & 5 & 5 \\
\hline $\begin{array}{l}\text { Instrument } \\
\text { used }\end{array}$ & $\begin{array}{l}\text { Perkin } \\
\text { Elmer } \\
\text { FT-IR }\end{array}$ & $\begin{array}{l}\text { Perkin } \\
\text { Elmer } \\
\text { l:T-IR }\end{array}$ & $\begin{array}{c}\text { Horiba } \\
\text { OCMA220 } \\
\text { ND-IR }\end{array}$ & $\begin{array}{c}\text { Horiba } \\
\text { OCMA } 220 \\
\text { ND-IR }\end{array}$ \\
\hline
\end{tabular}


this study ard peat.

\subsubsection{Adsorption isotherms}

Adsorption isotherm experiments were conducted using SMO,MCO,CO,RE,PW and peat in the jar test apparatus at room temperature $\left(21 \pm 0.5^{\circ} \mathrm{C}\right)$. The experiments were conducted in duplicate up to the cquilibrium time determined from the above tests. Six representative quantities of peat $(500,400,300,200,100$ and $50 \mathrm{mg})$ were mixed with $200 \mathrm{~mL}$ of the oil-containing waste at $60 \mathrm{rpm}$. At the end of the equilibrium time, all the samples were withdrawn, filtered using glass wool, and analyzed for the oil remaining in the waste after adsorption. Attempts were not made to quantify the oil retained by the glass wool as glass wool is a coalescing medium and not an adsorbent. During this filtration, it was noticed that very small amounts of fine peat particles escaped through the glass wool bed into the filtrate. The use of regular filter paper was considered and rejected for the filtration as it may filter out the oil remaining in the solution after mixing. These peat particles (present in the filtrate) when contacted witi, $\mathrm{CCl}_{4}$ for oil extraction leached and interfered with the oil measurements. This necessitated the detcrmination of correction factors for the leaching of drained -peat in contact with $\mathrm{CCl}_{4}$ solution. Since peat in $\mathrm{CCl}_{4}$ produced absorbances at the same wavelengths as that of oil (Smith 1976), it is possible to estimate the leaching of the drained-peat (as oil concentration in $\mathrm{mg} / \mathrm{L}$ ) using the following procedure.

All the oil from the oil-in-water dispersiors investigated was completely removed using $\mathrm{CCl}_{4}$ extractions. These oil-removed solutions were then mixed with 50 to 500 mg of peat as per the original isotherm procedure. Thus any absorbances observed 
in the extracted sample were caused by the contact of drained-peat with $\mathrm{CCl}_{4}$ (expressed as $\mathrm{mg} / \mathrm{L}$ of oil). Since there are no changes in the solvent and in the procedure for extracting oily matter, the extraction efficiency of the solvent remains the same. Thus absorbances by the oil-removed dispersions mainly indicated the interference of drained-peat with carbon tetrachloride and other chemicals (especially these present in cutting oil). A correlation between the amount of drained-peat and the interference as $\mathrm{mg} / \mathrm{L}$ of oil was established for all five oil-in-water dispersions from the six quantities of peat referred above. Corrections were then applied to the adsorption data before performing isotherm analyses. These corrections were needed only for batch kinetic and adsorption studies in which drained-extracted peat with $\mathrm{CCl}_{4}$ interfered with the measurement of oil. For column studies, there was no need to apply these corrections as the peat was not drained into the effluent to cause leaching with $\mathrm{CCl}_{4}$.

\subsubsection{Adsorption and desorption}

Batch adsorption and desorption experiments were conducted using $\mathrm{CO}$ samples with horticultural peat in a jar test apparatus. These experiments were conducted up to the equilibrium time determined earlier. Desorption experiments were continued after completing the adsorption experiments. At the end of the adsorption experiments, the peat fractions were carefully filtered. The filtrate was used for oil extraction and the filtered peat fractions were used for desorption experiments. These oil-sorbed peat fractions were mixed with $200 \mathrm{~mL}$ of tap water in a jar test ar aratus at $60 \mathrm{rpm}$. The experiments were conducted at room temperature $\left(21 \pm 0.5^{\circ} \mathrm{C}\right)$, up to the equilibrium time determined for adsorption. At the end of desorption, the samples were filtered and the oil desorbed into water was determined. These experiments were duplicated and the data were analyzed for adsorption and desorption of oil. 


\subsubsection{Column experiments}

Column studies were conducted in a $100 \mathrm{~mm}$ diameter, $600 \mathrm{~mm}$ long cast acrylic pipe. Horticultural peat of $300 \mathrm{~mm}$ depth was used in the experinents. The peat was slipported at the bottom by a $50 \mathrm{~mm}$ thick gravel packing over a circular perforated horizontal acrylic plate. A $25 \mathrm{~mm}$ thick gravel layer was placed on top of the peat to prevent the movement of peat particles due to falling water drops. The schematics of the column arrangement is presented in Figure 3.2. While filling the column with peat, the sides of the column were tapped gently for uniform packing. The packed density was calculated using the weight of peat and the volume of the column.

In the absence of published information on the performance of Saskatchewan horticultural peat for oil removal, it was decided to try an eight-hour test as a preliminary trial. The blended oil-in-water dispersions were kept in a feed tank where they were continuously mixed using $0.01 \mathrm{hp}, 5000 \mathrm{rpm}$ mixture (Greiner Scientific Corporation, U.S.A, Model 77-912-02) to maintain the homogeneity of the emulsion being fed. From this feed tank, the emulsion was pumped into the column at flow rates of 12 , 48 , and $300 \mathrm{~mL} / \mathrm{min}(2.13,8.52$ and $53.28 \mathrm{~m} / \mathrm{d})$ using a Motomatic motor generator with a servodyne speed controller (Cole-Parmer Instrument Co, USA., Model EC- E $650 \mathrm{MG})$. The effluent from the column was monitored for oil each hous during the experimental run. A sample volume of $200 \mathrm{~mL}$ was withdrawn each time for $\mathrm{CCl}_{4}$ extraction.

At the end of one eight-hour run, using a flow rate $12 \mathrm{~mL} / \mathrm{min}$, the oil-sorbed peat was backwashed with hot water at $60^{\circ} \mathrm{C}$, at a flow rate of $24 \mathrm{~mL} / \mathrm{min}(4.26$ $\mathrm{m} / \mathrm{d}$ ). The backwashing lasted approximately $4 \mathrm{~h}$ in view of the low flow rate. After backwashing, "he run was continued for another 8 -hours at the $12 \mathrm{~mL} / \mathrm{min}$ flow rate. 


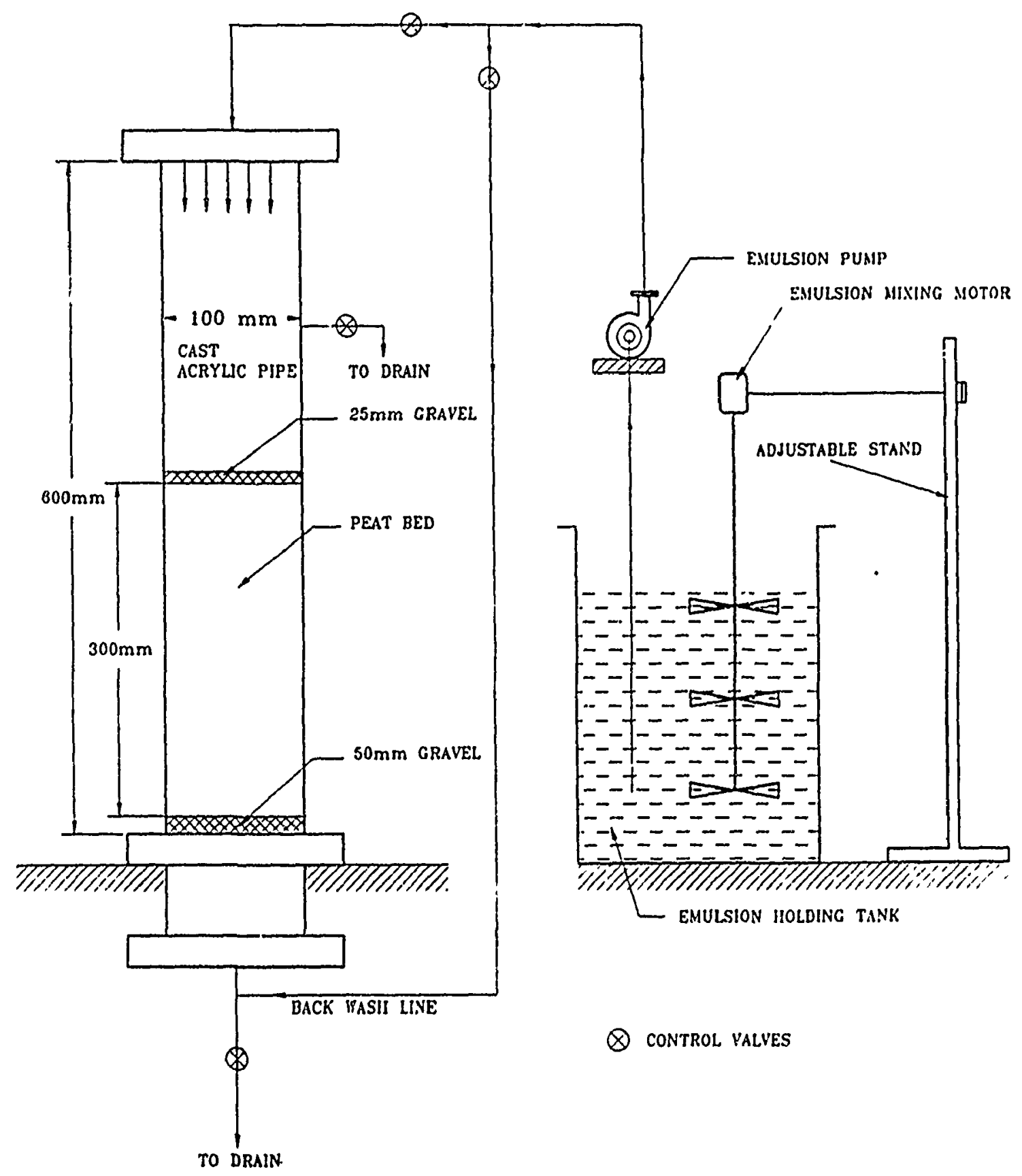

Figure 3.2. Column arrangement 


\subsubsection{Comparison with other media.}

Two types of pretreated horticultural peat, (wet-heated-oven dried and wet-pyrolyzed at $150^{\circ} \mathrm{C}$ ) were considered for comparing oil removal efficiencies with other media (sand, coal, polypropylene, Fiber glass, Amberlite XAD-2 and activated carbon). The two-pretreated peat samples were selected based on higher oil-binding capacity observed in earlier batch tests. Experiments were conducted in a $10 \mathrm{~mm}$ glass column with a $300 \mathrm{~mm}$ medium depth. Polypropylene and fiber-glass mats were cut into smaller pieces and pushed into the column without heavy compression. SMO and $\mathrm{CO}$ emulsions, at a flow rate of $2.90 \mathrm{~mL} / \mathrm{min}(53.28 \mathrm{~m} / \mathrm{d})$, were used. Effluent oil concentrations were monitored every hour. The performances of these media were compared on the basis of the average oil removal efficiencies in an eight-hour run.

\subsubsection{Breakthrough studies.}

Column breakthrough studies were conducted using horticultural peat. The 300 mm peat bed was used continuously until its exhaustion. These studies were conducted at a flow rate of $50 \mathrm{~mL} / \mathrm{min}(8.8 \mathrm{~m} / \mathrm{d})$ for $\mathrm{SMO}, \mathrm{MCO}$, and $\mathrm{PW}$ and 25 $\mathrm{mL} / \mathrm{min}(4.4 \mathrm{~m} / \mathrm{d})$ for $\mathrm{CO}$ and $\mathrm{RE}$ samples. These flow rates were selected on the basis of oil removal efficiencies obtained earlier for three different flow rates $(12,48$ and $300 \mathrm{~mL} / \mathrm{min})$. The column arrangement used was the same as the one employed earlier (Figure 3.2). Effluent oil concentrations were measured every twelve hours until breakthrough. These experiments were replicated and the breakthrough data were analyzed using the Thomas kinetic equation (2.16). A mass balance was performed to compare the column solid-phase concentration obtained using the Thomas equation. The time-dependent solid-phase concentration was analyzed using equation 2.17 to 
determine the adsorption rate constants for different oils by horticultural peat.

\subsubsection{Breakdown mechanisms}

A $2.4 \mathrm{~m}$ long experimental column of $100 \mathrm{~mm}$ diameter with arrangements as shown in Figure 3.3 was set-up. Horticultural peat of $1000 \mathrm{~mm}$ depth was used and manometers were installed at $200,300,400,600,800$, and $1000 \mathrm{~mm}$ depths for monitoring the pressure drop across the peat bed. Correspondingly, six sample ports were used to collect samples for measuring oil concentration, diameter of the oil droplets and drop densities. Six different flow rates of $331,297,264,231,198$, and 165 $\mathrm{mL} / \mathrm{min}(58.75,52.70,46.7,41.5,35.4$, and $29.4 \mathrm{~m} / \mathrm{d})$ were used in the experiments. The maximum flow rate of $331 \mathrm{~mL} / \mathrm{min}$ corresponded to an application rate of 1 $\mathrm{gpm} / \mathrm{sq} . \mathrm{ft}$. These experiments were duplicated.

Synthetic oil-in-water emulsions using SMO and the emulsifiers oleic acid and triethanolamine were used. An influent oil concentration of $131 \mathrm{mg} / \mathrm{L}$ was maintained for all the runs. The experiments were terminated at the time of oil breakthrough or when the maximum allowable head $(1.4 \mathrm{~m})$ over the peat bed was reached, whichever occurred first. The drop diameter and densities were measured using a Spectrex laser particle counter (Spectrex Corporation, U.S.A., Model SPC-510).

In conducting experiments with two-phase flows, (water and oil) the general procedure was to fill the system with single-phase (pure water without oil) and measure the pressure drop across the bed for various flow rates. The Carman-Kozeny constant $\left(k_{1}\right)$ would then be calculated from pressure drop data for comparison with the literature value (Sherony and Kintner 1971b). In the absence of published information on $k_{1}$ values for peat, experiments using a single-phase were monitored for equilitrium pressure drop. The latter was visually monitored by observing minimum fluctuations 


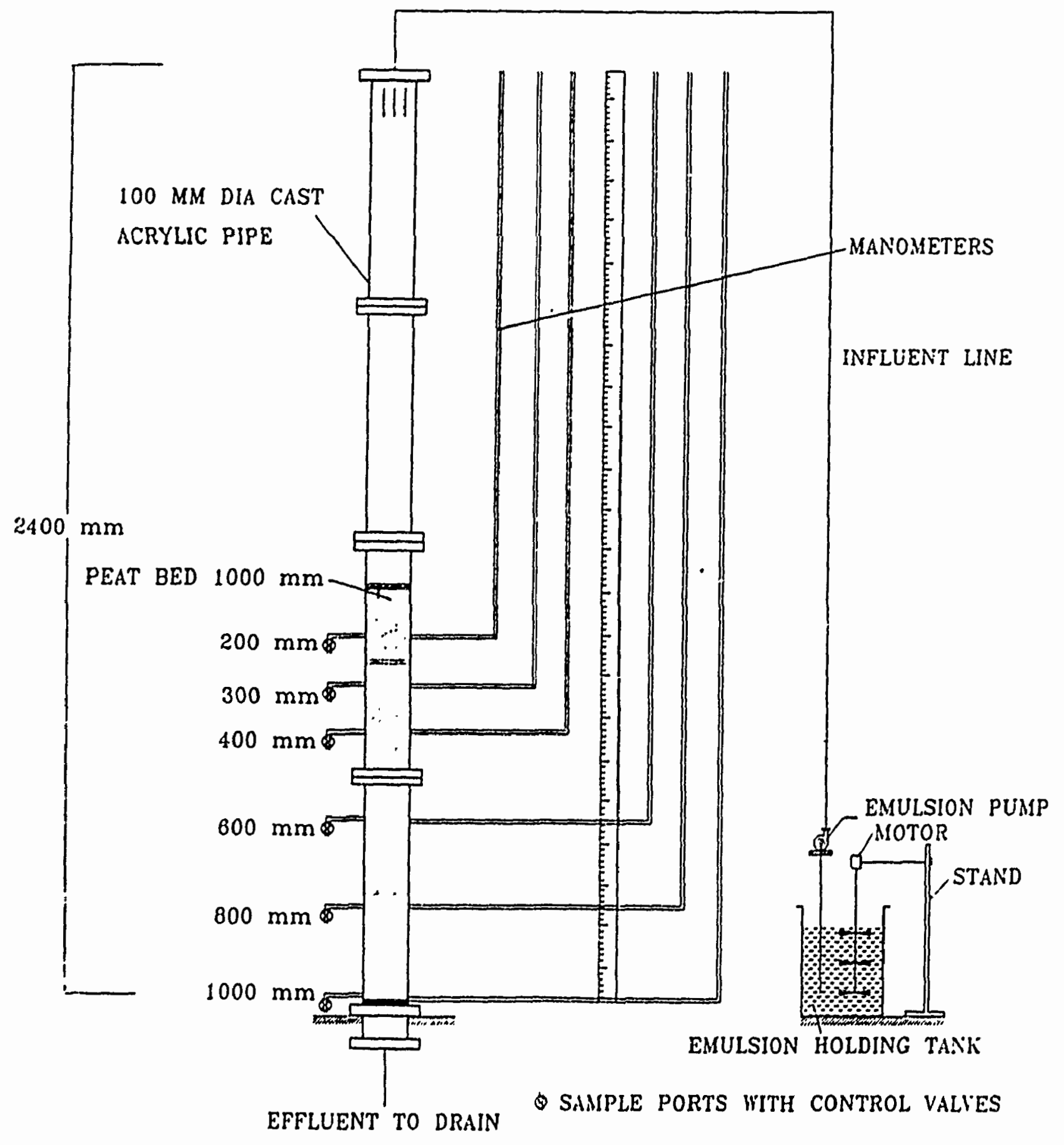

Figure 3.3. Column arrangements for a study of the breakdown mechanisms 
of water levels in the manometer. After reaching a steady-state condition (complete saturation), the oil-in-water emulsion was allowed in the bed and the pressure drop was monitored for the two-phase flow. These experiments were replicated.

\subsubsection{Bacterial activity}

Two different experiments were conducted to quantify the bacterial activity in a $300 \mathrm{~mm}$ horticultural peat treating oil-in-water emulsions.

The first experiment was conducted in a $100 \mathrm{~mm}$ diameter, $600 \mathrm{~mm}$ long cast acrylic column with suitable inlet, outlet and pumping arrangements as shown in Figure 3.4. The preparation of the SMO emulsion, and the method of pumping were similar to the eight-hour column experiments described in 3.2.4. Peat samples from the oil-sorbed bed were withdrawn from three different locations. These samples were collected at $0,1,2$, and 7 days for bacterial incubation. The experiments were conducted continuously for seven days at a flow rate of $16.67 \mathrm{~mL} / \mathrm{min}(3 \mathrm{~m} / \mathrm{d})$. The oil-sorbed peat samples collected from the three locations of the peat bed were vortexed in ringer solution for 10 minutes $(1 \mathrm{mg}$ in $9 \mathrm{~mL}$ ). A series of dilutions was inade and the diluted samples were spread on two different media, PAF and $\mathrm{BH}_{4}$, and incubated at room temperature for 48 hours. Total bacterial colonies were counted using a Darkfield Quebec colony counter (American opti- - Company, U.S.A., Model 3329), and the results were expressed as colonies per gra:" of wet peat. At time 0 , the results were expressed as colonies per gram of dry peat as oil-in-water emulsions were not present in the bed at that time.

Bacterial colonies present in the influent and effluent liquid samples were determined by diluting $1 \mathrm{~mL}$ of sample in $9 \mathrm{~mL}$ of ringer solution, followed by successive 


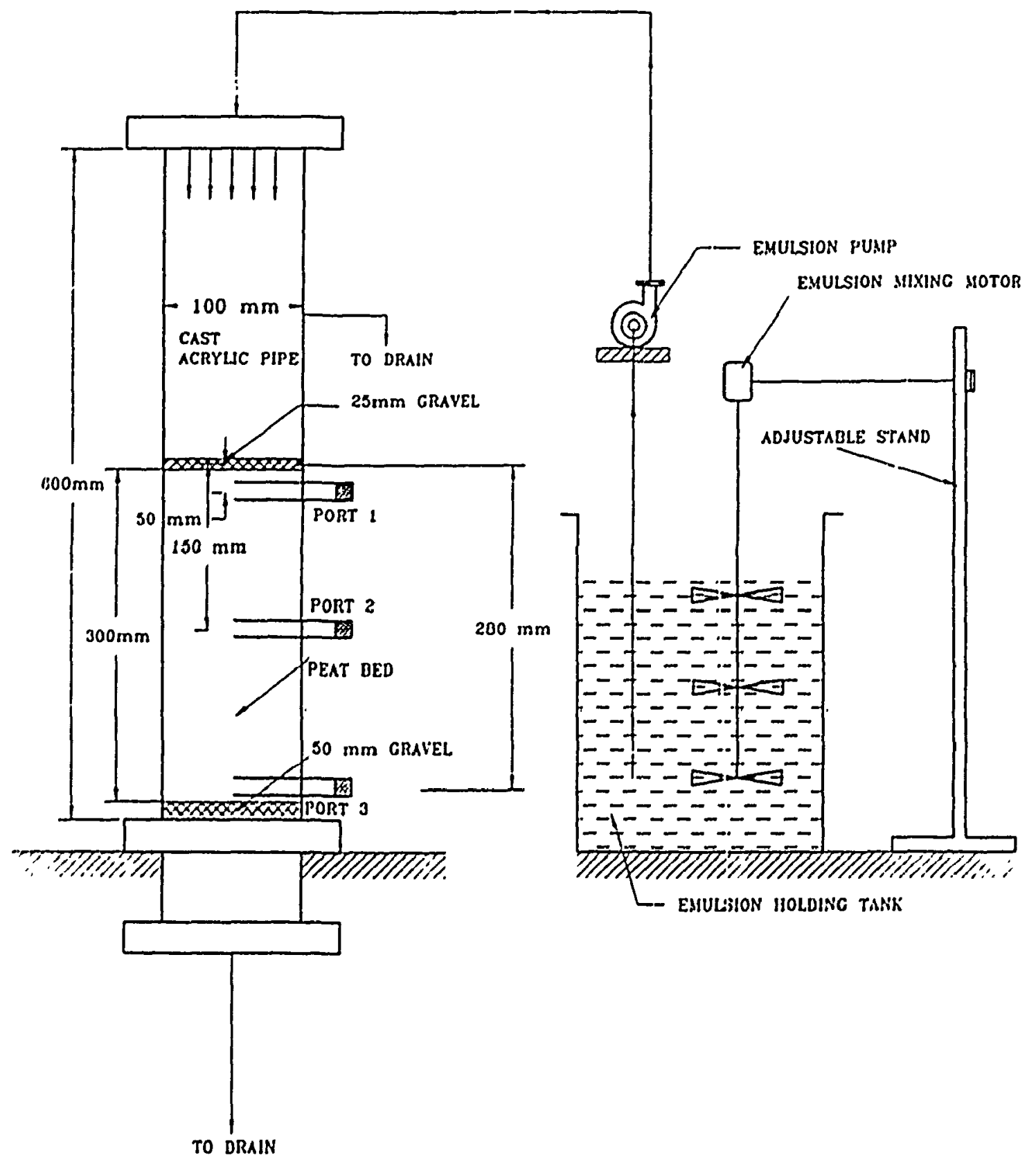

Figure 3.4. Columu arrangement for the bacter:ial studies 
dilutions and incubation. The results were expressed as colonies per $\mathrm{mL}$ of oil-inwater emulsions. The effluent oil concentration from the peat bed was monitored every 8 hours during the seven-day experiment.

A second set of experiments was conducted using the three peat reactors as shown in Figure 3.5:

1. Reactor 1: Control reactor, using sterilized horticultural peat. Horticultural peat was filled into a $10 \mathrm{~mm}$ diameter glass column for a depth of $300 \mathrm{~mm}$. The entire column along with the peat was sterilized in an autoclave at a steam pressure of $103.4 \mathrm{kPa}$ ( $15 \mathrm{psi})$ for 15 minutes and used in the experiment to treat oil-in-water emulsions.

2. Reacter 2: Actual reactor, using horticultural peat ( $300 \mathrm{~mm}$ depth) in a $10 \mathrm{~mm}$ diameter glass tube.

3. Reactor 3: Enhanced reactor, using horticultural peat dosed with Bacto nutrient broth (Difco laboratories, U.S.A.), to enhance the growth of bacteria. Nutrient broth at a rate of $1.3 \mathrm{~g} / 100$ gram peat was added to the peal bed.

SMO emulsion (with emulsifiers oleic acid and triethanolamine), was used in the experiments at a flow rate of $0.164 \mathrm{~mL} / \mathrm{min}(3 \mathrm{~m} / \mathrm{d})$, the same flow rate as in the first experimeñit. The emulsion was simultaneously pumped into these three reactors, and the effluent oil concentrations were monitored everyday. The experiment was conducted continuously for seven days. Oil-sorbed peat samples were collected from the top and bottom portions of the reactors at day 1,2,5, and 7. All the peat samples collected were vortexed in a ringer solution ( $1 \mathrm{mg}$ in $9 \mathrm{~mL})$ and incubated with different dilutions for 48 hours at room temperature using a $\mathrm{BH}_{4}$ medium. After 


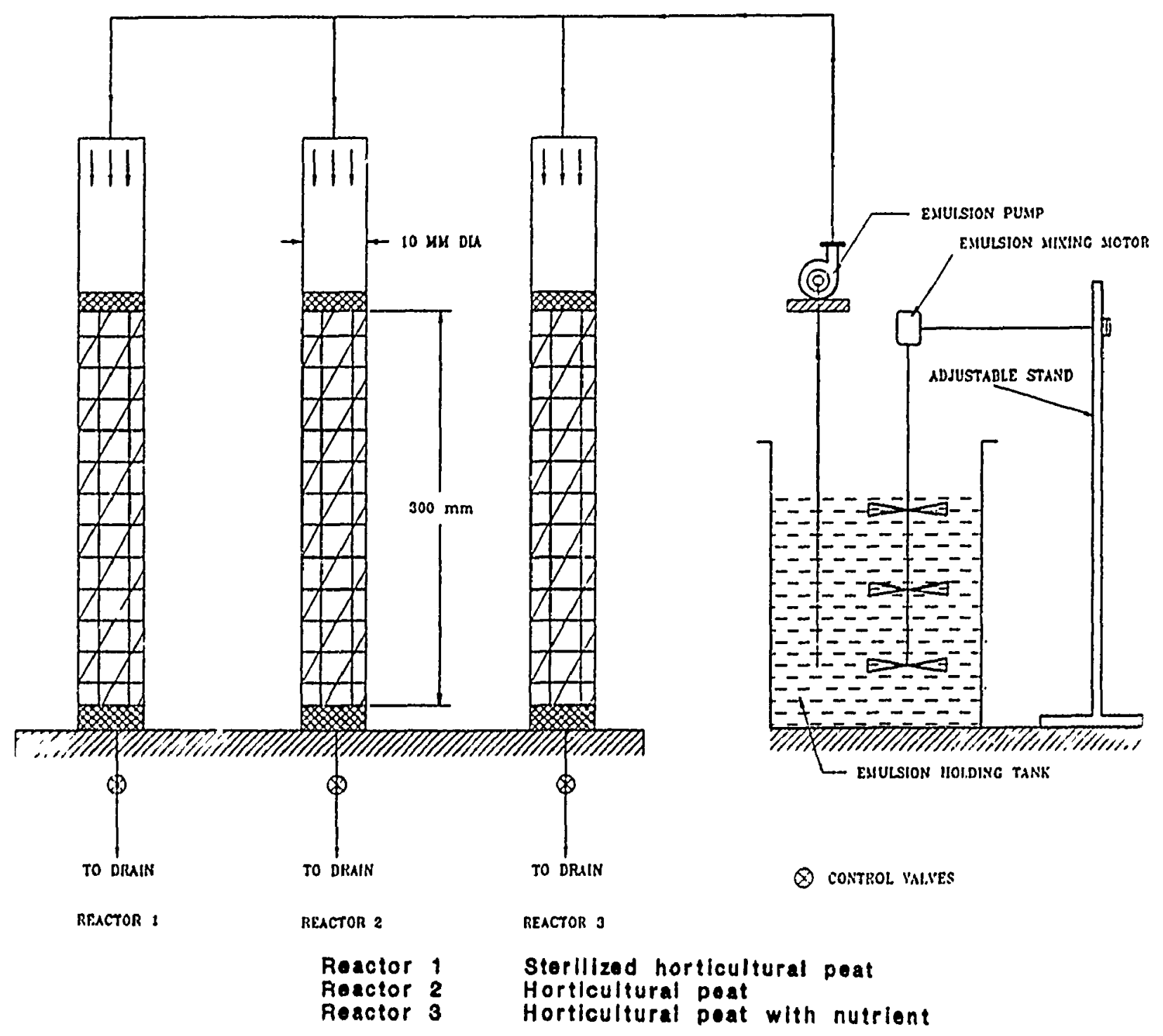

Figure 3.5. Column arrangements for comparative bacterial studies 
the incubation time, the bacterial colonies were counted and expressed as colonies per gram of wet or dry peat, respectively. 


\section{RESULTS AND DISCUSSION}

\subsection{Characteristics of Materials Used}

\subsubsection{Peat, pretreated peat and other media}

Characteristics of the horticultural peat used in the experiments are presented in Table 4.1. The effective size of the peat particles ranged from 0.15 to $0.22 \mathrm{~mm}$. The porosity was found to be 79.2 percent, and the fiber content was 68.13 weight percent. Thus, peat can be regarded as a fibrous and porous material. While the average particle diameter was $1.605 \mathrm{~mm}$, the average pore diameter was $15.85 \pm 11.93$ $\mu \mathrm{m}$. The surface area of the peat was measured as $0.98 \mathrm{~m}^{2} / \mathrm{g}$. The particle size range showed that the fines (having diameters $<0.85 \mathrm{~mm}$ ) were over 59 weight percent of the total. The moisture content of the peat was $58.6 \mathrm{wt} \%$. The oil-binding capacity was found to be 7.85 and $7.53 \mathrm{~kg} / \mathrm{kg}$ of dry peat for SMO and MCO, respectively. The oil-binding capacities for two different oils with viscosities of 135 and $50 \mathrm{mPa} . \mathrm{s}$ did not differ appreciably. D'Hennezel and Coupal (1972) observed an increase in oilbinding capacity with a decrease in oil viscosity. The maximum oil-binding capacity was reported as $9.8 \mathrm{~kg} / \mathrm{kg}$ of peat for a crude oil having a viscosity of $27.5 \mathrm{mPa}$.s. Environment Canada (1983) reported that the oil-binding capacity of peat was 8 to 12 times of its dry weight.

Characteristics of the pretreated peat samples are presented in Tables 4.2 and 4.3. The maximun oil-binding capacities of 8.4 and 8.9 ( $\mathrm{kg}$ of oil per $\mathrm{kg}$ of dry peat) were obtained for (i) wet-heated and oven-dried, and (ii) wet-pyrolyzed peat $\left(150^{\circ} \mathrm{C}\right)$, respectively. 
Table 4.1. Characteristics of horticultural peat

\begin{tabular}{|c|c|c|c|}
\hline Characteristics & Range & Mean & Std.dev \\
\hline \multicolumn{4}{|l|}{ Particle size range } \\
\hline (a) Foreign matter (wt\%) & 0 & & \\
\hline (b) Coarse fiber $(>2.36 \mathrm{~mm})(\mathrm{wt} \%)$ & 13.2 to 15.2 & 14.2 & 1.0 \\
\hline (c) Medium fiber $(2.36$ to $0.85 \mathrm{~mm})(\mathrm{wt} \%)$ & 25.7 to 26.5 & 26.1 & 0.4 \\
\hline (d) Fines $(\mathrm{dia}<0.85 \mathrm{~mm})(\mathrm{wt} \%)$ & 58.9 to 60.7 & 59.8 & 0.9 \\
\hline Average pore diameter $(\mu \mathrm{m})$ & $\therefore .65$ to 30.05 & 15.85 & 14.2 \\
\hline Average particle diameter $(\mathrm{mm})$ & 0.27 to 2.95 & 1.61 & 1.34 \\
\hline \multicolumn{4}{|l|}{$\mathrm{pH}$ at $21^{\circ} \mathrm{C}$} \\
\hline (a) In distilled water & 5.8 to 6.0 & & \\
\hline & \\
\hline $\begin{array}{l}\text { Moisture content (wt\%) } \\
\text { (a) Method I (wt\%) }\end{array}$ & 50 to 70 & 55 & 5 \\
\hline (b) Method II (wt\%) & 57.9 to 59.3 & 58.6 & 0.7 \\
\hline Sand content (wt\%) & 2.2 to 3.0 & 2.6 & 0.4 \\
\hline Ash content (wt\%) & 4.5 to 5.1 & 4.8 & 0.3 \\
\hline Organic matter content (wt\%) & 35.9 to 39.1 & 37.5 & 1.6 \\
\hline \multicolumn{4}{|l|}{ Grain size analysis } \\
\hline (a) coefficient of uniformity & 3.3 to 4.4 & 3.85 & 0.55 \\
\hline (b) Coefficient of concavity & 0.98 to 1.66 & 1.32 & 0.34 \\
\hline \multicolumn{4}{|l|}{ Oil binding capacity } \\
\hline (a) for SMO ( $\mathrm{kg} / \mathrm{kg}$ of dry peat) & 7.56 to 8.14 & 7.85 & 0.29 \\
\hline (b) for MCO ( $\mathrm{kg} / \mathrm{kg}$ of dry peat) & 7.16 to 7.90 & 7.53 & 0.37 \\
\hline Fiber cortent (wt\%) & 66.2 to 70.06 & 68.13 & 1.93 \\
\hline Porosity (\%) & 77.8 to 80.60 & 79.2 & 1.40 \\
\hline Specific gravity & 0.078 to 0.094 & 0.086 & 0.008 \\
\hline Surface area $\left(\mathrm{m}^{2} / \mathrm{g}\right)$ & & 0.98 & \\
\hline Degree of humification(von Post) & $\mathrm{H}_{4}$ to $\mathrm{H}_{6}$ & $\mathrm{H}_{5}$ & \\
\hline Cation exchange capacity (meq/100g) & 71.7 to 73.5 & 72.6 & 0.90 \\
\hline
\end{tabular}


Table 4.2. Characteristics of pretreated peat

\begin{tabular}{||l|c|c|c|c|c|c|c||}
\hline \hline \multicolumn{1}{|c|}{ Description } & HORT & OD-1 & OD-3 & WH \&A & WH \&O & ACID & ALKALI \\
\hline \hline $\begin{array}{l}\text { Oil-binding } \\
\text { capacity (kg/kg) }\end{array}$ & 7.85 & 6.8 & 7.1 & 8.0 & 8.4 & 2.0 & 4.5 \\
$\begin{array}{l}\text { Moisture } \\
\text { content (wt\%) }\end{array}$ & 56.9 & 6.4 & 6.8 & 10.3 & 6.7 & 18.5 & 6.7 \\
$\begin{array}{l}\text { Ash content (wt\%) } \\
\text { Organic matter } \\
\text { content (wt\%) }\end{array}$ & 4.6 & 5.1 & 5.0 & 3.0 & 4.6 & 1.4 & 12.7 \\
pH in distilied \\
water
\end{tabular}


Table 4.3. Characteristics of pretreated peat

\begin{tabular}{|c|c|c|c|c|c|c|}
\hline \multirow[t]{2}{*}{ Description } & \multicolumn{6}{|c|}{ Wet pyrolysis $\left({ }^{\circ} \mathrm{C}\right)$} \\
\hline & 150 & 175 & 200 & 225 & 250 & 275 \\
\hline $\begin{array}{l}\text { Oil-binding } \\
\text { capacity }(\mathrm{kg} / \mathrm{kg})\end{array}$ & 8.9 & 6.5 & $4 . \%$ & 4.5 & 3.8 & 3.6 \\
\hline $\begin{array}{l}\text { Moisture } \\
\text { content (wt\%) }\end{array}$ & 6.9 & 5.2 & 3.3 & 1.9 & 1.4 & 0.84 \\
\hline $\begin{array}{l}\text { Ash } \\
\text { content (wt\%) }\end{array}$ & 2.8 & 3.0 & 3.7 & 3.8 & 4.6 & 5.1 \\
\hline $\begin{array}{l}\text { Organic matter } \\
\text { content (wt\%) }\end{array}$ & 90.3 & 91.8 & 93.0 & 94.3 & 94 & 94.0 \\
\hline $\begin{array}{l}\mathrm{pH} \text { in } \\
\text { distilled } \\
\text { water }\end{array}$ & 6.1 & 5.9 & 5.5 & 5.8 & 5.8 & 6.1 \\
\hline CEC (meq/100g) & 74.4 & 104.2 & 107.9 & 113.5 & 156.6 & 171.7 \\
\hline
\end{tabular}


In the case of the wet-pyrolyzed peat samples, the oil-binding capacities decreased steadily from 8.9 to $3.6 \mathrm{~kg}$ of oil per $\mathrm{kg}$ of dry peat, as the pyrolysis temperature was increased from $150^{\circ} \mathrm{C}$ to $275^{\circ} \mathrm{C}$. A study by Thun et al. (1983b), using slightly decomposed milled Sphagnum peat moss from Finland (Penelia peat), reported an increase in oil-binding capacity from 5.46 to $9.9 \mathrm{~kg}$ of oil per $\mathrm{kg}$ of dry peat, when the pyrolysis temperature was increased from $150^{\circ} \mathrm{C}$ to $550^{\circ} \mathrm{C}$. The oil-binding capacity of untreated Finnish peat was reported as $3.42 \mathrm{~kg}$ oil per $\mathrm{kg}$ of dry peat as compared to $7.85 \mathrm{~kg}$ of oil per $\mathrm{kg}$ of dry peat obtained in the present study for Saskatchewan horticultural peat using SMO. A comparison of oil-binding capacities for the Saskatrhewan and Finnish peats are presented in Table 4.4. The oil-binding capacity of untreated Saskatchewan horticultural peat is approximately twice that of the Finnish Penelia peat. This could be an influencing factor for the divergent behavior of Saskatchewan peat under elevated pyrolysis temperatures.

Smith et al.(1980) showed that peat exhibited enhanced CEC after acid treatment. Correlations between CEC and oil-binding capacities have not been reported in the published literature. CEC is an important property for an adsorbent in environmental engineering applications. The results presentet in Tables 4.2 and 4.3 showed that all the pretreated samples except(i) wet-heated-oven-dried and (ii) acid-treated peat have higher CECs compared to a CEC value of $72.6 \mathrm{meq} / 100 \mathrm{~g}$ obtained for untreated horticultural peat. Also, the CECs were found to increase with the degree of humification which is in agreement with the findings of Smith et al. (1980). In the case of (i) wet-heated-oven-dried and (ii) acid-treated peats, which showed higher oil-binding capacity before treatment, the CECs were low $(72.5$ and $59.5 \mathrm{meq} / 100 \mathrm{~g}$ respectively). A study in Poland by Sapek et al. (1988) showed that the CECs of peat 
Table 4.4. Comparison of oil-binding capacities of Finnish and Saskatchewan peats under different pyrolysis temperatures

\begin{tabular}{|c|c|c|}
\hline \multirow{2}{*}{$\begin{array}{l}\text { Pyrolysis temperature } \\
{ }^{\circ} \mathrm{C}\end{array}$} & \multicolumn{2}{|c|}{ Oil-binding capacity $(\mathrm{kg}$ oil $/ \mathrm{kg}$ peat) } \\
\hline & $\begin{array}{l}\text { Penelia peat } \\
\text { Finland }\end{array}$ & $\begin{array}{l}\text { Saskatchewan peat } \\
\text { Canada }\end{array}$ \\
\hline $\begin{array}{l}\text { Horticultural } \\
\text { peat at room } \\
\text { temperature }\end{array}$ & 3.42 & 7.85 \\
\hline 150 & 5.46 & 8.9 \\
\hline 175 & 6.58 & 6.5 \\
\hline 200 & - & 6.5 \\
\hline 225 & 6.78 & 4.5 \\
\hline 250 & 6.95 & 3.8 \\
\hline 275 & - & 3.7 \\
\hline 300 & 7.7 & - \\
\hline 350 & 6.95 & \\
\hline 400 & 6.49 & \\
\hline 450 & 7.41 & \\
\hline 500 & 8.12 & \\
\hline 550 & 9.0 & \\
\hline 600 & 8.66 & \\
\hline
\end{tabular}


samples decreased with an increase in the surface area of peat. The values of BET surface area, CEC and oil-binding capacities for the horticultural and pretreated peat samples are presented in Table 4.5. A comparison of the CEC and surface area values for all pretreated peat samples shows that generally there is no correlation between t.lese two properties. Only with pyrolyzed samples, the CEC increased steadily from $74.4 \mathrm{meq} / 100 \mathrm{~g}\left(\right.$ at $150^{\circ} \mathrm{C}$ ) to $171.7 \mathrm{meq} / 100 \mathrm{~g}\left(\right.$ at $\left.275^{\circ} \mathrm{C}\right)$, corresponding with an increase in surface area from $0.87 \mathrm{~m}^{2} / \mathrm{g}\left(150^{\circ} \mathrm{C}\right)$ to $11.59 \mathrm{~m}^{2} / \mathrm{g}\left(275^{\circ} \mathrm{C}\right)$. This is contrary to the observation of Sapek et al.(1988). However, these authors have postulated that CEC capacity would increase with surface area. No general correlations can be abserved between (i) oil-binding capacity and surface area and (ii) oil-binding capacity and CEC. It is, ho vever, difficult to conclude that CEC and oil-binding capacity are independent of surface area. Further, difficulties were experienced in reproducing the surface areas of certain peat samples. It is also observed that a wide variability exists among the surface area values quoted in the literature. The surface areas of peat reported in the literature are summarized in Table 4.6. for comparison. Surface areas as high as $300 \mathrm{~m}^{2} / \mathrm{g}$ to as low as $0.399 \mathrm{~m}^{2} / \mathrm{g}$ were reported. Tinh et al. (1971) while reporting the surface area as $220 \mathrm{~m}^{2} / \mathrm{g}$ (using the lodine number method) mentioned that the iodine may have reacted with the peat to yield higher surface areas.

The surface areas reported by Poots and Mckay (1979) and Allen (1987) did not vary appreciably for a wide range of particle sizes $(150$ to $1000 \mu \mathrm{m})$. This is not consistent with the general trend that the surface area would increase with a decrease in particle size. These variations suggest that 2 , standard procedure needs to be established for measuring micro-pores associated with fibrous peat samples. The correlations between surface area, CEC and oil-binding capacity also needs to be 
Table 4.5. Surface area, CEC and oil-binding capacities of different peats

\begin{tabular}{|c|c|c|c|}
\hline Peat sample & $\begin{array}{c}\text { BET surface } \\
\text { area } \\
\left(\mathrm{m}^{2} / \mathrm{g}\right)\end{array}$ & $\begin{array}{c}\text { CEC } \\
\text { meq } / 100 \mathrm{~g}\end{array}$ & $\begin{array}{c}\text { Oil-binding } \\
\text { capacity } \\
(\mathrm{kg} \mathrm{SMO} / \mathrm{kg} \text { of peat })\end{array}$ \\
\hline HORT & 0.98 & 72.6 & 7.85 \\
\hline OD-1 & 0.94 & 126.5 & 7.10 \\
\hline OD-3 & 0.80 & 113.5 & 6.8 \\
\hline WH\&A & 0.90 & 96.7 & 8.0 \\
\hline ACID & 0.73 & 59.5 & 2.0 \\
\hline ALKALI & 0.43 & 57.7 & 4.5 \\
\hline P150 & 0.87 & 74.4 & 8.9 \\
\hline P175 & 5.27 & 104.9 & 6.5 \\
\hline P200 & 3.84 & 107.9 & 4.7 \\
\hline P225 & 16.06 & 113.5 & 4.5 \\
\hline P250 & 12.78 & 156.6 & 3.8 \\
\hline P275 & 11.59 & 171.7 & 3.6 \\
\hline
\end{tabular}


Table 4.6. Surface area of peat samples

\begin{tabular}{||l|l|c|c|l||}
\hline \hline Peat sample & $\begin{array}{c}\text { Method of } \\
\text { measurement }\end{array}$ & $\begin{array}{c}\text { Particle } \\
\text { size }(\mu \mathrm{m})\end{array}$ & $\begin{array}{c}\text { Surface area } \\
\mathrm{m}^{2} / \mathrm{g}\end{array}$ & \multicolumn{1}{|||}{ Reference } \\
\hline Quebec peat( $\left.\mathrm{H}_{1}\right)$ & Iodine No. & & 220 & Tinh et al. (1971) \\
& & & & Poots and McKay \\
Sphthern Ireland & BET & $150-1000$ & $19-28.7$ & $(1980)$ \\
moss & Methylene & & & \\
& blue & $150-1000$ & $77.5-122.2$ & \\
Northern Ireland & Telon blue & $150-1000$ & $5.2-11.8$ & \\
Sphagnum & Mercury & & & \\
moss & porosimetry & $150-1000$ & $2.33-2.62$ & Allen (1987) \\
Peat moss & BET & & & \\
Moorish peat & Water vapour & & 0.399 & La Poe(1985) \\
& & & 345 & Sapek \\
Saskatchewan & & & & et al. (1988). \\
horticultural & & & & Present \\
peat & BET & $150-240$ & 0.98 & \\
OD-1 & BET & $150-240$ & 0.94 & \\
OD-3 & BET & $150-240$ & 0.80 & \\
WH\&AD & BET & $150-240$ & 0.90 & \\
WH\&OD & BET & $150-240$ & 1.18 & \\
ACID & BET & $150-240$ & 0.73 & \\
ALKALI & BET & $150-240$ & 0.43 & \\
P150 & BET & $150-240$ & 0.87 & \\
P175 & BET & $150-240$ & 5.27 & \\
P200 & BET & $150-240$ & 3.84 & \\
P225 & BET & $150-240$ & 16.06 & \\
P250 & BET & $150-240$ & 12.78 & \\
P275 & $150-240$ & 11.59 & \\
\hline \hline
\end{tabular}


investigated further. In addition, surface properties like zeta potential may influence CEC, and therefore a knowledge of zeta potential may aid in a better understanding of the properties of peat.

The characteristics of the other media used in the studies are summarized in Table 4.7. The packed densities reported therein were actually measured at the time of conducting the column experiments and the other values were reported by the manufacturer.

\subsubsection{Oil-in-water emulsions}

The characteristics of the three oils (SMO, MCO and $\mathrm{CO}$ ) and the two solvents $\left(\mathrm{CCl}_{4}\right.$ and Freon 113) provided by the suppliers are consolidated in Tables 4.8 and 4.9 , respectively. The characteristics of the two produced water samples are presented in Table 4.10. The characterization of different oil-in-water emulsions, based on the diameter of the oil droplets, are summarized in Table 4.11. These typical analyses showed that both SMO and MCO, which were prepared by mechanical agitation, can be classified as dispersed and emulsified based on the mean drop size of $35.86 \pm 14.21$ $\mu \mathrm{m}$. CO emulsion had a mean drop size of $9.30 \pm 4.85 \mu \mathrm{m}$, and therefore is classified as ensulsified and soluble. The RE, which has been treated once in a pond at the refinery site in Regina, is classified as dispersed, emulsified and soluble due to the oil drop diameter range of $15.88 \pm 11.05 \mu \mathrm{m}$. PW emulsions, which were formed during the fire flooding operations of enhanced oil recovery at a production well near Swift Current, have the smallest diameter of oil droplets of $7.31 \pm 5.74 \mu \mathrm{m}$. Therefore, PW emulsions are highly stable and are classified as emulsified and soluble oil.

The SMO emulsion prepared with the addition of chemicals such as triethanulamine and oleic acid (for promoting emulsification and used in the study of breakdown 
Table 4.7. Characteristics of the media used in the experimenls for comparison with peat

\begin{tabular}{||l|c|c|c||}
\hline \hline \multicolumn{1}{|c|}{ Medium } & $\begin{array}{c}\text { Particle size } \\
(\mathrm{mm})\end{array}$ & $\begin{array}{c}\text { Moisture content } \\
(\mathrm{wt} \%)\end{array}$ & $\begin{array}{c}\text { Packed density } \\
\left(\mathrm{kg} / \mathrm{m}^{3}\right)\end{array}$ \\
\hline \hline Horticultural \\
peat & $0.15-0.24$ & 58.6 & 70 \\
WH\&O & $0.15-0.24$ & 6.7 & 97.6 \\
P150 & $0.15-0.24$ & 6.9 & 97.6 \\
Coal & $<1.8$ & & 763.9 \\
Sand & $<1.8$ & & 1813.1 \\
Fiberglass & $<0.85$ & & 114.6 \\
Amberlite (XAD-2) & & & 781 \\
Polypropylene & & & 80.6 \\
AC-400 & $0.55-0.75$ & & 560 \\
\hline \hline
\end{tabular}


Table 4.8. Characteristics of oils used in the experiments

\begin{tabular}{|c|c|c|c|}
\hline Description & SMO & $\mathrm{MCO}$ & $\mathrm{CO}$ \\
\hline Viscosity at $20^{\circ} \mathrm{C}(\mathrm{mPa} . \mathrm{s})$ & 130 & 50.7 & - \\
\hline Density at $15^{\circ} \mathrm{C}\left(\mathrm{kg} / \mathrm{m}^{3}\right)$ & 853.5 & 899.9 & 956.6 \\
\hline $\begin{array}{l}\text { Interfacial tension } \\
\text { with water }(\mathrm{mN} / \mathrm{m})\end{array}$ & 56.47 & 37.42 & - \\
\hline $\begin{array}{l}\text { Contact angle } \\
\text { with peat (degree) }\end{array}$ & 21 & 27 & - \\
\hline Field location & & $\begin{array}{c}\text { Midale } \\
\text { Saskatchewan }\end{array}$ & \\
\hline Sample description & Light & Crude & $\begin{array}{l}\text { Clearedge } \\
\text { EP 284 }\end{array}$ \\
\hline Supplier & $\begin{array}{c}\text { Fisher } \\
\text { Scientific Co. }\end{array}$ & $\begin{array}{l}\text { Saskatchewan } \\
\text { Research Council } \\
\text { Regina }\end{array}$ & $\begin{array}{c}\text { Castrol } \\
\text { Canada Inc., }\end{array}$ \\
\hline
\end{tabular}


Table 4.9. Characteristics of two solvents used for extracting oil from oil-in-water emulsion

\begin{tabular}{||l|c|c||}
\hline \hline \multicolumn{1}{|c|}{ Description } & $\mathrm{CCl}_{4}$ & Freon 113 \\
\hline \hline $\begin{array}{l}\text { Density at } 25^{\circ} \mathrm{C} \\
\left(\mathrm{kg} / \mathrm{m}^{3}\right)\end{array}$ & 1584 & 1575 \\
Boiling point $\left({ }^{\circ} \mathrm{C}\right)$ & $76.7 \pm 0.1$ & $47-48$ \\
Formula weight & 153.83 & 187.38 \\
Supplier & $\begin{array}{c}\text { Fisher } \\
\text { Scientific } \\
\text { U. S. A. }\end{array}$ & $\begin{array}{c}\text { Aldrich } \\
\text { Chemical } \\
\text { U. S. A. }\end{array}$ \\
\hline \hline
\end{tabular}


Table 4.10. Characteristics of two produced water samples used in the experiments

\begin{tabular}{||l|c|c||}
\hline \multicolumn{1}{|c|}{ Description } & $\mathrm{PW}_{1}$ & $\mathrm{PW}_{2}$ \\
\hline \hline Salinity (g/L) & 4 & 50 \\
Conductivity (S/m) & 6.5 & 72 \\
Total solids (mg/L) & 14,046 & 578,530 \\
Suspended solids (mg/L) & 1270 & 94 \\
Dissolved solids (mg/L) & 12,776 & 587,436 \\
Total carbon (mg/L) & 7525 & 117.5 \\
Total organic carbon(mg/L) & 7500 & 87.5 \\
Total inorganic carbon (mg/L) & 25 & 30 \\
pH & 6.9 & 6.7 \\
Oil (mg/L) & 537.14 & 28.19 \\
\hline \hline
\end{tabular}


Table 4.11. Results of emulsion classification based on a typical analysis of diameter of oil droplets

\begin{tabular}{|c|c|c|c|}
\hline Type of emulsion & Mean dia. $(\mu \mathrm{m})$ & $\operatorname{Range}(\mu \mathrm{m})$ & Emulsion classification \\
\hline $\mathrm{SMO} / \mathrm{MCO}$ & 35 & $50-21$ & $\begin{array}{l}\text { Dispersed and } \\
\text { emulsified }\end{array}$ \\
\hline $\mathrm{CO}$ & 9 & $14-4$ & $\begin{array}{l}\text { Emulsified and } \\
\text { soluble }\end{array}$ \\
\hline $\mathrm{RE}$ & 15 & $26-4$ & $\begin{array}{l}\text { Dispersed and } \\
\text { soluble }\end{array}$ \\
\hline PW & 7 & $13-1$ & $\begin{array}{l}\text { Emulsified and } \\
\text { soluble }\end{array}$ \\
\hline $\begin{array}{l}\text { SMO with } \\
\text { emulsifiers }\end{array}$ & 21 & $31-11$ & $\begin{array}{l}\text { Dispersed and } \\
\text { emulsified }\end{array}$ \\
\hline
\end{tabular}


mechanisms) was classified as dispersed and emulsified as the mean drop diameter was found to be $21.6 \pm 10 \mu \mathrm{m}$. Typical photographs of these emulsions are shown in APPENDIX B.

\subsubsection{Analytical methods for oil measurement}

A statistical analysis was conducted to compare the differences between the four methods of extracting and measuring oil. The results are summarized in Tables 4.12 and 4.13 for SMO and MCO, respectively. It is seen that the extraction efficiencies for all the four methods ranged from 93 to 99 percent. A comparison of the differences in oil concentrations from the standard values was made for the four methods to check the statistical validity of the significance of these differences. The results, presented in Table 4.14 showed that the differences are insignificant for all four methods compared to a significance level of 0.001 . Thus, the variability that may arise due to a change in instrument and procedures is not likely to affect the results. The calibration curves obtained for the measurement of oil using $\mathrm{CCl}_{4}$ for $\mathrm{SMO}$ and $\mathrm{MCO}$ (in Beckman/Perkin Elmer IR spectrophotometer) are shown in Figures 4.1 and 4.2 , respectively.

\subsection{Batch Tests}

\subsubsection{Horticultural peat}

\subsubsection{Equilibrium time}

The plots of oil concentration versus time for the five different oil-in-water emulsions are shown in Figures 4.3 to 4.7 .

Based on these plots, an equilibrium time of three hours was chosen for RE and 
Table 4.12. Observed oil concentration for different methods using SMO

\begin{tabular}{||r|r|r|r|r|r|r|r|r||}
\hline \multirow{3}{*}{ SOC $^{\dagger}$} & \multicolumn{2}{|c|}{} & & \multicolumn{2}{|c|}{} & \multicolumn{2}{|c||}{} & \multicolumn{2}{|c||}{} \\
& \multicolumn{2}{|c|}{ M1 } & \multicolumn{2}{|c|}{ M2 } & \multicolumn{2}{|c|}{ M3 } & \multicolumn{2}{|c}{ M4 } \\
\cline { 2 - 9 } & MOC & OE & MOC & OE & MOC & OE & MOC & OE \\
\hline \hline 10 & 9.4 & 94 & 9.3 & 93 & 9.5 & 95 & 9.5 & 95 \\
20 & 18.5 & 93 & 18.6 & 93 & 18.6 & 93 & 18.2 & 91 \\
30 & 29.1 & 97 & 29 & 97 & 29.2 & 97 & 29.1 & 97 \\
40 & 38.2 & 96 & 38.4 & 96 & 38.3 & 96 & 38.4 & 96 \\
50 & 49.0 & 98 & 48.1 & 96 & 48.4 & 97 & 47.2 & 94 \\
100 & 97.9 & 98 & 97.4 & 97 & 98 & 98 & 98 & 98 \\
125 & 122.6 & 98 & 121.7 & 97 & 122 & 98 & 123 & 98 \\
150 & 145.8 & 97 & 146.9 & 98 & 146 & 97 & 146 & 97 \\
175 & 172.3 & 98 & 171.4 & 98 & 171 & 98 & 169 & 97 \\
200 & 187.6 & 94 & 189.6 & 95 & 188 & 94 & 189 & 95 \\
250 & 244.6 & 98 & 245.3 & 98 & 241 & 96 & 240 & 96 \\
300 & 297.8 & 99 & 297.4 & 99 & 293 & 98 & 291 & 97 \\
350 & 347.9 & 99 & 348.2 & 99 & 342 & 98 & 340 & 97 \\
400 & 395.4 & 99 & 396.9 & 99 & 381 & 95 & 382 & 96 \\
450 & 442.3 & 98 & 447.6 & 99 & 437 & 97 & 438 & 97 \\
500 & 498.2 & 99 & 498.4 & 99 & 481 & 96 & 490 & 98 \\
& & & & & & & & \\
\hline \hline
\end{tabular}

$\dagger$ Standard oil concentration (mg/L)

$\ddagger$ Measured oil concentration (mg/L)

Oil extracted (\%). 
Table 4.13. Observed oil concentration for different methods using MCO

\begin{tabular}{|c|c|c|c|c|c|c|c|c|}
\hline \multirow[t]{2}{*}{$\operatorname{soc}^{\dagger}$} & \multicolumn{2}{|c|}{ M1 } & \multicolumn{2}{|c|}{ M2 } & \multicolumn{2}{|c|}{ M3 } & \multicolumn{2}{|c|}{ M4 } \\
\hline & MOCF & OEI & $\mathrm{MOC}$ & $\mathrm{OE}$ & MOC & $\mathrm{OE}$ & MOC & $\mathrm{OE}$ \\
\hline 10 & 9.5 & 95 & 9.7 & 97 & 9.4 & 94 & 9.8 & 98 \\
\hline 20 & 18.7 & 94 & 19.1 & 96 & 18.9 & 95 & 19.2 & 96 \\
\hline 30 & 29.4 & 98 & 29.4 & 98 & 29.1 & 97 & 29.5 & 98 \\
\hline 40 & 38.1 & 95 & 39.1 & 98 & 39.2 & 98 & 39.4 & 99 \\
\hline 50 & 48.4 & 97 & 48.9 & 98 & 49.3 & 99 & 48.1 & 99 \\
\hline 100 & 97.1 & 97 & 98.1 & 98 & 98 & 98 & 98 & 98 \\
\hline 125 & 121.9 & 98 & 124.1 & 99 & 122 & 98 & 123 & 98 \\
\hline 150 & 144.2 & 96 & 148.1 & 99 & 145 & 97 & 146 & 97 \\
\hline 175 & 171.9 & 98 & 148.1 & 99 & 145 & 97 & 146 & 97 \\
\hline 200 & 186.2 & 93 & 194.6 & 97 & 191 & 96 & 193 & 97 \\
\hline 250 & 241.2 & 96 & 247.1 & 99 & 242 & 97 & 243 & 97 \\
\hline 300 & 296.1 & 99 & 297.4 & 99 & 294 & 98 & 298 & 99 \\
\hline 350 & 347.1 & 99 & 297.4 & 99 & 294 & 98 & 298 & 99 \\
\hline 400 & 392.6 & 98 & 398.1 & 99 & 391 & 98 & 397 & 99 \\
\hline 450 & 443.6 & 98 & 448.2 & 97 & 443 & 98 & 448 & 99 \\
\hline 500 & 496.2 & 99 & 498.6 & 99 & 492 & 98 & 497 & 99 \\
\hline
\end{tabular}

$\dagger$ Standard oil concentration (mg/L)

$\ddagger$ Measured oil concentration $(\mathrm{mg} / \mathrm{L})$

I Oil extracted (\%) 
Table 4.14. Statistical parameters for the differences in oil concentration from standard value

\begin{tabular}{||l|c|c|c|c|c||}
\hline Description & Mean & $\begin{array}{c}\text { Standard } \\
\text { deviation }\end{array}$ & $\begin{array}{c}\text { Standard error } \\
\text { of mean }\end{array}$ & $\begin{array}{c}t \\
\text { ratio }\end{array}$ & $\begin{array}{c}\text { Probability } \\
>\|t\|\end{array}$ \\
\hline SMO & & & & & \\
Method 1 & 0.02767 & 0.02156 & 0.00533 & 5.13 & 0.0001 \\
Method 2 & 0.0278 & 0.02161 & 0.00540 & 5.16 & 0.0001 \\
Method 3 & 0.03636 & 0.01385 & 0.00346 & 10.50 & 0.0001 \\
\hline MCO & 0.03801 & 0.01350 & 0.00463 & 8.22 & 0.0001 \\
Method 1 & 0.03104 & 0.01904 & 0.00476 & 6.52 & 0.0001 \\
Method 2 & 0.01606 & 0.01160 & 0.00290 & 5.54 & 0.0001 \\
Method 3 & 0.02724 & 0.01463 & 0.00366 & 7.45 & 0.0001 \\
Method 4 & 0.01857 & 0.01191 & 0.00298 & 6.24 & 0.0001 \\
\hline \hline
\end{tabular}




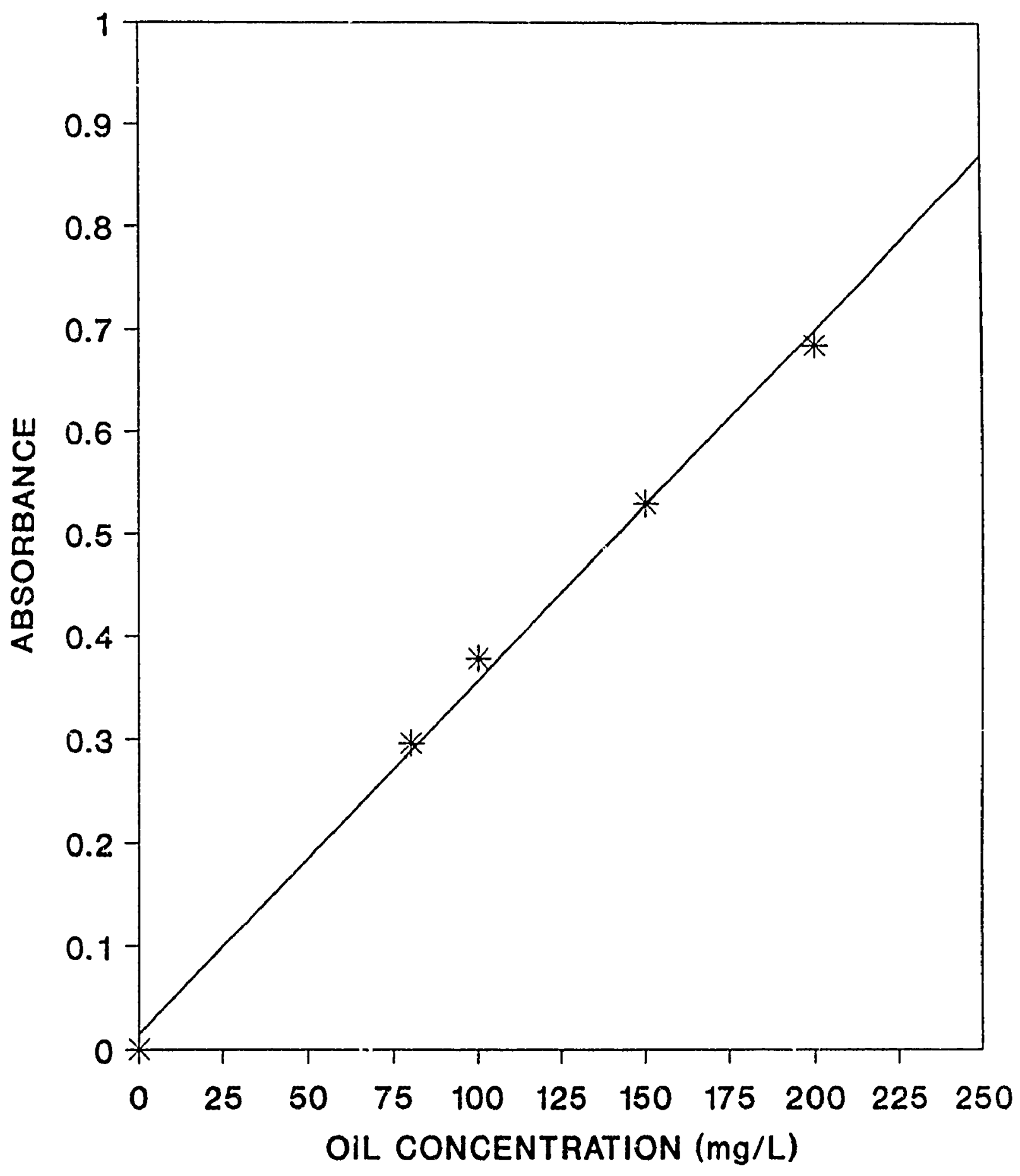

Figure 4.1. Calibration for the measurement of oil using SMO 


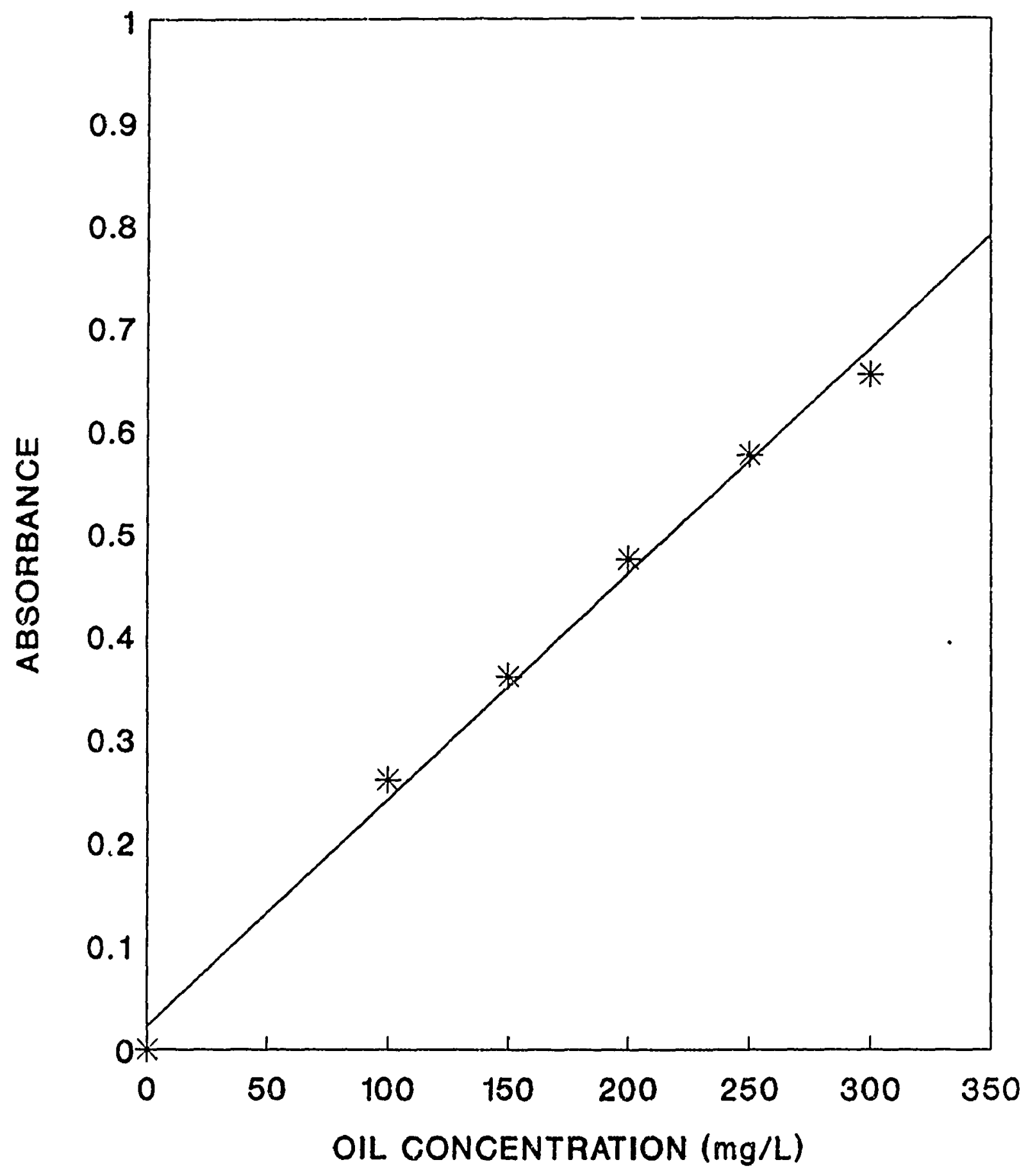

Figure 4.2. Calibration for the measurement of oil using MCO 


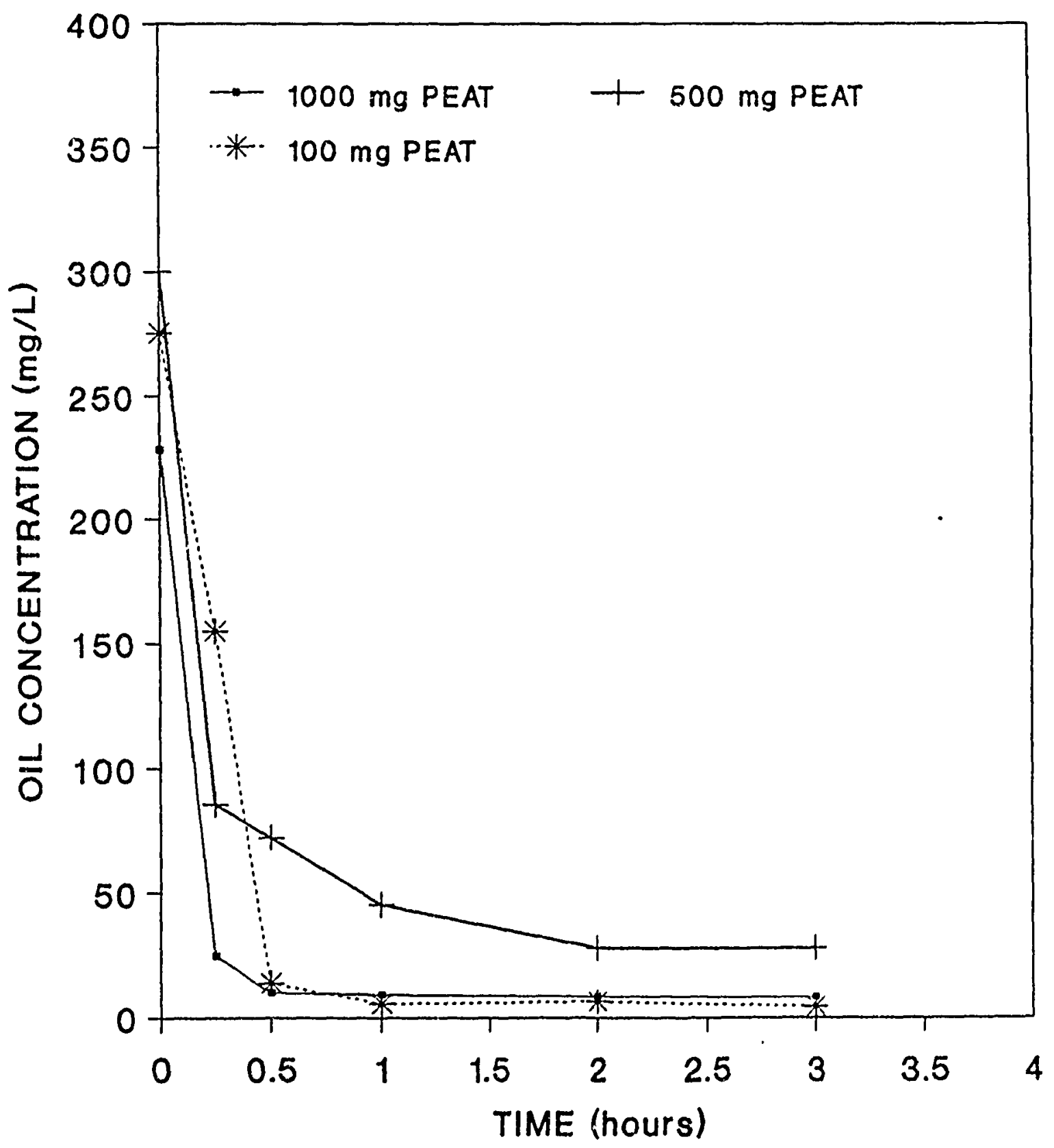

Figure 4.3. Equilibrium time for the adsorption of SMO by herticultural peat 


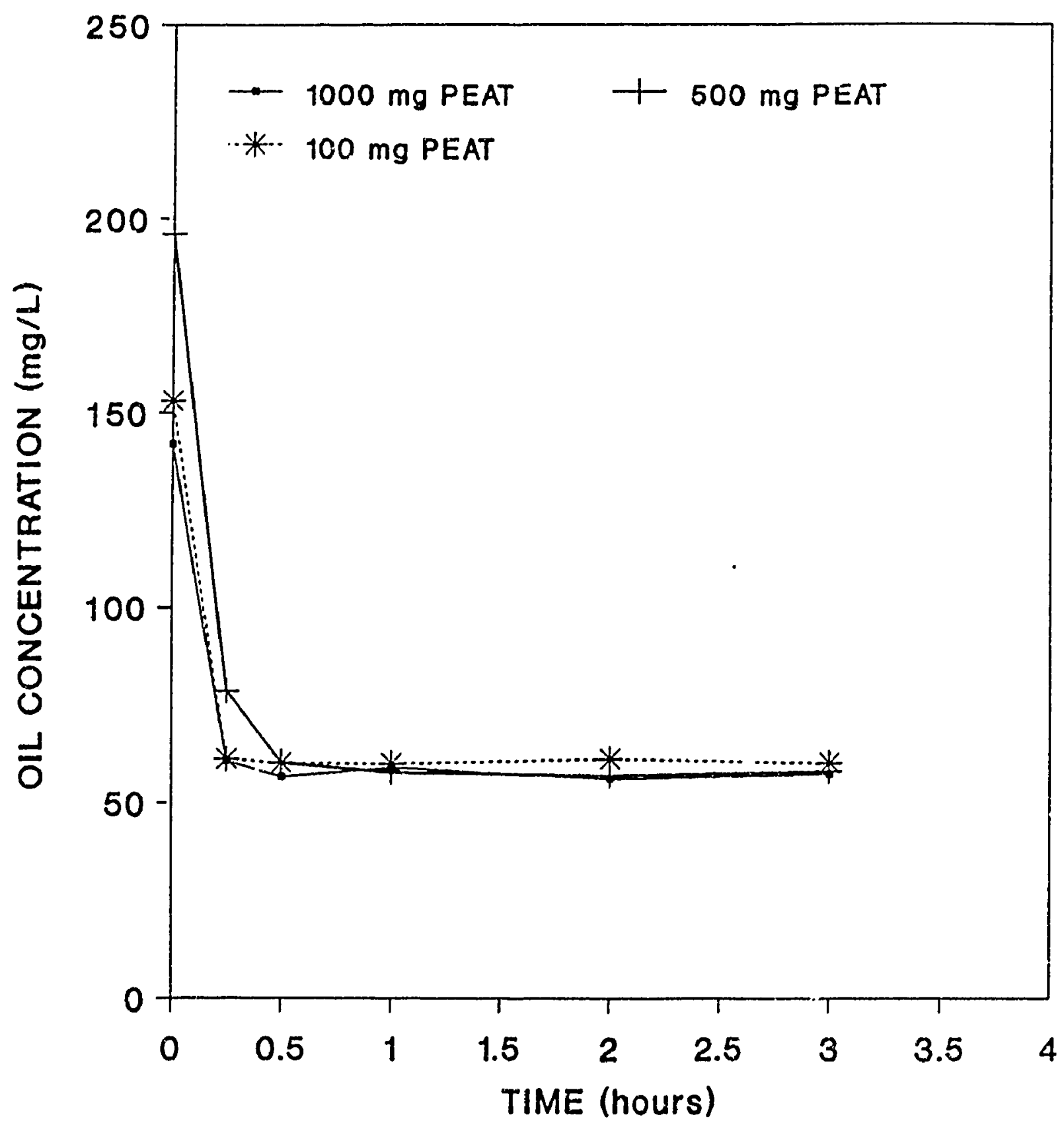

Figure 4.4. Equilibrium time for the adsorption of MCO by horticultural peat 


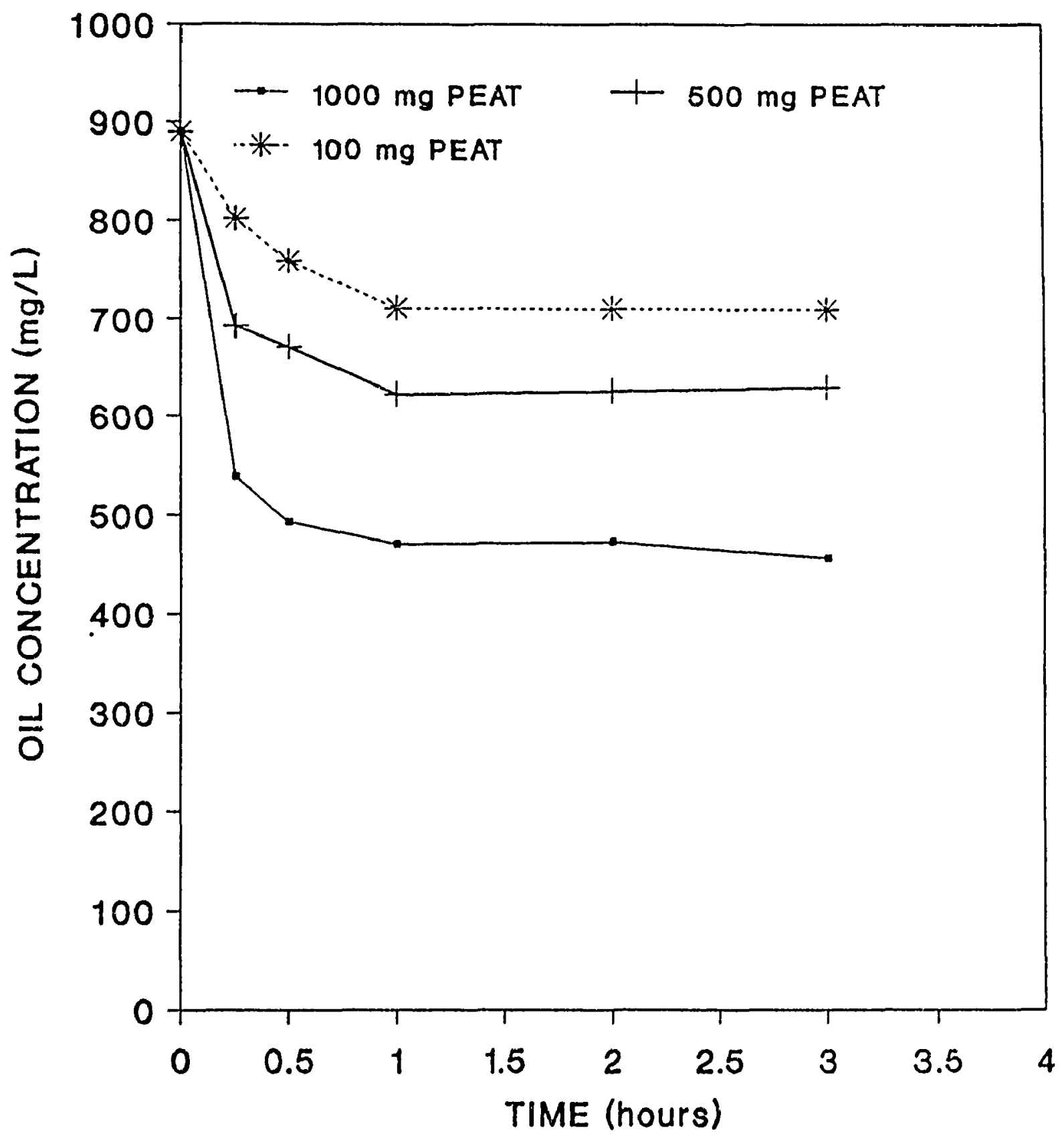

Figure 4.5. Equilibrium time for the adsorption of $\mathrm{CO}$ by horticultural peat 


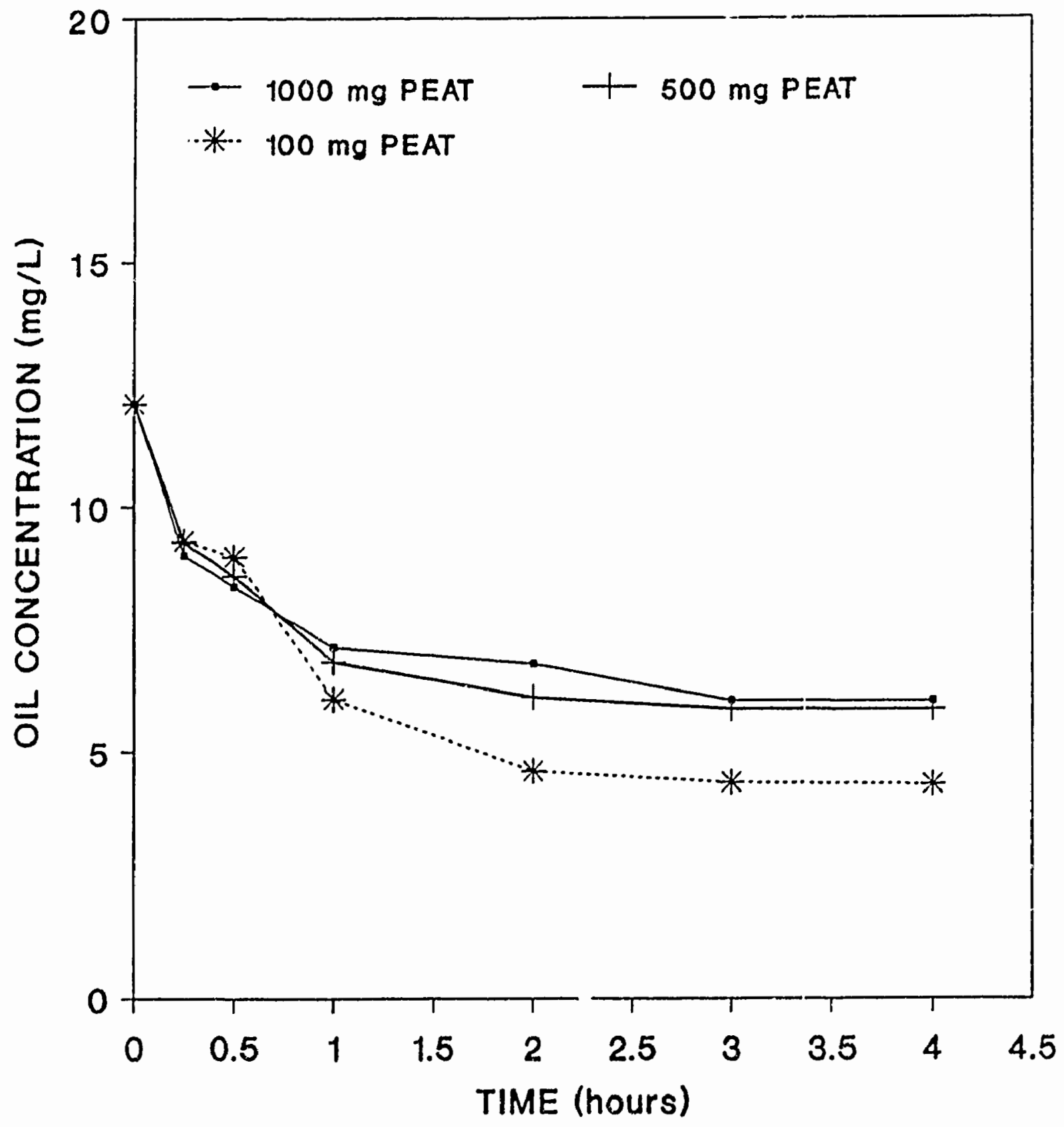

Figure 4.6. Equilibrium time for the adsorption of $R E$ by horticultural peat 


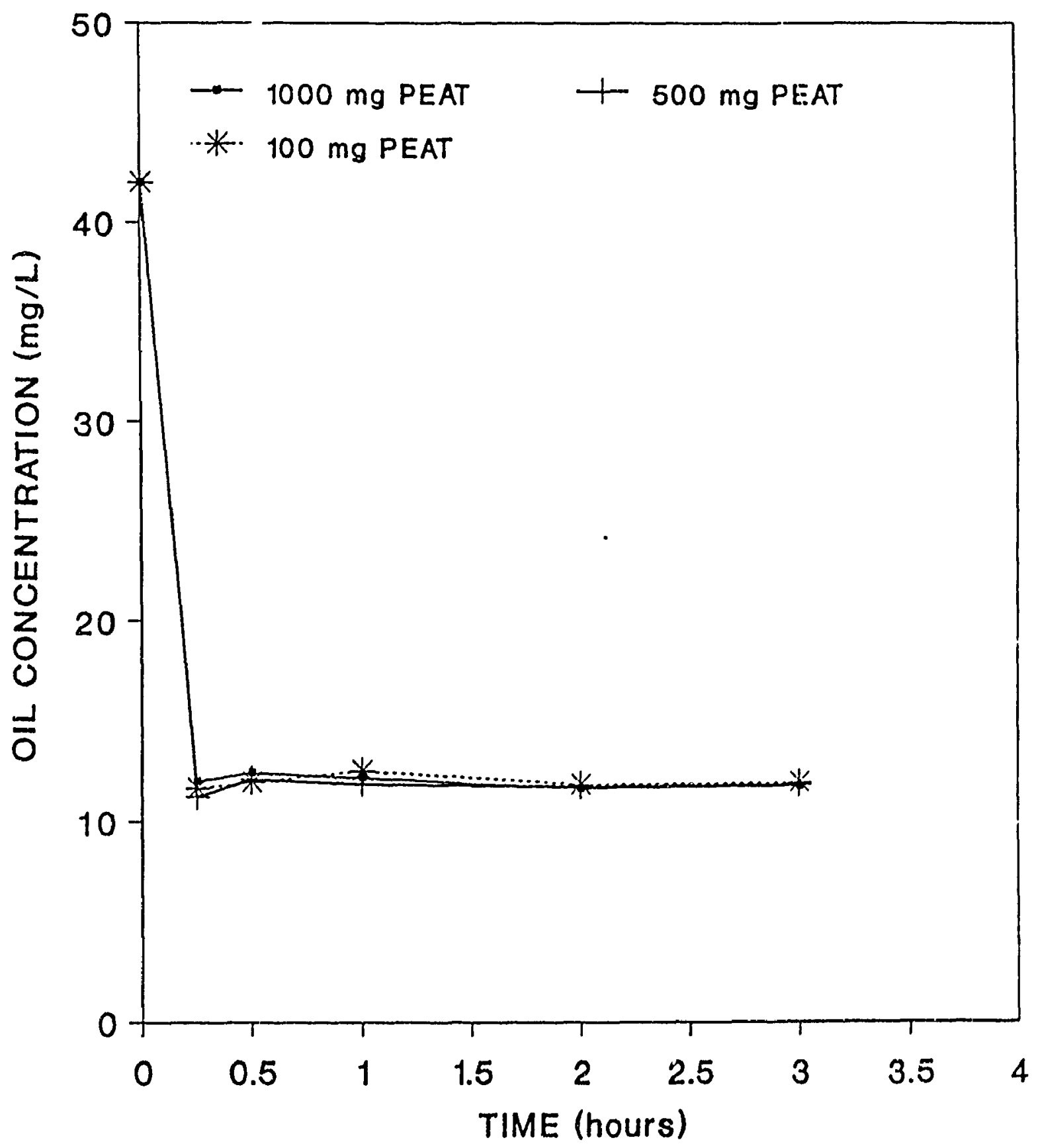

Figure 4.7. Equilibrium time for the adsorption of PW by horticultural peat 
two hours for SMO, MCO, CO and PW emulsions. Pushkarev et al. (1983) pointed out that the time required to establish adsorption equilibrium was 20 to 30 minutes for all types of oils.

The oil removal efficiencies obtained at the equilibrium time from these batch tests are presented in Table 4.15. Gererally, the percentage oil removal varied from 21 to 98 depending upon the type of emulsion. These results indicate that peat can be a good medium far removing oil from some emulsions. The low removal rates (21 to 40 percent) obtained for $\mathrm{CO}$ may be an indication of the limitations of peat in treating chemically stabilized emulsions.

\subsubsection{Adsorption isotherm}

The data collected from the adsorption isotherm experiments were analyzed for a best linear fit of the three well known adsorf.10n isotherms used in the field of environmental engineering (Langmuir, Freundlich and BET equations), using regression analysis. Before performing the analyses, corrections were applied to eliminate the interference of drained-peat with the measurement of oil using correlations established ( $\mathrm{v}$ Figure 4.8). The interference was maximum for $\mathrm{CO}$ indicating that the chemicals presen in the $\mathrm{CO}$ ?ached heavily with peat when extracted with $\mathrm{CCl}_{4}$.

The results of the regression equations obtained (for SMO, MCO, CO and RE) are presented in Tables 4.16 and 4.17. It was observed that the Langmuir and Freundlich isotherms have negative correlations for $\mathrm{SMO}, \mathrm{MCO}$, and $\mathrm{CO}$, while positive correlations were obtained for the BET model in describing the adsorption process.

The statistical parameters presented in Table 4.17 satisfied the appropriate $t$ and $F$ tests. The statistical tests confirm that the linearized adsorption isotherms provide 
Table 4.15. Oil removal efficiencies using horticultural peat from batch kinetic studies

\begin{tabular}{||l|c|c|c||}
\hline \hline Emulsion & $\begin{array}{c}\text { Initial oil } \\
\text { concentration } \\
\mathrm{mg} / \mathrm{L}\end{array}$ & $\begin{array}{c}\text { Oil concentration } \\
\text { at equilibrium } \\
\mathrm{mg} / \mathrm{L}\end{array}$ & $\begin{array}{c}\text { Oil } \\
\text { removal } \\
\%\end{array}$ \\
\hline \hline SMO & & & \\
1.0g peat & 228.3 & 8.3 & 96 \\
1.5g peat & 300.0 & 28.1 & 91 \\
0.1g peat & 275.0 & 4.4 & 98 \\
MCO & & & \\
1.0g peat & 142.0 & 56.8 & 60 \\
0.5g peat & 196.0 & 60.4 & 69 \\
0.1g peat & 153.0 & 60.1 & 61 \\
CO & & & \\
1.0g peat & 890.0 & 537.9 & 40 \\
0.5g peat & 890.0 & 700.7 & 21 \\
0.1g peat & 890.0 & 647.7 & 27 \\
RE & & & \\
1.0g peat & 12.1 & 6.0 & 50 \\
0.5g peat & 12.1 & 5.9 & 52 \\
0.1g peat & 12.1 & 4.4 & 64 \\
PW & & & \\
1.0g peat & 41.98 & 11.64 & 72 \\
0.5g peat & 41.98 & 11.72 & 72 \\
0.1g peat & 41.98 & 11.81 & 72 \\
\hline \hline
\end{tabular}




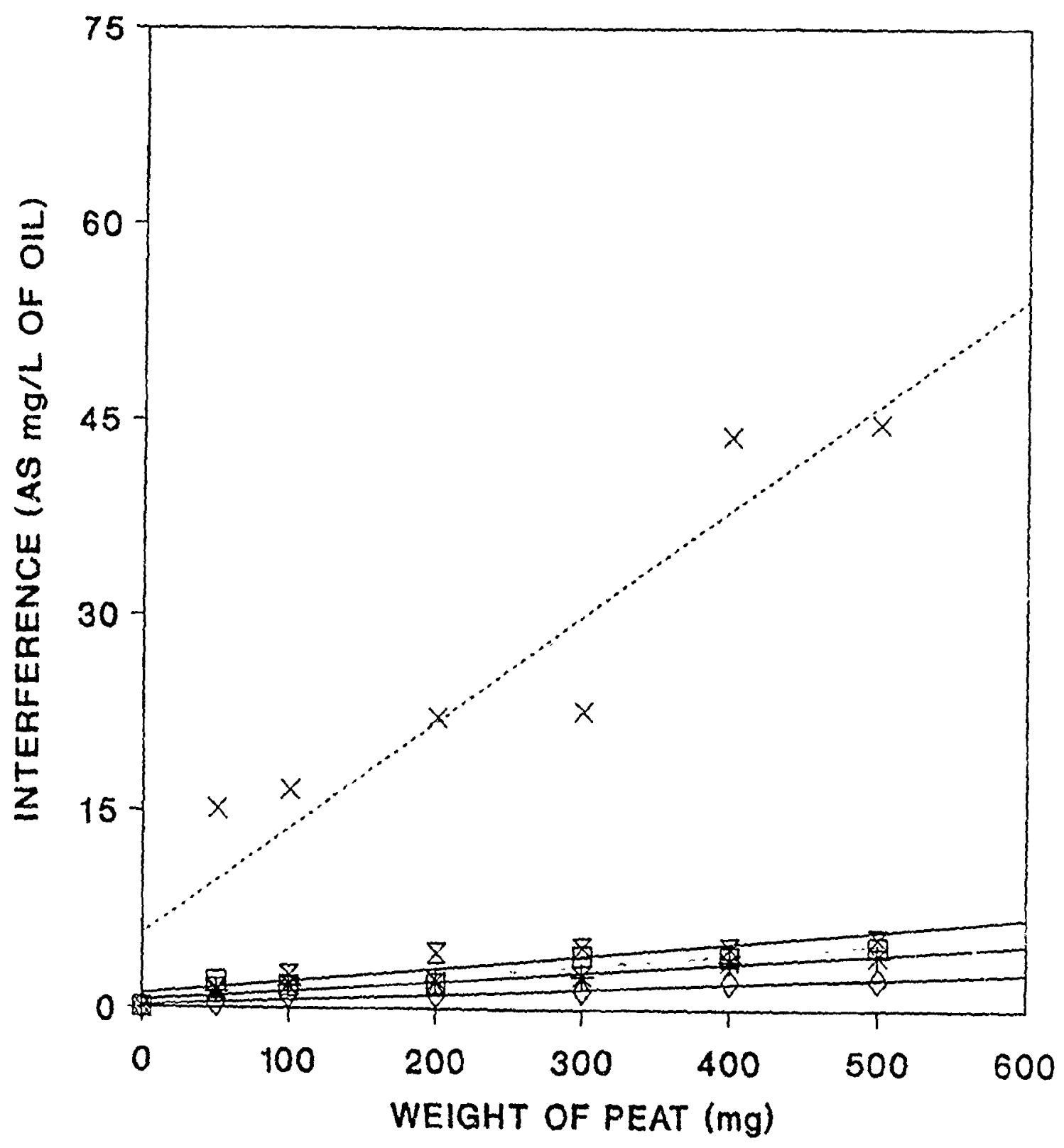

* SMO $\square$ MCO *X. CO $\rightarrow$ RE -ZPW

Figure 4.8. Interferesce of drained-peat with carbon tetrachloride solution 
Table 4.16. Regression equations for the Langmuir and Freundlich isotherms

\begin{tabular}{|c|c|c|}
\hline Description & Equation & $\begin{array}{l}\text { Correlation } \\
\text { coefficient }\end{array}$ \\
\hline Langmuir ${ }^{\dagger}$ & & \\
\hline SMO & $y=18.57-298 x$ & -0.788 \\
\hline $\mathrm{MCO}$ & $y=27.2-718 x$ & -0.467 \\
\hline $\mathrm{CO}$ & $\because=4.15-393 x$ & -0.768 \\
\hline $\mathrm{RE}$ & $y=481-464 x$ & 0.0 .17 \\
\hline Freundlich & & \\
\hline SMO & $y=3.48-2.97 x$ & -0.860 \\
\hline $\mathrm{MCO}$ & $y=1.92-1.72 x$ & -0.401 \\
\hline $\mathrm{CO}$ & $y=3.73 \cdot 1.69 x$ & -0.824 \\
\hline $\mathrm{RE}$ & $y=3.10+0.417 x$ & 0.156 \\
\hline
\end{tabular}

$\dagger_{\mathrm{y}}=\frac{1}{\frac{2}{m}}$ and $x=\frac{1}{C}$ in Langmuir equation

$\ddagger \mathrm{y}=\log \frac{x}{m}$ and $x=\log C$ in Freundlich equation 
Table 4.17. Statistical analyses for the BET isotherm

\begin{tabular}{||l|c|c|c|c|c||}
\hline \hline Emulsion & BET $^{\dagger}$ equation & $\begin{array}{c}\text { Correlation } \\
\text { coefficient }\end{array}$ & $\begin{array}{c}\text { Standard } \\
\text { deviation }\end{array}$ & $t_{c}^{\ddagger}$ & $F_{c}$ \\
\hline \hline SMO & $y=-1.61+22.5 \mathrm{x}$ & 0.850 & 0.413 & 3.23 & 10.47 \\
MCO & $\mathrm{y}=-9.57+53 \mathrm{x}$ & 0.831 & 2.34 & 2.99 & 8.95 \\
$\mathrm{CO}$ & $\mathrm{y}=-5.09+5.43 \mathrm{x}$ & 0.880 & 0.470 & 3.71 & 13.73 \\
$\mathrm{RE}$ & $\mathrm{y}=-4343+8908 \mathrm{x}$ & 0.736 & 1213 & $2.18^{*}$ & $4.71^{*}$ \\
\hline \hline
\end{tabular}

$\dagger y=\frac{C}{(C,-C) \frac{r}{m}}$ and $x=\frac{C}{C}$ in BET equation.

$\ddagger$ and are calculated values of $t$ and $F$

$t_{0.05}=$ table value at $5 \%$ significance level $=2.776$

$F_{0.05}=$ table value at $5 \%$ significance level $=7.71$

$-t_{0.10}=$ table value at $10 \%$ significance level $=2.132$

" $F_{0.10}=$ table value at $10 \%$ significance level $=4.54$ 
a reasonable fit of the data. The level of significance was high (10\%) in the case of RE, indicating the scatter of the dependent and independent variables. Pushkarev et al. (1983) indicated that the adsorption of oil was rarely described by simple isotherms like those of Langmuir and of Freundlich and observed that the isotherms describing adsorption of oil were generally complicated by extreme points due to the complex process of adsorption. Linearized plots of the BET adsorption of SMO, MCO, CO and RE by horticultural peat are shown in Figure 4.9 through 4.12 .

The BET model represents an isotherm reflecting apparent multilayer adsorption. The number of molecular layers of SMO formed on peat was calculated by using the molecular weight of SMO and the surface area of the peat. The area covered by each molecule of SMO was calculated as $\frac{2}{3}$ power of the molecular volume assuming a spherical shape (Bell and Tsezos 1988). The monolayer covered per unit weight of peat was calculated as $0.589 \mu \mathrm{g} / \mathrm{g}$ of peat. Using this value and the BET adsorption equation, the number of layers formed for different $\frac{x}{m}$ values were then computed. The results presented in Table 4.18 demonstrate the multilayer adsorption of SMO by peat.

In the case of PW, the adsorption did not follow the BET equation (as was the case of SMO, MCO, $\mathrm{CO}$ and $\mathrm{RE}$ ) on the basis of correlation coefficients obtained for the best linear fit. The adsorption isotherm was represented by the Langmuir and the Freundlich equations. It is likely that the presence of high concentrations of dissolved solids and alkalinity in the produced water may be one of the factors responsible for this divergent behavior in the adsorption process. The Langmuir and the Freundlich isotherms for the adsorption of oil from produced water by peat are shown in Figures 4.13 and 4.14 respectively. 


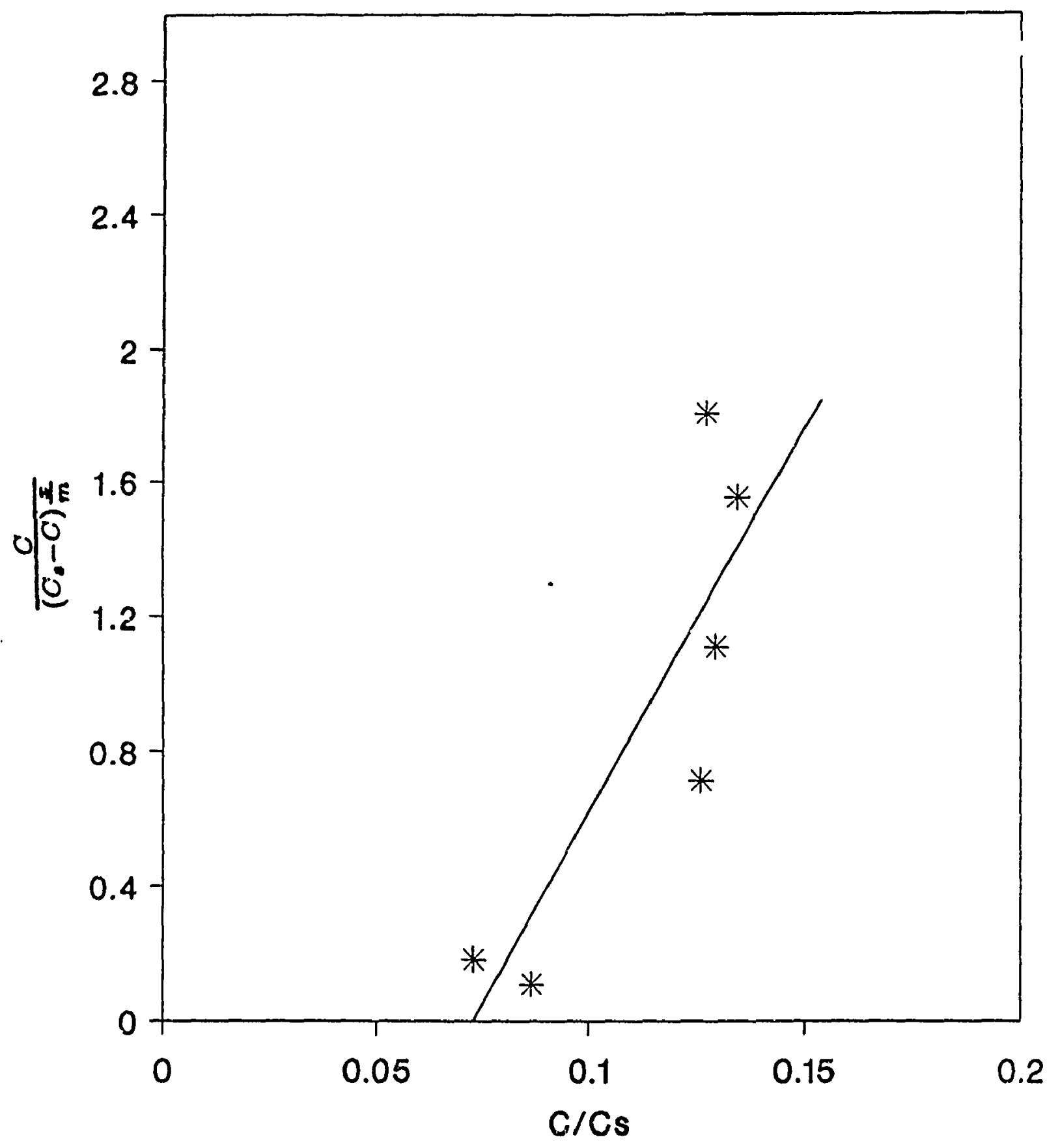

Figure 4.9. BET isotherm for the adsorption of SMO by horticultural peat 


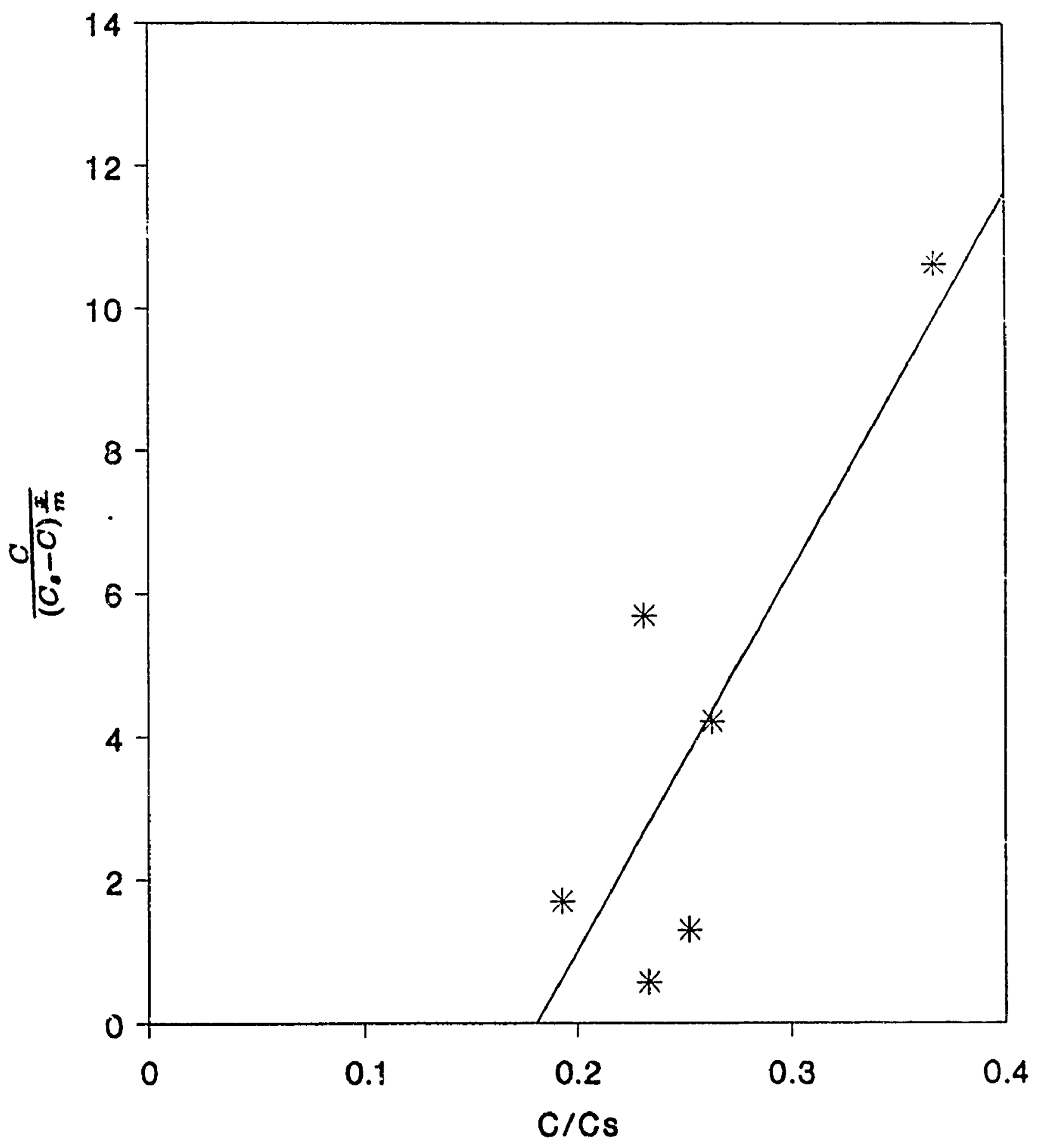

Figure 4.10. BET isotherm for the adsorption of MCO by horticultural peat 


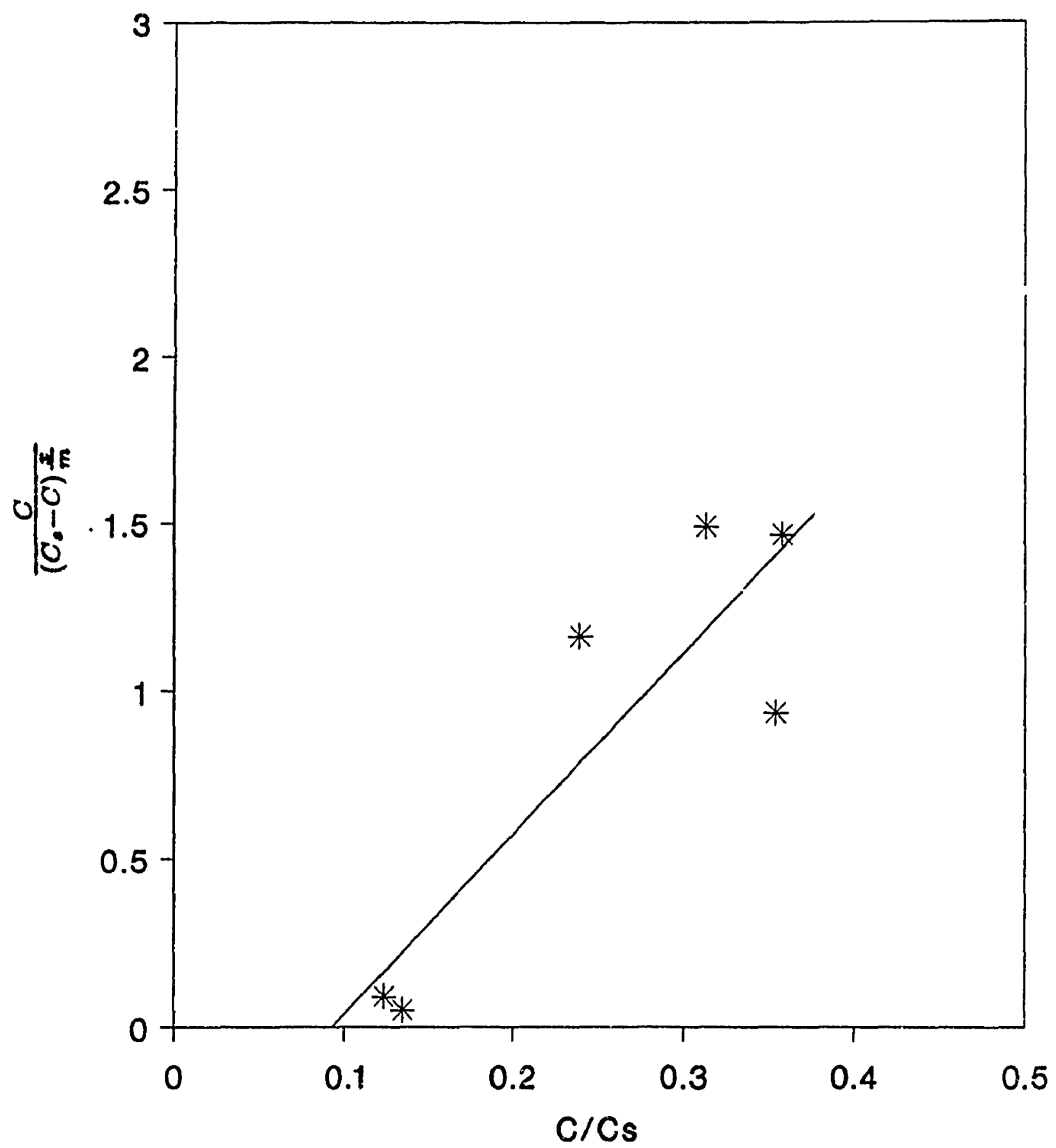

Figure 4.11. BET isotherm for the adsorption of $\mathrm{CO}$ by horticultural peat 


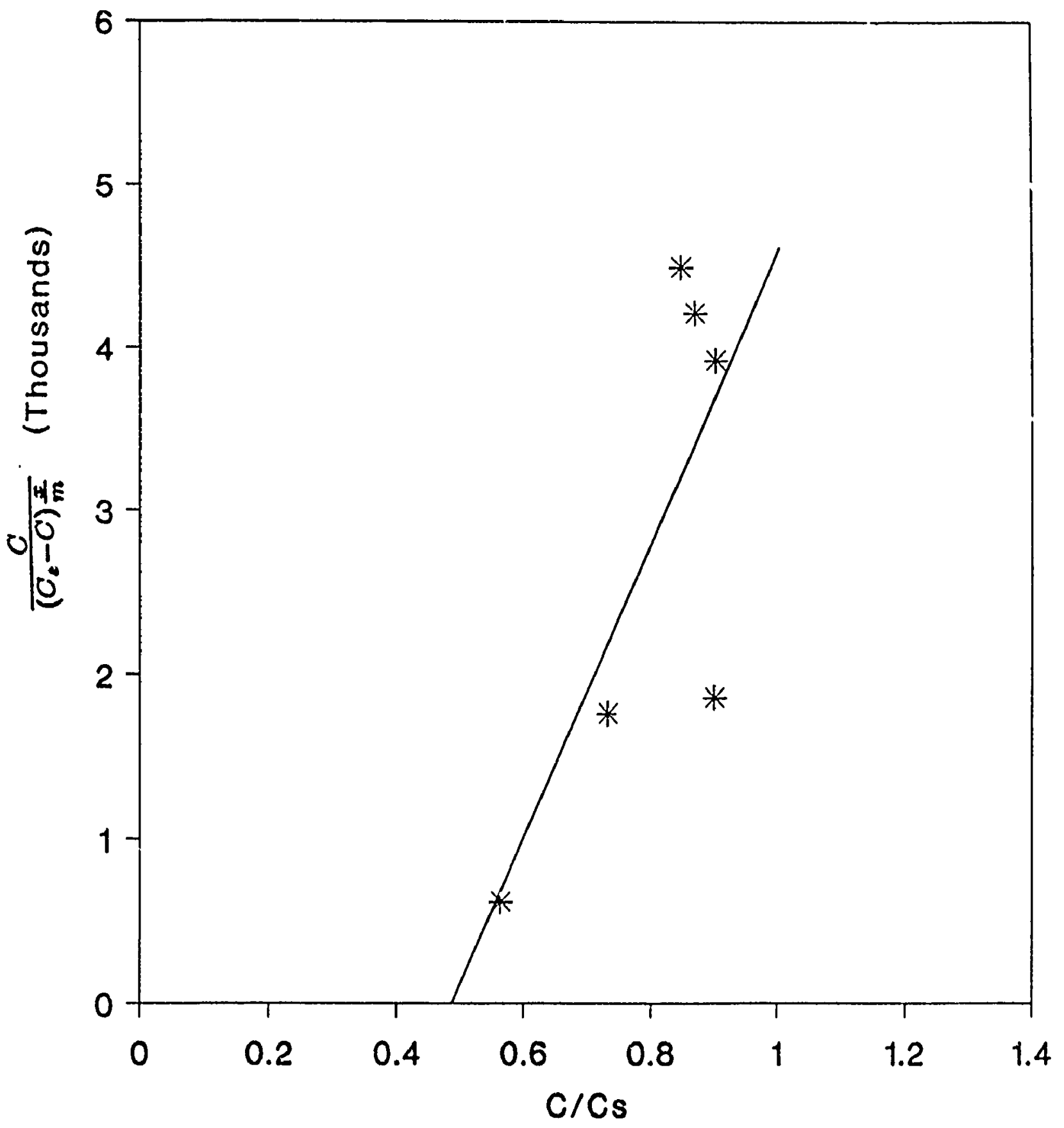

Figure 4.12. BET isotherm for the adsorption of RE by horticultural peat 
Table 4.18. Number of molecular layers for the BET adsorption of oil by horticultural peat

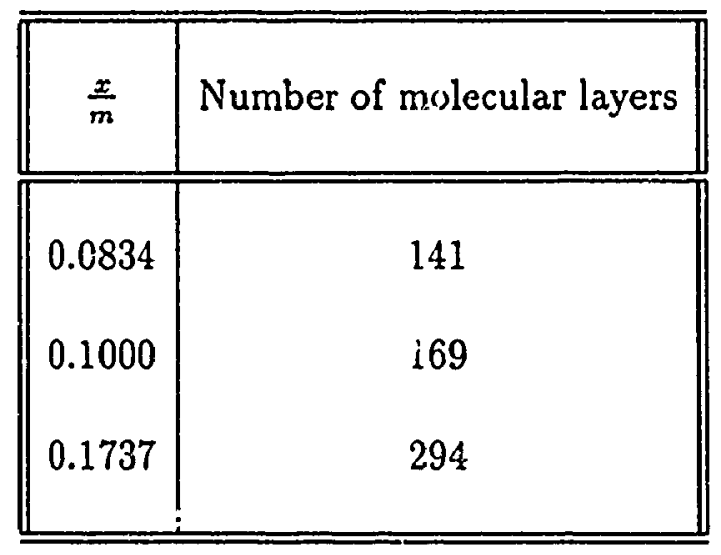

Density of SMO $=0.8535 \mathrm{~g} / \mathrm{cm}^{3}$

Molecular weight of SMO (approx.) $=422$

Molecular volume of SMO $=491.43 \mathrm{~cm}^{3} / \mathrm{g}$ mole

Area covered by each molecule $=1.1645 \mathrm{~nm}^{2}$

Surface area of peat $=0.98 \mathrm{~m}^{2} / \mathrm{g}$ 


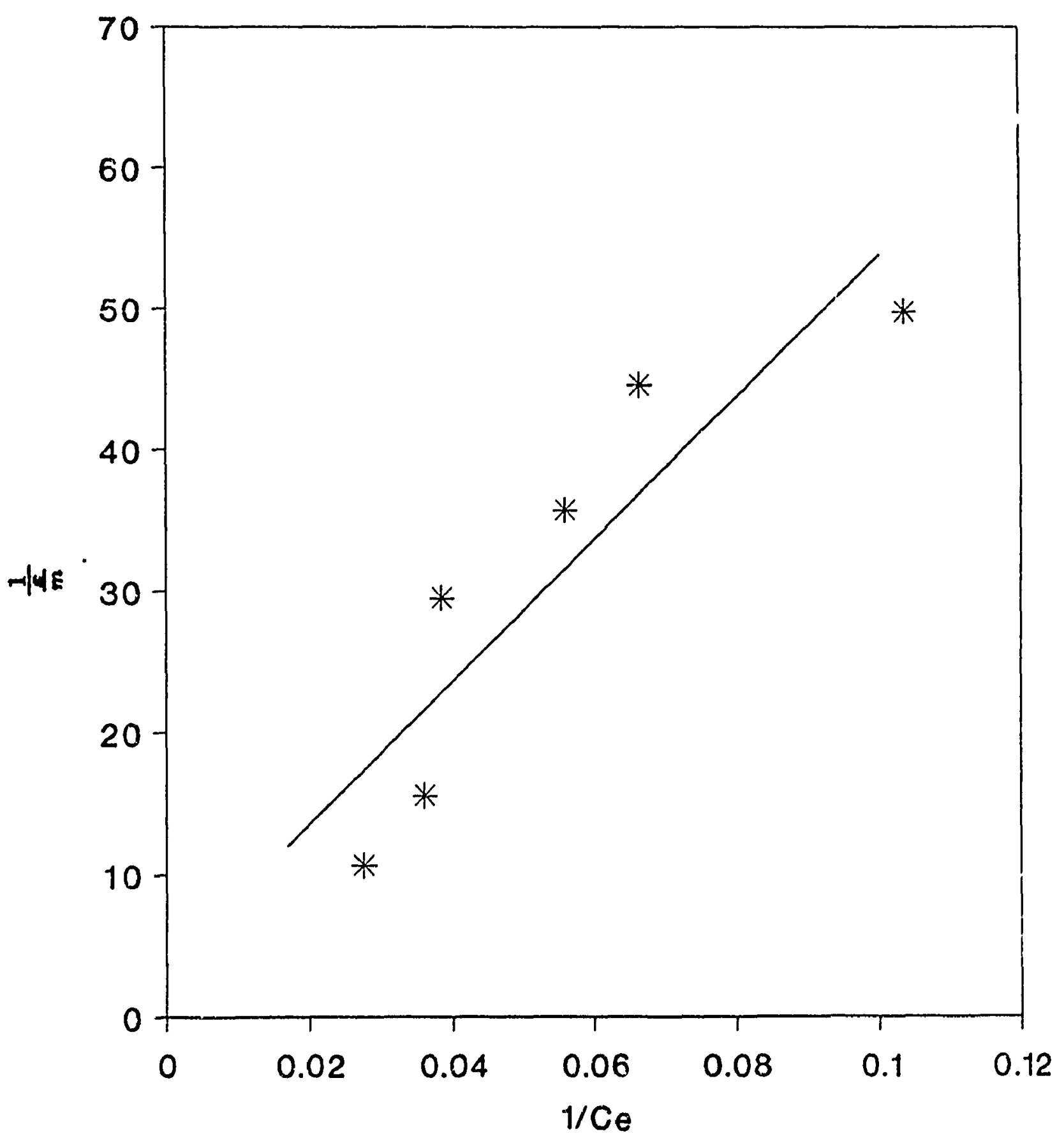

Figure 4.13. Langmuir isotherm for the adsorption of oil from PW by horticultural peat 


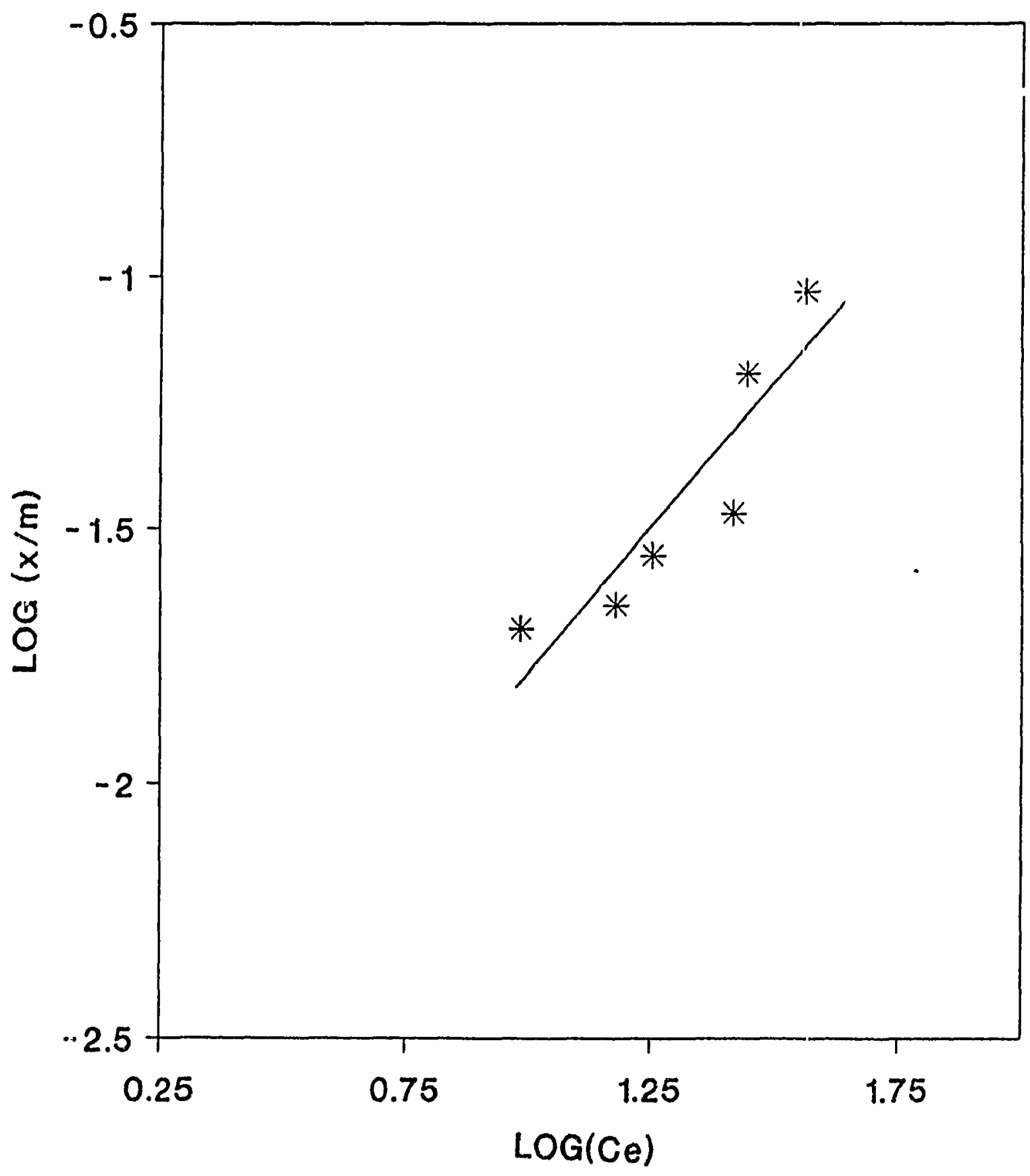

Figure 4.14. Freundlich isotherm for the adsorption of oil from PW vy horticultural peat 
The $t$ and $F$ tests for the regression equations oblained (Table 4.19) confirm that the linearized adsorption isotherms provide a reasonable fit of the data.

Adsorption can be classified as favorable or unfavorable depending upon the value of the equilibrium parameter $\mathrm{R}$ defined earlier (equation 2.3). For the adsorption of oil from $P W$ by peat, the value of $R$ was calculated as $C .0334$. Since $R$ is $<1$ and $>$ 0 , the adsorption is favorable (Weber and Chakravorti 1974).

The constants involved in the adsorption cquations for all the five emulsions are consolidated in Table 4.20 .

\subsubsection{Pretreated peat}

\subsubsection{Adsorption isotherms with SMO}

The data collected for the adsorption of SMO onto pretreated peat samples were analyzed for best linear fit using regression analyses for the Langmuir, Freundlich and BET isotherms. These results are summarized in Table 4.21. The adsorption equations having the highest positive correlation coefficients were selected to describe the adsorption of SMO onto different peat samples (Table 4.22).

It is seen that except for two pretreated peat samples (OD-1 and OD-3), all other samples have correlation coefficients ranging from 0.64 to 0.99 . The weight of SMO adsorbed per unit weight of pretreated sample $\left(\frac{x}{m}\right)$, caiculated using the adsorption equations in Table 4.22, are shown in Figures 4.15 and 4.16.

A comparison of the shapes of the isotherms shown in Figure 4.15 with the one shown earlier (Figure 2.2) indicated that the adsorption is favorable for acid-treated peat and pyrolyzed $\left(175^{\circ} \mathrm{C}\right)$ peat samples. The adsorption was found to be linear in the case of pyrolyzed $\left(150^{\circ} \mathrm{C}\right)$ peat and unfavorable for alkali-treated peat. 
Table 4.19. Statistical analyses for the Langmuir and the Freundlich isotherm equations

\begin{tabular}{||l|c|c|c|c|c||}
\hline \hline Isotherm & Regression & $r^{*}$ & $S_{y}^{\dagger}$ & $t_{c}^{\ddagger}$ & $F_{c}^{\ddagger}$ \\
\hline \hline Langmuir & $y=3.62+501 \mathrm{x}$ & 0.9 & 7.65 & 4.98 & 16.67 \\
Freundlich* & $y=-2.93+1.15 \mathrm{x}$ & 0.904 & 0.127 & 4.24 & 17.96 \\
BET** & $y=10.4+13.6 \mathrm{x}$ & 0.52 & 4.10 & & \\
\hline
\end{tabular}

\# Correlation coefficient between ordinates $\mathrm{x}$ and $\mathrm{y}$

$\dagger$ Standard deviation

$\ddagger_{t_{c}}$ and $F_{c}$ are calculated values

$t_{0.05}=$ table values at $5 \%$ significance level $=2.776$

$F_{0.05}=$ table value at $5 \%$ significance level $=7.71$

If $y=\frac{1}{\frac{1}{m}}$ and $x=1 / C$ in Langmuir equation

* $y=\log _{m} x$ and $x=\log C$ in Freundlich equation

$* y=\frac{C_{C}}{\left(C_{0}-C\right) \frac{z}{m}}$ and $x=\frac{C}{C_{0}}$ in BET equation. 
Table 4.20. Isotherm constants for horticultural peat and emulsions

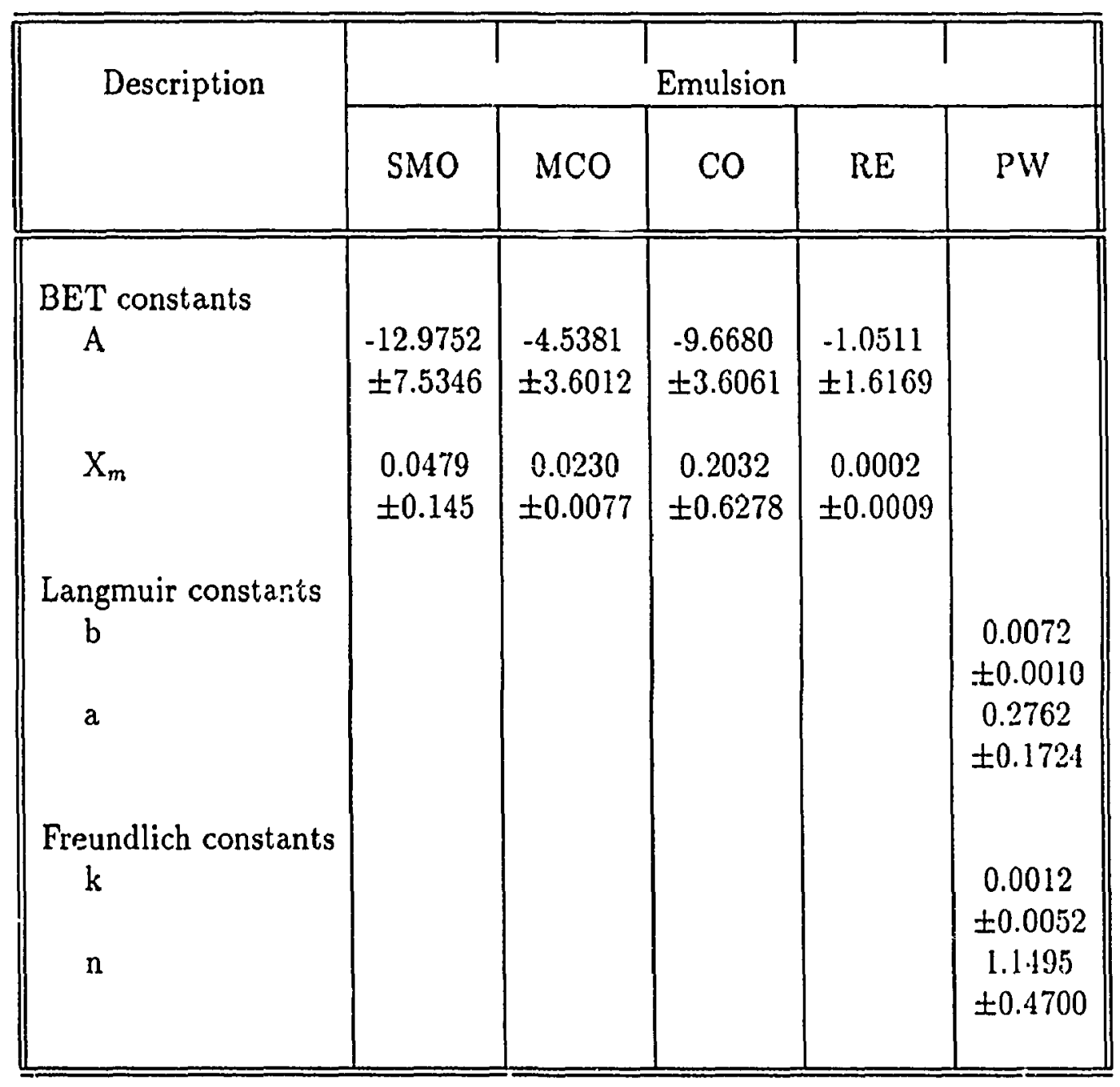


Table 4.21. Results of the regression analysis for the adsorption of SMO onto pretreated peat samples

\begin{tabular}{|c|c|c|c|}
\hline \multirow[t]{2}{*}{ Peat sample } & \multicolumn{3}{|c|}{ Regression equation of isotherm } \\
\hline & Langmuir ${ }^{\dagger}$ & Freundlich $\ddagger$ & BET \\
\hline $\begin{array}{l}\text { OD-1 } \\
r^{*} \\
\text { OD-3 } \\
r \\
\text { WH\&A } \\
r \\
\text { WH\&O } \\
r \\
\text { ACID } \\
r \\
\text { ALKALI } \\
r \\
\text { P150 } \\
r \\
\text { P175 } \\
r \\
\text { P200 } \\
r \\
\text { P225 } \\
r \\
\text { P250 } \\
r \\
\text { P275 } \\
r\end{array}$ & $\begin{array}{c}y=8.42-43.8 x \\
-0.03 \\
y=10.4-23.1 x \\
-0.45 \\
y=41.9-1210 x \\
-0.72 \\
y=-2.46+56.8 x \\
0.850 \\
y=-1.89+111 x \\
0.93 \\
y=-2.07+64.7 x \\
0.96 \\
y=-10.1+263 x \\
0.92 \\
y=-18.5+1188 x \\
0.90 \\
y=-17.9+1305 x \\
0.98 \\
y=22.1-235 x \\
-0.11 \\
y=13.7-41.9 x \\
-0.6 \\
y=19.8-601 x \\
-0.7\end{array}$ & $\begin{array}{c}y=1.53-1.59 x \\
-0.16 \\
y=-5.67+3.07 x \\
2.41 \\
y=2.64-2.14 x \\
-0.48 \\
y=-2.32+1.97 x \\
0.79 \\
y=-2.67+1.69 x \\
0.88 \\
y=-3.99+3.08 x \\
0.98 \\
y=-4.25+2.95 x \\
0.86 \\
y=-7.42+4 x \\
0.85 \\
y=-7.65+4.01 x \\
0.99 \\
y=0.222-0.823 x \\
-0.20 \\
y=4.17-2.88 x \\
-0.82 \\
y=3.32-2.29 x \\
-0.92\end{array}$ & $\begin{array}{c}y=-0.825+14.6 x \\
0.26 \\
y=16.8-66.8 x \\
-0.42 \\
y=-21.6+91.7 x \\
0.86 \\
y=0.416-5.92 x \\
-0.57 \\
y=0.605-3.20 x \\
-0.57 \\
y=0.318-1.99 x \\
-0.93 \\
y=1.96-13.9 x \\
-0.82 \\
y=7.56-19.8 x \\
-0.71 \\
y=7.34-20.2 x \\
-0.97 \\
y=-7.63+48.5 x \\
0.64 \\
y=-8.16+43.8 x \\
0.73 \\
y=-7.67+41.9 \\
0.81\end{array}$ \\
\hline
\end{tabular}

$\dagger \mathrm{y}=\frac{1}{\mathrm{i}}$ and $\mathrm{x}=\frac{1}{\mathrm{C}}$ in Langmuir equation

$\ddagger y=\log \frac{x}{m}$ and $x=\log C$ in Freundlich equation

I $\mathrm{y}=\frac{C}{\left(C_{0}-C\right)_{m}^{\frac{x}{m}}}$ and $\mathrm{x}=\frac{C}{C_{0}}$ in BET equation

\# Correlation coefficient between ordinates $x$ and $y$ 
Table 4.22. Adsorption isotherms for pretreated peat with SMO

\begin{tabular}{||l|l|l|c||}
\hline Peat sample & $\begin{array}{c}\text { Type of } \\
\text { adsorption }\end{array}$ & \multicolumn{1}{|c|}{$\begin{array}{c}\text { Regression } \\
\text { equation }\end{array}$} & $\begin{array}{c}\text { Correlation } \\
\text { coefficient }\end{array}$ \\
\hline HORT & BET $^{\dagger}$ & $y=-1.61+22.5 x$ & 0.85 \\
OD-1 & BET & $y=-0.825+14.6 x$ & 0.26 \\
OD-3 & Freundlich & $y=-5.67+3.07 x$ & 0.42 \\
WH\&A & BET & $y=-21.6+91.7 x$ & 0.86 \\
WH\&O & Langmuir & $y=-2.46+56.8 x$ & 0.85 \\
ACID & Langmuir & $y=-1.89+111 x$ & 0.93 \\
ALKALI & Freundlich & $y=-3.99+3.08 x$ & 0.98 \\
P150 & Langmuir & $y=-10.1+263 x$ & 0.92 \\
P175 & Langmuir & $y=-18.5+1188 x$ & 0.90 \\
P200 & Freundlich & $y=-7.15+4.01 x$ & 0.99 \\
P225 & BET & $y=-7.63+48.5 x$ & 0.64 \\
P250 & BET & $y=-8.16+43.8 x$ & 0.73 \\
P275 & BET & $y=-7.67+41.9 x$ & 0.81 \\
\hline \hline
\end{tabular}

$\dagger \mathrm{y}=\frac{C}{\left(C_{0}-C\right)_{m}^{x}}$ and $\mathrm{x}=\frac{C}{C_{0}}$ in BET equation

$\ddagger_{y}=\log \frac{x}{m}$ and $x=\log C$ in Freundlich equation

If $y=\frac{1}{\frac{2}{m}}$ and $x=\frac{1}{C}$ in Langmuir equation 

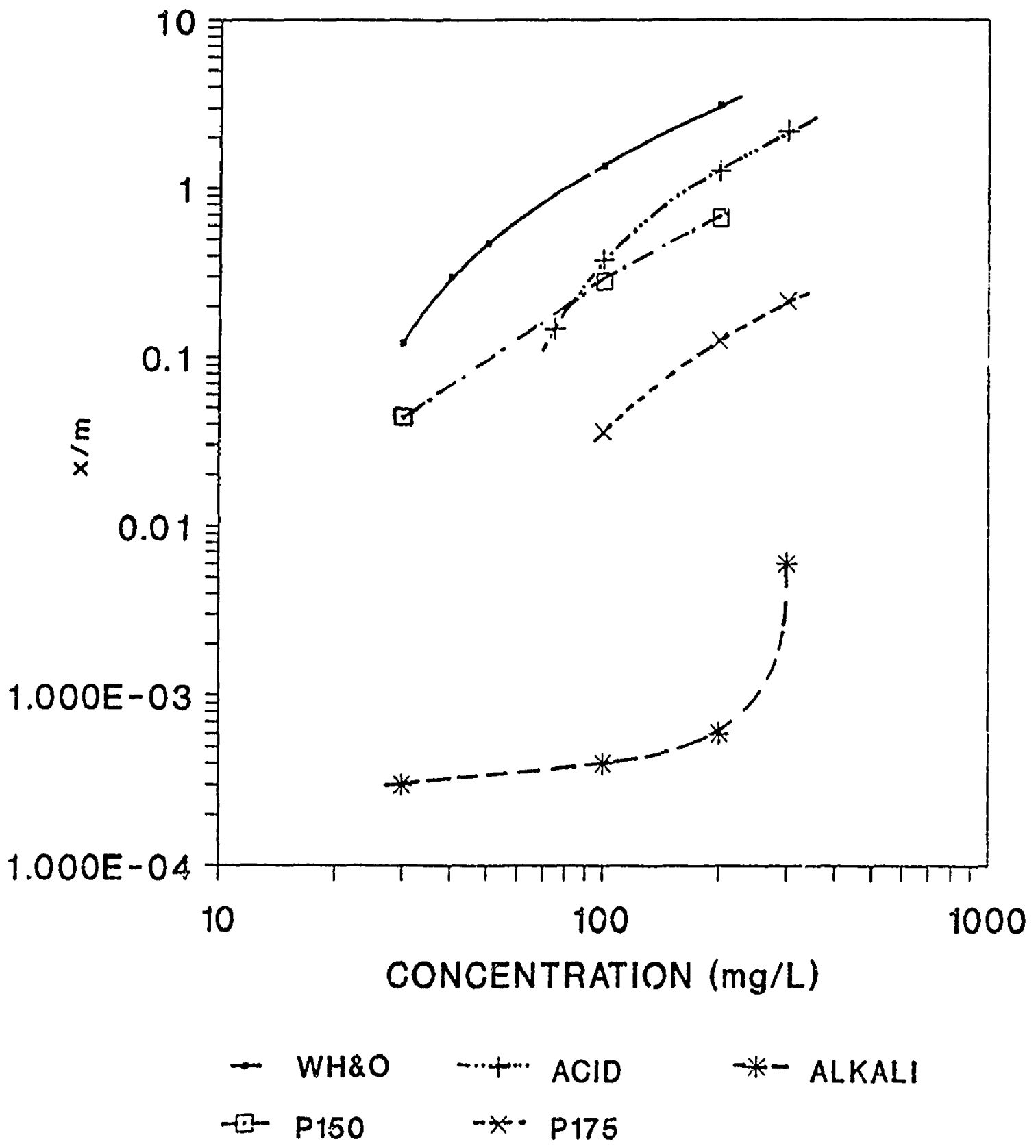

Figure 4.15. Predicted Langmuir and Freundlich adsorption of SMO by peat samples 


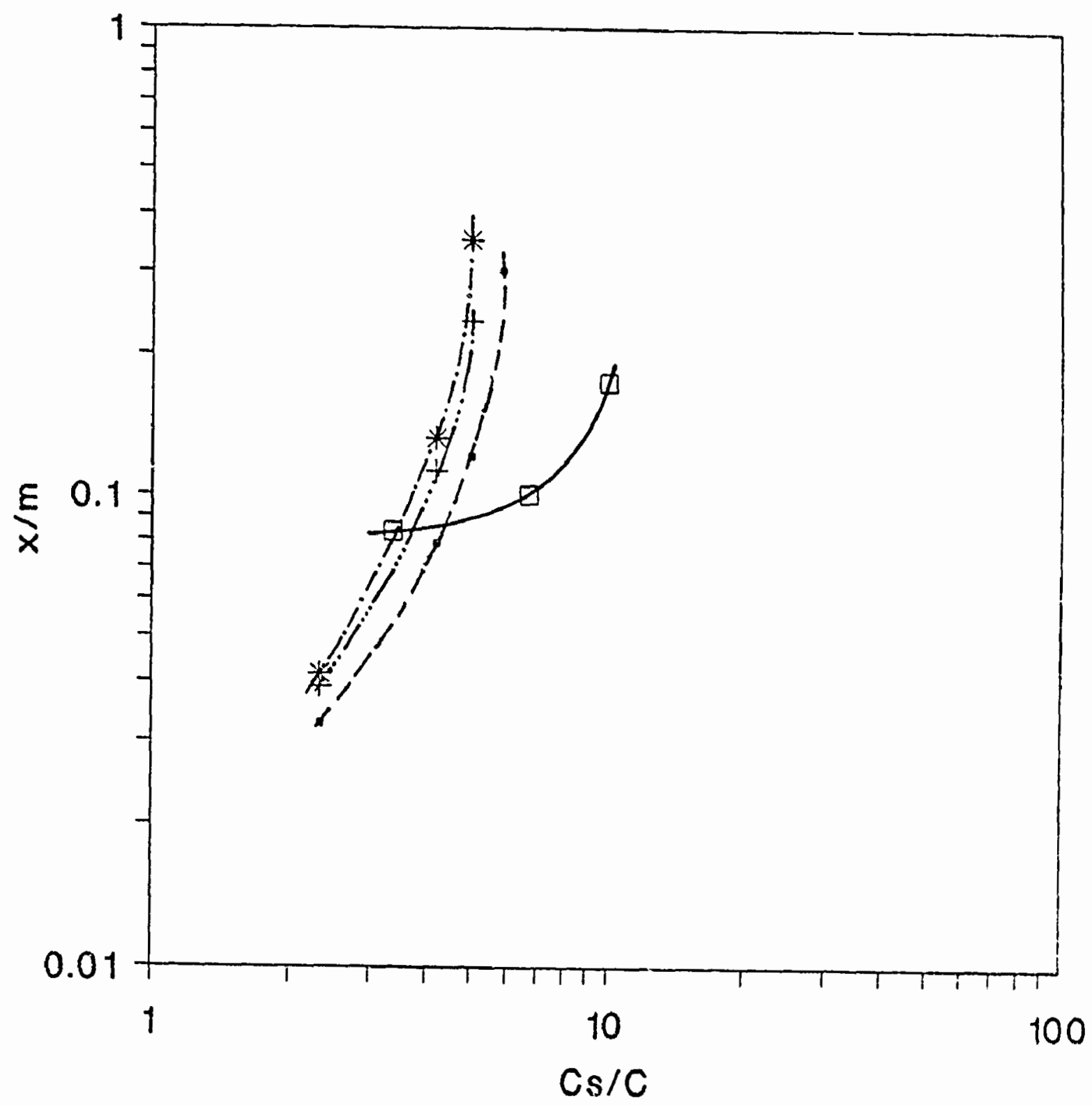

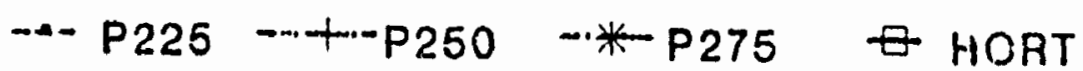

Figure 4.16. Predicted BET adsorption of SMO by peat samples 
From these plots, the $\frac{x}{m}$ values were consolidated and presented in Table 4.23 in order of maximum to minimum adsorption capacity.

Generally, all pretreated peat samples except pyrolyzed (P150 and P225) and alkali-treated peat samples have shown an improvement in oil adsorption capacity compared to horticultural peat. These results also showed that the oil adsorption capacity generally increased with an increase in pyrolysis temperature. The oiladsorption values obtained for acid-treated peat validated the earlier findings of Smith et al. (1976) that the sulfuric-acid treated Michigan peat was very effective in removing oil.

\subsubsection{Adsorption and desorption isotherms with $\mathrm{CO}$}

\section{Adsorption}

The data collected for the adsorption of $\mathrm{CO}$ onto peat samples were analyzed for best linear fit using the regression analyses for the Langmuir, the Freundlich and the BET isotherms. These results are summarized in Table 4.24. The adsorption equations having the highest positive correlation coefficient were selected to describe the adsorption of $\mathrm{CO}$ by peat samples (Table 4.25).

It is seen from this table that except for the pyrulyzed $\left(175^{\circ} \mathrm{C}\right)$ peat sample, all other samples have correlation coefficients greater than 0.7. Values of $\frac{x}{m}$ for different concentration ranges calculated using these adsorption equations are presented in Figures 4.17 and 4.18 for comparison.

A comparison of the isotherm shapes (Figure 4.17) with the isotherm shapes classified and presented by Weber and Chakravorti (1974) (Figure 2.2) indicates that the 
Table 4.23. Predicted Oil adsorption capacity of peat sample with SMO

\begin{tabular}{||l|c||}
\hline Type of peat & $\mathrm{kg}$ of oil adsorbed/kg of peat \\
\hline WH\&O & 0.1 to 3 \\
ACID & 0.15 to 2 \\
P275 & 0.04 to 0.35 \\
P175 & 0.03 to 0.25 \\
P225 & 0.03 to 0.25 \\
HORT & 0.08 to 0.15 \\
P150 & 0.08 七0 0.16 \\
ALKALI & 0.03 to 0.15 \\
\hline \hline
\end{tabular}


Table 4.24. Results of the regression equations for the adsorption of $\mathrm{CO}$ onto peat sample

\begin{tabular}{|c|c|c|c|}
\hline Method & Langmuir $\dagger$ & Freundlich ${ }^{\ddagger}$ & BET' 9 \\
\hline $\begin{array}{l}\text { HORT } \\
\mathrm{r}^{\#} \\
\text { OD-1 } \\
\mathrm{r} \\
\text { OD-3 } \\
\mathrm{r} \\
\text { WH\&A } \\
\mathrm{r} \\
\text { WH \&O } \\
\mathrm{r} \\
\text { ACID } \\
\mathrm{r} \\
\text { ALKALI } \\
\mathrm{r} \\
\text { P150 } \\
\mathrm{r} \\
\text { P175 } \\
\mathrm{r} \\
\text { P200 } \\
\mathrm{r} \\
\text { P225 } \\
\mathrm{r} \\
\text { P250 } \\
\mathrm{r} \\
\text { P275 } \\
\mathrm{r}\end{array}$ & $\begin{array}{c}y=0.39+22.04 x \\
0.33 \\
y=0.45+15.53 x \\
0.32 \\
y=0.05+46.98 x \\
0.76 \\
y=-1.80+134.09 x \\
0.93 \\
y=-1.23+93.7 x \\
0.97 \\
y=-0.54+75.28 x \\
0.88 \\
y=-2.37+424.84 x \\
0.46 \\
y=-4.17+336.1 x \\
0.76 \\
y=-2.18+210.8 x \\
0.49 \\
y=-1.61+78.11 x \\
0.84 \\
y=-1.43+71.72 x \\
0.73 \\
y=-1.13+66.16 x \\
0.88 \\
y=-0.99+57.34 x \\
0.85\end{array}$ & $\begin{array}{c}y=-1.12+0.72 x \\
0.45 \\
y+-0.90+0.61 x \\
0.46 \\
y=-1.70+1.02 x \\
0.76 \\
y=-7.61+4.52 x \\
0.91 \\
y=-5.78+3.55 x \\
0.94 \\
y=-3.34+1.98 x \\
0.89 \\
y=-7.07+3.42 x \\
0.58 \\
y=-13.14+7.28 x \\
0.74 \\
y=-8.42+4.65 x \\
0.50 \\
y=-6.71+4.5 x \\
0.76 \\
y=-6.20+4.19 x \\
0.69 \\
y=-5.19+3.46 x \\
0.77 \\
y=-4.67+3.17 x \\
0.73\end{array}$ & $\begin{array}{c}\mathrm{y}=-0.06+1.71 \mathrm{x} \\
0.78 \\
\mathrm{y}=-0.12+1.72 \mathrm{x} \\
0.70 \\
\mathrm{y}=-0.18+2.12 \mathrm{x} \\
0.84 \\
\mathrm{y}=1.57-2.58 \mathrm{x} \\
0.82 \\
\mathrm{y}=1.02-1.60 \mathrm{x} \\
0.89 \\
\mathrm{y}=0.60+0.056 \mathrm{x} \\
0.1 \\
\mathrm{y}=-2.52+5.48 \mathrm{x} \\
0.10 \\
\mathrm{y}=4.45-6.77 \mathrm{x} \\
0.62 \\
\mathrm{y}=3.0-3.77 \mathrm{x} \\
0.32 \\
\mathrm{y}=0.74-1.88 \mathrm{x} \\
0.67 \\
\mathrm{y}=0.68-1.66 \mathrm{x} \\
0.56 \\
\mathrm{y}=0.66-1.31 \mathrm{x} \\
0.65 \\
\mathrm{y}=0.54-1.12 \mathrm{x} \\
0.59\end{array}$ \\
\hline
\end{tabular}

$\dagger_{y}=\frac{1}{m}$ and $x=\frac{1}{C}$ in Langmuir equation

$\ddagger y=\log \frac{x}{m}$ and $x=\log C$ in Freundlich equation

If $\mathrm{y}=\frac{C}{\left(C_{0}-C\right)_{m}^{\frac{x}{m}}}$ and $\mathrm{x}=\frac{C}{C_{0}}$ in BET equation

\# Correlation coefficient between ordinates $\mathrm{x}$ and $\mathrm{y}$. 
Table 4.25. Adsorption isotherms for the pretreated peat and $\mathrm{CO}$

\begin{tabular}{||l|c|c|c||}
\hline \hline Peat sample & $\begin{array}{c}\text { Adsorption } \\
\text { isotherm }\end{array}$ & Regression equation & $\begin{array}{c}\text { Cocrelation } \\
\text { coefficient }\end{array}$ \\
\hline OD-1 & BET ${ }^{\dagger}$ & $\mathrm{y}=-0.12+1.72 \mathrm{x}$ & 0.70 \\
OD-3 & BET & $\mathrm{y}=-0.18+2.12 \mathrm{x}$ & 0.84 \\
WH\&A & Langmuir & $\mathrm{y}=-1.80+134.09 \mathrm{x}$ & 0.93 \\
WH\&O & Langmuir & $\mathrm{y}=-1.23+93.7 \mathrm{x}$ & 0.97 \\
ACID & Freundlich & $\mathrm{y}=-3.34+1.98 \mathrm{x}$ & 0.89 \\
ALKALI & Freundlich & $\mathrm{y}=-7.07+3.42 \mathrm{x}$ & 0.58 \\
P150 & Langmuir & $\mathrm{y}=-4.17+336.1 \mathrm{x}$ & 0.76 \\
P175 & Freundlich & $\mathrm{y}=-8.42+4.65 \mathrm{x}$ & 0.50 \\
P200 & Langmuir & $\mathrm{y}=-1.61+78.11 \mathrm{x}$ & 0.84 \\
P225 & Langmuir & $\mathrm{y}=-1.43+71.72 \mathrm{x}$ & 0.73 \\
P250 & Langmuir & $\mathrm{y}=-1.13+66.16 \mathrm{x}$ & 0.88 \\
P275 & Langmuir & $\mathrm{y}=-0.99+57.3 \mathrm{x}$ & 0.85 \\
\hline \hline
\end{tabular}

$\dagger_{y}=\frac{C}{\left(C_{s}-C\right)_{\frac{1}{m}}^{\frac{x}{m}}}$ and $\mathrm{x}=\frac{C}{C_{\mathrm{t}}}$ in BET equation

$\ddagger y=\frac{1}{x}$ and $x=\frac{1}{C}$. in Langmuir equation

$\mathrm{y}=\log \frac{x}{m}$ and $\mathrm{x}=\log \mathrm{C}$ in Freundlich 

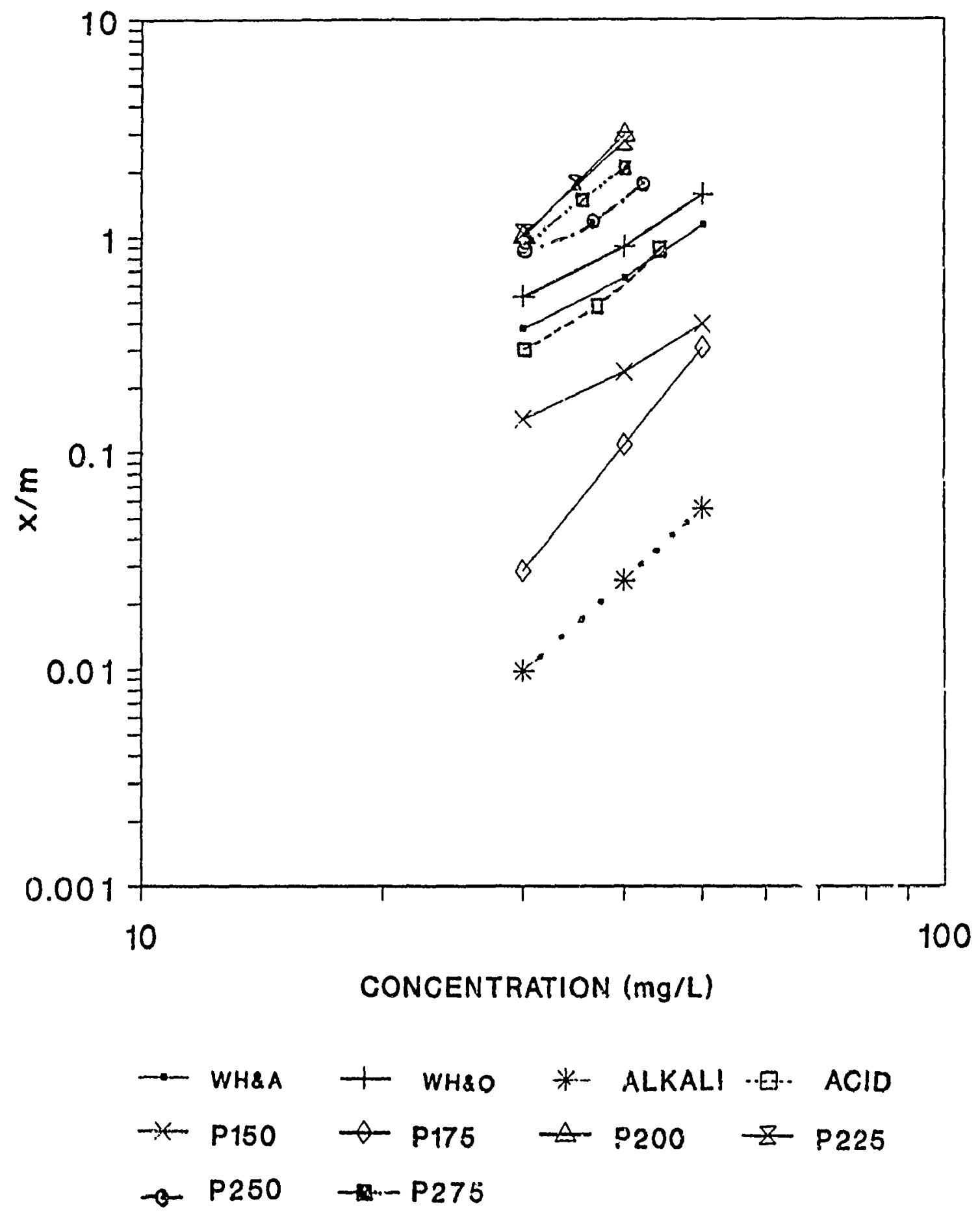

Figure 4.17. Predicted Langmuir and Freundlich adsorption of $\mathrm{CO}$ by pretreated peat samples 


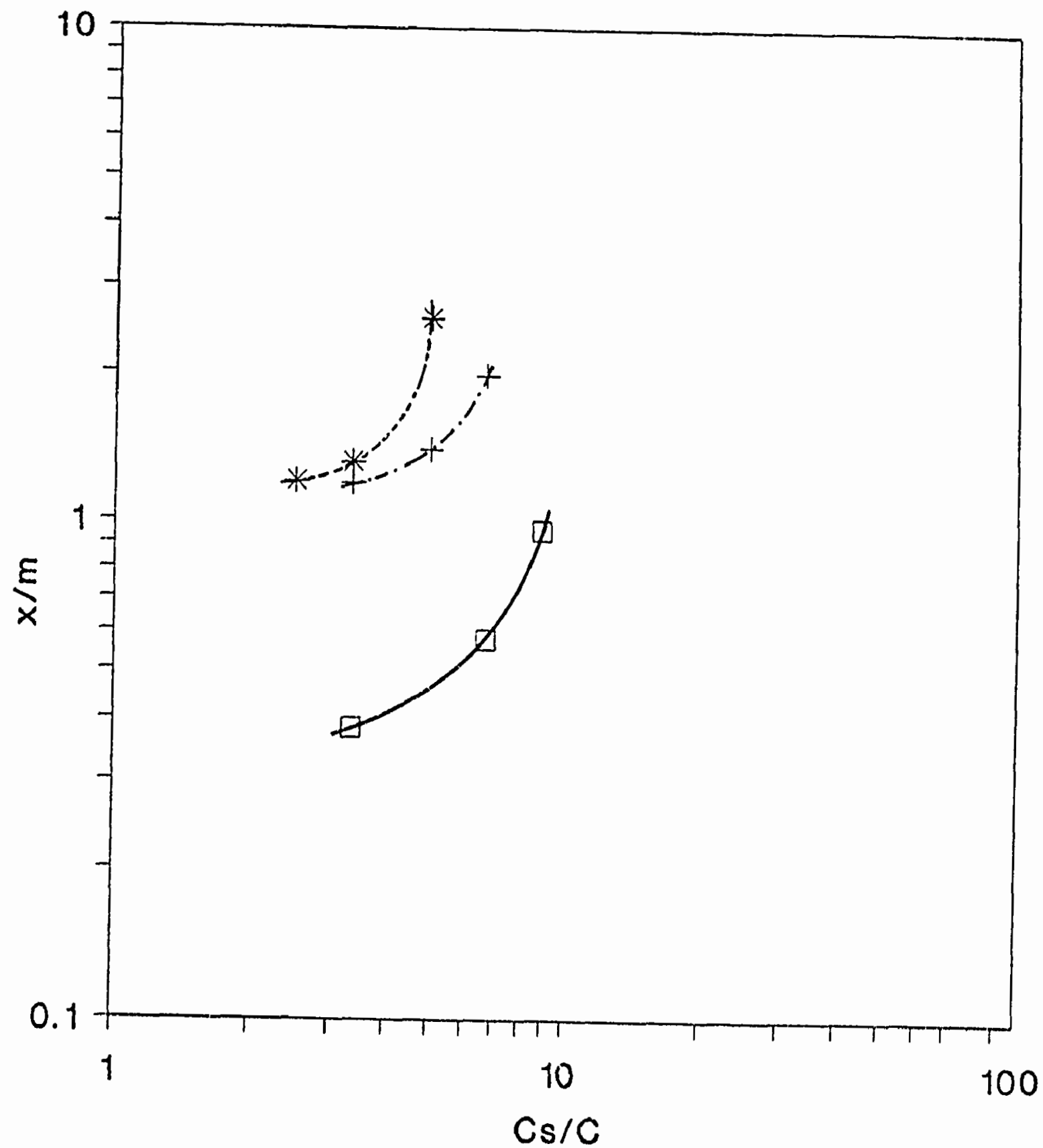

-+ OD1 -* OD3 $\because$ HORT

Figure 4.18. Predicted BET adsorption of $\mathrm{CO}$ by pretreated peat samples 
adsorption of $\mathrm{CO}$ by P200, P225, and acid-treated samples is favorable. The adsorption of $\mathrm{CO}$ by other pretreated peat samples namely: WH\&A, WH\&O, ALKALI, $\mathrm{P} 150$ and $\mathrm{P} 175$, are found to be linear (favorable).

The weight of oil adsorbed per unit weight of peat $\left(\frac{x}{m}\right)$ values calculated using these plots is presented in Table 4.26 in order of maximum to minimum oil adsorption capacity. Some of the pretreated peat samples (ALKALI, and P150), did not show any increase in oil-adsorption capacity as compared to the oil-adsorption capacity of the horticultural peat. The acid-treated peat, OD-1, OD-2, WH\&A, WH\&O, P200, P225, and P275 showed enhanced oil-adsorption capacities after treatment.

These oil-adsorption capacities for pretreated samples when compared with the surface areas of pretreated peat (Table 4.6) did not show any correlation. This further shows that the adsorption may be influenced by other surface properties of the peat sample than just the surface area alone.

\section{Desorption}

The desorbed oil concentration was found to be less than $4 \mathrm{mg} / \mathrm{L}$ for all the yeat samples for a contact time of 2 hours (APPENDIX F). Attempts were not made to determine the equilibrium desorption time. A fit of the desorption isotherm was not considered due to low desorbed oil concentration.

\subsection{Column Tests}

\subsubsection{Eight-hour tests with peat}

The hourly effluent oil concentrations from the $0.3 \mathrm{~m}$ deep horticultural peat bed for three different flow rates $(12,48$ and $300 \mathrm{~mL} / \mathrm{min})$ and the five oil-in-water 
Table 4.26. Predicted Oil adsorption capacity for peat samples with $\mathrm{CO}$

\begin{tabular}{|l|c||}
\hline Type of peat & $\mathrm{kg}$ of oil adsorbed $/ \mathrm{kg}$ of peat \\
\hline \hline P200 & 1.0 to 2.90 \\
P225 & 1.04 to 2.75 \\
P275 & 1.08 to 2.20 \\
P250 & 0.93 to 1.91 \\
WH\&O & 0.53 to 1.57 \\
OD-3 & 1.19 to 1.33 \\
WH\&A & 0.35 to 1.13 \\
OD-1 & 1.23 to 1.05 \\
ACID & 0.38 to 1.0 \\
HORT & 0.38 to 0.95 \\
ALKALI & 0.01 to 0.50 \\
P150 & 0.14 to 0.39 \\
P175 & 0.028 to 0.31 \\
\hline
\end{tabular}


emulsions are presented in Figures 4.19 to 4.23 . The influent and the average effluent oil concentrations and the average percentage oil removals are presented in Table 4.27.

These results indicate that for mechanically prepared emulsions such as SMO and MCO, which are dispersed and emulsified, oil removal efficiencies greater than 96 percent were achieved irrespective of the influent oil concentration and flow rates investigated. For a chemically stabilized emulsion su $\mathrm{sh}$ as $\mathrm{CO}$, which is emulsified and soluble, the oil removal decreased from 96 to 34 percent when the flow rate was increased from 12 to $100 \mathrm{~mL} / \mathrm{min}$. Thus, for emulsions such as $\mathrm{CO}$, the oil removal was dependent on the flow rate. A flow rate of $300 \mathrm{~mL} / \mathrm{min}$ for this emulsion could not be applied due to the very high loss of head measured over the filter in the first hour of the run. This showed that there are limitations in using peat to treat such chemically stabilized emulsions. In the case of treated and highly stable oil-in-water emulsions such as RE (which is dispersed, emulsified and soluble), the oil removal efficiency was found to be 92 percent at $12 \mathrm{~mL} / \mathrm{min}$ flcw compared to 68.5 percent at $300 \mathrm{~mL} / \mathrm{min}$.

The peat column proved to be very effective in treating two different produced waters, PW1 with a low oil concentration $(28.2 \mathrm{mg} / \mathrm{L})$ and a high salinity $(50 \mathrm{~g} / \mathrm{L})$ and PW2, with a high oil concentration $(531.1 \mathrm{mg} / \mathrm{L})$ and a low salinity $(4 \mathrm{~g} / \mathrm{L})$. In both the cases, the oil removal efficiencies exceeded 80 percent irrespective of flow rates. There was approximately 10 percent reduction in the oil removal efficiency for PW2 when the flow rate was increased from 48 to $300 \mathrm{~mL} / \mathrm{min}$. Even though produced waters are highly stable oil-in-water emulsions, the oil removal efficiencies exceeded 80 percent, indicating the effectiveness of peat in removing oil from produced waters. 


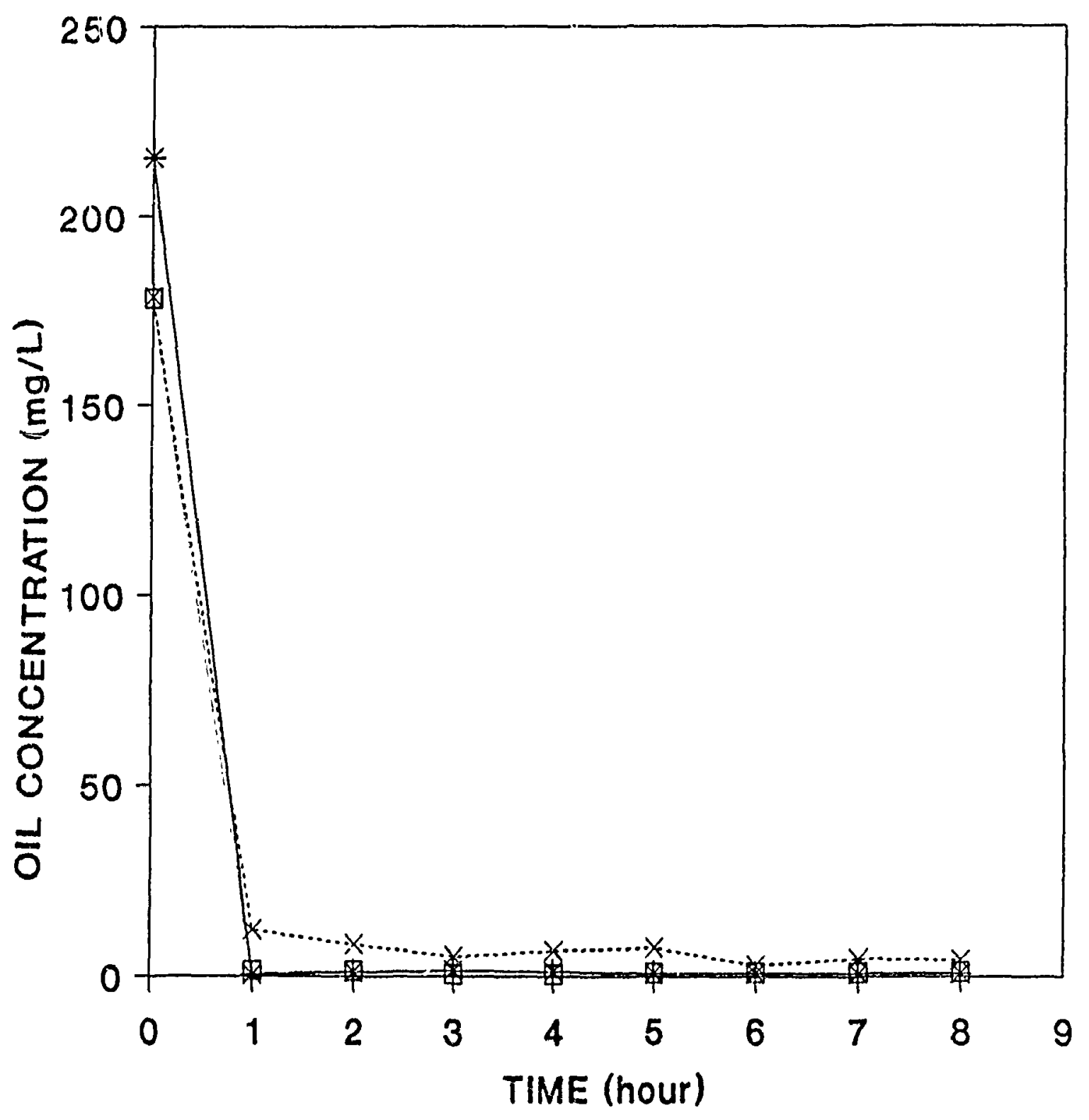

* $12 \mathrm{~mL} / \mathrm{min}$ - $48 \mathrm{~mL} / \mathrm{min} \quad \cdots \times \cdots 300 \mathrm{~mL} / \mathrm{min}$

Figure 4.19. Effluent oil concentrations from eight-hour run using SMO 


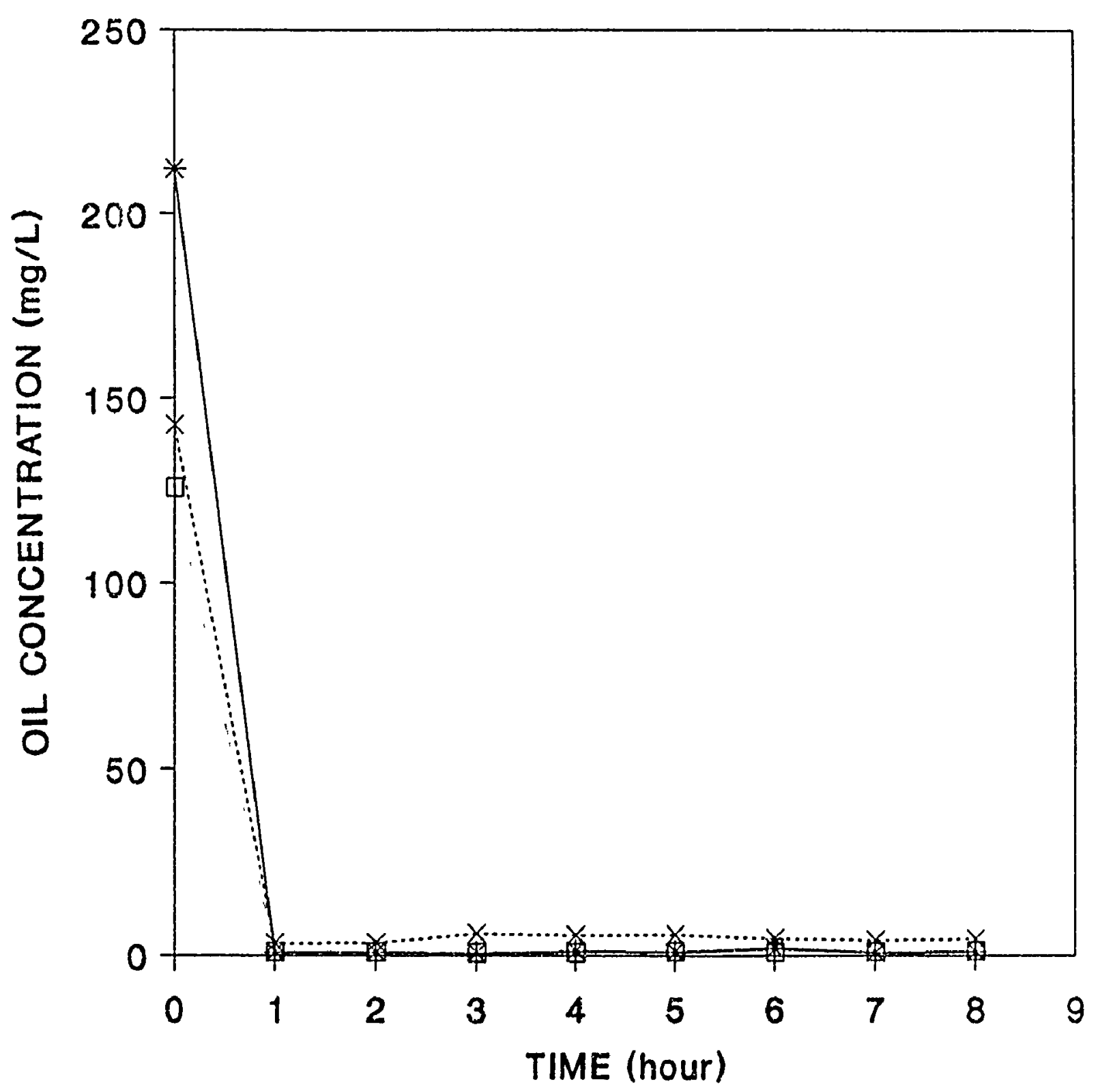

* $12 \mathrm{~mL} / \mathrm{min} \cdot \square 48 \mathrm{~mL} / \mathrm{min} \quad \cdots \times 300 \mathrm{~mL} / \mathrm{min}$

Figure 4.20. Effluent oil concentrations from eight-hour run using MCO 


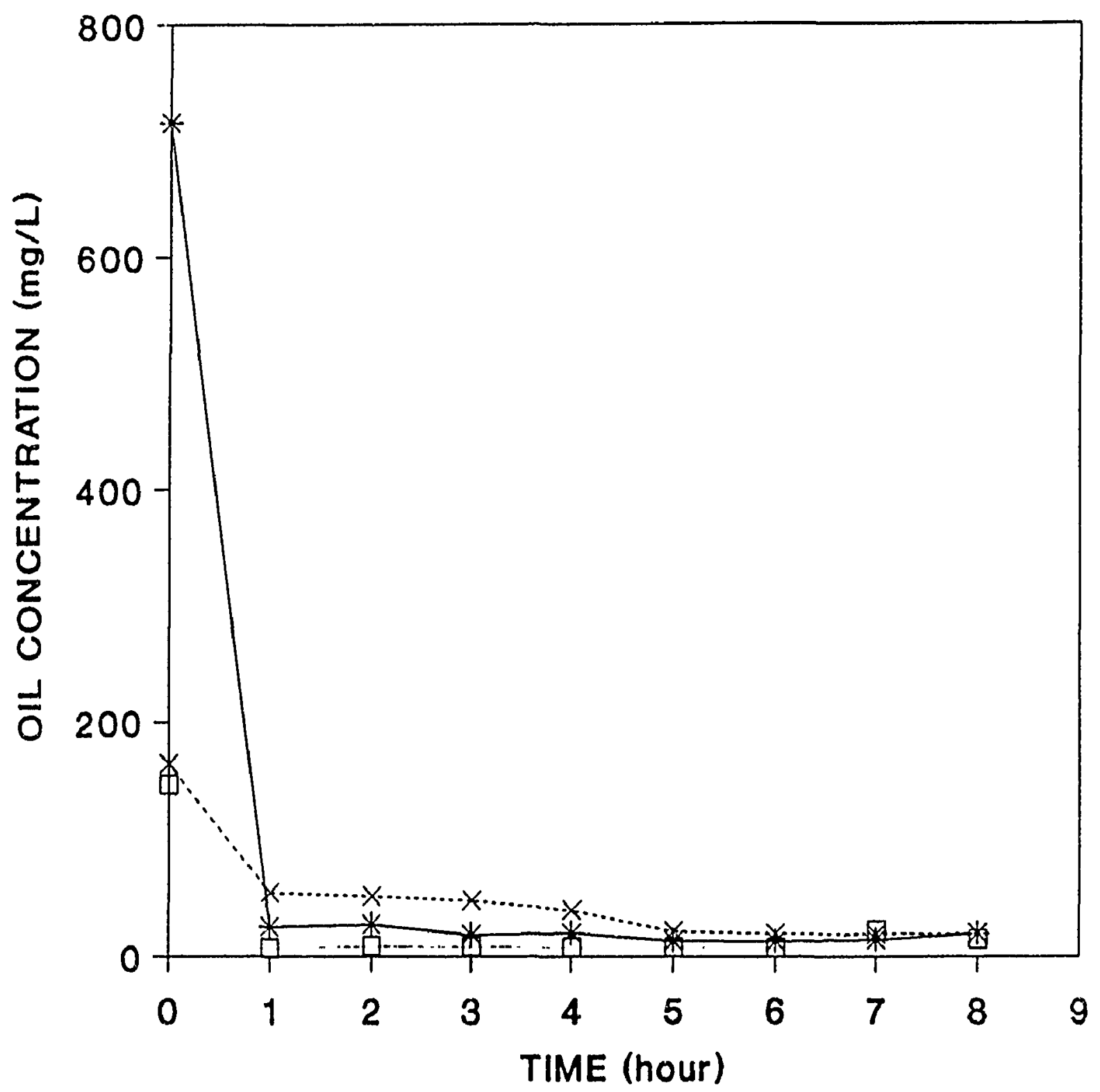

* $12 \mathrm{~mL} / \mathrm{min} \quad \square-48 \mathrm{~mL} / \mathrm{min} \quad \cdots \times \cdots 300 \mathrm{~mL} / \mathrm{min}$

Figure 4.21. Effluent oil concentrations from eight-hour run using $\mathrm{CO}$ 


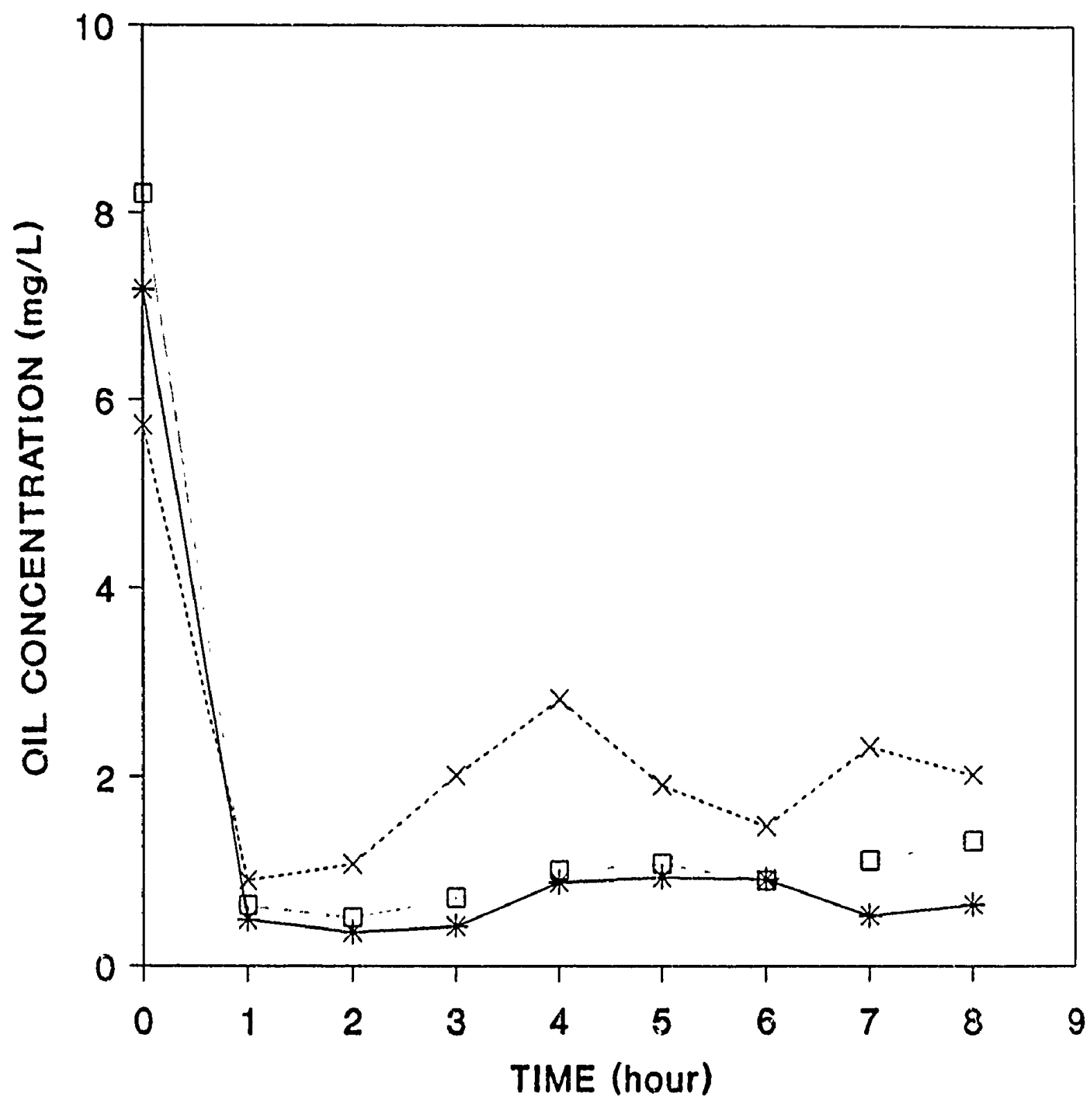

* $12 \mathrm{~mL} / \mathrm{min} \quad \cdot 48 \mathrm{~mL} / \mathrm{min} \quad \cdots \times \cdot 300 \mathrm{~mL} / \mathrm{min}$

Figure 4.22. Effluent oil concentrations from eight-hour run using RE 


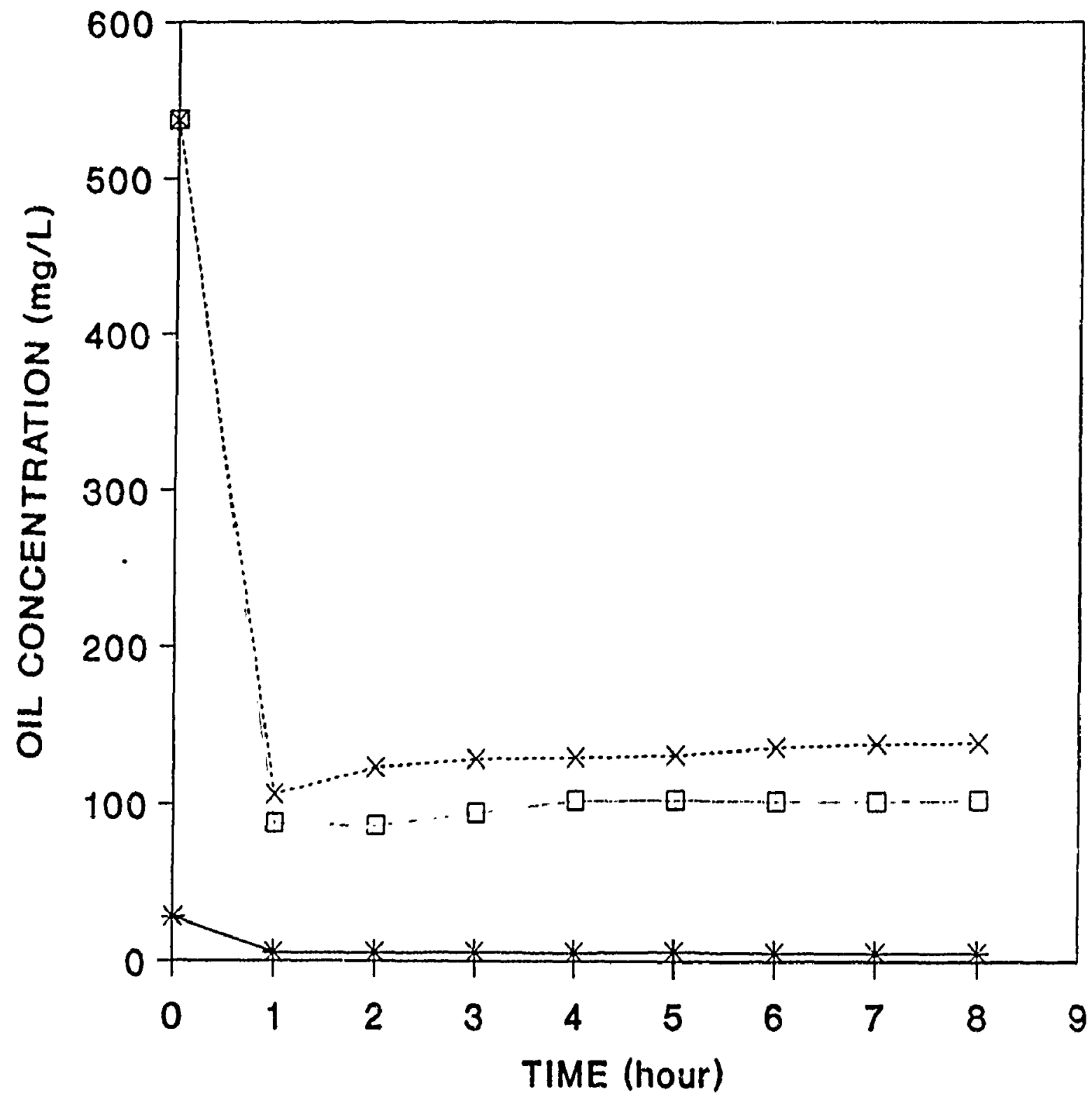

* $12 \mathrm{~mL} / \mathrm{min} \quad \boxminus-48 \mathrm{~mL} / \mathrm{min} \quad \cdots \times 300 \mathrm{~mL} / \mathrm{min}$

Figure 4.23. Effluent oil concentrations from eight-hour run using PW 
Table 4.27. Results of eight.hour column studies

\begin{tabular}{|c|c|c|c|c|c|c|}
\hline \multirow[t]{2}{*}{ Description } & \multicolumn{6}{|c|}{ Oil-in-water emulsion } \\
\hline & SMO & $\mathrm{MCO}$ & $\mathrm{CO}$ & $R E$ & PW1 & PW2 \\
\hline $\begin{array}{l}\text { Flow } 12 \mathrm{~mL} / \mathrm{min} \\
\text { (1) Influent oil } \\
\text { concentration (mg/L) } \\
\text { (2) Average effluent oil } \\
\text { concentration (mg/L) } \\
\text { (3) Average percentage } \\
\text { oil removal } \\
\text { Flow } 48 \mathrm{~mL} / \mathrm{min} \\
\text { (1) Influent oil } \\
\text { concentration (mg/L) } \\
\text { (2) Average effluent oil } \\
\text { concentration (mg/L) } \\
\text { (3) Average percentage } \\
\text { oil removal } \\
\text { Flow } 300 \mathrm{~mL} / \mathrm{min} \\
\text { (1) Influent oil } \\
\text { concentration (mg/L) } \\
\text { (2) Average effuent oil } \\
\text { concentration(mg/L) } \\
\text { (3) Average percentage } \\
\text { oil removal } \\
\text { Flow } 100 \mathrm{~mL} / \mathrm{min} \\
\text { (1) Influent oil } \\
\text { concentration (mg/L) } \\
\text { (2) Average effluent oil } \\
\text { concentration } \\
\text { (3) Average percentage } \\
\text { oil removal }\end{array}$ & $\begin{array}{c}178.6 \\
6.5 \\
96.4\end{array}$ & $\begin{array}{r}142.8 \\
4.6 \\
96.8\end{array}$ & $\begin{array}{r}164.2 \\
108.4 \\
34.0\end{array}$ & $\begin{array}{r}5.7 \\
1.8 \\
68.5\end{array}$ & $\begin{array}{c}5.6 \\
80.2\end{array}$ & $\begin{array}{l}537.1 \\
86.5 \\
81.8\end{array}$ \\
\hline
\end{tabular}

* Run could not be conducted beyond 1 hour due to the build-up of a high head of water over the filter. Therefore, a flow rate of $100 \mathrm{rnL} / \mathrm{min}$ was used for $\mathrm{CO}$ only. 
These results generally showed that the capacity of peat to remove oil from different oily wastes depended on the type of oil-in-water emulsion and the flow rate investigated. Within the viscosity range studied (130 and $50 \mathrm{mPa} . \mathrm{s}$ ), no appreciable differences in oil removal efficiencies were observed that could be attributed to oil viscosity.

\subsubsection{Eight-hour tests with other media}

Based on the performances of pretreated peat samples in the batch adsorption tests, two pretreated peat samples i.e., (i) wet-heated and oven.dried and (ii) wet pyrolyzed $\left(150^{\circ} \mathrm{C}\right)$, were selected for eight-hour colur.n experiments to compare the oil removal efficiencies with horticultural peat and six other media such as sand, coal, polypropylene, fiber glass, Amberlite (X.AD-2) and activated carbon. The results are shown in Figures 4.24 to 4.27 for SMO and CO emulsions, respectively.

The average oil removal efficiencies of these media were compared for SMO and CO (Figure 4.28). While the oil removal efficiencies were 46 to 99 percent with SMO, it decreased to 35 to 71 percent with $\mathrm{CO}$. The performance of peat with SMO was comparable to a commercial sorbent XAD-2 as reported by Smith et al. (1976). However, with $\mathrm{CO}$ the horticultural peat removed only 35 percent compared to 59 percent by XAD-2. This further demonstrates that it is difficult to treat a soluble oil like $\mathrm{CO}$ in a peat bed.

For the $\mathrm{CO}$ emulsion, there was an improvement in the oil removal efficiencies of the two pretreated peat samples compared to horticultural peat. The oil removal efficiencies of the horticultural peat increased from 35 to 39 and 43 percent for WH\&O and $\mathrm{P} 150$ peat samples, respectively. Thus, while the ability of horticultural peat in removing oils is restricted, it can be improved by pretreatment. 


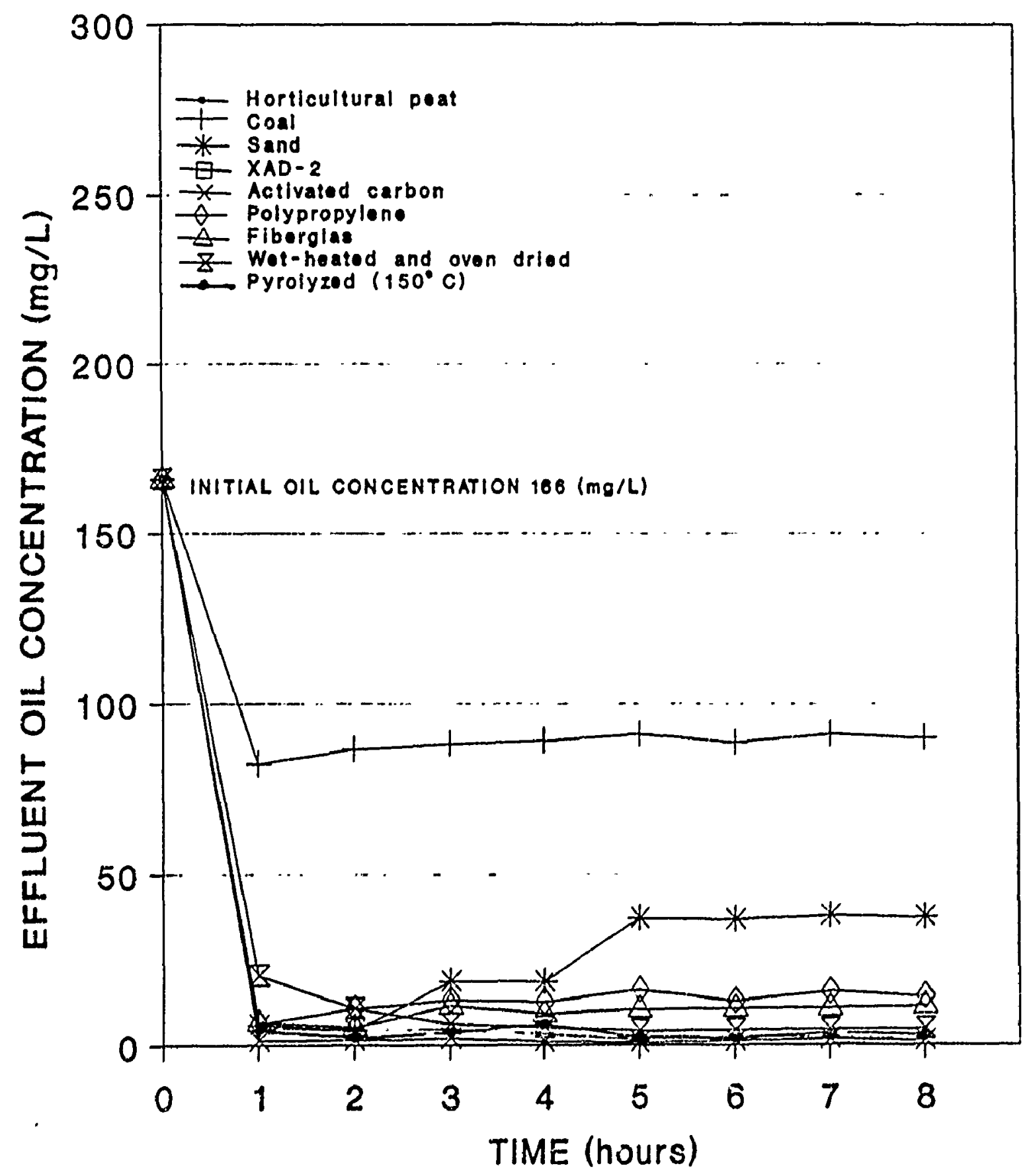

Figure 4.24. Effluent oil concentrations from eight-hour column test,s using SMO emulsion 

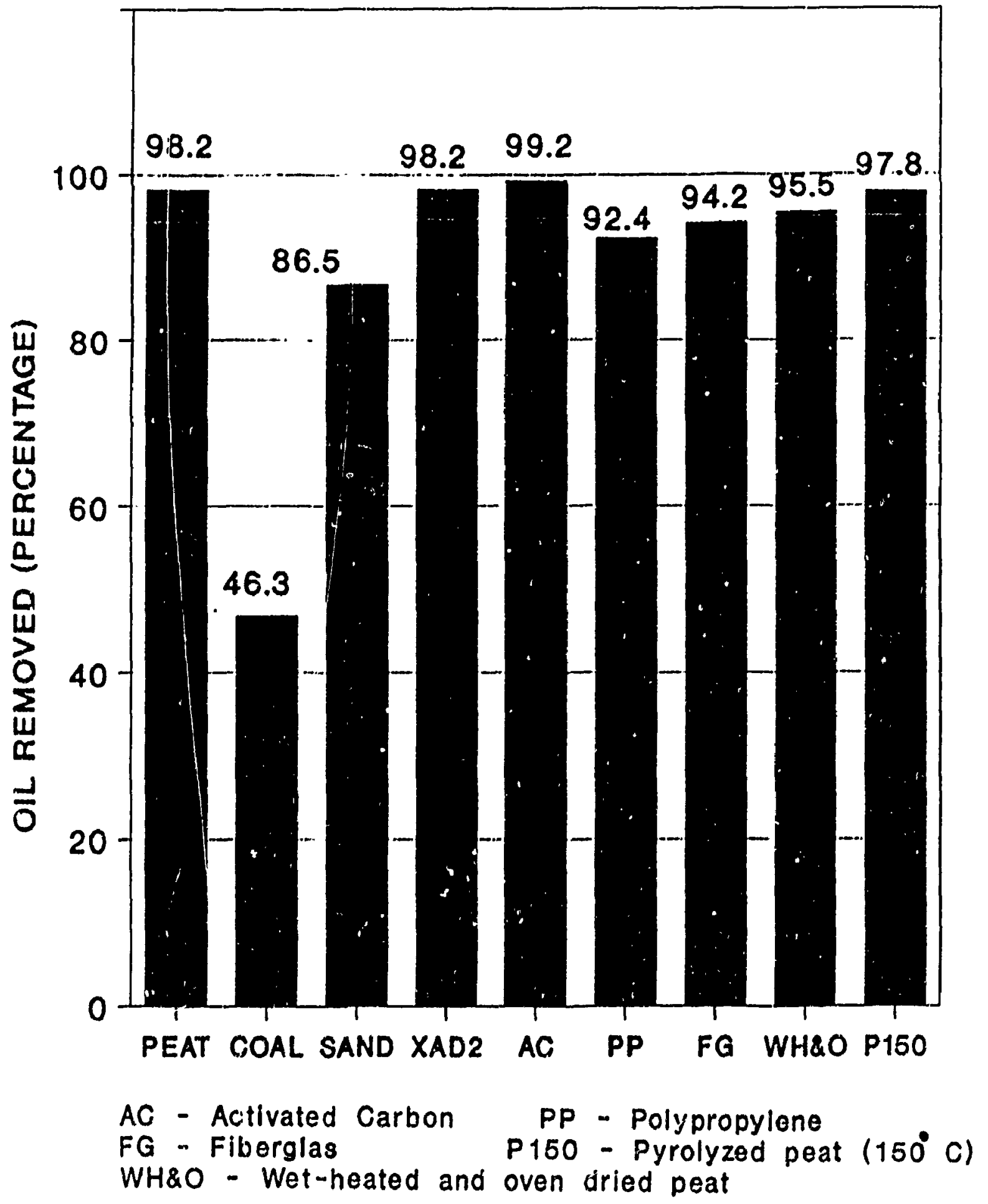

Figure 4.25 Average percentage of oil removed from eight-hour column tests using SMO emulsion 


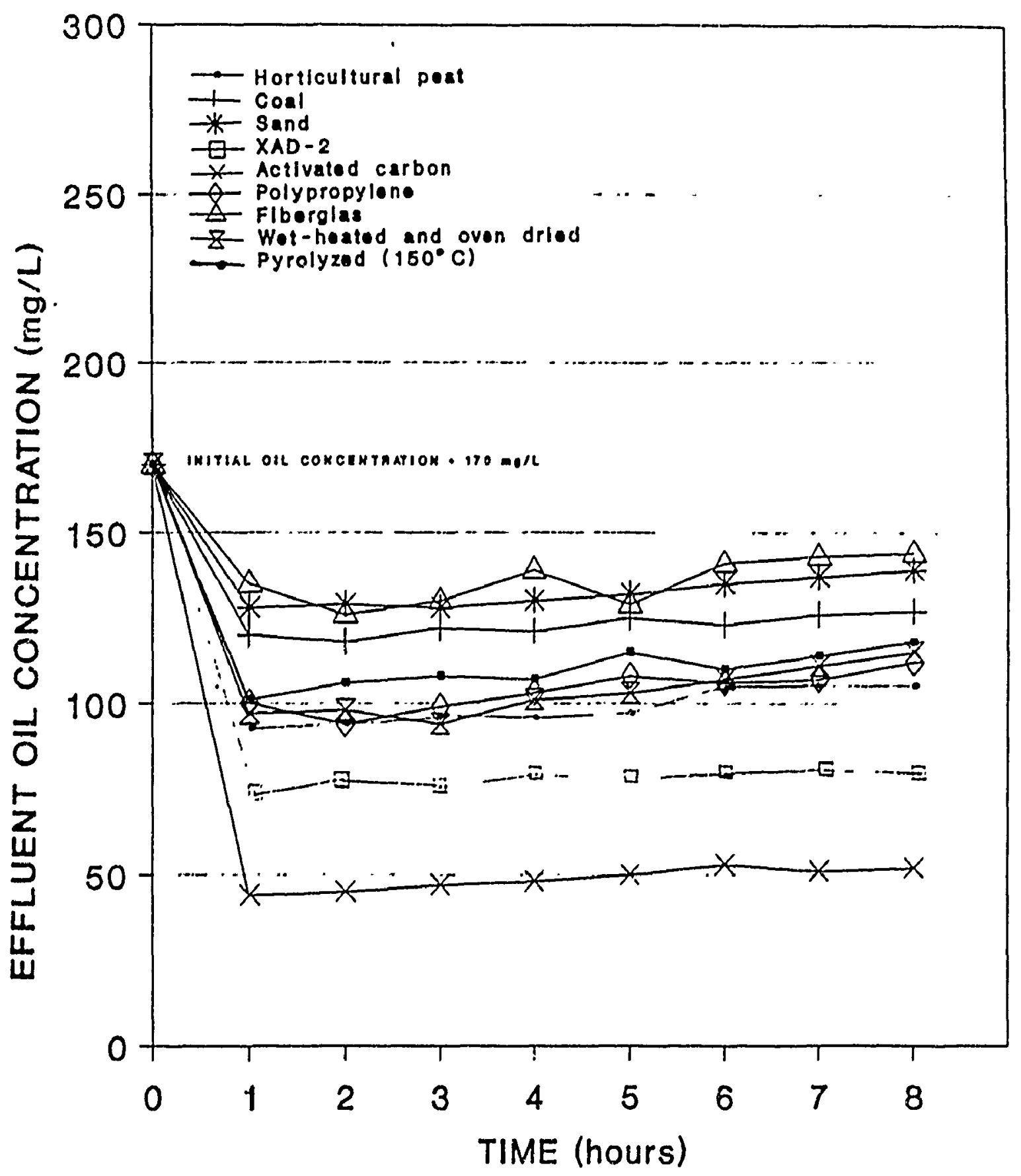

Figure 4.26 Effluent oil concentrations from eight-hour column tests using $\mathrm{CO}$ emulsion 

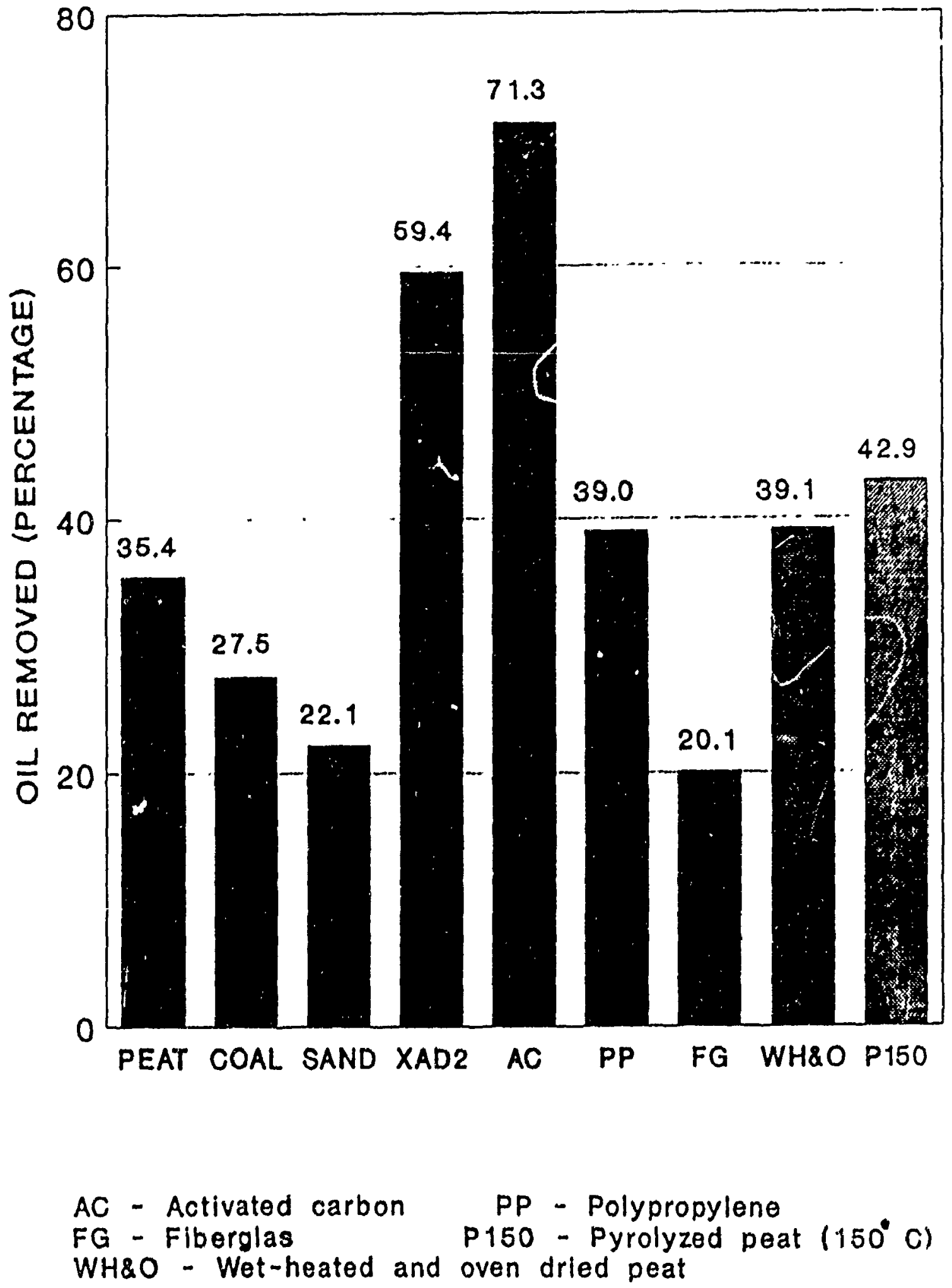

Figure 4.27 Average percentage of oil removed from eight-hour column tests using $\mathrm{CO}$ emulsion 


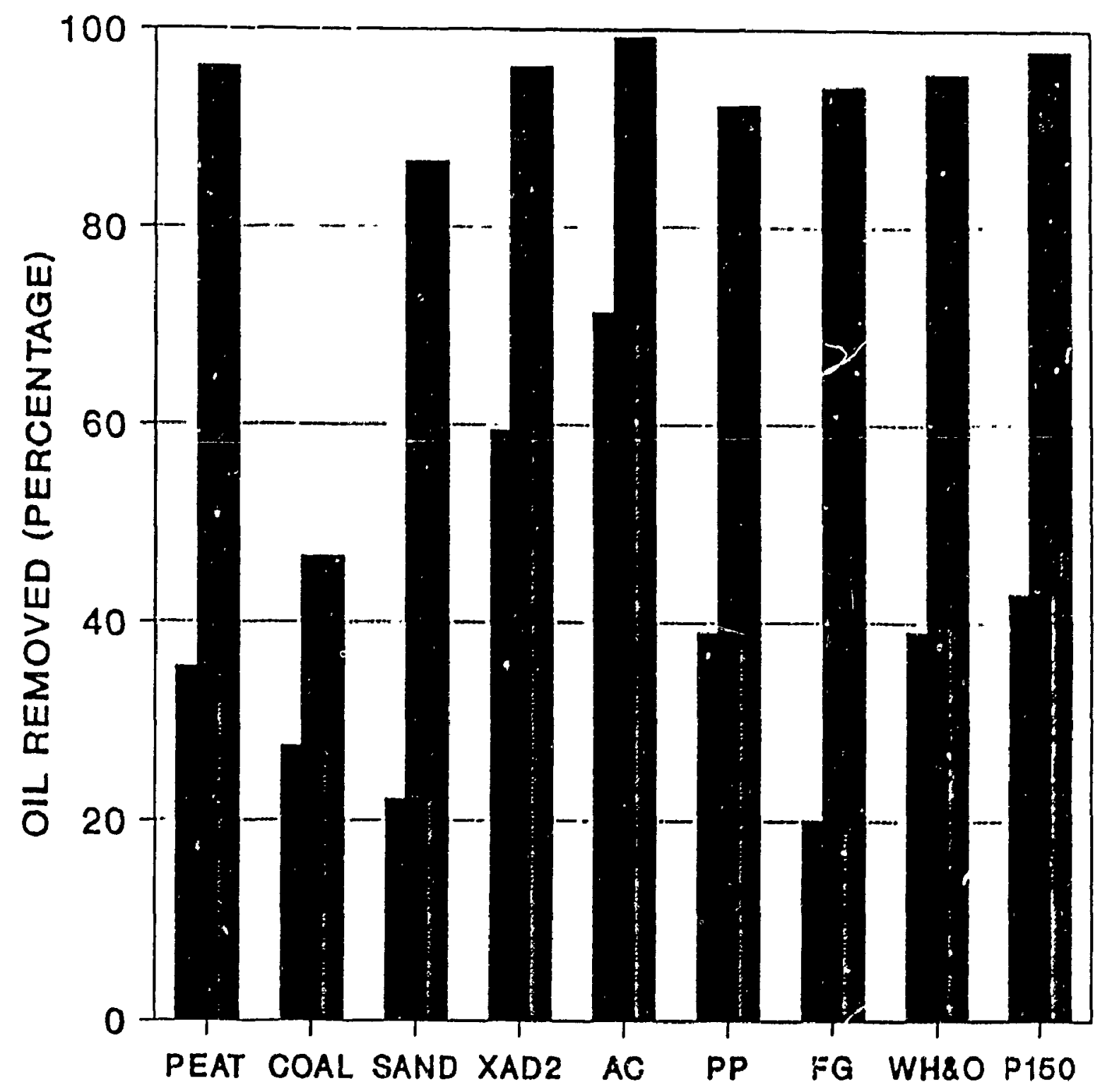

CO SMO

$A C$ - Activated carbon PP - Polypropylene

$F G$ - Fiberglas P150 - Pyrolysed peat $\left(150^{\circ} \mathrm{C}\right)$ WH\&O - Wet-heated and oven dried peat

Figure 43.8 Comparative oil removal efficiencies for $\mathrm{SMO}$ and $\mathrm{CO}$ emulsions 


\subsubsection{Breakthrough studies with horticultural peat}

Based on the average oil removal efficiencies obtained from the eight-hour column tests, a flow of $50 \mathrm{~mL} / \mathrm{min}$ was usea in the experiments for SMO, MCO and PW. A flow rate of $25 \mathrm{~mL} / \mathrm{min}$ was used for $\mathrm{CO}$ and $\mathrm{RE}$ emulsions. These experiments lasted about 10,15 and 11 days for SMO, MCO and PW respectively, and 3 and 13 days for $\mathrm{CO}$ and RE, respectively. The breakthrough curves obtained in a $300 \mathrm{~mm}$ peat bed are presented in Figures 4.29 through 4.33 . The data collected were analyzed using Thomas' equation (2.16) for evaluating the maximum solid phase concentration $\left(q_{0}\right)$ and the Thomas rate constant $(k)$. The equation (2.16) was linearized and rearranged as:

$$
\log \left[\frac{C_{0}}{C}-1\right]=\left[\frac{k q_{0} M}{Q}\right]-\left[\frac{k C_{0} V}{Q}\right]
$$

The linearized Thomas equation plots are shown in Figures 4.34 through 4.38. From these plots the $k$ and $q_{0}$ were calculated. The statistical $t$ and $F$ test results summarized in Table 4.28 confirm that the linearized Thomas equation provides a reasonable fit of the data. The reaction rate constant $(k)$ and the maximum solidphase concentration of the solute $\left(q_{0}\right)$ calculated using Thomas equation are presented in Table 4.29. The value of $q_{0}$ for SMO (1.58) was very much higher than the corresponding $\frac{x}{m}$ values obtained in batch studies as 0.08 to $0.16 \mathrm{~kg} / \mathrm{kg}$ (Table 4.23 ). For $\mathrm{CO}$, the value of $q_{0}(0.140)$, was found to be low as compared to the batch adsorption results $(0.38$ to 0.95$)$ (Table 4.26$)$.

The performance of the peat column was better than the results obtained in the batch adsorption studies using SMO. A mass balance was performed to compare the actual $\frac{x}{m}$ values at the end of breakthrough with the ones obtained using Thomas 


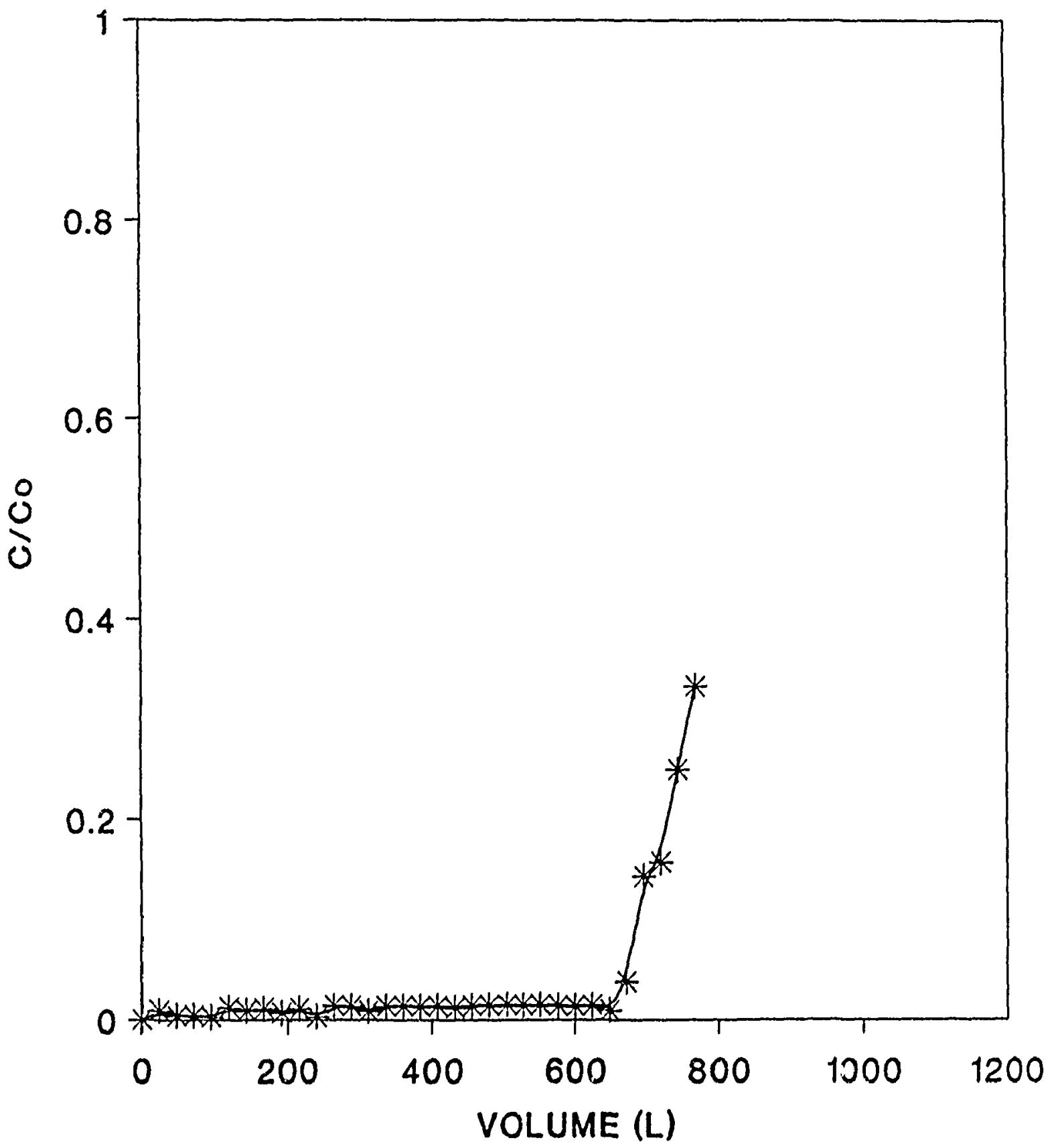

Figure 4.29. Breakthrough curve for SMO and horticultural peat 


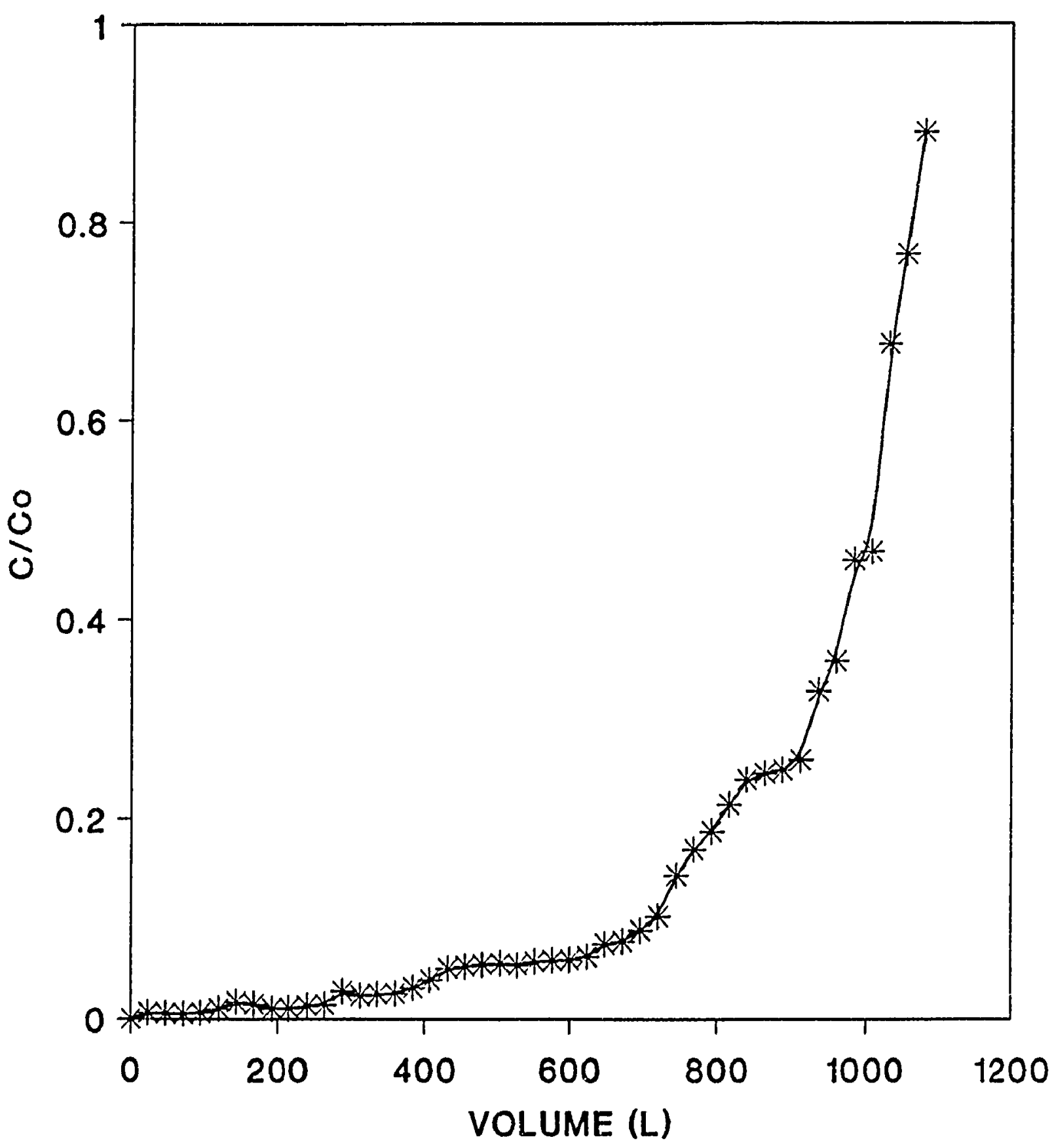

Figure 4.30. Breakthrough curve for $\mathrm{MCO}$ and horticultural peat 


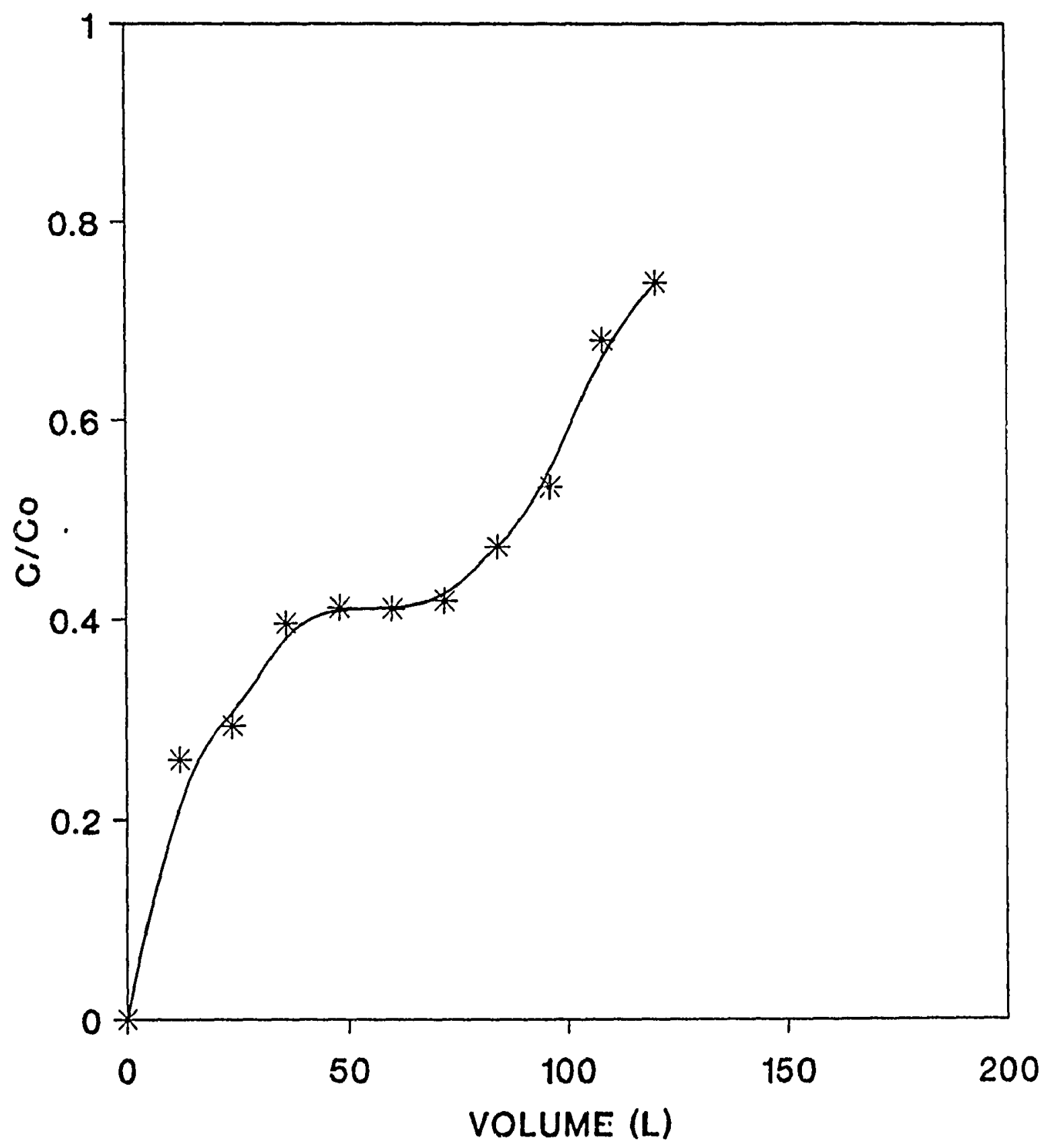

Figure 4.31. Breakthrough curve for $\mathrm{CO}$ and horticultural peat 


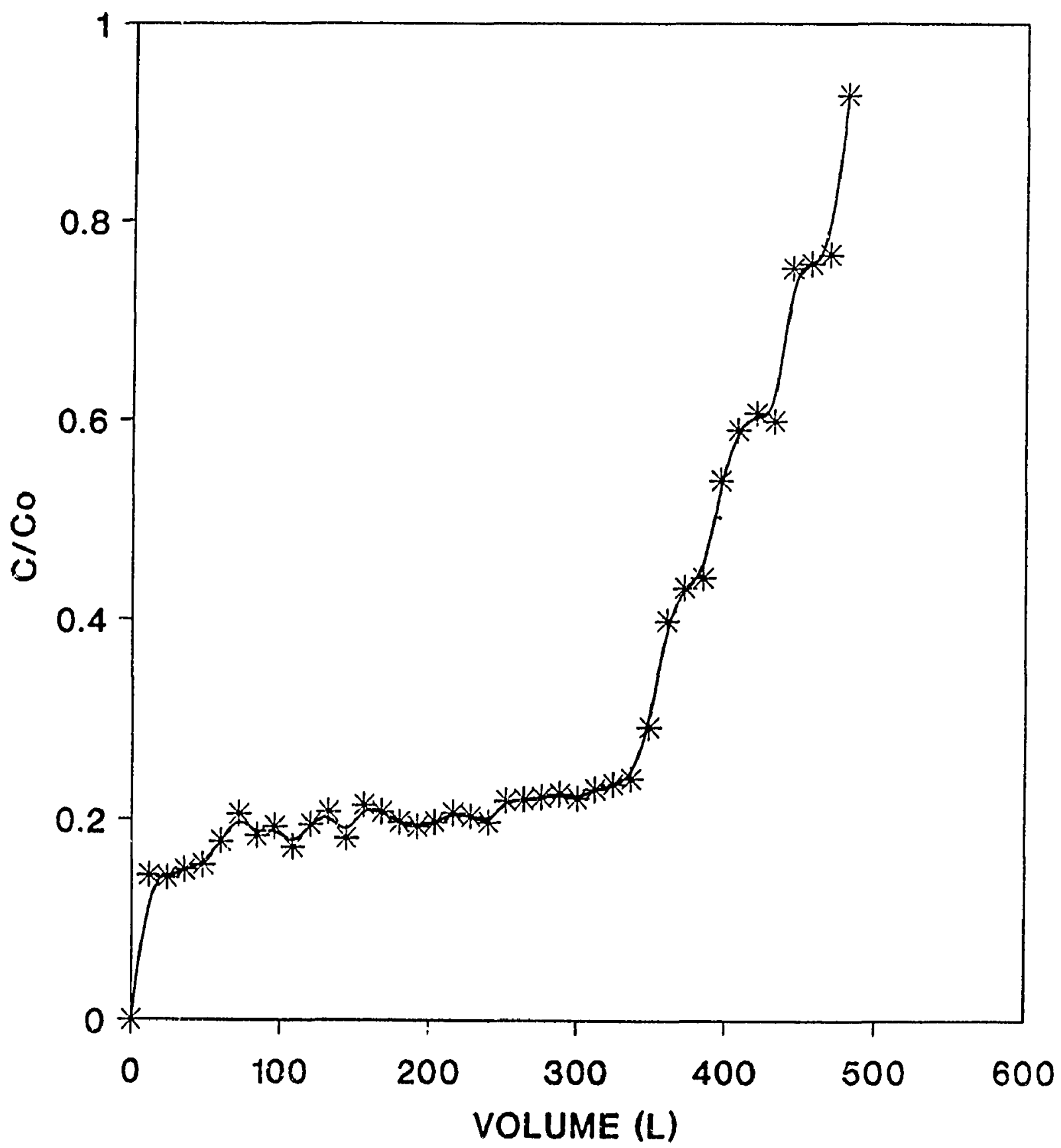

Figure 4.32. Breakthrough curve for $\mathrm{RE}$ and horticultural peat 


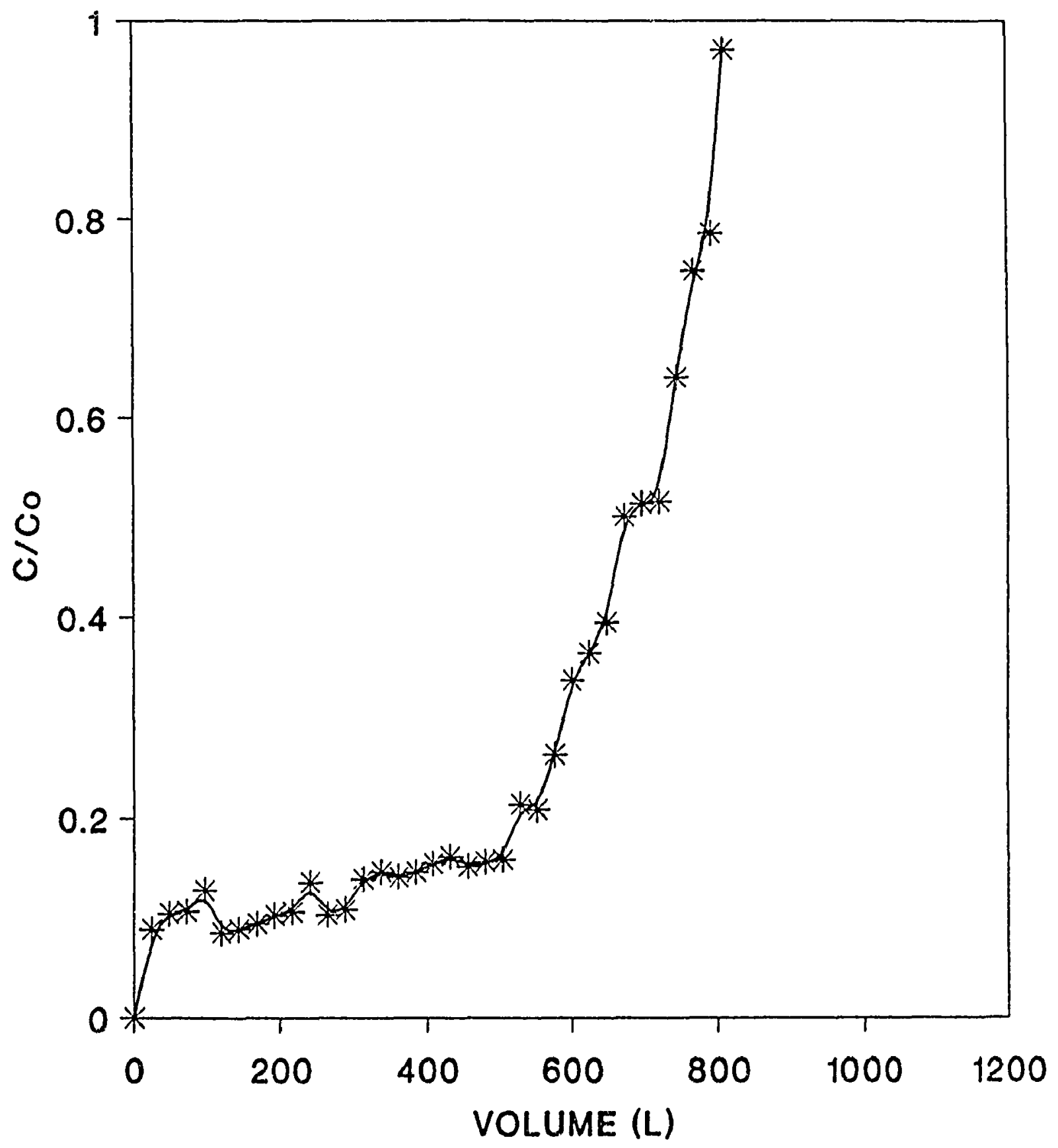

Figure 4.33. Breakthrough curve for PW and horticultural peat 


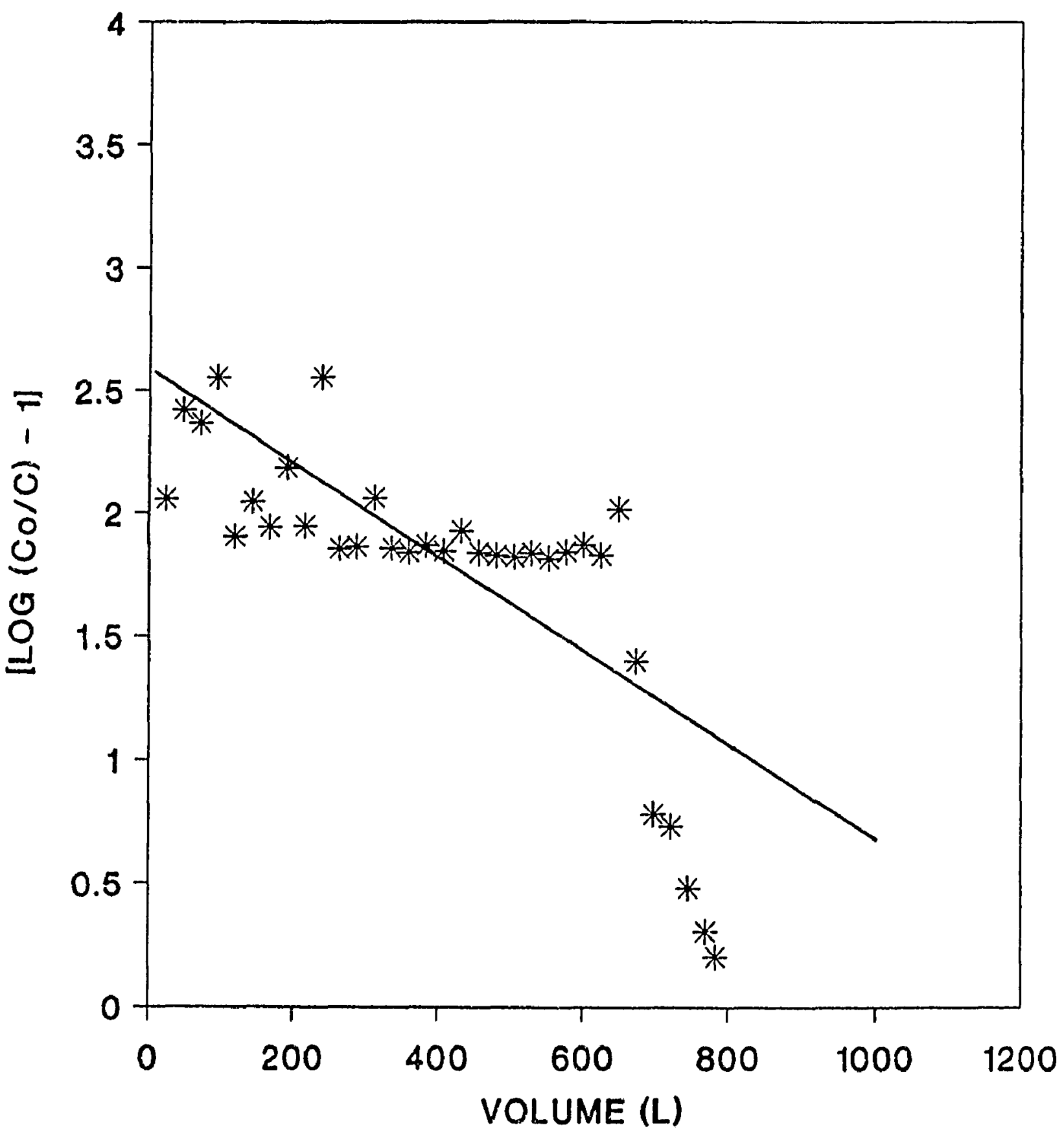

Figure 4.34. Linearized Thomas plot for SMO 


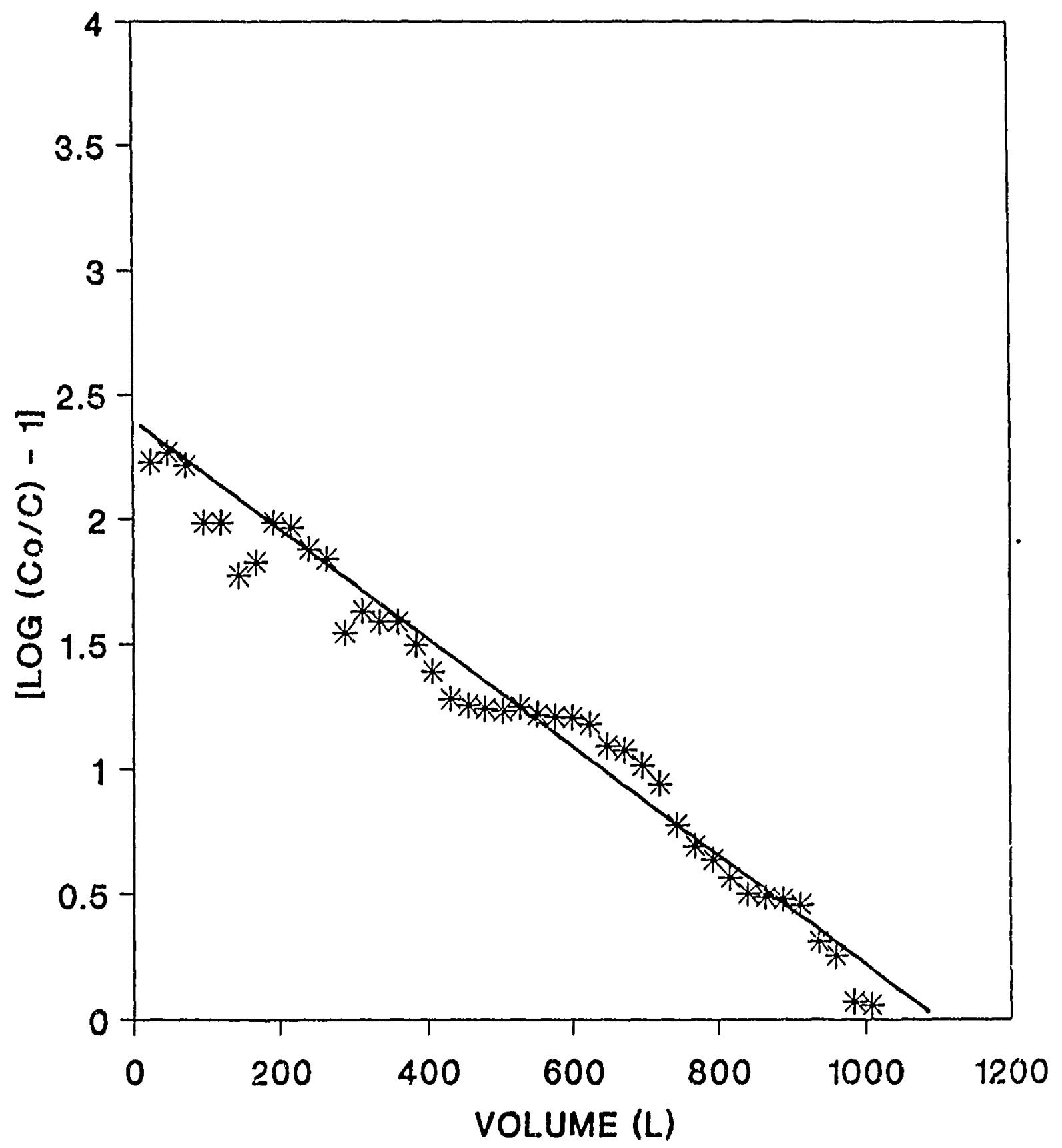

Figure 4.35. Linearized Thomas plot for MCO 


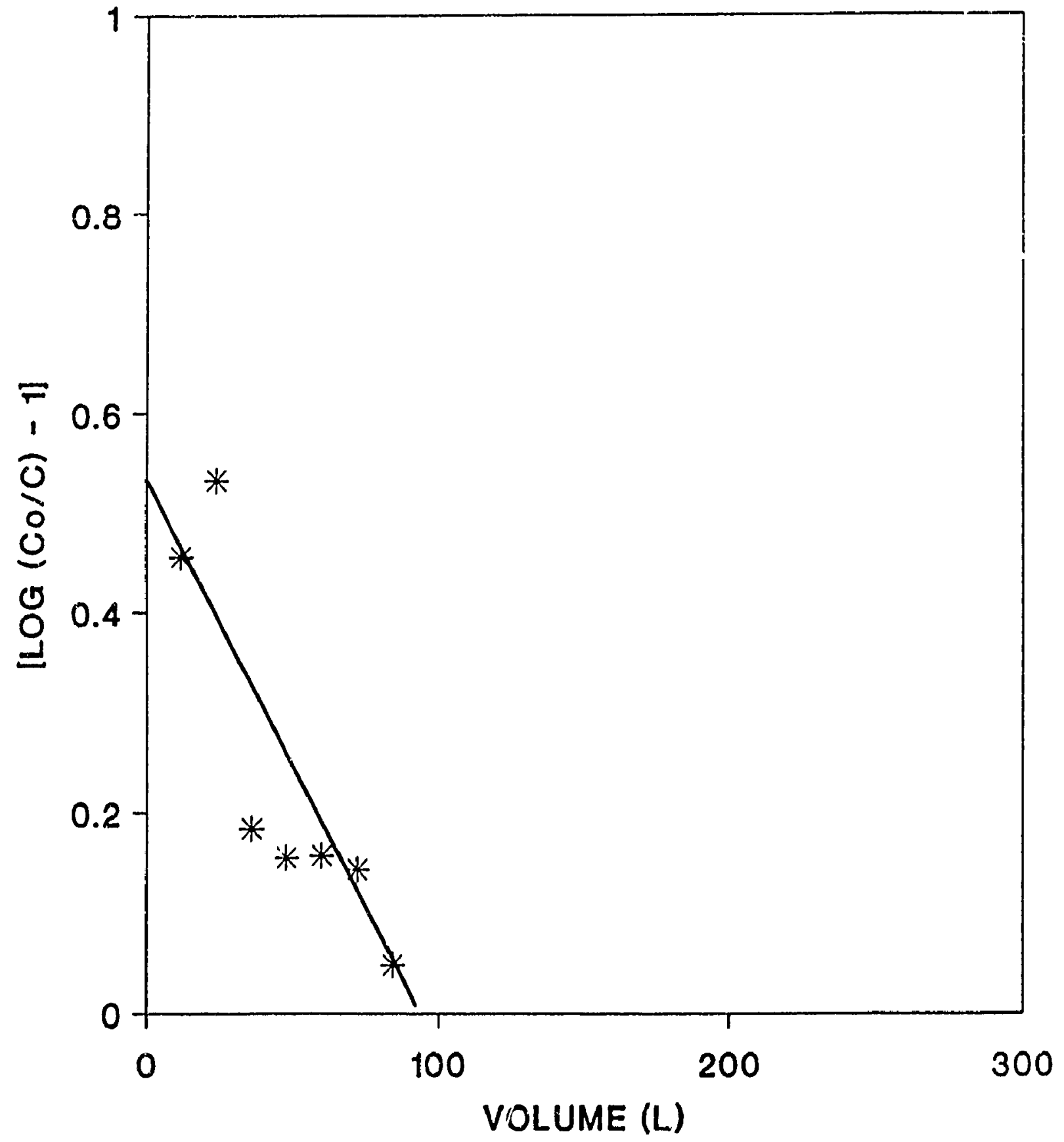

Figure 4.36. Linearized Thomas plot for CO 


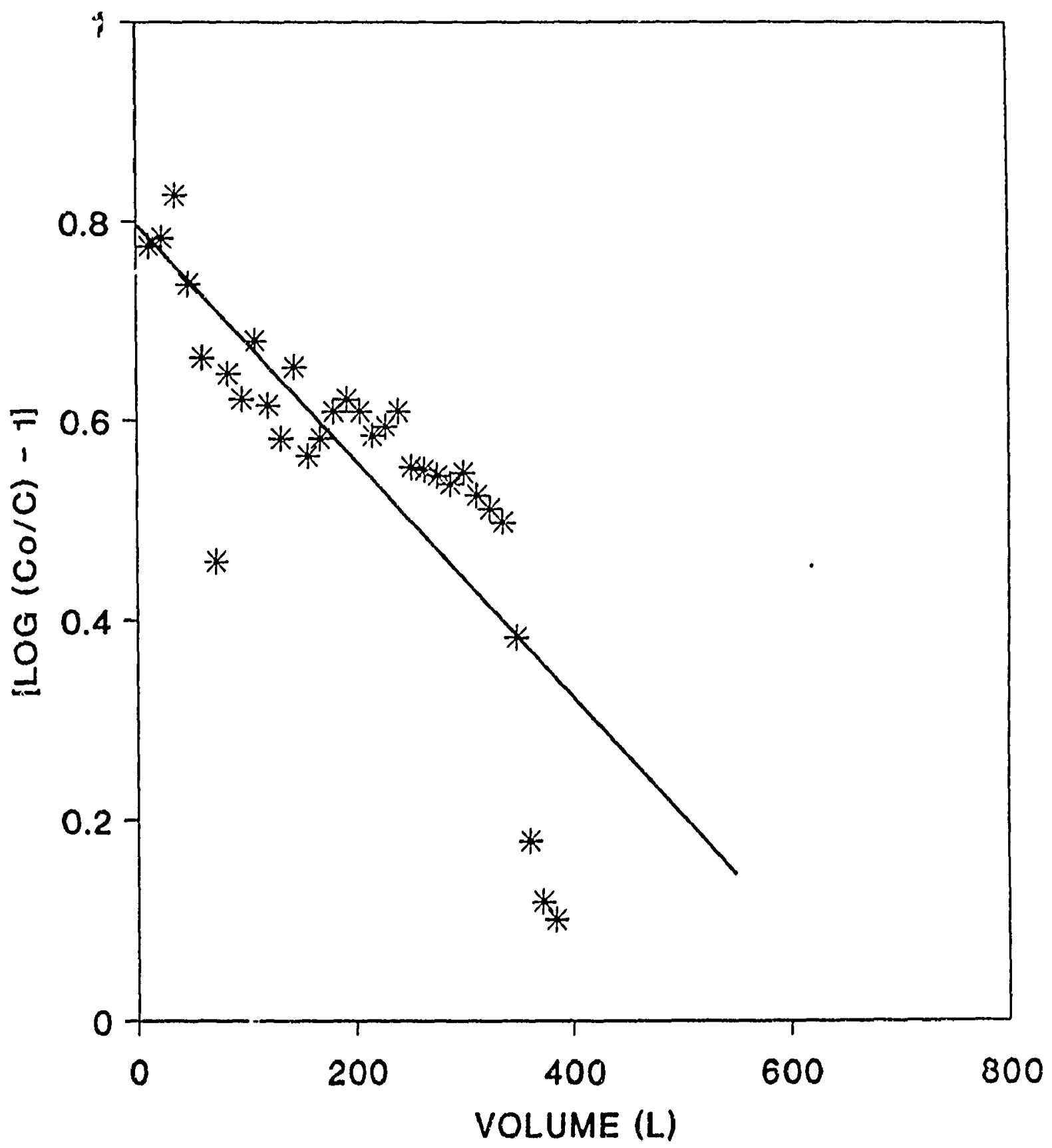

Figure 4.37. Linearized Thomas plot for RE 


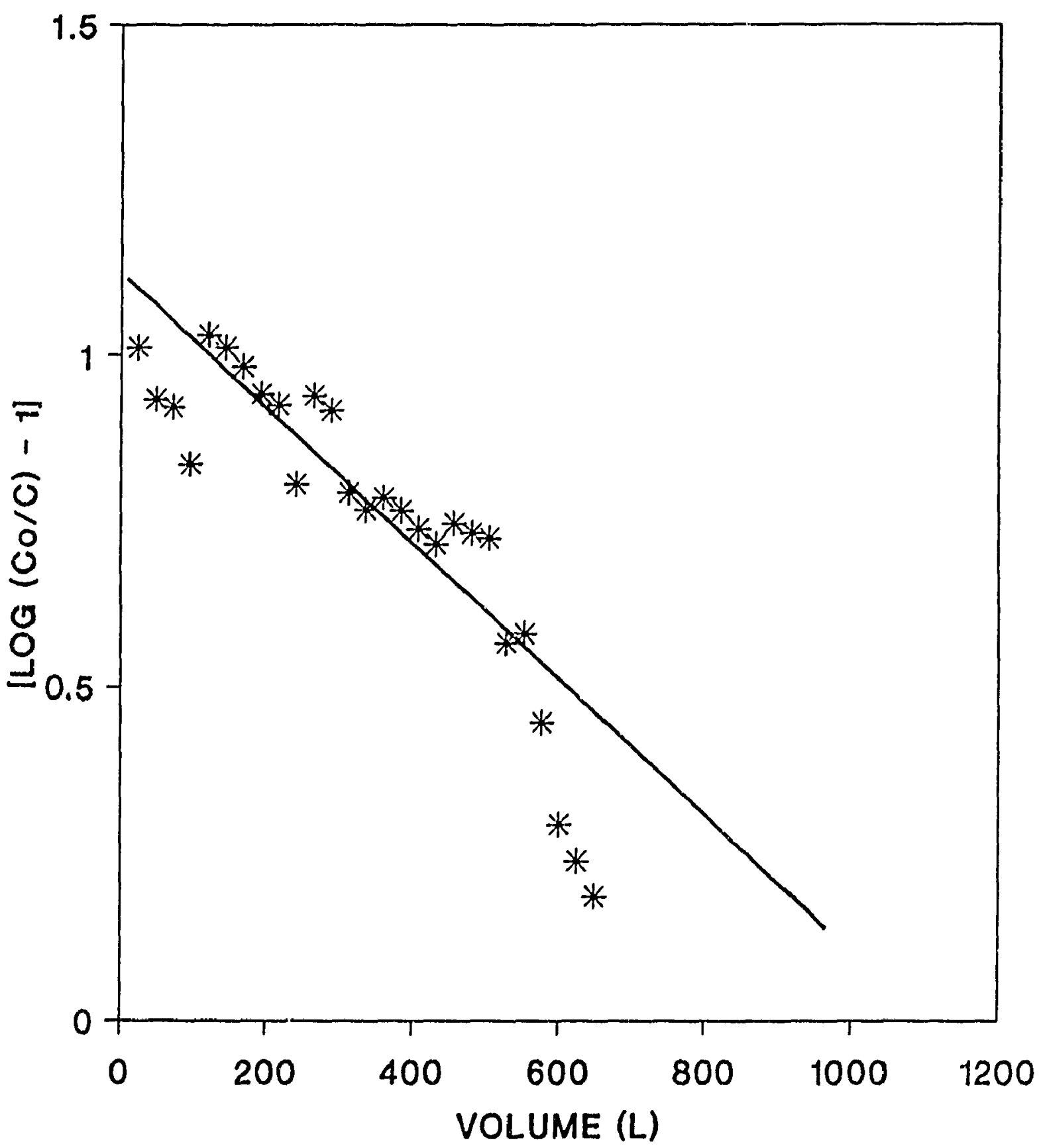

Figure 4.38. Linearized Thomas plot for PW 
Table 4.28. Statistical parameters for Thomas equation

\begin{tabular}{||l|l|c|c|c|c|c|c||}
\hline Emulsion & $\begin{array}{c}\text { Regression } \\
\text { equation }\end{array}$ & $r^{\ddagger}$ & $s^{I}$ & $t_{c}^{*}$ & $t_{i}^{*}$ & $F_{c}^{*}$ & $F_{i}^{*}$ \\
\hline \hline SMO & $\mathrm{y}=2.55-0.002 \mathrm{x}$ & -0.77 & 0.38 & -18.79 & 1.70 & 46.06 & 4.17 \\
$\mathrm{CO}$ & $\mathrm{y}=2.32-0.0021 \times$ & -0.99 & 0.11 & -37.9 & 1.684 & 1439.74 & 19.5 \\
$\mathrm{RE}$ & $\mathrm{y}=0.529-0.006 \mathrm{x}$ & -0.87 & 0.10 & -3.88 & 2.571 & 15.06 & 19.3 \\
$\mathrm{PW}$ & $\mathrm{y}=0.790-0.0012 \mathrm{x}$ & -0.80 & 0.10 & -7.12 & 2.042 & 50.56 & 19.5 \\
\hline \hline
\end{tabular}

$\dagger y=\left[\frac{C_{0}}{C}-1\right]$ and $x=\left[\frac{k C_{0} V}{Q}\right]$ in Thomas equation.

$\ddagger$ Correlation coefficient between ordinates $x$ and $y$

TStandard deviation

* Calculated values

- Table values at $5 \%$ significance level 
Table 4.29. Values of Thomas constants

\begin{tabular}{||l|c|c||}
\hline \hline Emulsion & $k(\mathrm{~L} / \mathrm{h}-\mathrm{kg})$ & $q_{0}(\mathrm{~kg} / \mathrm{kg})$ \\
\hline SMO & 27.65 & 1.58 \\
MCO & 30.22 & 1.33 \\
CO & 32.37 & 0.140 \\
RE & 210.02 & 0.034 \\
PW & 85.94 & 0.198 \\
\hline \hline
\end{tabular}


equation. The comparisons are presented in Table 4.30. It can be seen from the table that except for SMO, the actual $\frac{x}{m}$ values calculated using mass balance were comparable to the values obtained using the Thomas equation.

A comparison of the breakthrough curves (Figures 4.29 to 4.33 ) with the one presented by Weber and Chakravorti (1974) (Figure 4.39) shows that adsorption is very favorable for SMO and favorable or linear for $\mathrm{MCO}, \mathrm{RE}$ and $\mathrm{PW}$. In the case of $\mathrm{CO}$, the adsorption was found to be not favorable. This is consistent with the earlicr observations in the batch and eight-hour column studies that it is difficult to treat $\mathrm{CO}$ with peat.

The column breakthrough data were further analyzed in order to calculate the adsorption rate constant $(k)$ presented in equation 2.17 , for the five different oils and the horticultural peat. The linearized plots of uptake vs time $e^{\frac{1}{2}}$ are shown in Figures 4.40 to 4.44 , and the statistical details for these plots are summarized in Table 4.31 for all emulsions investigated.

The high correlation coefficient $(r)$ values obtained for the linear fit of equation 2.17 suggests that uptake of oil by peat can well be described by a simple equation involving time. The rate constants $k$ (the slope of the linear regression line) for SMO and $\mathrm{MCO}$ were nearly equal $(0.073 \mathrm{~kg}$ per $\mathrm{kg}$ of oil per unit weight of adsorbent per $\sqrt{t})$. The rate constant for RE $(0.0013)$ was found to be the lowest. The values of $k$ for $\mathrm{CO}$ and $\mathrm{PW}$ emulsions were found to be nearly equai (0.0152 and 0.0105$)$ respectively, even though, the initial oil concentration differed significantly between the two emulsions (278.2 and $38.4 \mathrm{mg} / \mathrm{L}$ respectively). It is, therefore reasonable to conclude that $\mathrm{CO}$ was poorly adsorbed onto horticultural peat when compared with the other emulsions investigated (SMO, MCO, RE and PW). This is consistent with 
Table 4.30. Comparison of $\frac{x}{m}$ values from column breakthrough studies

\begin{tabular}{|c|c|c|c|c|c|}
\hline Description & SMO & $\mathrm{MCO}$ & $\mathrm{CO}$ & $\mathrm{RE}$ & PW \\
\hline $\begin{array}{l}\text { (1) Average influent oil } \\
\text { concentration (mg/L) }\end{array}$ & 217.9 & 210.03 & 278.2 & 8.91 & 38.4 \\
\hline (2) Flow rate $(\mathrm{mL} / \mathrm{min})$ & 50 & 50 & 25 & 25 & 50 \\
\hline $\begin{array}{l}\text { (3) Mass of peat used } \\
\text { for } 0.3 \mathrm{~m} \text { depth }(\mathrm{kg})\end{array}$ & 0.175 & 0.175 & 0.175 & 0.175 & 0.175 \\
\hline $\begin{array}{l}\text { (4) Effluent breakthrough } \\
\text { oil concentration(mg/L) }\end{array}$ & 83.92 & 186.98 & 205.28 & 8.26 & 37.23 \\
\hline (5) $\frac{C}{C_{0}}$ & 0.385 & 0.890 & 0.738 & 0.927 & 0.969 \\
\hline (6) Breakthrough time (day) & 10.86 & 15.0 & 3.33 & 13.33 & 11.25 \\
\hline (7) Breakthrough volume (L) & 782 & 1080 & 120 & 480 & 810 \\
\hline (8) Mass of oil removed $(\mathrm{kg})$ & 0.1636 & 0.1948 & 0.0179 & 0.0029 & 0.0229 \\
\hline (9) $\frac{x}{m}(\mathrm{~kg} / \mathrm{kg})$ & 0.932 & 1.111 & 0.103 & 0.017 & 0.131 \\
\hline $\begin{array}{l}\text { (10) } \frac{x}{m} \text { obtained from } \\
\text { Thomas equation }(\mathrm{kg} / \mathrm{kg})\end{array}$ & 1.58 & 1.33 & 0.140 & 0.034 & 0.198 \\
\hline
\end{tabular}




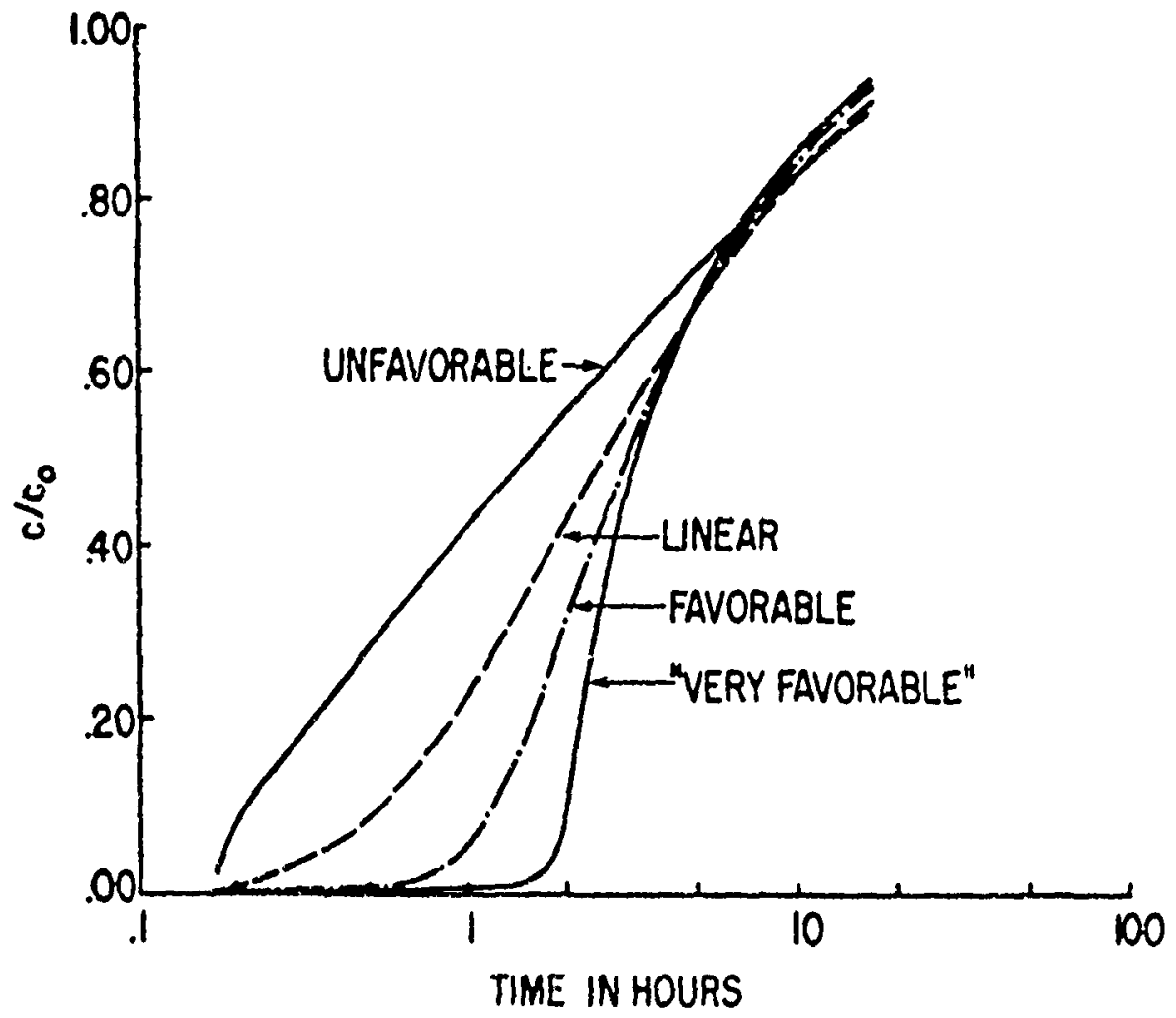

Figure 4.39. Shapes of breakthrough curves (Weber and Chakravorti 1974) 


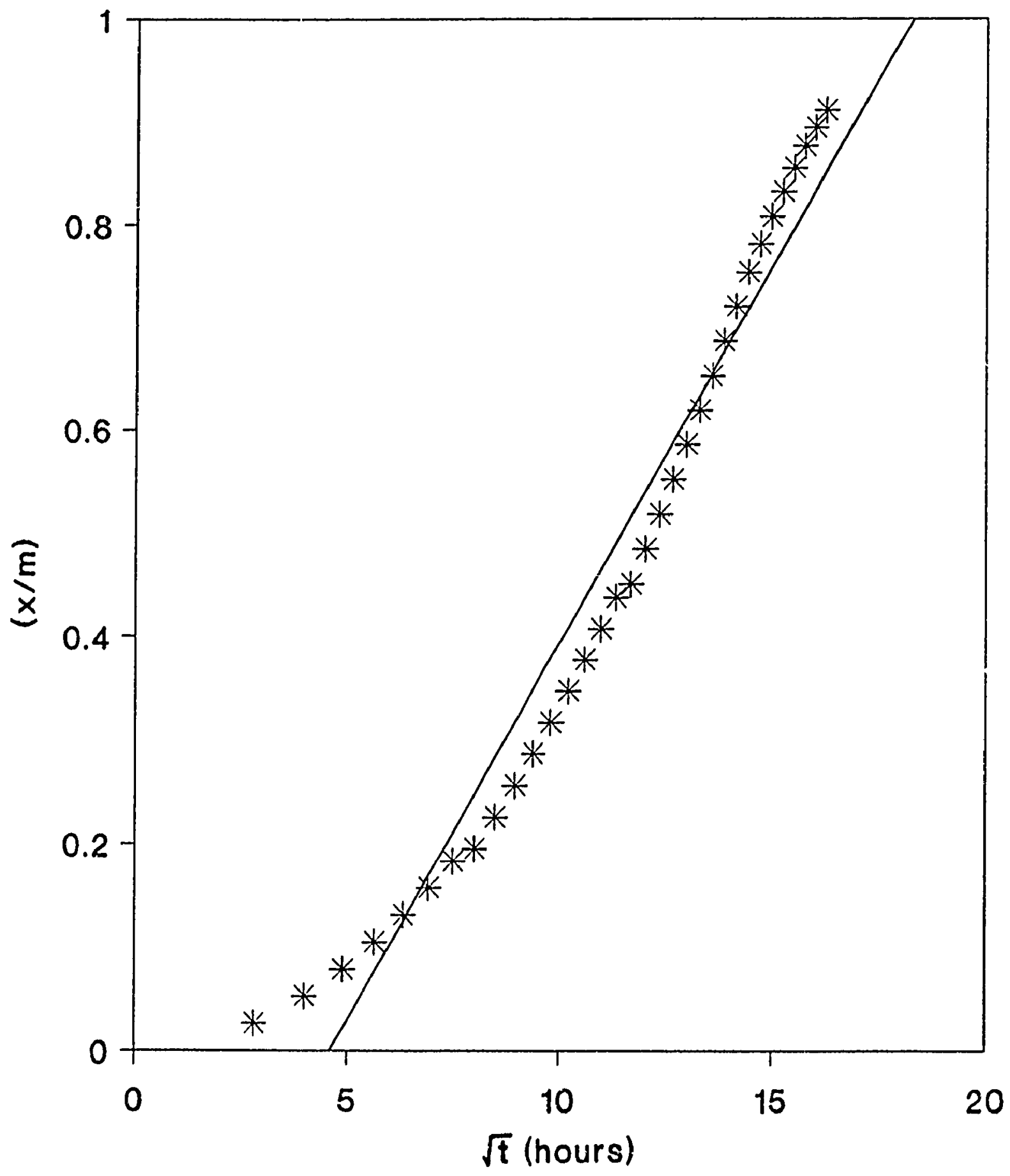

Figure 4.40. Uptake of SMO by horticultural peat 


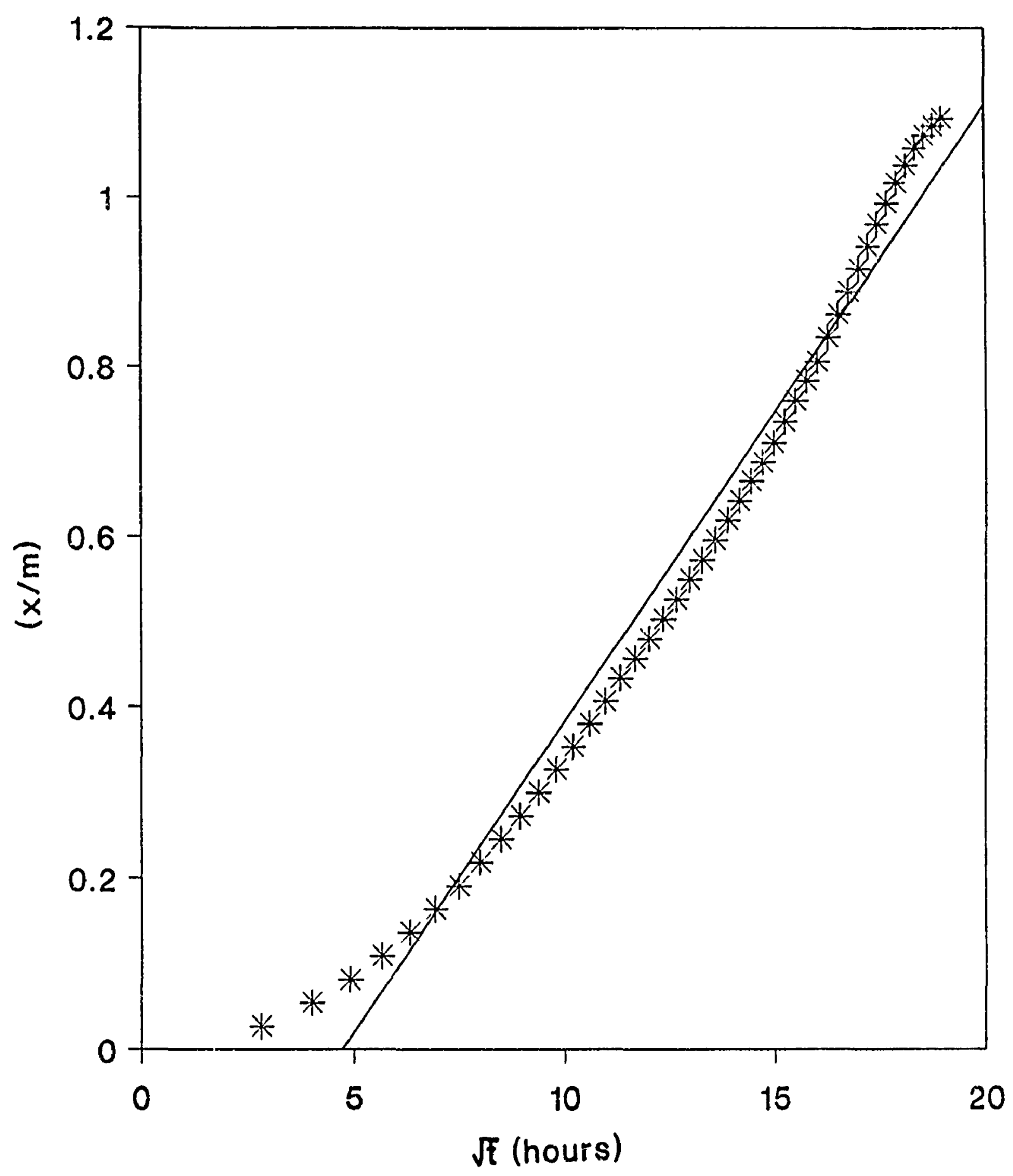

Figure 4.41. Uptake of $\mathrm{MCO}$ by horticultural peat 


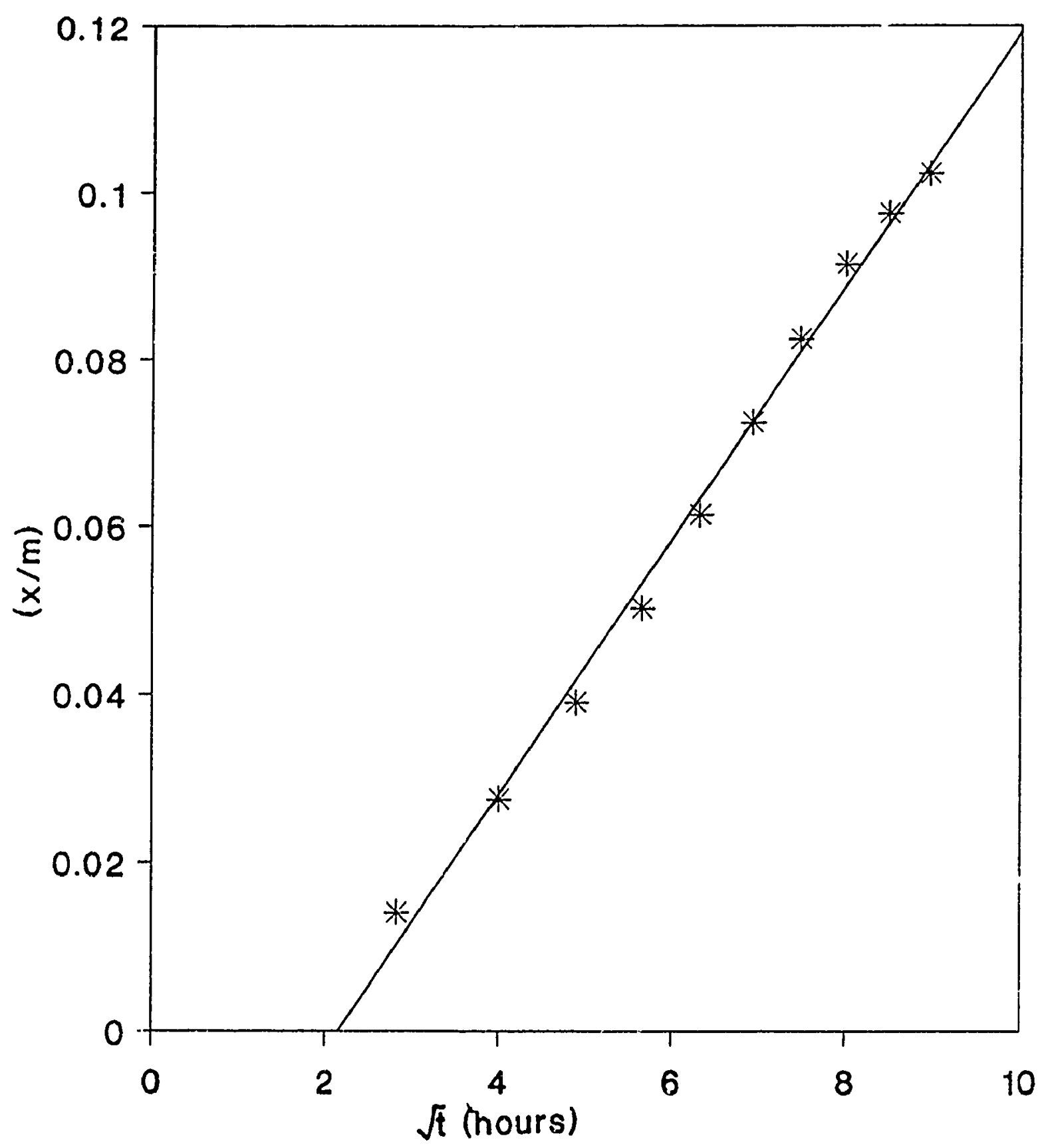

Figure 4.42. Uptake of $\mathrm{CO}$ by horticultural peat 


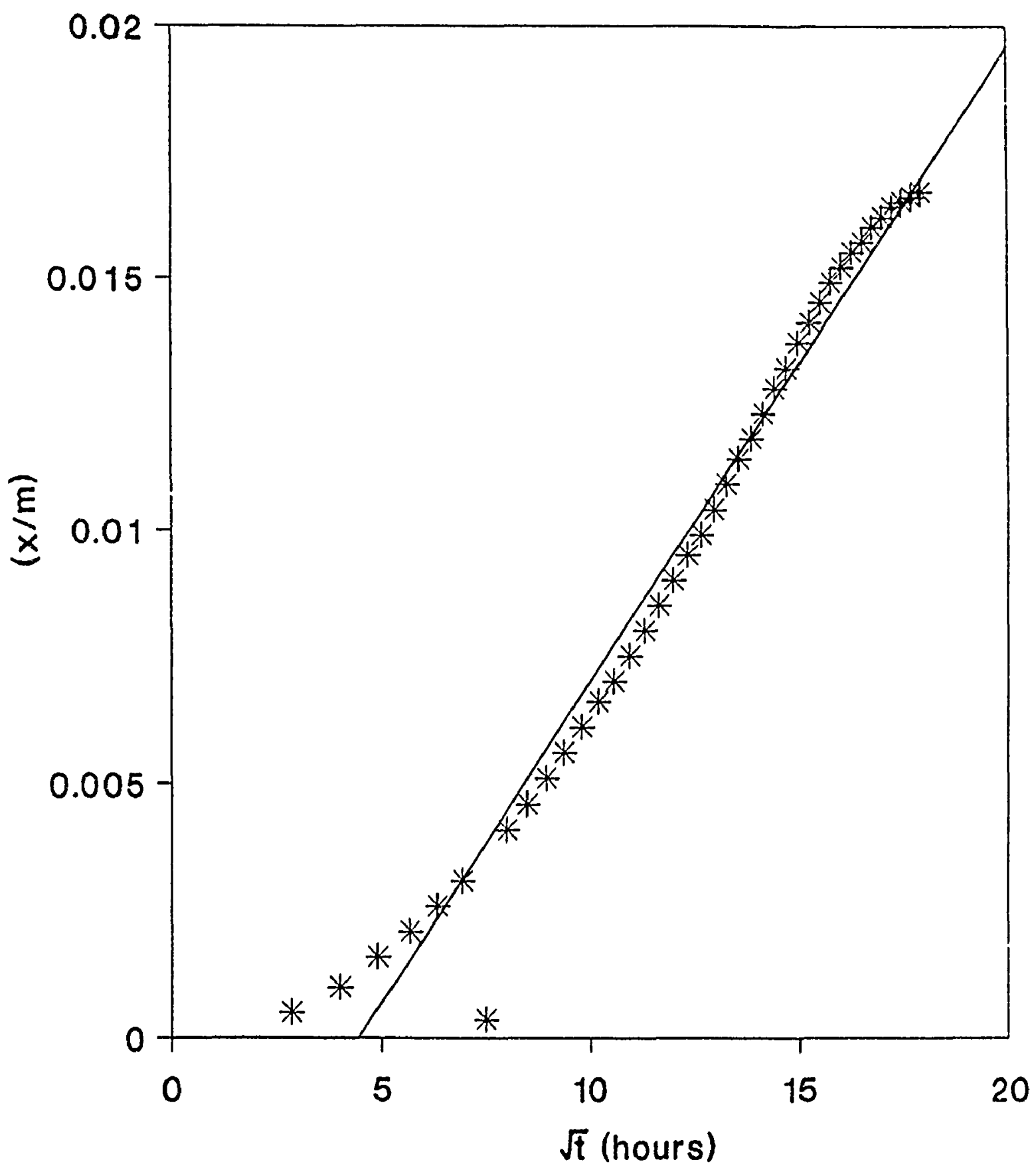

Figure 4.43. Uptake of oil from RE by horticultural peat 


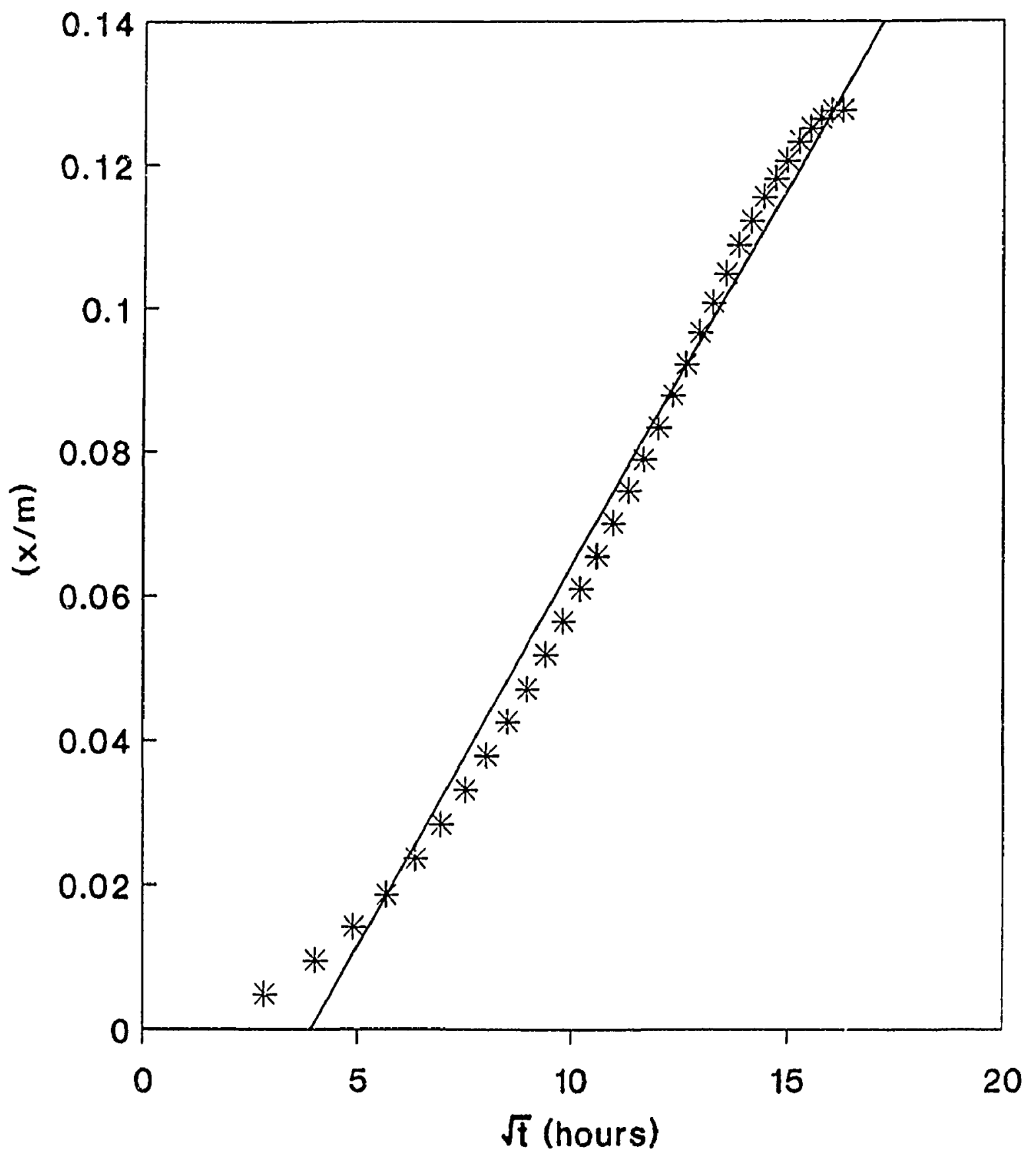

Figure 4.44. Uptake of oil from PW by horticultural peat 
Table 4.31. Statistical details for the linearized plots for the uptake of oil by horticultural peat

\begin{tabular}{|c|c|c|c|c|c|}
\hline \multirow[t]{2}{*}{ Description } & \multicolumn{5}{|c|}{ Emulsion } \\
\hline & SMO & $\mathrm{MCO}$ & $\mathrm{CO}$ & $\mathrm{RE}$ & PW \\
\hline $\begin{array}{l}\text { 1. Average initial oil } \\
\text { concentration }(\mathrm{mg} / \mathrm{L})\end{array}$ & 217.9 & 210.03 & 278.2 & 8.91 & 38.4 \\
\hline 2. Constant & -0.3375 & -0.3425 & -0.0328 & -0.0056 & -0.0411 \\
\hline $\begin{array}{c}\text { 3. Standard error of } \\
\text { Y (estimated) }\end{array}$ & 0.0584 & 0.0524 & 0.0024 & 0.0009 & 0.0051 \\
\hline 4. Correlation coefficient $(r)$ & 0.98 & 0.99 & 0.99 & 0.99 & 0.99 \\
\hline 5. Number of observations & 33 & 45 & 10 & 40 & 33 \\
\hline 6. Degrees of freedom & 32 & 43 & 8 & 38 & 31 \\
\hline 7. $x$ coefficient & 0.0732 & 0.0726 & 0.0152 & 0.0013 & 0.0105 \\
\hline 8. Std. error of coefficient & 0.0028 & 0.0018 & 0.0004 & 0.0001 & 0.0002 \\
\hline $\begin{array}{l}\text { 9. Rate constant }(k) \\
\left(\mathrm{kg} \text { of oil per time } e^{\frac{1}{2}}\right)\end{array}$ & 0.0732 & 0.0726 & 0.0152 & 0.0013 & 0.0105 \\
\hline
\end{tabular}


the earlier results which showed that $\mathrm{CO}$ was poorly adsorbed onto peat.

\subsubsection{Reuse and disposal of oil-sorbed peat}

The $0.30 \mathrm{~m}$ peat bed was backwashed after eight hours of continuous operation using hot water $\left(60^{\circ} \mathrm{C}\right)$. After backwashing, the bed was used for the next eight-hour run. The influent/effluent oil concentrations and the percentage of oil removed before and after backwashing are presented in Table 4.32. It was observed that there was no appreciable variation in the performance of the two cycles of operation. The $\mathrm{pH}$ of the effluent at the end of the second-hour period was approximately 7.5 for all the emulsions.

Since peat is an inexpensive medium ( $\$ 0.30$ per $\mathrm{kg}$ ), it is possible to replace oil-sorbed peat with fresh one. In order to estimate the calorific values of oil-sorbed peat, SMO, MCO, and $\mathrm{CO}$ were mixed (at $\frac{x}{m}$ values calculated in the breakthrough tests) with horticultural peat. The results of the determination of calorific values of horticultural and oil-sorbed peat are presented in Table 4.33.

It is seen that the oil-sorbed peats had higher calorific values than horticultural peat. The increase in calorific value ranged from 23 to 55 percent depending upon the type of oil. While a minimum increase of 23 percent was observed for $\mathrm{CO}$-sorbed peat, a maximum of about 52 to 55 percent was obtained for SMO-and $\mathrm{MCO}$-sorbed peat. The calorific values of SMO- and MCO-sorbed peats were more than that of lignite coal and similar to that of bituminous coal. Therefore, replacing the oil-sorbed peat in the peat filter with fresh horticultural peat and using the oil-sorbed peat as a secondary fuel appear to be a possible option. The cost associated with the two 
Table 4.32. Summary of column test results for backwashing

\begin{tabular}{|c|c|c|c|c|}
\hline Description & SMO & $\mathrm{MCO}$ & $\mathrm{CO}$ & $\mathrm{RE}$ \\
\hline $\begin{array}{l}\text { First 8-h cycle } \\
\text { (a) Influent oil } \\
\text { concentration }(\mathrm{mg} / \mathrm{L}) \\
\text { (b) Average effluent } \\
\text { oil concentration }(\mathrm{mg} / \mathrm{L}) \\
\text { (c) Average percentage } \\
\text { oil removed } \\
\text { Second 8-h cycle } \\
\text { (a) Influent oil } \\
\text { concentration (mg/L) } \\
\text { (b) Average effluent } \\
\text { oil concentration }(\mathrm{mg} / \mathrm{L}) \\
\text { (c) Average percentage } \\
\text { oil removed } \\
\text { pH at } 21{ }^{\circ} \mathrm{C} \\
\text { (a) Influent } \\
\text { (b) Effluent } \mathrm{pH} \\
\text { at the end of first 8-h } \\
\text { (c) Effluent } \mathrm{pH} \\
\text { at the end of second 8-h }\end{array}$ & $\begin{array}{c}215.3 \\
0.9 \\
99.5\end{array}$ & $\begin{array}{c}215.0 \\
1.1 \\
99.4\end{array}$ & $\begin{array}{l}715.2 \\
23.3 \\
96.7\end{array}$ & $\begin{array}{c}7.1 \\
0.5 \\
92.2\end{array}$ \\
\hline
\end{tabular}


Table 4.33. Calorific values of different peat samples and other materials

\begin{tabular}{|c|c|c|c|}
\hline \multirow{2}{*}{ Description } & \multicolumn{2}{|c|}{ Calorific value in } & \multirow{2}{*}{ Reference } \\
\hline & $\mathrm{J} / \mathrm{mol}$ & $\mathrm{Btu} / \mathrm{lb}$ & \\
\hline Horticultural peat ${ }^{\dagger}$ & 16,134 & 6,941 & Present study \\
\hline Horticultural peat $\ddagger$ & 16,791 & 7,224 & Present study \\
\hline Saturated peat & 14,304 & 6,145 & Present study \\
\hline SMO-sorbed peat & 29,757 & 12,902 & Present study \\
\hline MCO-sorbed peat & 27,841 & 11,977 & Present study \\
\hline CO-sorbed peat & 17,051 & 7,335 & Present study \\
\hline $\begin{array}{l}\text { Saskatchewan's } \\
\text { fuel peat }\end{array}$ & $\begin{array}{c}21,338 \text { to } \\
19,665\end{array}$ & $\begin{array}{l}8470 \text { to } \\
9190\end{array}$ & $\begin{array}{l}\text { Saskatchewan } \\
\text { Mineral Resources } \\
(1980)\end{array}$ \\
\hline Coal(Lignite) & $\begin{array}{c}20,083 \text { to } \\
24,267\end{array}$ & $\begin{array}{l}8650 \text { to } \\
10,450\end{array}$ & $\begin{array}{l}\text { Saskatchewan } \\
\text { Mineral Resources } \\
\text { (1980) }\end{array}$ \\
\hline Coal (Bituminous) & $\begin{array}{c}28,451 \text { to } \\
33,054\end{array}$ & $\begin{array}{c}12,250 \text { to } \\
14,250\end{array}$ & $\begin{array}{l}\text { Saskatchewan } \\
\text { Mineral Resources } \\
(1980)\end{array}$ \\
\hline Fuel oil (Heavy) & $\begin{array}{c}41,422 \text { to } \\
41,840\end{array}$ & $\begin{array}{c}17,800 \text { to } \\
18,000\end{array}$ & $\begin{array}{l}\text { Saskatchewan } \\
\text { Mineral Resources } \\
\text { (1980) }\end{array}$ \\
\hline
\end{tabular}

$\dagger$ air-dried

$\ddagger$ oven-dried at $103^{\circ} \mathrm{C}$

loss of oil observed while pressing the sample 
options, namely: (i) replacing and (ii) reusing the peat, is presented in APPENDIX. $\mathrm{E}$, and summarized in Table 4.34. It can be seen that the replacing option is very economical. However, the burning of peat may cause emissions which may cause air pollution. Certain air quality standards will have to be met for the emissions generated while combusting peat.

Paine and Blackem $: n$ (1987) discussed the environmental concerns arising from the combustion of peat and showed that $\mathrm{SO}_{2}$ emissions were within federal guidelines in Canada. The authors have also indicated that particulates produced during peat combustion could be effectively removed using standard devices such as electrostatic precipitators and cyclones. Further, the trace elements that are present in the peat were reported to be retained by bottom and fly ash. According to the authors the bottom and fly ash can be disposed of in properly designed land fills so that leachate from the ash does not contact the ground or surface waters. The authors have also indicated that the primary requirements in the combustion of peat are the control of nitrogen oxide formation and the complete combustion of polycyclic aromatic hydrocarbons. More studies in this area are required. In general there appears to be no serious threat to the air quality if peat were to be burnt as a fuel. The moisture that is present in the peat reduces the calorific values to some extent (Table 4.33). Therefore, moisture reduction options such as dry i .. i. ay have to be considered for increasing the calorific values further. Coupal and Lalancette (1976) indicated that the heat value of the peat was related to moisture as:

$$
\text { Net heat }(B T U)=100(x-10)
$$

where: 
Table 4.34. Cost of replacing and reusing oil-sorbed peat

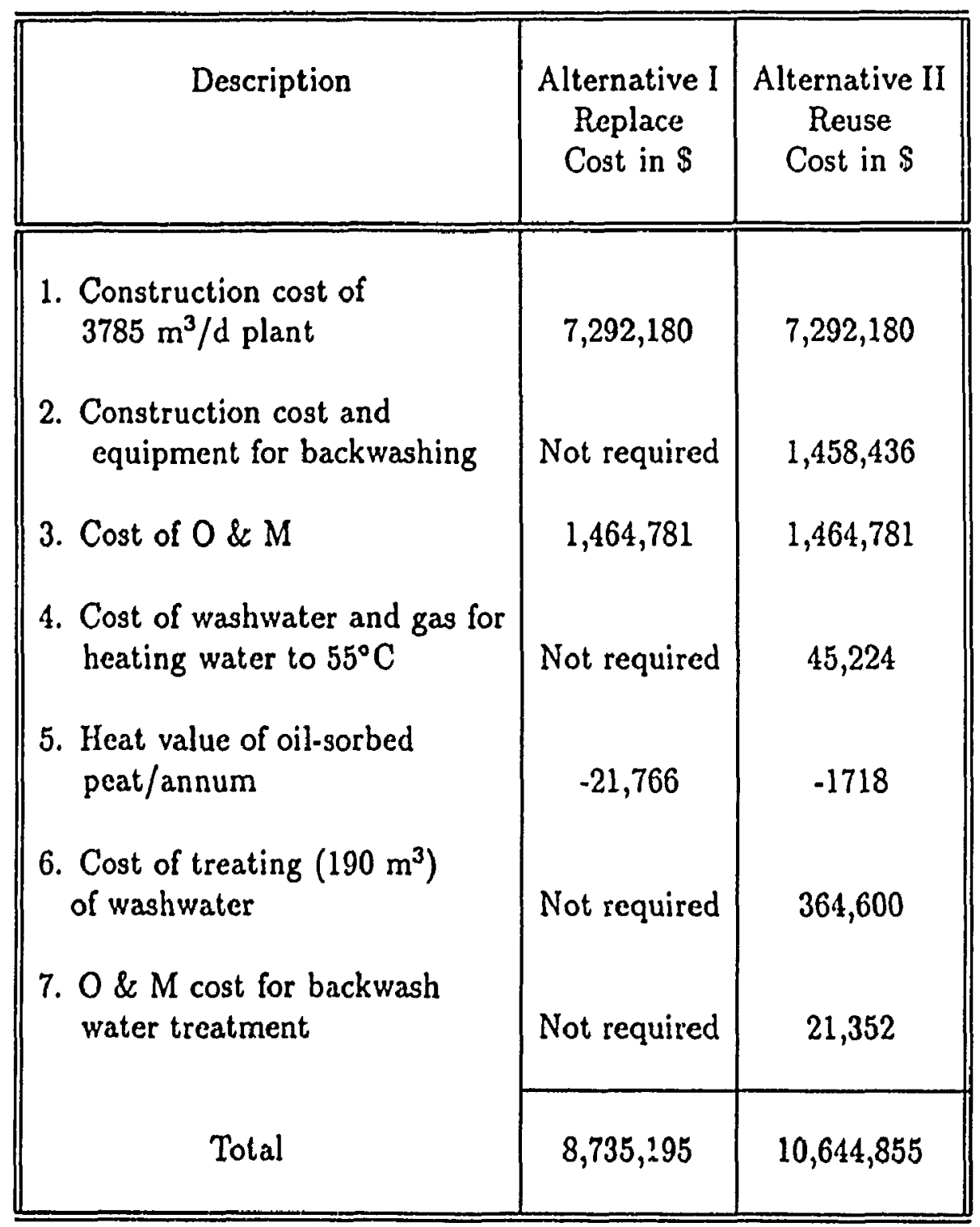


$x=$ percentage of dry peat in the wet mixture

The amount of oil released from horticultural peat (from an initial value of $2 \mathrm{~kg}$ oil $/ \mathrm{kg}$ of peat), due to the application of pressure is presented in Figures 4.45 to 4.47 for SMO, MCO and CO samples, respectively. From these plots it is seen that the amount of oil released depended on the type of oil, applied pressure and its duration. Within the pressure range investigated (689 to $13,788 \mathrm{kPa}$ ), SMO was released from peat starting at $2000 \mathrm{kPa}$, whereas, in the case of $\mathrm{MCO}$ and $\mathrm{CO}$, the starting point for the release of oil was at $5000 \mathrm{kPa}$. Obviously, maximum oil was released at a 14,000 $\mathrm{kPa}$ pressure, applied for 30 minutes. Experiments were not conducted beyond this time and pressure.

The amount of $\mathrm{SMO}, \mathrm{MCO}$ and $\mathrm{CO}$ released by applying a range of pressures over a constant time of 30 minutes are compared in Figure 4.48.

This figure clearly depicts that MCO was less-likely to be released from peat attaining a maximum oil recovery of only $0.2 \mathrm{~kg}$. The percentage of $\mathrm{MCO}$ released or recovered thus works out to be about 10 percent. Similarly, the maximum amount of SMO released was $0.7 \mathrm{~kg}$ resulting in percentage released or recovered of approximately 28 percent. $\mathrm{CO}$ was released to a maximum of $1.5 \mathrm{~kg}$ indicating a release or recovery of about 70 percent. Therefore, it can be concluded that MCO offered maximum resistance to pressure, while $\mathrm{CO}$ was released without much resistance.

I'hese results generally indicate that the spongy nature of peat can be advantageously used to squeeze oil from it for recovering the waste oil for use. Further it is environmentally more acceptable to dispose of oil-sorbed peat in a landfill or use it for land application when most of the oil from such a peat has been removed. 


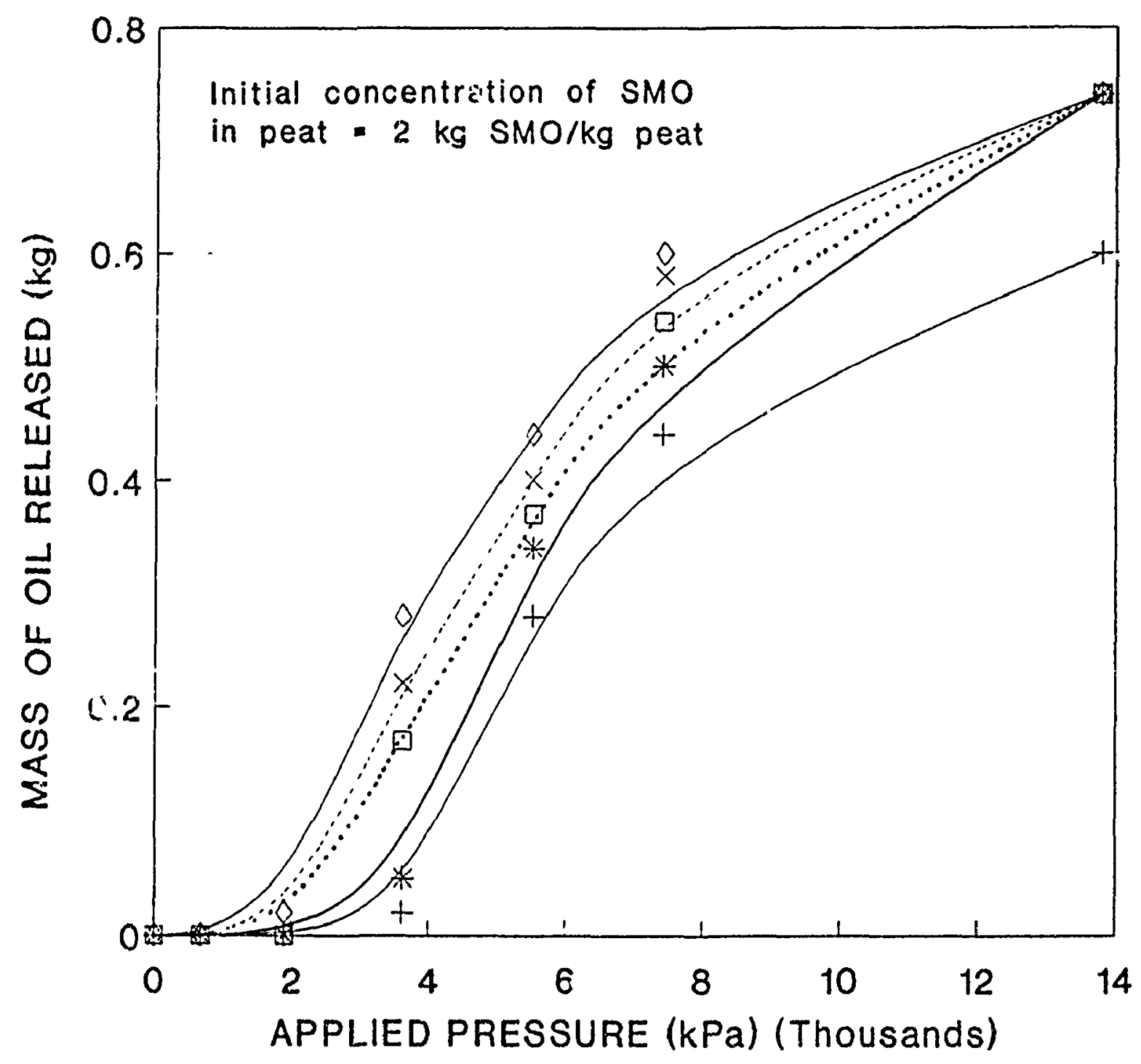

+0 minute $\rightarrow 5$ minutes $\cdots 10$ minutes
$\cdots \times 15$ minutes $\rightarrow 30$ minutes

Figure 4.45. Applied pressure vs SMO released 


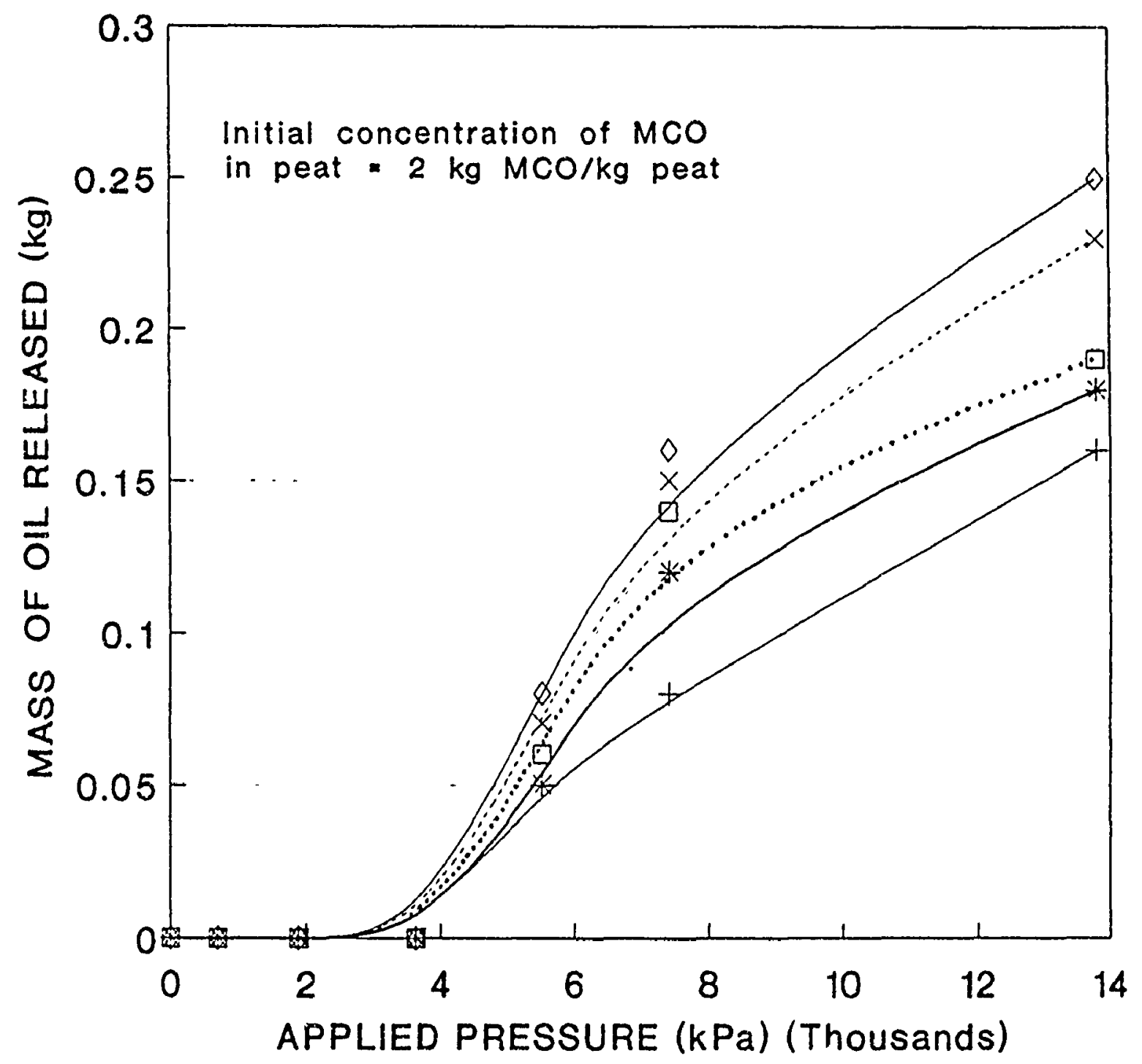

+0 minute $\rightarrow 5$ minutes $\rightarrow 10$ minutes
$\cdots \times 15$ minutes $\rightarrow 30$ minutes

Figure 4.46. Applied pressure vs $\mathrm{MCO}$ released 


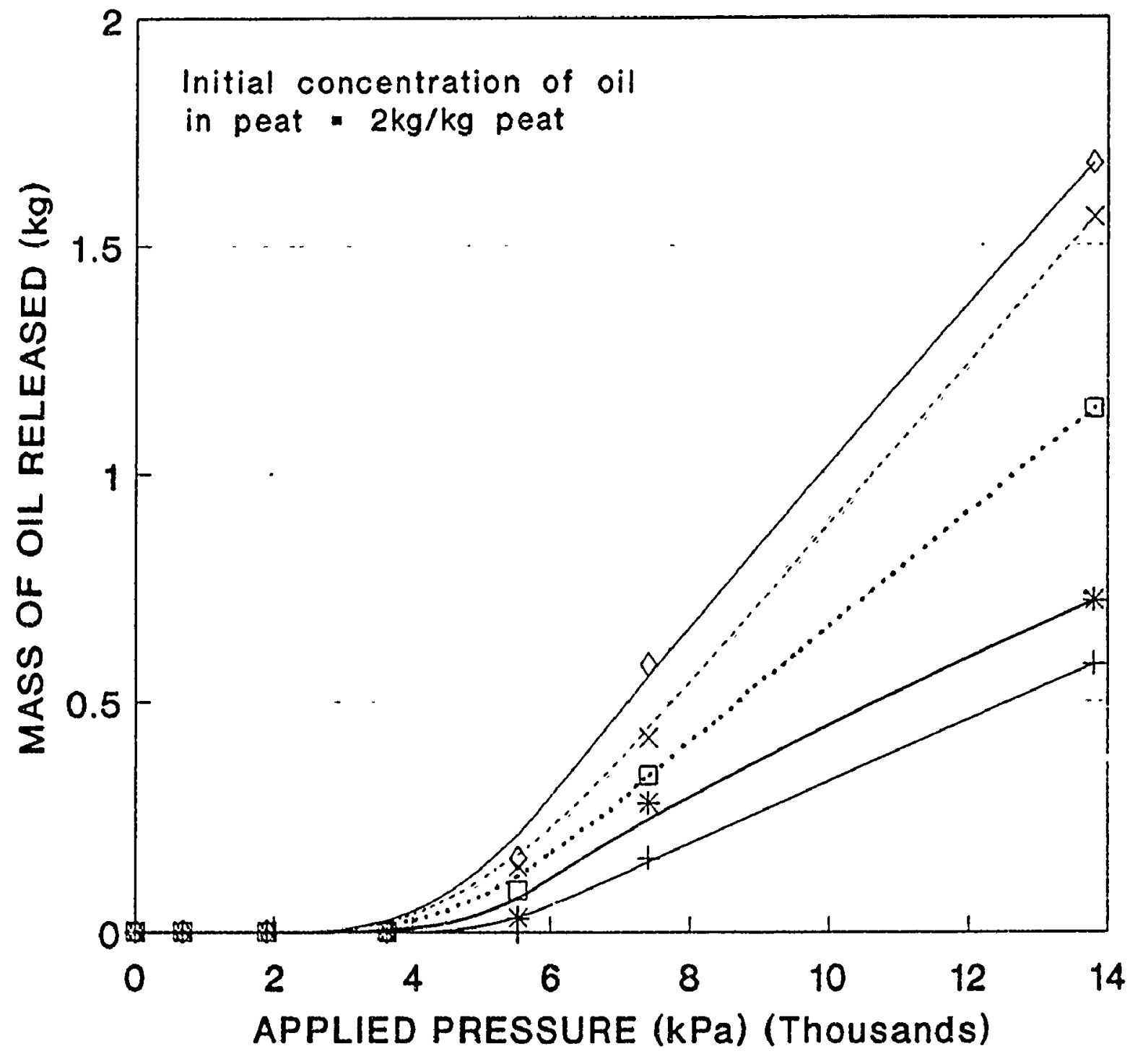
T 0 minute $\quad * 5$ minutes ...0... 10 minutes
.. $\times 15$ minutes $\neg 30$ minutes

Figure 4.47. Applied pressure vs CO released 


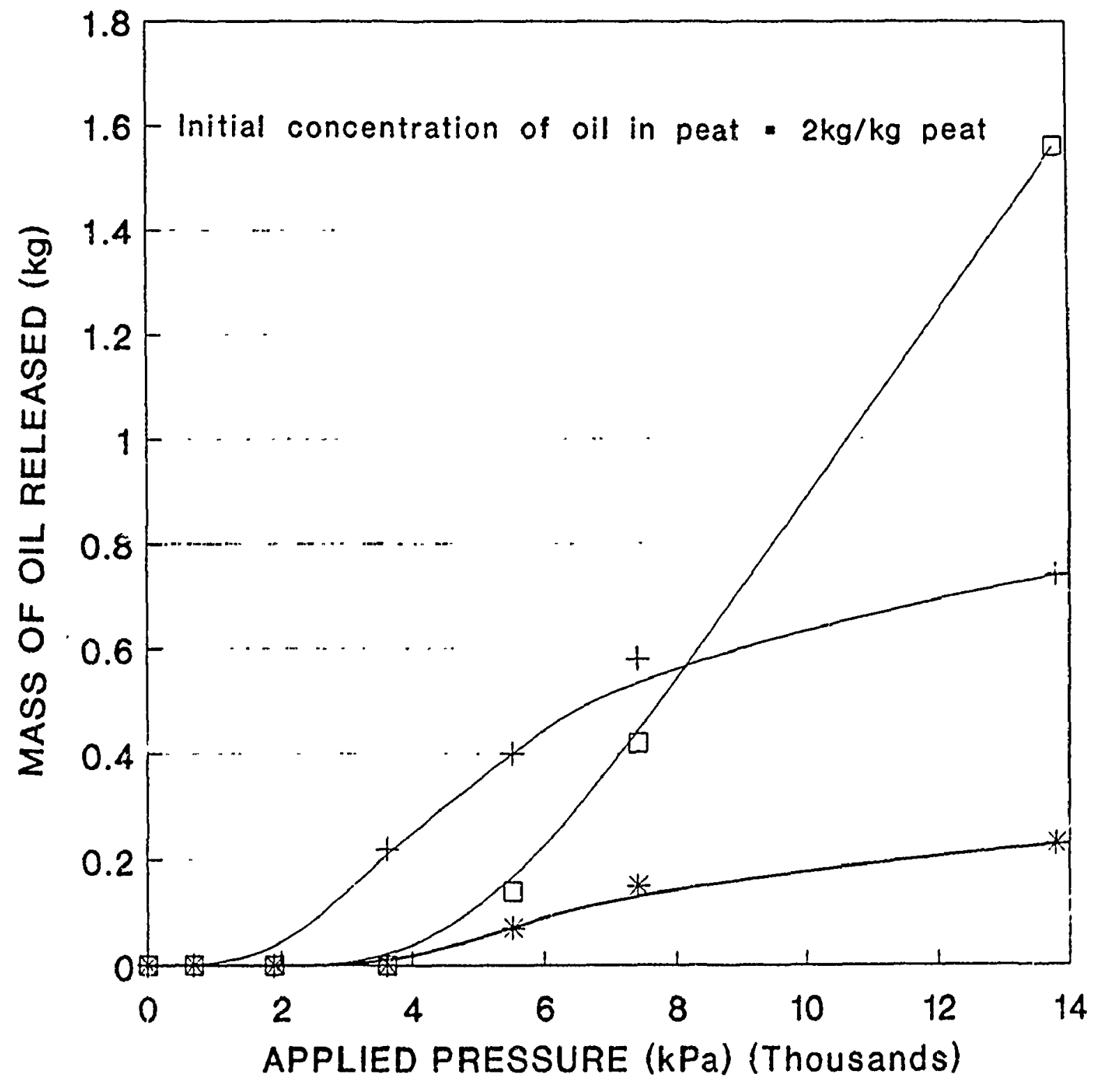

\section{$\rightarrow$ SMO $*$ MCO $\because \mathrm{CO}$}

Figure 4.48. Applied pressure vs amount of oil released for three oil samples at 30 minutes duration 


\subsection{Breakdown Mechanisms}

\subsubsection{Filtration}

The data collected from the experimental column were analyzed using equation 2.11 for predicting the head-loss across the peat bed. A plot of this is presented in Figure 4.49. Equation 2.11 plotted on log-log paper was found to be straight line (Sherony et al. 1978) as shown in Figure 4.50.

The average value of the Carman-Kozeny constant $\left(k_{1}\right)$ indicated by the slope of the regression line, was 3.39. Carman (1956) reported that the value of $k_{1}$ was in the range of 4.5 to 5.1 for medium spheres and postulated that a wide variability was inherent in the nature of $k_{1}$. Wiggins et al. (1939) studied fibrous materials (glass fibers, glass wool, fiber glass and yarn) and showed that the value of $k_{\mathfrak{l}}$ varied from 4 to 6.5 , depending upon the material and its porosity. Wyllie and Gregory (1955) reported $k_{1}$ values of 3 to 6 for various flat-sided shapes. Chieu et al. (1975) studied different fibrous coalescing media and found that the value of $k_{1}$ varied with porosity and reported a value of 4.4 for a porosity of 0.8 . Akers and Ward (1977) stated that the value of $k_{1}$ depended on part:- $e$ size, shape and packing of the bed. For beds of moderate pocosity, they reported values in the range of 3.5 to 6 . The variation of $k_{1}$ with void fraction $(\epsilon)$, consolidated from the literature by Akres and Ward (1977) and Rushton and Griffiths (1977), is presented in Figures 4.51 and 4.52 respectively.

From these figures it is seen that cylinders $(6.4 \mathrm{~mm})$ and plates $(1.6 \mathrm{~mm})$ have low $k_{1}$ values for low porosities of $0.33-0.36$. Cylinders and cotton fibers parallel to flow have low $k_{1}$ values (Figure 4.52). Carman (1956) concluded that the low values of $k_{1}$ can be attributed to the non-uniformity of the pore structurr. which is true in the case of peat, having a pore size distribution ranging from $1 \mu \mathrm{m}$ to over $1 \mathrm{~mm}$. 


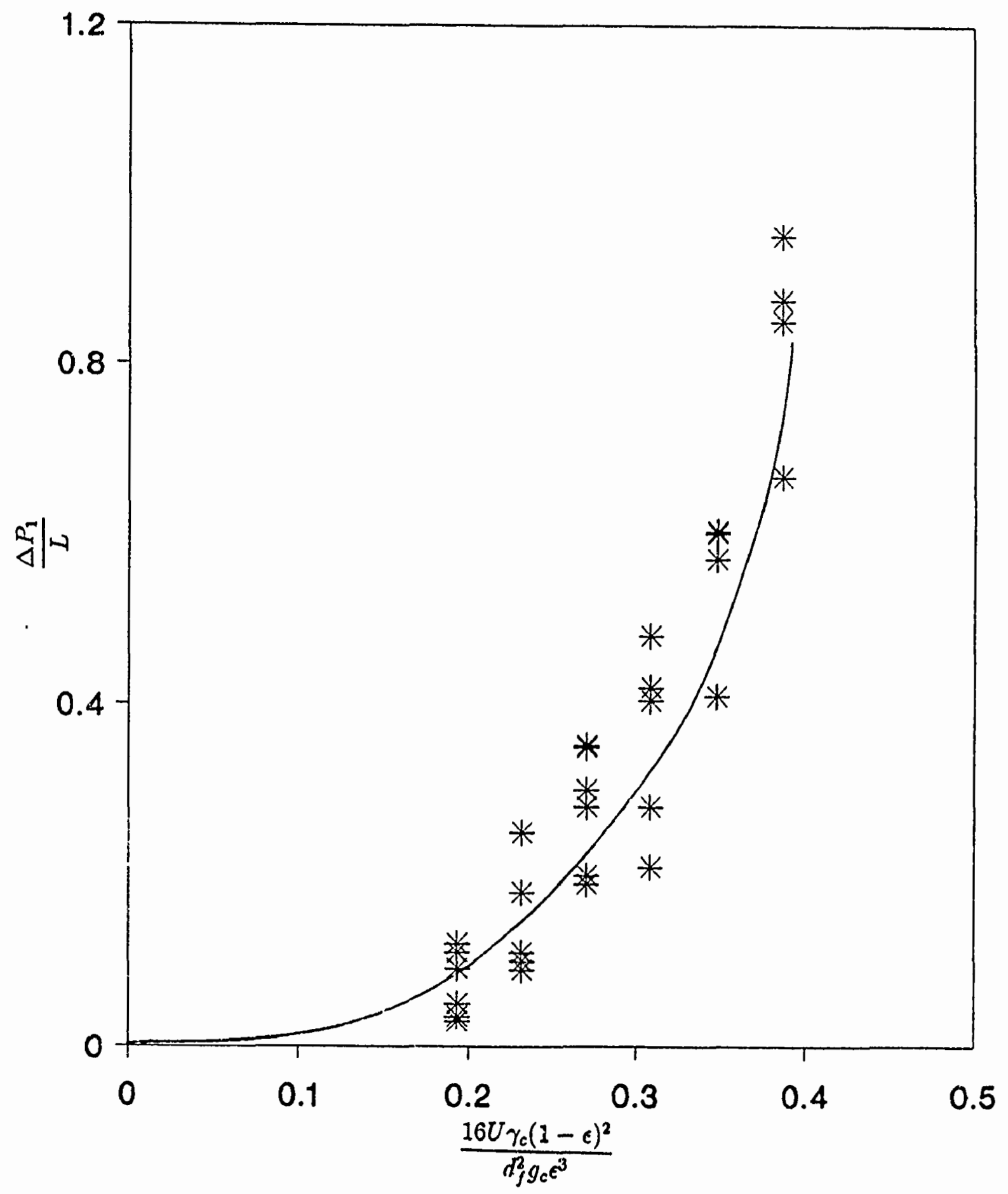

Figure 4.49 Plot of single-phase pressure drop 


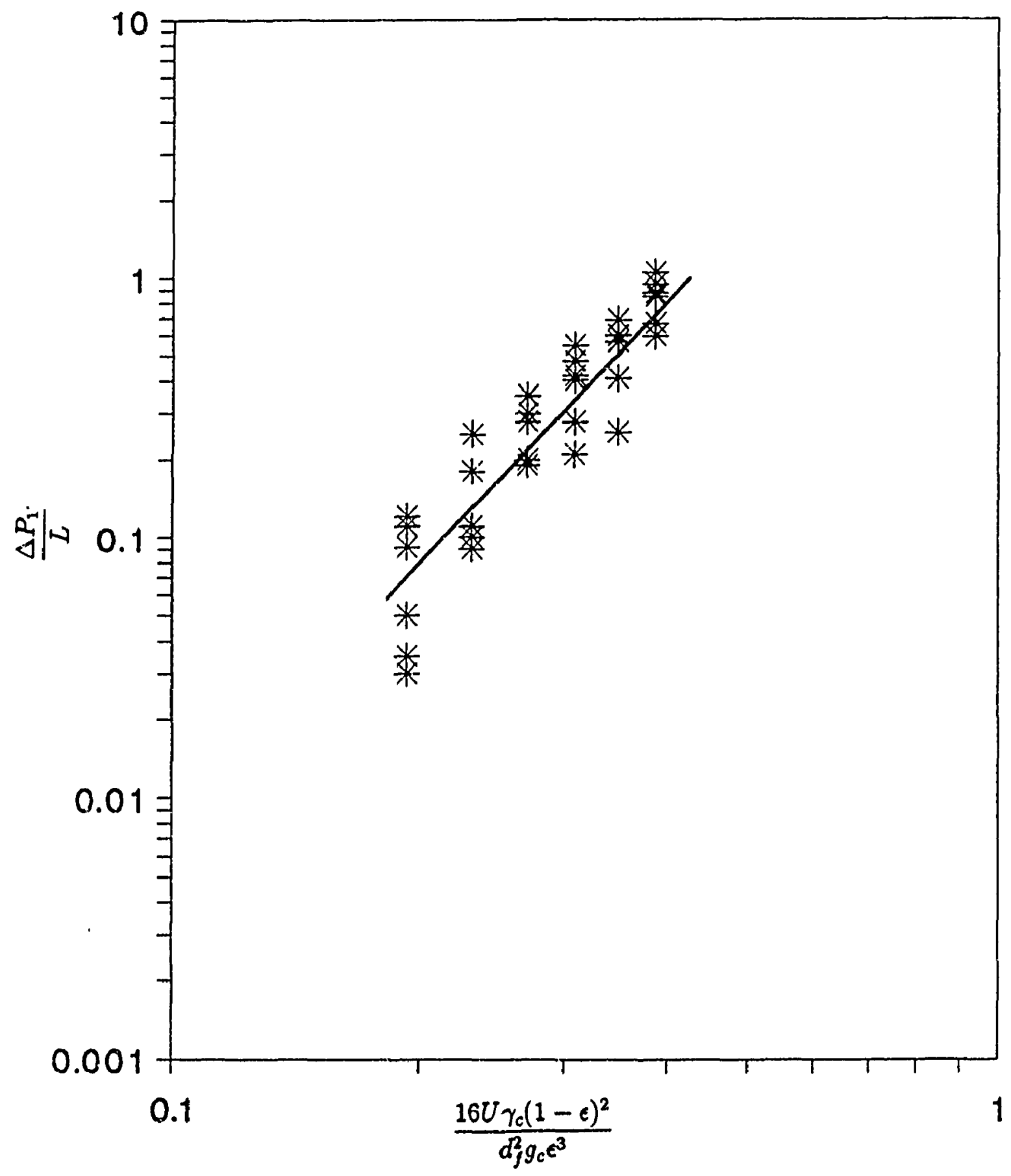

Figure 4.50. Linearized plot of single-phase pressure drop 


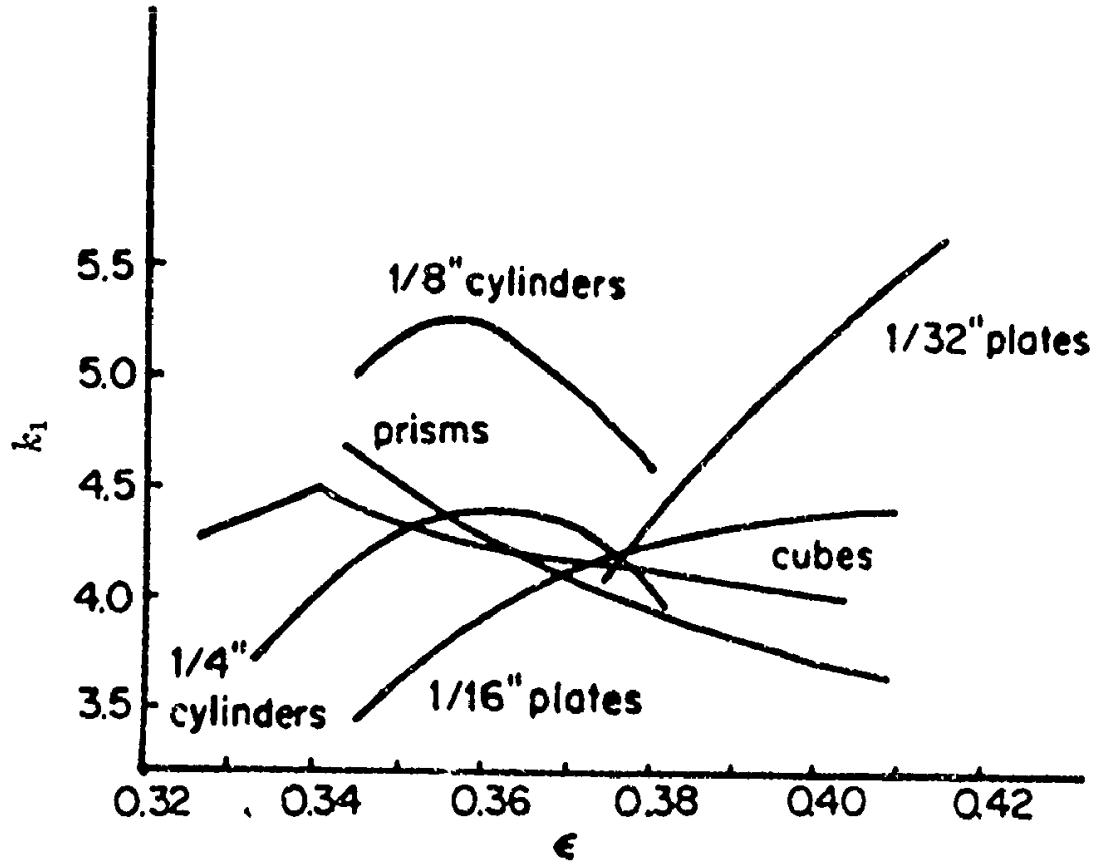

Figure 4.51. Variation of $k_{1}$ with void fraction for various shapes (Akers and Ward 1977) 


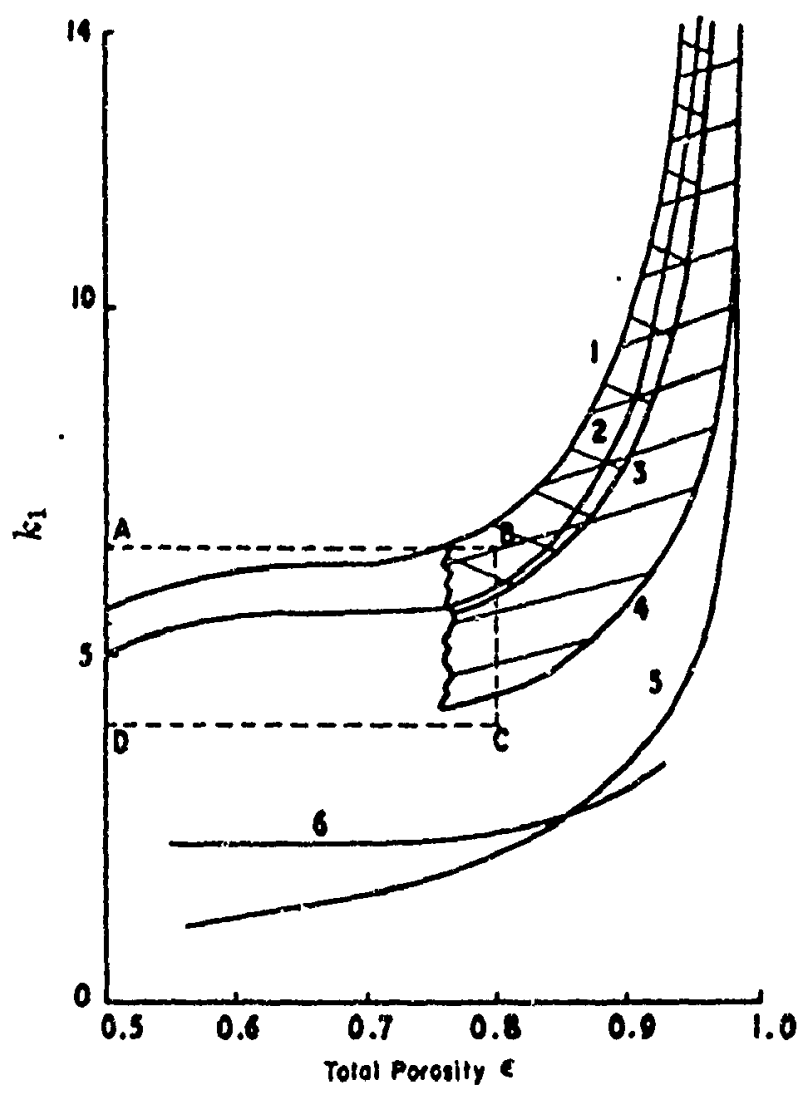

1,2 Random assemblieo of fibers

3 Random assemblies of wool fibers

4 Random assemblies of cotton fibers

5 Cylinders parallel to flow

6 Cotton fibers parallel to flow

Area marked $\|$ is for fibers that tend to lie parallel to normal flow Area marked // is for more random assemblies of fibers Values of Kozeny constant for measurements at lower porosities fall in rectangle $A B C D$

Figure 4.52. Experimental variation of Kozeny constant with total porosity for assemblies of fibers and cylinders (Rushton and Griffiths 1977) 
The specific permeability coefficient $\left(B_{o}\right)$ of peat, calculated using equation 2.9 with a $k_{1}$ value of 3.39 , was found to be $5.318 \times 10^{-11} \mathrm{~m}^{2}$. This value generally agrees with the values of permeability reported in the literature for in-situ peat, namely $10^{-13}$ to $10^{-11} \mathrm{~m}^{2}$ (Bear et al. 1968). Korpijaakko and Radforth (1974) shower that the hydraulic conductivity of peat decreased with an inczease in the degree of humification. They obtained a specific permeability coefficient of $1.36 \times 10^{-11} \mathrm{~m}^{2}$ for a moderately humified horticultural peat. Poots and McKay (1979) reported that the specific permeability of Sphagnum peat (available in Northern Ireland) varied from $5.5 \times 10^{-11}$ to $5.5 \times 10^{-10} \mathrm{~m}^{2}$ depending upon the particle size. The authors have reasoned that the peat having been dried, ground and sieved had a higher permeability than the value reported in the literature. The slightly high values of permeability coefficient $\left(B_{0}\right)$ obtained in the present study may also be due to the low values of $k_{1}$ obtained. With wide variations in shape, size and texture of peat, the value of $k_{1}$ obtained in this study appears to be reasonable.

Carman (1956) showed that the constant $k_{1}$ can be related to the shape factor $k_{0}$ as follows:

$$
k_{1}=k_{0} T^{2}
$$

where $T$ is the tortuosity factor. The value of $T$ depends on the pore structure of the medium. For a straight tunnel pore, the value of $T$ is 1.0. For random array of fibers and particles, it has been estimated from probability calculations that the value of $T$ is equal to $\frac{1}{c}$ (Johnston 1983 and ASTM 1984). Accordingly, for peat the value of $T$ was calculated as 1.26. Substituting $T$ and $k_{1}$ in equation $4.3, k_{0}$ was calculated as 2.17. The values of $k_{0}$ reported by Carman (1956) for various media shapes are 
presented in Table 4.35. Sakthivadivel et al. (1972) showed that for a wide range of geometrical shapes, $k_{0}$ varied between the extremes of 1.52 and 3.0 , with an average range of 2 to 2.5 . Thus, the value oi 2.17 for the shape factor $\left(k_{o}\right)$ obtained in this study appears to be reasonable.

The specific surface (the external surface) $\left(S_{o}\right)$ of peat can be calculated using the following relationship:

$$
B_{o}=\frac{\epsilon^{3}}{k_{1} S_{0}(1-\epsilon)^{2}}
$$

The specific surface area of horticultural peat was found to be $0.2533 \mathrm{~m}^{2} / \mathrm{cm}^{3}$ $\left(2533 \mathrm{~cm}^{2} / \mathrm{cm}^{3}\right)$. The specific surface area for different fibrous materials are presented in Table 4.36 for comparison. The value of $S_{0}$ can be used to calculate the external surface area available for flow, using the density of the medium.

Carman (1956) compared the different methods of measuring surface areas (BET adsorption method, air permeability method and liquid permeability methods) and showed that the liquid permeability method was most suited for a medium having low particle sizes. The surface area of peat with a mean pore diameter of $15.85 \pm 11.93$ $\mu \mathrm{m}$ can be advantageously measured using the permeability method.

The external surface area of peat available for flow was calculated as $3.365 \mathrm{~m}^{2} / \mathrm{g}$. The external surface area for peat reported by Sapek et al. (1988) using the nitrogen adsorption method ranged from 0.78 to $1.32 \mathrm{~m}^{2} / \mathrm{g}$ depending upon the degree of decomposition. It is also observed that the external surface area obtained using permeability measurements $\left(3.365 \mathrm{~m}^{2} / \mathrm{g}\right)$ is greater than the total surface area $(0.98$ $\mathrm{m}^{2} / \mathrm{g}$ ) obtained with the BET adsorption method. However, as pointed cut earlier, it will be possible to compare these values only when an accurate method is developed 
Table 4.35. Values of Shape factor $\left(k_{o}\right)$ for different shapes (Carman 1956)

\begin{tabular}{|c|c|}
\hline Shape & $k_{o}$ \\
\hline 1. Circle & 2.00 \\
\hline $\begin{array}{l}\text { 2. Ellipse, semi axes } \mathrm{a}, \mathrm{b} \text { : } \\
\text { (i) } \mathrm{a}=2 \mathrm{~b} \\
\text { (ii) } \mathrm{a}=10 \mathrm{~b}\end{array}$ & $\begin{array}{l}2.13 \\
2.45\end{array}$ \\
\hline 3. Square & 1.78 \\
\hline $\begin{array}{l}\text { 4. Rectangle, sides } a, b \text { : } \\
\text { (i) } a=2 b \\
\text { (ii) } a=10 b\end{array}$ & $\begin{array}{l}1.94 \\
2.65\end{array}$ \\
\hline 5. Parallel slit & 3.00 \\
\hline 6. Equilateral triangle & 1.67 \\
\hline 7. Annuli in pipes with concentric cores & $2.0-3.0$ \\
\hline $\begin{array}{l}\text { 8. Annuli in pipes with concentric cores, } \text { r2. }^{\circ} \mathrm{i} a_{1} \text { and } a_{2} \text { : } \\
\text { (i) } \mathrm{e}<0.7 \\
\text { (ii) } \mathrm{e}>0.7\end{array}$ & $\begin{array}{l}1.7-3.0 \\
1.2-2.0\end{array}$ \\
\hline
\end{tabular}

$e=$ eccentricity $=b /\left(a_{1}-a_{2}\right)$

$\mathrm{b}=$ distance between centres 
Table 4.36. Specific surface $\left(S_{\circ}\right)$ for different fibrous materials (Carman 1956)

\begin{tabular}{||l|c|c|c||}
\hline \hline \multicolumn{1}{|c|}{ Material of bed } & True $S_{\circ} \mathrm{cm}^{2} / \mathrm{cm}^{3}$ & $\epsilon$ & $k_{1}$ \\
\hline \hline Glass fibre 0.4 mm diameter & 101 & 0.685 & 6.5 \\
Copper wires 5 mm length & 394 & 0.830 & 6.0 \\
Glass wool & 2200 & $0.846-0.910$ & $4.0-4.9$ \\
Fiber glass & 7000 & $0.885-0.919$ & $4.5-6.0$ \\
Celanese yarn & 3000 & 0.90 & 5.0 \\
Glass wool + fibre glass & 4830 & 0.909 & 5.3 \\
\hline Horticultural peat & 2523 & 0.7 & 3.39 \\
\hline
\end{tabular}


to measure the internal and external surface areas for peat having a complex pore geometry. Considering the specific surface area values presented in Table 4.36, for different fibrous media, the value of the specific surface area obtained for peat $(0.2523$ $\mathrm{m}^{2} / \mathrm{cm}^{3}$ ) appears to be reasonable.

The Carman-Kozeny filtration equation (2.12) was used to predict the head-loss across a $1000 \mathrm{~mm}$ peat bed at different depths. The results of predicted and measured head-losses across the peat bed are shown in Table 4.37.

The predicted head-loss values at $200 \mathrm{~mm}$ depth were consistently higher than the measured values. At $1000 \mathrm{~mm}$ depth, the predictions were consistently lower than the measured values. Generally, the head-loss predictions were closer to the ubserved values at $1000 \mathrm{~mm}$ depth rather than at $200 \mathrm{~mm}$ depth. The difference in predicted and measured head-losses at $200 \mathrm{~mm}$ depth might be due to saturation of the peat bed by the oil droplets. This possibly indicates that as the influent oil concentration increases, the Carman.Kozeny equation may not yield accurate results for predicting the head-loss across the peat bed.

\subsubsection{Coalescence}

The efficiency of coalescence in the peat bed was calculated using average saturation values obtained from single and two phase álows. Sherony et al. (1978) have presented pressure drop data in the form of a friction factor plot. The dimensionless friction factor was defined as:

$$
f_{k}=\frac{k_{1}(1-\epsilon)}{N_{R e}}
$$


Table 4.37. Measured and predicted head-losses across peat bed for a two-phase flow (oil-in-water emulsion)

\begin{tabular}{||c|c|c|c|c||}
\hline \multirow{2}{*}{ Flow $(\mathrm{mL} / \mathrm{min})$} & \multicolumn{2}{|c|}{ Measured $\Delta P_{2}^{\dagger}$} & \multicolumn{2}{|c||}{ Predicted $\Delta P_{2}$} \\
\cline { 2 - 5 } & $200 \mathrm{~mm}$ & $1000 \mathrm{~mm}$ & $200 \mathrm{~mm}$ & $1000 \mathrm{~mm}$ \\
\hline \hline 165 & 0.007 & 0.314 & 0.026 & 0.132 \\
198 & 0.020 & 0.506 & 0.047 & 0.234 \\
231 & 0.047 & 0.700 & 0.076 & 0.373 \\
264 & 0.048 & 1.010 & 0.115 & 0.576 \\
297 & 0.059 & 1.33 & 0.160 & 0.833 \\
331 & 0.120 & 2.050 & 0.230 & 1.160 \\
\hline \hline
\end{tabular}

$\dagger$ Pressure drop in $m$ head of water 
Figure 4.53 shows the friction factor for single and two phase flow data as a function of $N_{R e} /(1-\epsilon)$.

The values for two-phase data were obtained using $\Delta P_{1} / \Delta P_{2}$, the degree of saturation $\left(\bar{S}_{d}\right)$ and $\epsilon_{t}$ the true void fractions of the peat bed using the relationship presented in equation 2.14. Figure 4.53 shows that the two-phase flow data were displaced upwards from the single-phase data. Generally, the two-phase data would approach the single-phase flow line at higher velocities (Sherony and Kintner 1971 $a$ and $b$ ). This figure is similar to the one reported in the literature for glass fibers (Sherony et al. 1978). The trend of the two-phase line approaching the single-phase flow line could not be observed in this case due to the low Reynolds numbers obtained in this study, which ranged from 0.005 to 0.01 , compared to 0.1 to 1 reported by Sherony et al. (1978). Sherony and Kintner (1971') postulated that the displacement was caused by the fact that the bed was retaining some dispersed phase. This retained material occupied space and affected the void fraction, available for flow. The authors have further indicated that the pressure drop and friction factor wore very sensitive to void fractions as shown in equations 2.11 and 2.12 . The permeability coefficient obtained for two-phase flow using the above equation (2.12) was $2.8 \times 10^{-11} \mathrm{~m}^{2}$. This permeability coefficient for the two-phase flow did not differ appreciably when compared to $5.318 \times 10^{-11} \mathrm{~m}^{2}$, obtained for the single-phase flow. This may be due to the negligible void space occupied by the dispersed oil dropiets $(131 \mathrm{mg} / \mathrm{L})$ compared to overall void space available in a $1000 \mathrm{~mm}$ depth peat bed. This is also indicated by the average saturation values of less than 8 percent obtained in the study. Ekman and Asplund (1975) obtained similar permeability coefficients for a peat using an oil-in-water emulsion of $1000 \mathrm{mg} / \mathrm{L}$. Their reported values ranged 


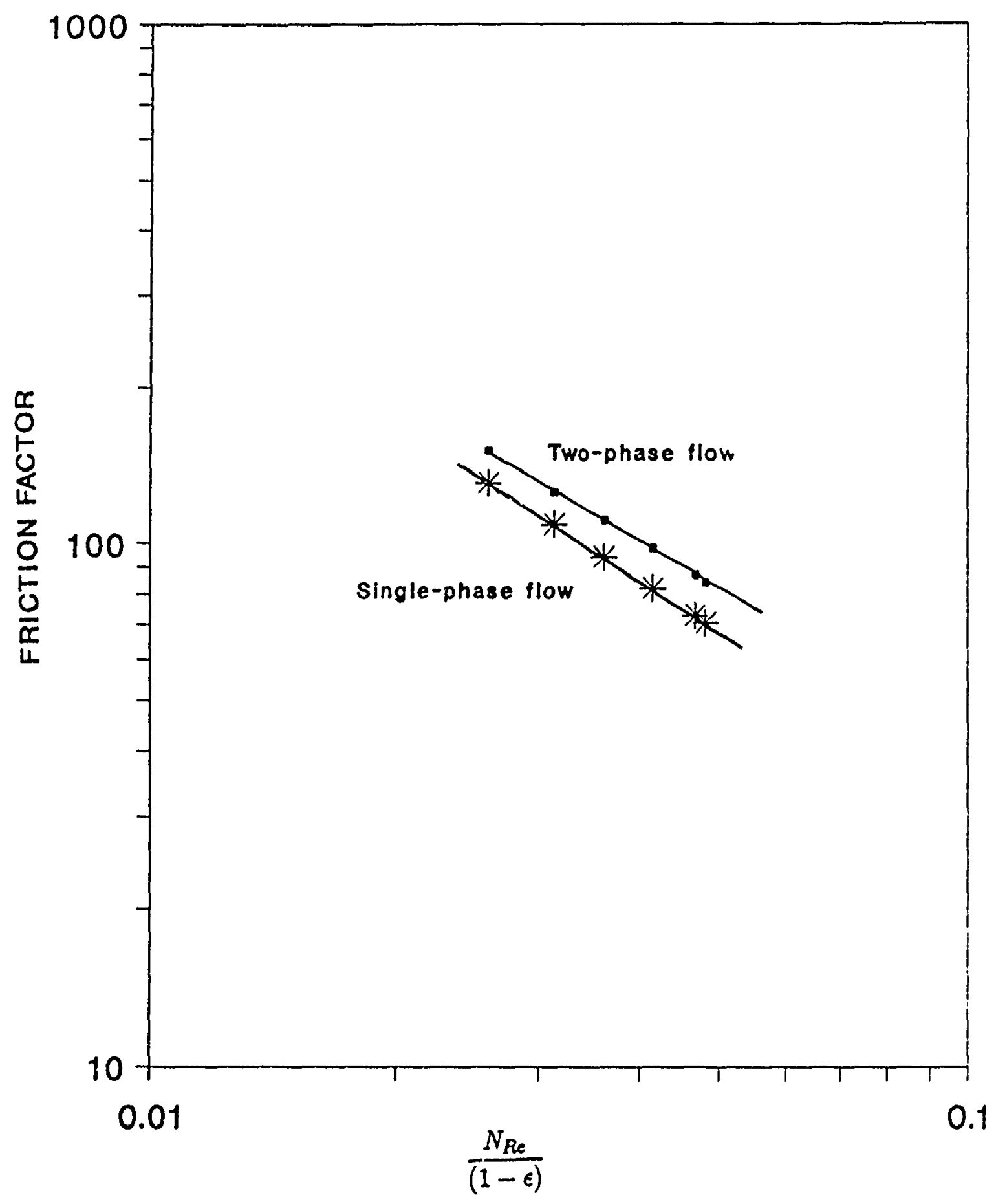

Figure 4.53. Friction factor plot 
from $1.5 \times 10^{-11}$ to $1.73 \times 10^{-8} \mathrm{~m}^{2}$. These are higher than the values obtained in the present study even though they have used an oil with a concentration of $1000 \mathrm{mg} / \mathrm{L}$ compared to $131 \mathrm{mg} / \mathrm{L}$ used in this study. Further, it is also observed that their value of the permeability coefficient for two-phase flow was on the higher side compared with the values of permeability coefficients reported in the literature for single-phase flow $\left(10^{-13}\right.$ to $\left.10^{-11} \mathrm{~m}^{2}\right)$ using water.

The overall coalescence efficiency $\left(\eta_{c}\right)$ was calculated using equations 2.13 and 2.15 . for the experimental values presented in Table 4.38. Figure 4.54 shows the plot of coalescence efficiency versus Reynolds number for different peat depths investigated.

It is seen that within the velocity region investigated, there is a general decrease in coalescence efficiency with an increase in velocity. This generally agrees with the findings of Vinson and Churchill (1970), and Rosenfeld and Wasan (1974). Sherony et al. (1978) showed that there was an increase in coalescence efficiency due to an increase in velocity. However, the Reynolds numbers were in the range of 0.1 to 1.0 in comparison to Reynolds numbers of the present study ( 0.005 to 0.01$)$. The coalescence efficiency was maximal for a flow rate of $198 \mathrm{~mL} / \mathrm{min}$ at all depths, indicating possibly, that $198 \mathrm{~mL} / \mathrm{min}$ may be the critical velocity for achieving maximum coalescence in the peat bed.

From Figure 4.54 it is observed that there was a decrease in coalescence efficiency with an increase in depth. This generally contradicts the observations of Sherony and Kintner (1971b) that coalescence efficiency increased with dejth. A maximum coalescence efficiency of 14 percent was obtained at $200 \mathrm{~mm}$ depth compared to a minimum value of 3 percent at $1000 \mathrm{~mm}$ depth. Coalescence efficiency as high as 50 percent has been reported in the literature (Sherony et al. 1978). Chieu et al. 
Table 4.38. Results of coalescence experiments

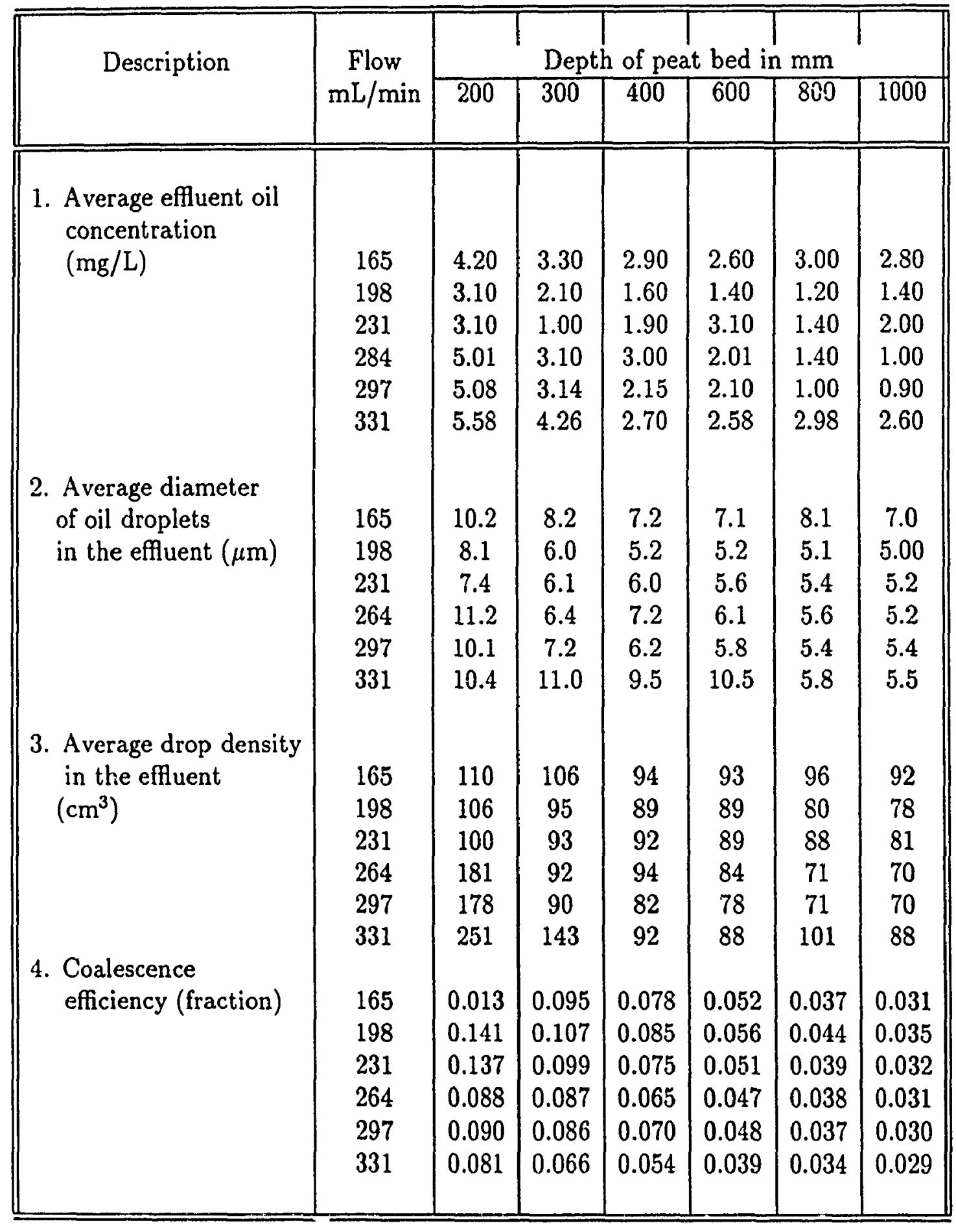


Table 4.38. Contd....

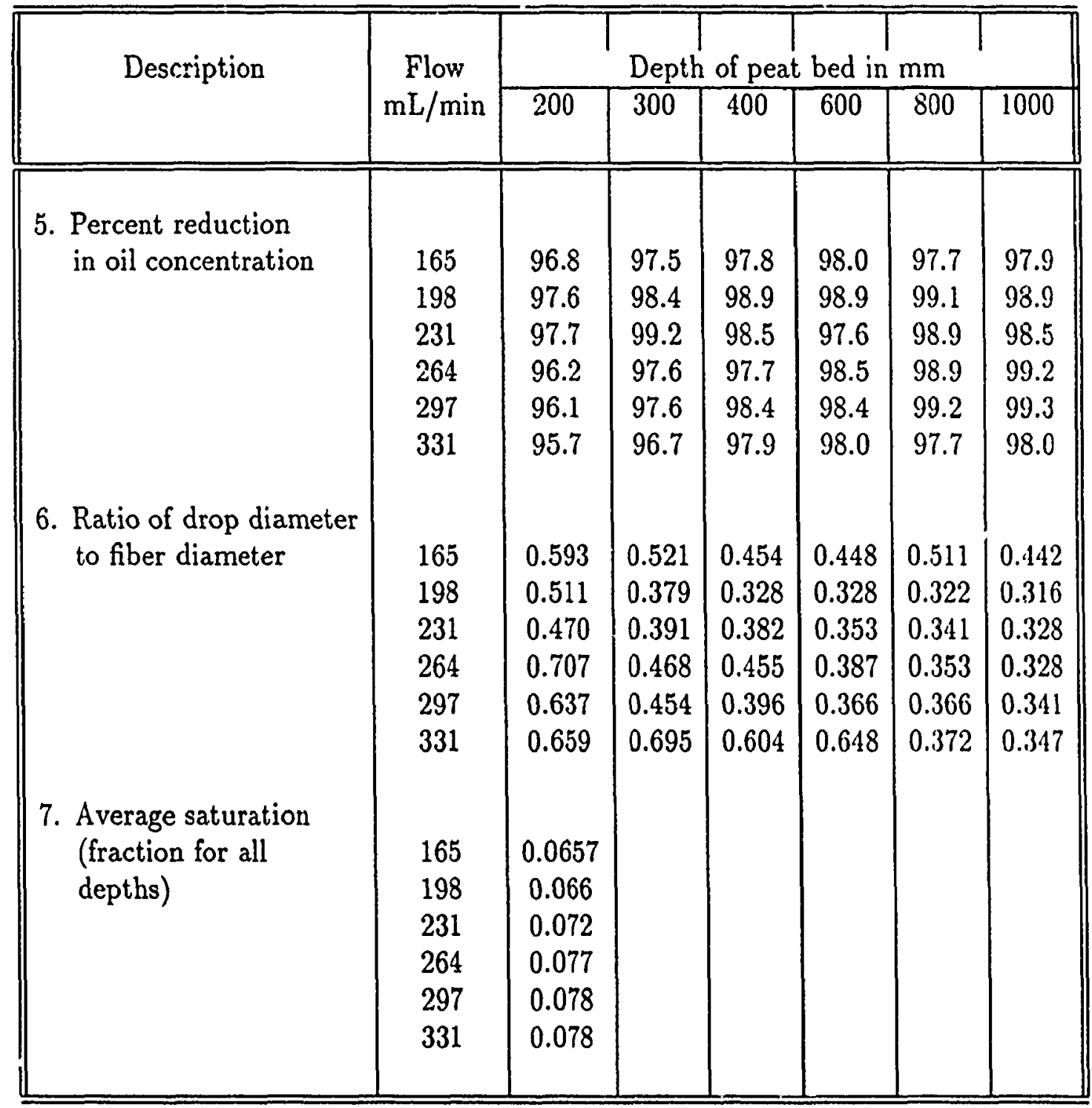




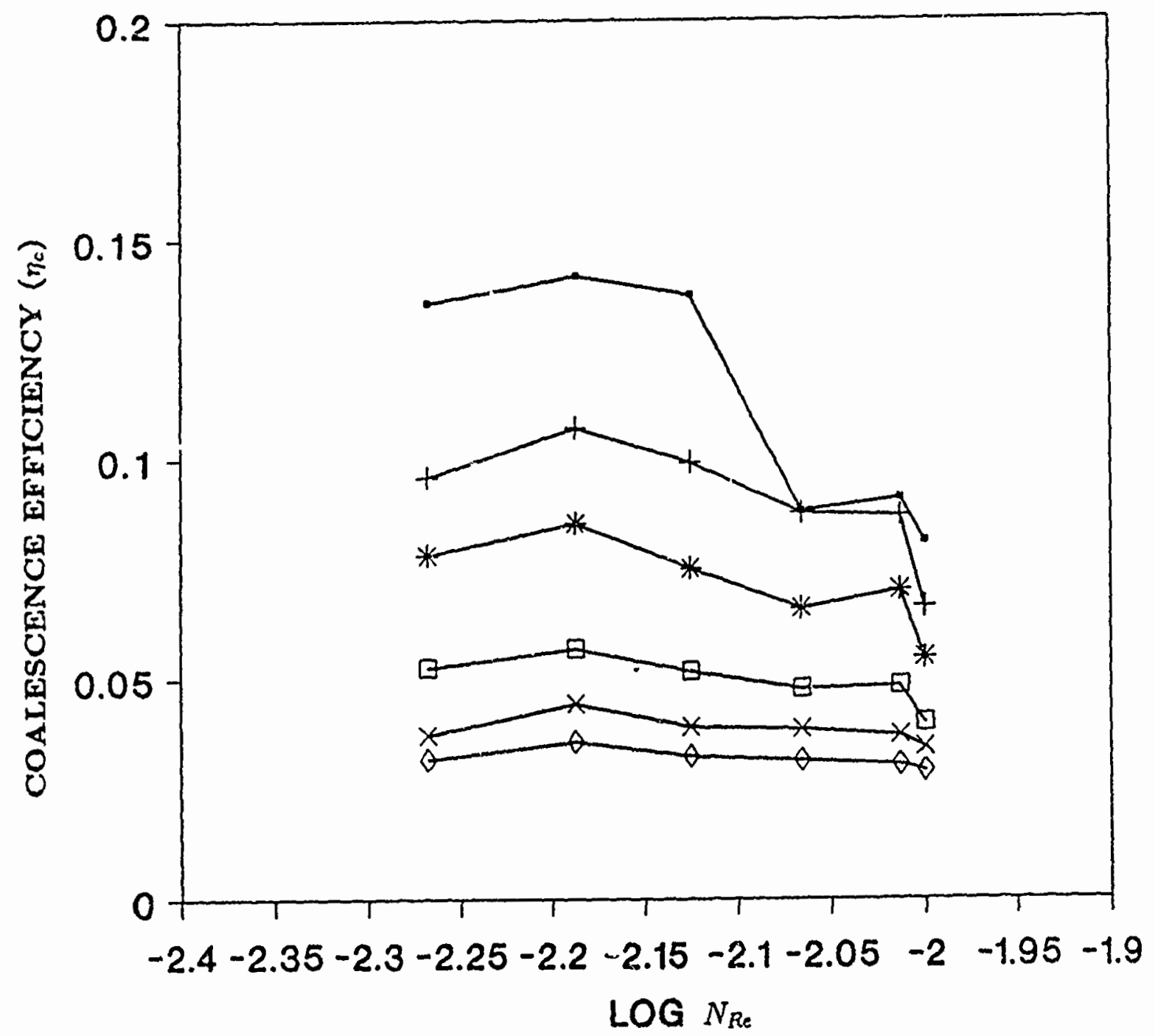

$\begin{array}{lll}\rightarrow 200 \mathrm{~mm} & +300 \mathrm{~mm} & * 400 \mathrm{~mm} \\ \rightarrow 600 \mathrm{~mm} & \leftarrow 800 \mathrm{~mm} & \rightarrow-1000 \mathrm{~mm}\end{array}$

Figure 4.54. Coalescence efficiency versus Reynolds number 
(1975) indicated that a minimum oil saturation of 10 to 15 percent was necessary for coalescence in a synthetic medium. In the present study, the maximum average saturation values never exceeded 8 percent (Table 4.38), posing limitations for the coalescence mechanism. The efficiency of coalescence vs Reynolds number consolidated from literature and presented by Sherony et al. (1978) is shown in Figure 4.55 for comparison.

It is seen from this figure that the coalescence efficiency decreases with a decrease in the ratio of drop diameter to fiber diameter. In the present study, this ratio dropped from a high of 0.707 (at $200 \mathrm{~mm}$ depth) to a low of 0.36 (at $1000 \mathrm{~mm}$ depth). This ratio would have increased with the depth if coalescence were to be effective, thereby increasing the efficiency of coalescence. This decrease in the ratio can be attributed to the filtration of drops within the peat bed. Further, the influent mean drop diameter was $21.6 \pm 10 \mu \mathrm{m}$ compared to less than $7 \mu \mathrm{m}$ for the effluent drop diameter. These observations support that while larger droplets were filtered out, the smaller droplets coalesced until they were large enough to be filtered. A steep decrease in coalescence efficiency, a decrease in oil concentration and a decrease in drop diameter of the effluent can all be attributed to the sequential action of filtration and coalescence. For all flow rates investigated, the efficiency of coalescence was approximately 3 percent at $1000 \mathrm{~mm}$ depth, ind cating that coalescence was not effective at greater depths. Thus, high stable oil-in-water emulsions, which are characterized by small drop diameters of say less than $10 \mu \mathrm{m}$ may not filter or coalesce in a peat bed. Murkes and Stockholm (1986) also observed such limitations and showed that small drops of less than $10 \mu \mathrm{m}$ would coalesce poorly in "Acropore" porous media. 


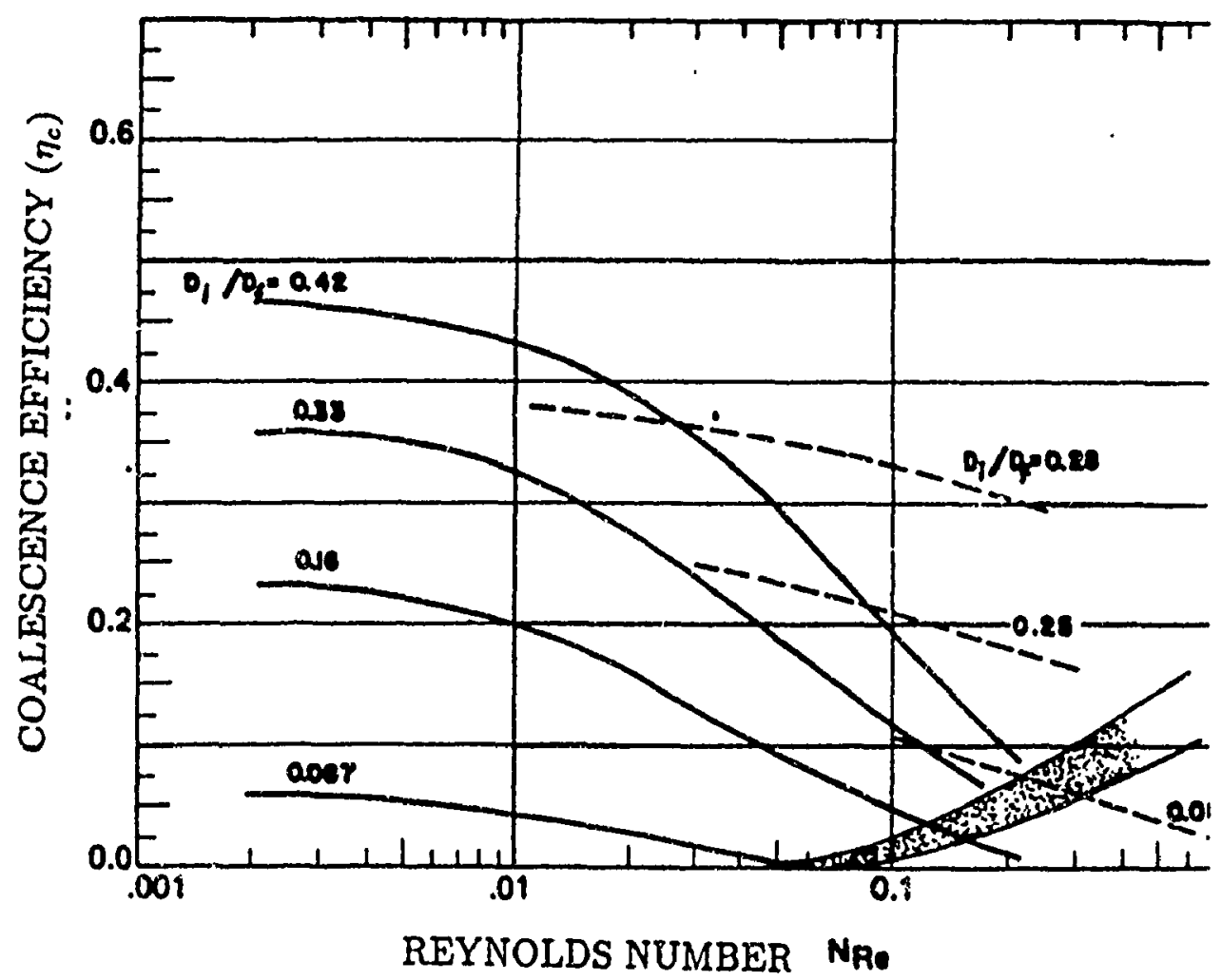

Figure 4.55. Coalescence efficiency vs Reynolds number (Sherony et al. 1978) 


\subsubsection{Adsorption}

In order to predict the time of breakthrough and the length of the mass transfer zone in the peat column using the HSDM equation it was required to obtain Freundlich constants describing adsorption in batch systems. The results of the regression equations obtained for the adsorption of chemically stabilized SMO-in-water emulsion by peat are presented in Table 4.39 .

These results showed that the BET equation having a linear correlation coefficient of 0.74 described better the adsorption of SMO (emulsified with chemicals) onto peat, compared to the Freundlich isotherm. Since the HSDM equation uses Freundlich constants, no further analysis using HSDM equation was pursued.

\subsubsection{Bacterial activity}

\subsubsection{With one reactor}

In the first study, the average oil concentration in the influent was $242.3 \pm 12.1$ $\mathrm{mg} / \mathrm{L}$ while the $300 \mathrm{~mm}$ horticultural peat bed produced an average effluent concentration of less than $2 \mathrm{mg} / \mathrm{L}$, throughout the seven-day period. During that time, the peat bed provided 99 percent of oil removal on an average. The bacterial counts of three peat samples and of the influent, and efflueni oil-in-water emulsions for the two media $\left(\mathrm{PAF}\right.$ and $\left.\mathrm{BH}_{4}\right)$ used are presented in Table 4.40.

A maximum bacterial population of $15.6 \times 10^{4}$ per $\mathrm{g}$ of wet-oil-saturated peat was observed at the end of the seventh day at port 1 . Plots of the log hacterial count versus time are shown in Figures 4.56 and 4.57 for the $\mathrm{PAF}$ and $\mathrm{BH}_{4}$ media respectively. A comparison of the bacterial population between $\mathrm{PAF}$ and $\mathrm{BH}_{4}$ showed that the difference is not appreciable. 
Table 4.39. Batch adsorption results for SMO (chemically emulsified) and peat

\begin{tabular}{|c|c|c|}
\hline Isotherm & Regression equation & Correlation coefficient $(r)$ \\
\hline 1. Langmuir & $1 /\left(\frac{x}{m}\right)=0.4545+17.79 / C$ & 0.27 \\
\hline 2. Freundlich & $\log (x / m)=-1.0617+0.6902 \log C$ & 0.40 \\
\hline 3. BET & $\frac{C}{(C s-C) x / m}=-0.0110+1.5308 \frac{C}{C_{s}}$ & 0.74 \\
\hline
\end{tabular}


Table 4.40. Total Bacterial Counts (One reactor, two media) For PAE medium

\begin{tabular}{||c|c|c|c|c|c||}
\hline \hline Day & Port1 & Port2 & Port3 & influent & Effluent \\
\hline \hline 0 & 0.64 & 0.64 & 0.64 & 0.26 & 0 \\
1 & 5.32 & 2.17 & 2.55 & 0.41 & 0.36 \\
2 & 13.13 & 10.55 & 10.30 & 0.39 & 0.35 \\
7 & 15.60 & 13.65 & 11.05 & 0.48 & 0.43 \\
\hline
\end{tabular}

\section{For BH4 Medium}

\begin{tabular}{||c|c|c|c|c|c||}
\hline \hline Day & Port1 & Port2 & Port3 & Influent & Effluent \\
\hline 0 & 0.33 & 0.33 & 0.33 & 0.071 & 0 \\
1 & 4.88 & 1.92 & 1.47 & 0.26 & 0.20 \\
2 & 11.83 & 8.15 & 7.7 & 0.37 & 0.23 \\
7 & 12.65 & 11.93 & 9.2 & 0.44 & 0.25 \\
\hline
\end{tabular}

At time 0 , the bacterial colonies at various ports are $\times 10^{4} / \mathrm{g}$ of dry peat At time 1 to 7 days, the bacterial colonies at various ports are $\times 10^{4} / \mathrm{g}$ of wet oil-saturated peat.

The bacterial colonies in the influent and effluent samples are $\times 10^{4} / \mathrm{mL}$ of oil-in-water emulsion. 


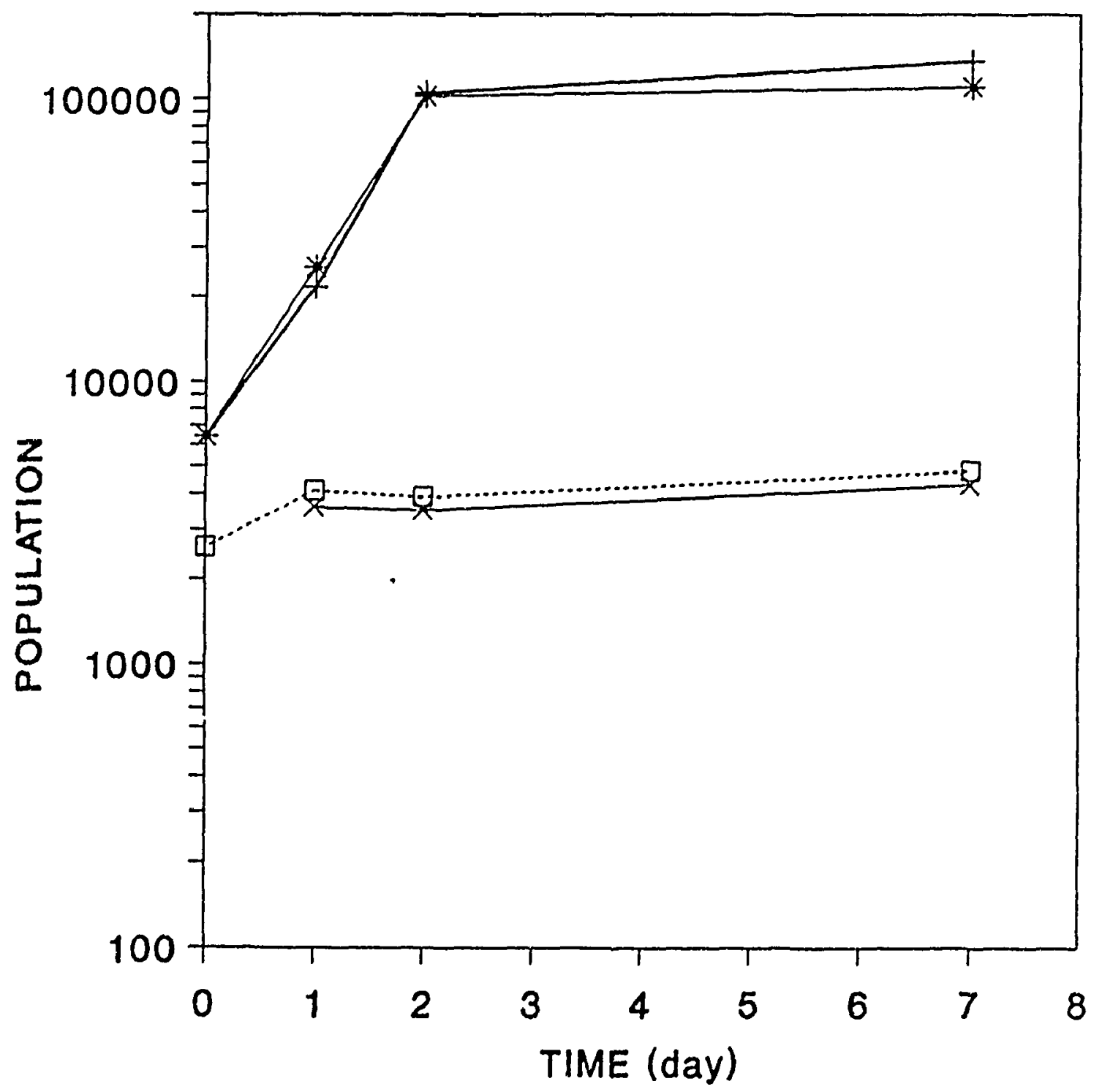

\section{- PORT $1+$ PORT 2 PORT 3 \\ $\because \boxminus-$ INFLUENT $\nleftarrow$ EFFLUENT}

Figure 4.56. Time vs log bacterial population (PAF) 


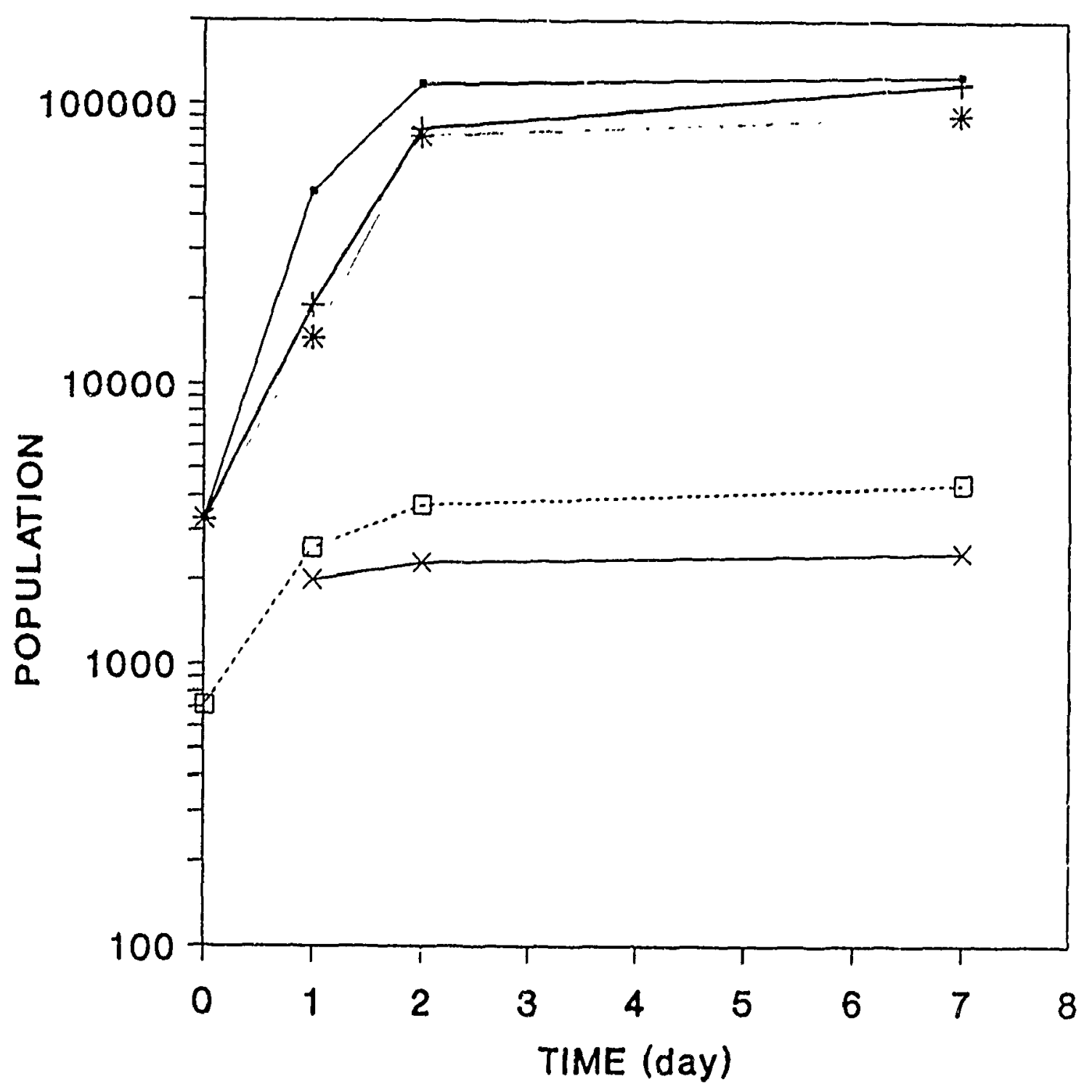

$\rightarrow$ PORT $1+$ PORT 2 * PORT 3

-曰- INFLUENT $*$ EFFLUENT

Figure 4.57. Time vs log bacterial population $\left(\mathrm{BH}_{4}\right)$ 
It can be seen from these plots that there is an increase in microbial population at all three ports over the seven-day period. However, with this experiment it was not possible to determine the relative importance of the bacterial action compared to adsorption or entrapment of oil. The maximum number of bacterial colonies observed in this study is less than the values quoted in the literature for in-situ peat $\left[28 \times 10^{4}\right.$ to $1 \times 10^{7}$ colonies per $\mathrm{g}$ (oven dry)].

\subsubsection{With three reactors}

The results of the bacterial experiments conducted with three reactors, namely reactor 1 (control reactor with sterilized horticultural peat), reactor 2 (actual reactor with horticultural peat) and reactor 3 (enhanced reactor with horticultural peat dosed with nutrients) are tabulated in Table 4.41.

The results were compared for reactors 1 and 2,2 and 3 , and 3 and 1. (Figures $4 . u 8$ through 4.60 ). Generally, the bacterial population increased over a period of

:n days for all three reactors. The increase reached maximum at the top and a minirnum at $300 \mathrm{~mm}$ depth (bottom). These comparisons showed a substantial increase in bacteria. colonies from reactor $1\left(2.8 \times 10^{3}\right)$ to reactors 2 and $3(1.7$ and $2.1 \times 10^{5}$, respectively).

There was a considerable increase in the bacterial population due to nutrient addition in reactor 3 compared to reactor 1 . However, it was not appreciable compared to reactor 2 . The increase in the bacterial colonies in reactor 1 showed that sterilized peat started supporting bacterial growth over a period of time.

The average oil removal from these three reactors was found to be $89.2,91.4$ and 90.8 percent, respectively (over a period of seven days). The high oil removal 


\begin{tabular}{||c|c|c|c|c||}
\multicolumn{3}{|c|}{ Table 4.41. Total bacterial colonies (three reactors) } \\
\hline \multirow{2}{*}{ Time (day) } & \multicolumn{4}{|c||}{ Bacterial population } \\
& Top & Bottom & Effuent & Influent \\
& & & & \\
\hline \hline & & & & \\
Reactor & & & & \\
0 & & & & \\
1 & 0.1 & 0.05 & $<0.01$ & 0.1 \\
2 & 0.16 & 0.10 & $<0.01$ & 0.38 \\
5 & 0.22 & 0.125 & 0.10 & 0.42 \\
7 & 0.28 & 0.15 & 0.10 & 0.56 \\
& & & & \\
Reactor 2 & & & & \\
& & & & \\
0 & 0.72 & 0.73 & - & 0.1 \\
1 & 4.63 & 3.42 & 0.1 & 0.2 \\
2 & 10.51 & 6.81 & 0.15 & 0.38 \\
5 & 13.24 & 7.92 & 0.169 & 0.42 \\
7 & 17.42 & 10.69 & 0.180 & 0.56 \\
Reactor 3 & & & & \\
\hline 0 & 0.71 & 0.72 & - & 0.1 \\
1 & 5.14 & 3.46 & 0.15 & 0.2 \\
2 & 9.61 & 7.21 & 0.12 & 0.38 \\
5 & 15.49 & 10.24 & 0.36 & 0.42 \\
7 & 21.64 & 14.84 & 0.31 & 0.56 \\
& & & & \\
\hline \hline
\end{tabular}

$\dagger$ At time 0 , the bacterial colonies at various ports are $\times 10^{4} / \mathrm{g}$ of dry peat At time 1 to 7 days, the bacterial colonies at various ports are $\times 10^{4} / \mathrm{g}$ of wet oil-saturated peat.

The bacterial colonies in the influent and effluent samples are $\times 10^{4} / \mathrm{mL}$ of oil-in-water cmulsion. 

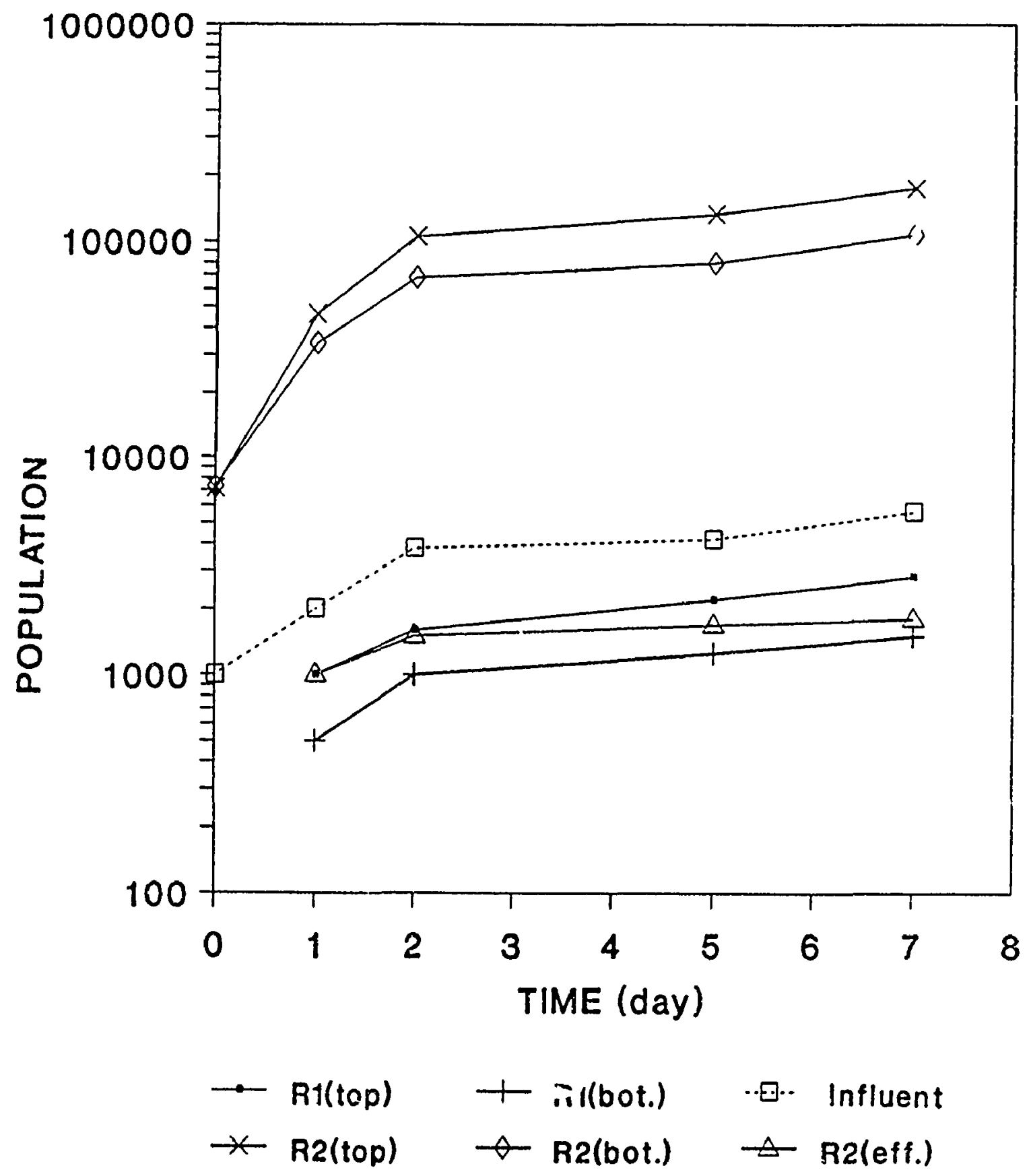

R1 - Reactor with sterilized horticultural peat R2 - Reactor with horticultural peat

Figure 4.58. Time vs log bacterial population for reactor $\mathrm{R} 1$ and $\mathrm{R} 2$ 

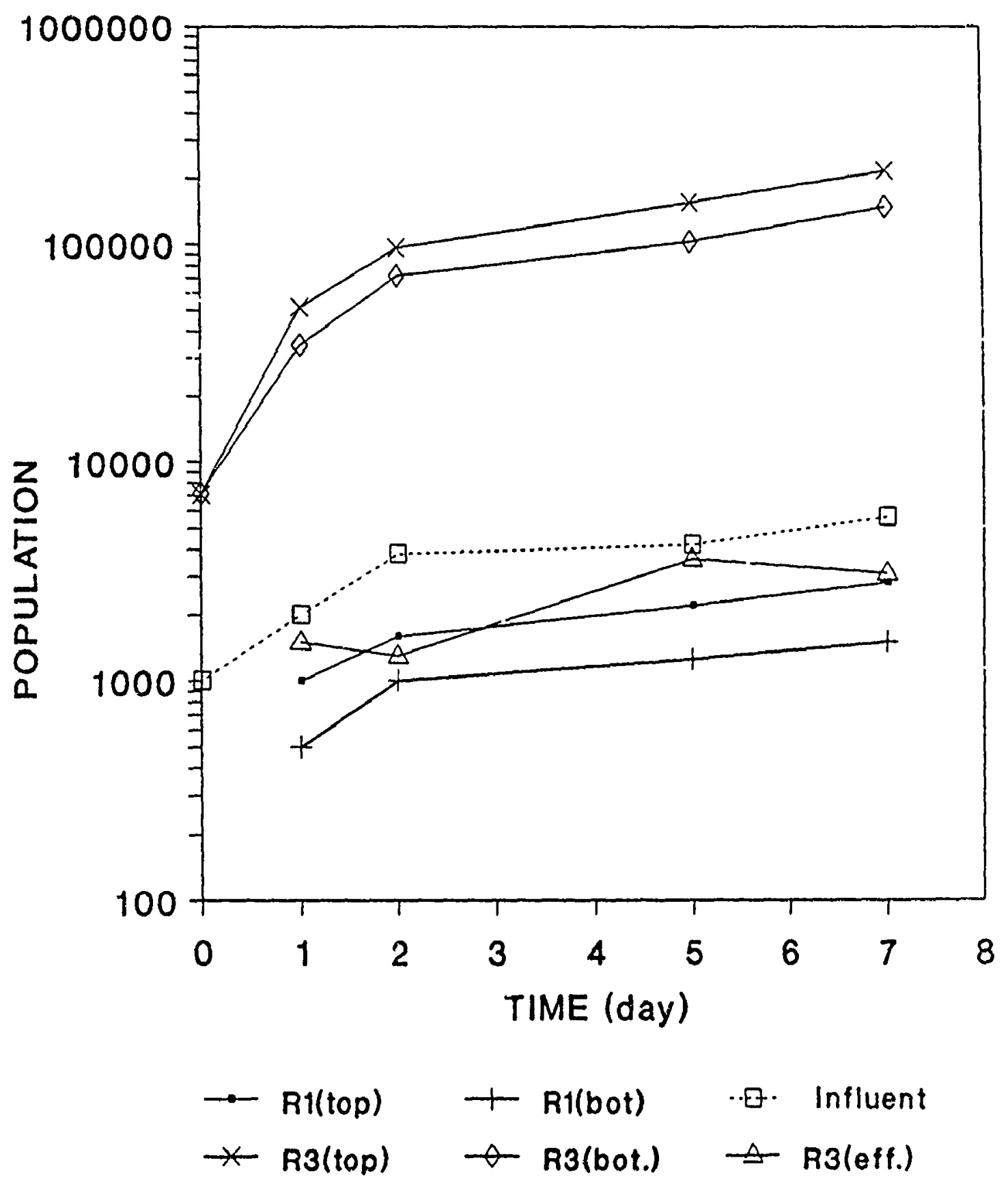

R1 - Reactor with sterilized horticultural peat

R3 - Reactor with horticultural peat

Figure 4.59. Time vs log bacterial population for reactor $\mathrm{Rl}$ and $\mathrm{R} 3$ 


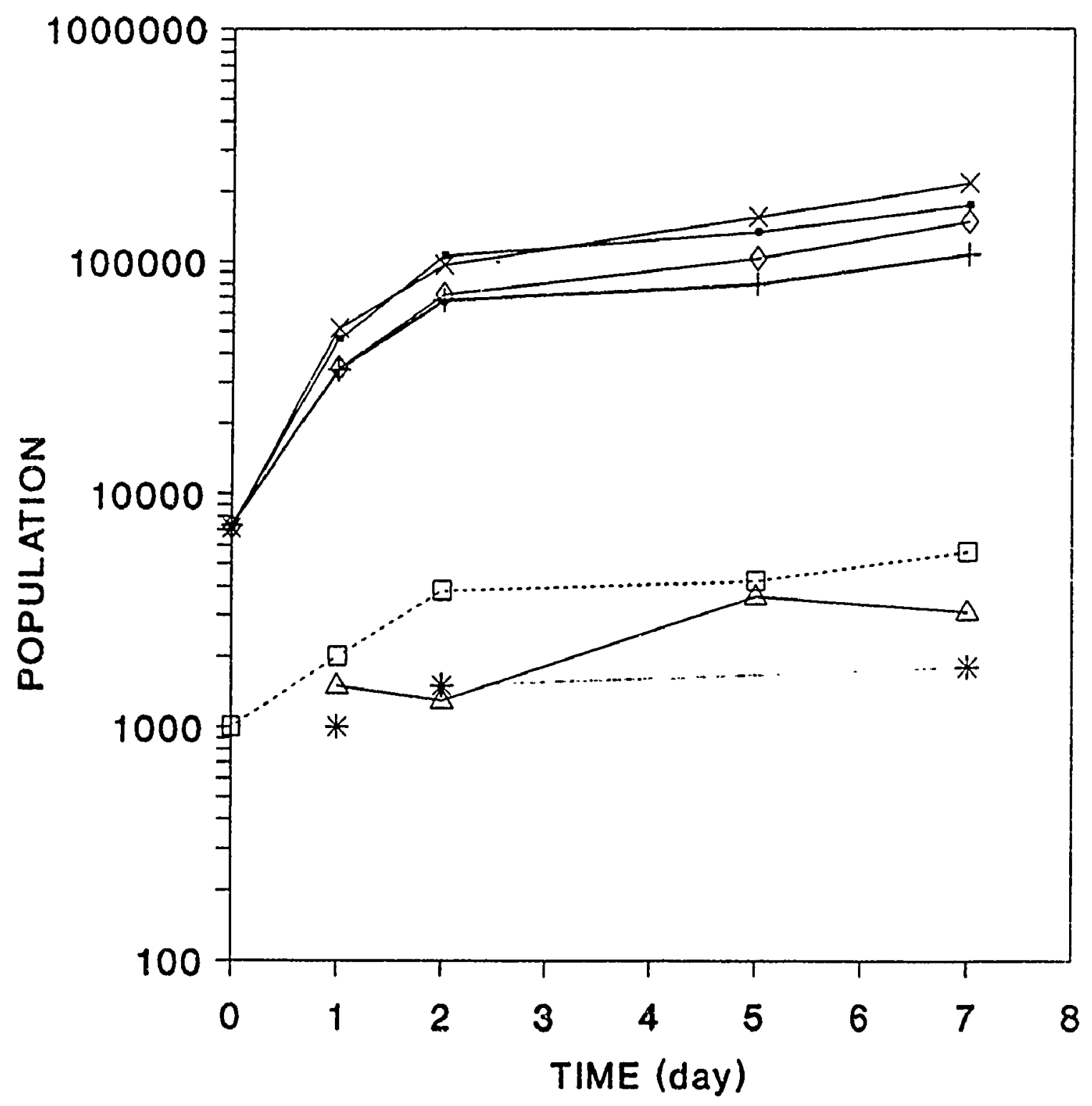

$\rightarrow \mathrm{R} 2$ (top) $+\mathrm{R} 2$ (bot) $* \mathrm{R} 2($ eff.) $\cdot \boxminus \cdot$ Influent $\rightarrow R 3(t o p) \rightarrow R 3($ bot.) $\rightarrow$ R3(eff.)

R3 - Reactor with horticultural peat and nutrients R2 - Reactor with horticultural peat

Figure 4.60. Time vs log bacterial population for reactor $\mathrm{R} 2$ and $\mathrm{R} 3$ 
efficiency (89.2) achieved in the sterilized peat possibly indicates that physical forces (like filtration, coalescence and adsorption) could be responsible for oil removal in a peat bed. The bacterial counts observed in these experiments were insignificant for considering the degradation of oil by bacteria. However, an attempt was made to estimate the amount of oil degraded by the maximum bacterial population $\left(2.1 \times 10^{5}\right.$ g) that was present in the peat bed. By assuming a mean reaction rate coefficient $\left(k_{e}\right)$ of $10 \times 10^{-4} \mathrm{~L} / \mathrm{mg}$-hr for a refinery waste (Grady and Lim 1980); and the dry weight of a bacterium (E-coli) as $2.8 \times 10^{-13} \mathrm{~g}$ (Brock and Madigan 19S8), the percent of oil degraded worked out to be less than 1 ( 0.2 percent, vide APPENDIX. E). Therefore, it is reasonable to conclude that within the seven-day time period, the breakdown of oil by bacteria in $300 \mathrm{~mm}$ peat bed was insignificant. This preliminary investigation lasted only seven days. Long-term studies would be necessary to provide a reliable determination of potential biological activity in the peat bed and its role in oil removal.

\subsection{General Discussion}

In the batch adsorption experiments, the adsorption of oil followed the BET isotherm for SMO, MCO, $\mathrm{CO}$ and $\mathrm{RE}$, and the Langmuir and the Freundlich equations for PW emulsions. For the pretreated peat samples, no general pattern in the adsorption process was observed. However, the adsorption of oil by pretreated peat followed one of the three well-known isotherms namely; the Langmuir, the Freundlich or the BET. The properties of peat, oil and oil-in-water emulsions are so heterogeneous in nature that it is difficult to explain the shift in these adsorption isotherms for different peat samples. These three isotherm equations have been applied only on 
an empirical manner to fit the adsorption data. The adsorption of oil is a complex process and very sensitive to process variables. The forces acting at the molecular level such as chemical bonding, ionic effects, polarization, and other energy interactions need to be considered in detail to understand the process of adsorption. It has already been pointed out that it is not always easy to distinguis' ${ }^{2}$, between physical and chemical adsorption (Weber 1972 and Ruthven 1984). I vertheless, from the results of the adsorption equations, it was possible to compare the oil-adsorption capacities for different peat samples. The properties of peat (surface area, CEC, polarity etc.), oil (viscosity, polarity) and oil-in-water emulsions (interfacial tension, zeta potential) need to be investigated further for understanding the adsorption process, as peat, oil and oil-in-water emulsions show wide variabilities in physical and chemical characteristics.

The effectiveress of peat in removing oil from oil-in-water emulsions has been documented in the literature. However, published information on the explanation for the breakdown of oil involved in the peat beds is scarce. An attempt was made in this study to identify the basic breakdown mechanisms such as filtration, coalescence, adsorption and bacterial activity using established models from the literature. The well-known Carman-Kozeny equation over predicted the head-loss at $200 \mathrm{~mm}$ depth and under predicted the head-loss at $1000 \mathrm{~mm}$ depth of peat bed. This might be due to saturation of the peat bed by the oil droplets at initial reaches. This possibly indicates that as the influent oil concentration increases, the Carman-Kozeny equation may not yield accurate results in predicting the head-loss across the bed.

A maximum coalescence efficiency of 14 percent was achieved at the initial depth of the peat bed $(200 \mathrm{~mm})$ and reduced to 3 percent at $1000 \mathrm{~mm}$ depth. Coalescence 
efficiency was limited by the ratio of oil diameter to the fiber diameter of the peat. Coalescence was not effective in the peat bed, when the oil drop diameter was less than $10 \mu \mathrm{m}$. The induced coalescence increased the oil drop diameter and aided in the filtration/adsorption process.

Though bacterial degradation of oil was not included within the scope of the present investigation, the negligible counts of bacterial colonies obtained over a sevenday period showed the role of bacteria in removing oil in a peat bed may not be signific ant. Long-term studies are needed to assess fully the potential biological activity in the peat bed and its contribution to oil removal. Therefore, it appears that all the mechanisms namely; filtration, coalescence, adsorption and bacterial action have an individual and/or collective role in the breakdown/removal of oil in the peat bed.

A comprehensive approach that collectively represents the physical, chemical and biological mechanisms involved in the breakdown of oil by peat needs to be considered for developing a mathematical model. Such a bio-physicochemical adsorption model for wastewater treatment was developed by Ying and Weber (1979) for glucose-activated carbon systems. This model combined the adsorption parameters (Freundlich constants, $\frac{x}{m}$ and the mass transfer coefficients) and biological parameters such as Monod kinetic constants. A more complete model was later suggested by Andrews and Tien (1981) for dissolved organics and activated carbon systems.

A bioadsorptive adsorber model for industrial wastewater treatment was presented by Kim and Pirbazari (1989) for dairy waste, land-fill leachate and activated carbon system. In this model, the adsorption was predicted using HSDM, and the biological action by fixed film kinetics. Recently, Speitel and Zhu (1990) have presented the summary of sensitivity analyses performed on bio-adsorption models. Their analyses 
showed that the three important parameters in the model were: (i) the Monod halfsaturation coefficient, (ii) the surface diffusion coefficient of activated carbon and (iii) the amount of initial biomass. It has also been pointed out by the authors that more research is needed for accurate predictions of the concentration profiles using these models. Further, with peat and oil-in-water emulsion systems it is essential to include coalescence and filtration processes also. The predictions of concentration profiles as well as head-loss across peat beds are essential for the design and operation of a full-scale operation unit. Therefore, a comprehensive model interacting the combined action of these principal mechanisms would lead to a better understanding of the breakdown of oil by peat and would aid in process control.

All experimental data are included in APPENDIX. F. 


\section{SUMMARY AND CONCLUSION}

\subsection{Summary}

The use of horticultural peat produced in Saskatchewan in treating five representative oil-in-water emulsions was demonstrated by a series of batch and continuous column studies. Generally, the adsorption of oil onto peat was well described by the $\mathrm{BET}$ isotherm for SMO, MCO, CO and RE. In the case of PW, the adsorption was well represented by the Langmuir and Freundlich isotherm.

Among the several pretreatment alternatives investigated for enhancing the oiladsorption capacity of the horticultural peat, wet-heated-oven-dried and wet-pyrolyzed (P150) peat showed higher oil-adsorption capacities. The oil-adsorption capacities, calculated based on adsorption isotherms, indicated that wet-heated-oven-dried and acid-treated peat have higher capacities than the untreated horticultural peat in adsorbing SMO from oil-in-water emulsions. The desorption experiments conducted showed that very little oil $(<3 \mathrm{mg} / \mathrm{L})$ was desorbed within 2 to 3 hours of equilibrium time, indicating that oil was well adsorbed onto peat.

The eight-hour column tests showed oil removal efficiencies to range from 34 to 99 percent depending upon the flow rate and the type of oil-in-water emulsions. Generally, the oil removal efficiencies decreased with an increase in flow. These decreases were not appreciable for SMO and MCO emulsions, whereas for CO, RE, and PW the decreases were appreciable. It was observed that SMO and MCO which represent unstable oil-in-water emulsions can be very effectively treated in a peat column (upto 
96 percent removal of oil), whereas RE and $\mathrm{PW}$ which represent highly stable oil-inwater emulsions were difficult to treat (oil removal efficiencies of 68 to 80 percent). For $\mathrm{CO}$ the oil removal efficiencies decreased considerably with flow rate (96 to 34 percent) indicating the limitations of peat in treatment of such a chemically stabilized emulsion.

Column studies conducted for comparing the performances of horticultural peat, two pretreated samples (wet-heated-oven-dried and wet-pyrolyzed P150), with six other media (sand, coal, fiberglass, polypropylene, XAL-2 and activated carbon) using SMO and $\mathrm{CO}$ emulsions showed that the performance of peat in removing oil (98 percent) from SMO-in-water emulsions was comparable to those of XAD-2 and activated carbon (99 percent). But in the case of $\mathrm{CO}$, the performance of peat was appreciably less when compared with XAD-2 and activated carbon.

Continuous column breakthrough experiments conducted to evaluate the exhaustion capacity of the $300 \mathrm{~mm}$ peat bed showed the oil-adsorption capacities to be 0.9 , $1.1,0.103,0.017$ and $0.131 \mathrm{~g}$ of oil per $\mathrm{g}$ of dry peat for SMO, MCO, CO, RE and PW emulsions, respectively. The analysis of column breakthrough data using Thomas' kinetic model resulted in similar values of $\frac{x}{m}$ values. (Table 4.30). The time dependent uptake of different oils by horticultural peat was described by a simple adsorption equation (2.17).

Backwashing the used peat bed with hot water $\left(55^{\circ} \mathrm{C}\right)$ was investigated for the reuse of used peat. It was found that replacing the used peat bed with a fresh one would be a better alternative than to regenerate the used pet. The oil-sorbed peat had higher calorific values indicating the possibility of using it as fuel material. It is possible to recover waste oil from oil-sorbed peat by the application of pressure 
due to the spongy nature of peat. The rate of release of $\mathrm{CO}$ from peat was fornd to be the highest (70percent) compared with 28 and 10 percent obtained for SMO and MCO samples respectively. This also confirms that peat has a better affinity for SMO/MCO than for CO.

While investigating the breakdown mechanisms involved in the peat bed in treating chemically stabilized SMO-in-water emulsions, a sequential action of filtration and coalescence mechanisms was observed. The efficiency of coalescence was approximately 14 percent at the initial depth $(200 \mathrm{~mm})$ and dropped to 3 percent at greater depth $(1000 \mathrm{~mm})$. The head loss across the peat filter can be predicted using the wellknown Carman-Kozeny filtration equation. The Carman-Kozeny constant $\left(k_{1}\right)$, the specific permeability $\left(B_{0}\right)$, tortuosity factor $(T)$, shape factor $(\phi)$, and specific surface $\left(\mathrm{S}_{0}\right)$ for the peat bed were determined.

The extent of bacterial action in the peat bed and its influence on the removal of oil from SMO-in -water emulsions were examined.

\subsection{Conclusions}

The following conclusions can be drawn from the study:

1. The equilibrium adsorption time for peat was found to be two hours for SMO, $\mathrm{MCO}, \mathrm{CO}$ and PW emulsions and three liours for RE.

2. Amongst the three well-known adsorption isotherms considered for the analyses, the BET isotherm described the adsorption of SMO, MCO, CO and RE onto peat. The adsorption of $\mathrm{PW}$ onto peat was described by the Langmuir and Freundlich isotherms. The applicability of these isotherms were considered only on an empirical basis. 
3. The oil-binding capacities of Saskatchewan horticultural peat were found to be 7.85 and $7.53(\mathrm{~kg} / \mathrm{kg}$ of dry peat) for SMO and MCO respectively.

4. Pyrolysis, acid-treatment and wet heating-oven drying of horticultural peat were found to be effective pretreatment options for enhancing the oil-adsorption capacity of the horticultural peat. NO correlations could be established among the surface area, oil-binding capacity, oil-adsorption capacity and CEC.

5. The desorption of SMO and $\mathrm{CO}$ from differc it peat samples was found to be negligible $(<4 \mathrm{mg} / \mathrm{L})$ within two hours of contact time.

6. Generally, the oil removal efficiencies in a $300 \mathrm{~mm}$ peat bed decreased with an increase in flow rates. For mechanically prepared emulsions such as SMO and MCO (which are less stable), the oil removal efficiency exceeded 96 percent. For a chemically stabilized emulsion like $\mathrm{CO}$ (which is highly stable), the percentage oil removal ranged from 34 to 96 depending upon the flow rate. The RE emulsion (which is stable) was effectively treated at an oil removal rate of 68 to 92 percent depending upon the flow rate. For PW, which is produced in the field as brine solutions (highly stable), peat removed 70 to 80 percent of the oil depending upon the flow rate. The efficiency was independent of the initial oil concentration in the case of PW.

7. The analyses of the continuous breakthrough column experiments data showed the following: 


\begin{tabular}{lccc}
\hline Type & $\begin{array}{c}\text { Breakthrough } \\
\text { oil concentration } \\
(\mathrm{mg} / \mathrm{L})\end{array}$ & $\begin{array}{c}\text { Breakthrough } \\
\text { time } \\
(\text { day })\end{array}$ & $\begin{array}{c}\text { Oil removed } \\
\text { at breakthrough } \\
(\%)\end{array}$ \\
\hline SMO & 15 & 9.41 & 93 \\
MCO & 15 & 8.92 & 92 \\
CO & 100 & 0.9 & 64 \\
RE & 2 & 7.8 & 78 \\
PW & 15 & 8.9 & 60 \\
\hline
\end{tabular}

8. The Thomas kinetic equation constants $\left(k\right.$ and $\left.q_{0}\right)$ were evaluated from the breakthrough studies. The $q_{0}$ values compared reasonably well with the values found by a mass balance approach.

9. The disposal of oil-sorbed peat can be carried out in several ways. Due to the increased calorific values of oil-sorbed peat (23 to 55 percent increase depending upon the type of oil), its use as a secondary fuel for heating appears to be an option (Table 4.33). The spongy nature of peat can be advantageously used to squeeze oil for recovering waste oil for use (about 28 to 70 percent is released depending upon the type of oil). It is environmentally more acceptable to dispose of oil-sorbed peat in a landfill or use it for land application, when most of the oil from such a peat has been removed.

10. The head-loss and the average oil saturation values were predicted using the well-known Carman Kozeny equation. The Carman-Kozeny constant was fcund to be 3.39 for the horticultural peat. The efficiency of coalescence in peat bed was found to decrease with an increase in flow rate. A maximum coalescencin efficiency of 14 percent was achieved at $200 \mathrm{~mm}$ peat depth. The coalescence 
efficiency decreased to 3 percent at $1003 \mathrm{~mm}$ depth and was found to be more or less independent of flow rate at this depth. Further, there was also a decrease in oil droplet diameter and oil concentration with depth. This was attributed to the sequential action of oil filtration and coalescence involved in the peat bed. Coalescence and/or filtration of highly stable oil-in-water emulsions (characterized by oil droplets of say less than $10 \mu \mathrm{m}$ ) may not be effective in a peat bed.

11. The bacterial growth at the top of the peat bed increased from $0.71 \times 10^{4}$ to $2.1 \times 10^{5}$ colonies per $\mathrm{g}$ of $\mathrm{dry}$ and wet-oil-saturated peat respectively, over a seven-day period. Long-term studies would be necessary to assess the potential biological activity in the peat bed and its role in oil removal.

\subsection{Practical Application of the Research}

In view of the increased environmental concerns, industrial effluent discharge regulations for the discharge of oil-contairing wastewaters are becoming more stringent req̨uiring higher oil removal. In addition, industries arc hard-pressed to reclaim the once-through process water for reuse within the plant which requires almost 100 percent oil removal.

Among the existing treatment options fos treating oily wastewaters, only ultra filtration and carbon adsorption have been shown to achieve very low effluent oil concentrations in the range of $0-10 \mathrm{mg} / \mathrm{L}$ (vide Table 1.5). This polishing or tertiary treatment is limited only to soluble and emulsified oils due to very high cosi associated with it (pretreatment requirements, cost of membrane, regeneration cost etc.) as the influent oil concentration needs to be less than $5 \mathrm{mg} / \mathrm{L}$ (Figure 1.1). 
An inexpensive medium like peat was found io have a good potential for treating certain oil-in-water emulsions. Studies also showed that the sorption potential of peat can be enhanced by acid or heat treatment.

The results of the present study demonstrated that peat by the combined action of filtration, coalescence and sorption can remove up to 99 percent of the oil from typical oil-in-water emulsions. Low effluent oil concentrations ranging from 1 to $10 \mathrm{mg} / \mathrm{L}$ having oil drop diameters of less than $10 \mu \mathrm{m}$ have been achieved in these investigations. Peat can either be used as a contact vessel (in fill and draw type) or in a column (continuous flow) as a medium for treating oil-in-water emulsions. The batch adsorption sysien.s mostly operate on a fill-and-draw basis and are limited to small wastewater volumes. Only one reaction vessel may be required if all the wastewater is generated over an 8 to 12 hours period. Once the reaction vessel is filled with oily waters, peat can be added and the mixture can be agitated for a set time to enable the system to approach equilibrium. The vessel can then be drained and prepared to receive another load of vastes. If wastewater is to be fed continuously, then two tanks may be used and alternated in the fill-and-draw modes. It is already noted that the BET isotherm described the adsorption process better for $\mathrm{SMO}, \mathrm{MCO}, \mathrm{CO}$ and RE, and the Langmuir or Freundlich isotherms for PW emulsions. By applying the respective adsorption equations and the constants involved in the equation (Table 2.20 ), it is possible to calculate the amount of peat required to reduce the oil in the oily water to a desired concentration. The details of such a design are presented in Appendix $\mathrm{C}$ and summarized in Table 5.1.

These calculations are based on oil removal efficiencies of 86 to 87 percent for a daily oily water flow of $150 \mathrm{~m}^{3} / \mathrm{d}(39,700 \mathrm{gpd})$. The design is practical except in the 
Table 5.1. Peat required to treat $150 \mathrm{~m}^{3} / \mathrm{d}(39700 \mathrm{gpd})$ in batch adsorption system

\begin{tabular}{||l|c|c|c|c|c||}
\hline \hline \multicolumn{1}{|c|}{ Description } & SMO & MCO & CO & RE & PW \\
\hline \hline $\begin{array}{l}\text { Influent oil } \\
\text { concentration (mg/L) }\end{array}$ & 115 & 115 & 250 & 15 & 50 \\
$\begin{array}{l}\text { Effluent oil } \\
\text { concentration (mg/L) }\end{array}$ & 15 & 15 & 100 & 2.1 & 7 \\
Oil removal efficiency (\%) & 87 & 87 & 60 & 86 & 86 \\
$\frac{x}{m}$ (kg oil/kg of peat) & 0.0551 & 0.023 & 0.2336 & 0.00025 & 0.0109 \\
$\begin{array}{l}\text { Peat required } \\
\text { per day (kg) }\end{array}$ & 273 & 652 & 56 & 7442 & 592 \\
\hline \hline
\end{tabular}


case of $\mathrm{RE}$ where peat requirements are excessive. The effluent oil levels achieved (15 $\mathrm{mg} / \mathrm{L}$ ) are generally acceptable for discharge to receiving waters or sanitary sewer systems. The used peat can be drained, dried and used as a fuel as it has higher calorific values or disposed of in a landfill. The design capacity of the reaction vessel will reflect the minimum reaction time (equilibrium time) required and the volume of wastewatc: to be treated. The applicability of these adsorption isotherms were considered only on an empirical basis to model the adsorption of oil by peat. For medium or big industries, peat filters can be designed for use on a continuous basis. Two columns may be required. Once the first column is exhausted at the predesigncd effluent level, the second column may be operated while the first column is drained and refilled with peat for the next operation. The design of such a continuous peat column can be carried out using the kinetic rate constants derived in this study. Fur this design, certain effluent oil levels have to be assumed. In the case of SMO, MCO and $\mathrm{PW}$, since the oil removal efficiencies were excellent, a breakthrough concentration of $15 \mathrm{mg} / \mathrm{L}$ of oil was applied in the design as per the Environment Canada (1976) discharge regulation. In the case of $\mathrm{CO}$, (which was found difficult to treat because of high stability of the emulsion) the $15 \mathrm{mg} / \mathrm{L}$ criterion cannot be met. However, for the purpose of comparison an effluent oil level of $100 \mathrm{mg} / \mathrm{L} \mathrm{n}$ assumed. Similarly, in the case of RE (having an influent oil concentration around $10 \mathrm{mg} / \mathrm{L}$ ) an effluent oil concentration of $2 \mathrm{mg} / \mathrm{L}$ was used in the design. In addition to the Thomas kinetic equation, a design based on a scale-up approach was also attempted for comparison.

A model design calculation for treating $150 \mathrm{~m}^{3} / \mathrm{d}(39,700 \mathrm{gpd})$ of wastewater using both approaches is presented in Appendix D. The design information olstained is consolidated in Table 5.2 . 
Table 5.2. Results of the scale-up and kinetic design of a continuous column adsorber for treating $150 \mathrm{~m}^{3}$ (35700 gpd) of wastewater flow

\begin{tabular}{|c|c|c|c|c|c|}
\hline Description & SMO & $\mathrm{MCO}$ & $\mathrm{CO}$ & $\mathrm{RE}$ & PW \\
\hline Unit flow rate $(L / h)$ & 3 & 3 & 1.5 & 1.5 & 3 \\
\hline $\begin{array}{l}\text { Influent oil } \\
\text { concentration }(\mathrm{mg} / \mathrm{L})\end{array}$ & 217.9 & 210.0 & 278. 2 & 8.91 & 38.4 \\
\hline $\begin{array}{l}\text { Breakthrough oil } \\
\text { concentration }(\mathrm{mg} / \mathrm{L})\end{array}$ & 15 & 15 & 100 & 2.0 & 15 \\
\hline $\begin{array}{l}\text { Experimental } \\
\text { breakthrough volume (L) } \\
\text { Scale-up model }\end{array}$ & 678 & 642 & 32 & 284 & 644 \\
\hline Mass of peat required $(\mathrm{kg})$ & 369 & 369 & 736 & 736 & 369 \\
\hline $\begin{array}{l}\text { Volume treated } / \mathrm{kg} \text { of } \\
\text { peat }(\mathrm{kg} / \mathrm{L})\end{array}$ & 3874 & 3667 & 182 & 1624 & 3682 \\
\hline $\begin{array}{l}\text { Design breakthrough } \\
\text { time (day) }\end{array}$ & 9.5 & 9.0 & 0.9 & 8.0 & 9.06 \\
\hline $\begin{array}{l}\text { Design breakthrough } \\
\text { volume }\left(\mathrm{m}^{3}\right) \\
\text { Kinetic medel }\end{array}$ & 1430 & 1353 & 134 & 1194 & 1359 \\
\hline Mass of peat required $(\mathrm{kg})$ & 358 & 410 & 617 & 812 & 288 \\
\hline
\end{tabular}


In both approaches the calculated mass of peat required did not vary appreciably. The results showed that the design

\subsection{Recommendations for Further Study}

The following recommendations are made for further study:

1. The properties of peat such as surface area, CEC, polarity, particle size etc., need to be correlated with emulsion properties such as zeta potential, interfacial tension, polarity, etc. for a better understanding of the sorption of oil.

2. A standard test procedure needs to be established for measuring the surface area of peat having a complex pore geometry.

3. The removal of other pollutants such as COD, heavy metals, odor producing compounds (which are typically found in many oily discharges) by peat can be studied as peat is capable of removing many of them.

4. The efficiency of oil removal by peat also needs to be investigated for food processing wastes (consisting essentially of polar oils), as the five oily wastes considered in the study were of petroleum (non-polar) origin.

5. A comprenensive mathematical model describing the combined action of filtration, coalescence, sorption and bacterial action needs to be developed.

6. The possibility of developing a complete biological peat-reactor for degrading oil needs to be explored. Further adding acclimatized microbial degraders to the peat bed may be investigated to increase the biological degraciation rates in peat bed. 
7. A dual media filter with gypsum and peat can be investigated as the use of gypsum in breaking down complex emulsions has been the subject of research in the recent past.

8. The disposal options available for oil-sorbed peat (land-filling and land cultivation) need to be investigated further to understand the long-term environmental effects due to desorption and migration of sorbed oil. 


\section{REFERENCES}

Abouguendia, Z. M., Godwin, R. C., Baschak, L. A., (1987). An evaluation of the effects of land application of oil and gas drilling wastes on soils and crops in the Kindersly and Estevan regions of Saskatchewan, - A summary Report, Saskatchewan Research Council Technical Report No. 218, Saskatchewan, Canada.

Adams, C. E. and Eckenfelder, W. W. Jr. (1974). Process design techniques for industrial waste treatment, Enviro Press, Nashville, Tennessee, U. S. A.

Adamson, A. W. (1977). Physical chemistry of suifaces, John Wiley and Sons, New York, U.S. A.

Akers, R. J. and Ward, A. S. (1977). "Liquid filtration theory and filtration pretreat. ment." In: Filtration Principles and Practices, Part I, C. Orr, editor, Marcel Dekker, Inc., New York, U. S. A. 169 - $2 u ̛$.

Alden, L. and Forsberg, S. (1987). "Waterbinding and dewatering of peat." Procecdings of the Symposium'87 Wetlands/Peatlands, Edmonton, Alberta, Canada. 39 - 41.

Allen, S. J. (1987). "Equilibrium adsorption isotherm for peat." Fuel, 66, 1171 - 1175.

Alvarado, D. A. and Marsden, S. S. (1979). "Flow of oil-in-water emulsions through tubes and porous media." Society of Petroleum Engineering Journal, 19, 369 - 377.

American Petroleum Institute (1958). Manual on disposal of refinary waters, IV , 733, New York, U. S. A.

Amerisan Petroleum Institute (1969). Manual on disposal of refinary wastcs, V, New York, U. S. A.

American Public Health Association (1985). Standard methods for the examination 
of water and wastewater, 16th Edition, American Public Health Association, New York, U. S. A.

American Society for Testing and Materials (1958). Standard test method for dry preparation of soil samples for particle - size analysis and determination ASTM D421 - 58, Philedelphia, U. S. A.

American Society for Testing and Materials (1960). Standard test method for oil absorption of pigments by Gardner Coleman method, ASTM D 1483-60, Philadelphia, U.S. A.

American Society ior Testing and Materials (1963). Standard test method for particlesize analysis of soils, ASTM D422-63, Philadelphia, U. S. A.

American Society for Testing and Materials (1969). Standard Classification of peats, mosses, humus and related products, ASTM D2607-69, Philadelphia, U. S. A.

American Society for Testing and Materials (1971a). Standard test method for moisture, asn and organic matier of peat materials, ASTM L2974-71, Philadelphia, U. S. A.

American Society for Testing and Materials (1971b). Standard test method for sand content of peat materials, ASTM D2975-71, Philadelphia, U. S. A.

American Society for Testing and Materials (1971c). Standard test method for $\mathrm{pH}$ of peat materials, ASTM D2976-71, Philadelphia, U. S. A.

American Society for Testing and Materials (1971d). Standard test method for particlesize range of peat materials, ASTM D2977-71, Philadelphia, U. S. A.

American Society for Testing and Materials (1984). Staniard practice for calculating the avirage circular-capillary-equivalent pore diameter in filter media from measurements of porosity and permeability, ASTM F 902-84, Philadelphia, U. S. A.

Andrews, G. F. and Tien, C. (1981). "Bacterial film growth in adsorbent surface." 
American Industrial Chemical Engineering Journal, 27(3), 396-403.

Asplund,D., Ekman,E. and Thun,R. (1978). "Counter-current peat filtration of wastewater." Proceedings of the 5th International Peat Congress, International Peat Society, Poznam, Poland, 358 - 371.

Association of Environmental Engineering Professors (AEEP) (1988). Environmental engineering unit operations and unit processes laboratory manual, M.T. Suidan, editor, Department of Civil Engineering, University of Illinois at Urbana-Champaign, U.S. A.

Atlas, R. M. (1981). "Microbial degradation of petroleum hydrocarbons: An environmental perspective." Microbial Review, 45, 180-209.

Atlas, R. M. (1988). "Biodegradation of hydrocarbons in the environment."In: Environme ntul Biotechnology: Reducing risks from environmental chemicals through biotcchnology G.

S. Omenn, Editor, Plenum Press, New York, U.S.A.

Baker, J. H. and Griffiths, R. P. (1984). "Effects of oil on bacterial activity in marine and freshwater sediments." Proceedings of the 3rd International Symposium on Microbial Ecology, Michigan State University, 546 - 551.

Bartha, R. and Atlas, R. M. (1977). "The microbiology of aquatic oil spills." Advanccs in Applied Microbiology, 22, 225 - 266.

Bear, J., Zaslaraky, D. and Irmay, S. (1968). Physical principles of water percolation and seepage, UNESCO, Paris.

Bear, J. (1972). Dynamics of Fluids in Porous Media, American Elsevier Publishing Company, Inc., New York, U. S. A.

Becher, P. (1977). Emulsions theory and practice, R. E. Krieger Publishing Company, New York, U. S. A.

Beckman Instruments, Inc., (1968), Note 68-2, U. S. A. 
Belanger, A., Potvin, D., Cloutier, R., Caron, M. and Theriault, G. (1988). Peat: A resource of the future, Centre De Recherche Premier, Quebec, Canada.

Bell, J. P., Tsezos, M. (1988). "The selectivity of bioadsorption of hazardous organics by microbial biomass." Water Research, 22(10), $1245-1251$.

Benefield, L. D., Judkins, J. F. Jr. and Weand, B. L. (1982). Process chemistry for water and wastewater treatment, Printice-Hiall, Inc., Englewood Cliffs, New Jersey, U.S. A.

Biederbeck, V. O. and Jacques, R. M. S. (1988). Using oilywaste disposal fer erosion proffing of sandy cultiveted soils, Agricultural Canada, Soils and Environment Section, Energy Research and Development Project No.24106, Swift Current, Saskatchewan, Canada.

Biederbeck, V. O. (1989). "Putting wastes to use for soil conservation and entanced agricultural production." Extended summury of paper presented at the National BIOQUAL'89 meeting on applications of environmental biotechnologs to major industrial sectors, Alberta Research Council, Edmonton, Canada.

Bird, P. M. and Rapport, D. J. (1986). State of the environmental report for Canada. Environment Canada, Minister of Supply and Services, Cat.No EN 21-54/1986E, Ottawa, Canada.

Blokker, P. C. (1971). "Prevention of water polution from refineries." W'ater pollution by oil, P. Hepple, editor, The Institute of Petroleum, London, 21 - 45.

Bohart, G. S. and Adams, E. Q. (1920). "Some aspects of the behavior of charcoal with respect to chlorine." Journal of the American Chemical Society, 42, 523 - 544.

Brock, T.D. and Madigan, M. T. (1988). Biology of microorganisms, Prentice Hall, New Jersey, U. S. A.

Brooks, J. L. (1989). "Microbial activity in the peat wastewater treatment system." Paper Presented at the Peat and Peatlands Symposium, Quebec, Canada. 
Brown, J. L. and Farnham, R. S. (1980). "Effect of temperature and water content on the rewetting potential of peat." Proceedings of the 6th International Peat Congress, International Peat Society, Minnesota, U. S. A., 520 - 522.

Brunauer, S. (1943). The adsorption of gases and vapors, I physical adsorption, Princeton University Press, London.

Carlberg. S, R. (1980). "Oil pollution of the marine environment." Chemistry and biochemistry of estuaries, E. Olausson and I. Calo, editors, John Wiley, Chichester, U. K., 367 - 402.

Carman, P. C. (1956). Flow of gases through porous media, A.cademic Press, Inc., New York, U. S. A.

Cavagnaro, P. V. and Kaszubowski, K. E., (1988). "Pretreatment limits for fats, oils and grease." Proceedings of the 43rd Annual Purdue Industrial Wasle Confcrcnce, Lewis Publishers, Michigan, U. S. A.

Chieu, J. N., Schechter, R. S., Humenick, M. J. and Gloyna, E. F. (1975). Coalscence of emulsified wastes by fibrous bed, Technical Raport EHE-75-05, CRWR-126, Department of Civil Engineering, University of Texas at Austin, U.S.A.

Christensen, P. J. and Cook, F. D. (1970). "The microbiology of Alberta Muskeg." Canadian Journal of Soil Science, 50, 171 - 178.

Clark, R. C. and Brown, D. W. (1977). "Petroleum: Properties and analyses in biotic and abiotic systems." Effects of petroleum on arctic and subarctic marine environments and organisms,, D. C. Malins, editor, Academic Press, Inc., New York.

Clark, R. M. and Lykins, B. W. Jr.(1989). Granular activated carbon, Lewis Publishers, Michigan, U. S. A. $235-255$.

Cohen, A. D. (1987). Proposed ASTM standard: Standard test method for the laboratory determination of the fiber content of peat samples by dry weight, AST'M sub. committee D18.18 
Collins, J. (1982). A peat research directory for Cancda. Division of Energy Research and Development, National Research Council of Canada, Ottawa.

Cooney, J. J. and Summers, R. J. (1976). "Hydrocarbon-using microorganisms in three freshwater ecosystems." Proceedings of the Third International Biodegradation Symposium,, J. M. Sharply and A. M. Kaplan, editors, Applied Science Publishers Ltd, London, 141 - 155.

Coupal, B. and Lalancette, J. M. (1976). "The treatment of wastewaters with peat moss." Water Research, 10(12), 1071 - 1077.

Crittenden, J. C. and Weber, W. J. Jr. (1978a). "Predictive model for design of fixed bed adsorbers: parameter estimation and inodel development." Journal of the Environmental Engineering Division, ASCE, 104(EE2), 185 - 197.

Crittenden, J. C. and Weber, W. J. Jr. (1978b). "Model for design of multicomponent adsorption systems." Journal of the Environmental Engineering Division, ASCE, 104(EE6), $1175-1195$.

Crittenden, J. C. Hand, D. W., Arora, H. and Lykins, B. J. (1987). "Design considerations for GAC Treatment of Organic Chemicals." Journal American Water Works Association, 79, $74-82$.

Day, J. H., Rennie, P. J., Stanek, W. and Raymond, G. P. (1979). Peat Testing Manual, Naiional Research Council of Canada (NRCC), Associate Committee on Geotechnical Research, Technical Memorandum No125, Ottawa, Ontario, Canada.

Department of Energy, Mines and Resources (1985). Technical and economic as. sessment of the application of membrane technology for treating oil/water/mineral emulsions, Final Report(I), Literature Review, Report by Zenon Environmental Inc., Canada.

De Young, H. G. (1988). "EPA and industry push for new superfund solutions." Chemical Week, 142(8), 28 - 32.

D'Hlennezel, F. and Coupal, B. (1972). "Peat moss: A natural adsorbent for oil 
spills." The Canadian Mining and Metallurgical Bulletin, 65, 51 - 53 .

Eckenfelder, W. W. Jr. (1981). Application of adsorption to wastewater treatment, Enviro Press, Inc., Nashville, U. S. A.

Ekman, E. and Asplund, D. (1975). Peat in wastewater treatment, Report No5, Technical Research Centre of Finland, Fuel and Lubricant Research Laboratory, Otaniemi, Finland.

Environment Canada (1976a). A study of the solubility of oil in water, Report EPS4-EC-76-1, Ottawa, Ontario, Canada.

Environment Canada (1976b). Guideleines for effluent quality and wastewater irealment at federal eastablishments, Report EPS-1-EC. 76-1, Ottawa, Ontario, Canada.

Environment Canada (1982). Oil and dispersants in Canadian seas-research apprisal and recommendations. Report EPS-3-EC-82-2, Ottawa, Ontario, Canada.

Environment Canada (1983). Selection Criteria and laboratory evaluation of oil spills sorbents: Update II, Report EPS-4-EP-83-4, Ottawa, Canada.

Environment Canada (1987). Environmental status report for the Canadian petroleum refining industry 1983 - 84, Report EPS-1/PN/1, Ottawa, Ontario, Canada.

Farnham, R. S. and Finney, H. R. (1965). "Classification and properties of organic soils." Advance Acron 7, 115 - 162.

Foght, J. M. and Westlake, D. W. S. (1987). "Biodegradation of hydrocarbons in freshwater." oil in fresh water: Chemistry, biology, counter measure technology, J. II. Vandermeulen and S. E. Hrudey, editors, Pergamon Press, New York, U. S. A., 217 .230 .

Fornwalt, J. J. and Hutchins, R. A. (1966). "Purifying liquids with activated carbon." Chemical Engineering, 73, 155 - 161. 
Forster, R. L. Mayer, J. E. and Firstman, S. I. (1973). Port collection and separation facilities for oily wastes, Final Report to U. S. Department of Commerce Maritime Administration, Washington, D. C., U. S. A.

Fuchsman, C. H. (1980). Peat industrial chemistry and technology, Academic Press, New York, U.S.A.

Fuchsman, C. H. (1987). "Needs and opportunities for new insights into the reltionship of peat to water." Proceedings of Symposium'87 Wetlnds/Peatlands, Edmonton, Alberta, Canada. 3 - 6.

Given, P. H. and Dickenson, C. H. (1975). "Biochemistry and microbiology of peats." Soil Biochemistry, E. A. Paul and A. D. McLaren, editors, Marcel Dokker, New York, $123-212$.

Gloyna, E. F. and Pereda, P. M. (1971). "Separation of oil from wastewater with crushed graphite ore," Proceedings of the 26th Purdue Industrial Waste Confercnce, Lewis Publishers, Michigan, U. S. A., 308 - 317.

Gopal, E. S. R. (1968). "Principles of emulsion formation." Emulsion science, P. Sherman, editor, Academic Press, Inc., London, 1 - 75.

Grady, C. P. L. Jr. and Lim, H. C. (1980). Biological wastewater treatment, Marcel Dekker, Inc., Nwe York, U. S. A.

Gray, A. C. Jr. (1975). "Fight flotables with chemicals." Water and Waste Engineering, 12, (1), 33.

Griffiths, R. P., Caldwell, B. A., Broich, W. A. and Mortia, R. Y. (1981). "Longterm effects of crude oil on uptake and respiration of glucose and glutamate in arctic and subarctic marine sediments." Applied Environmental Microbiology, 42, 792 - 801.

Griffiths, R. P., Caldwell, B. A., Broich, W. A. and Mortia, R. Y. (1982). "The long-term effects of crude oil on microbial processes in subrctic marine sediments." Estuarian Coastal Shelf Science, 15, 183 - 198. 
Gruenfeld, M. (1973). "Extractions of dispersed oils from water for quantitative analysis by infrared spectrophotometry." Environmental Scien.ce and Technology, 7, $636-639$.

Gunkel, W. and Grossman, G. (1980). "Oil, oil-dispersants and related substances in the marine environment." Helgolander Meeresunters, 33, 164 - 181. (cited in Foght and Westlake 1981).

Haight, M. (1987). "Drilling wastes: Hazardous or harmless." Alaska Construction and Oil, 28(12), $10-13$.

Hall, K. R., Eagleton, L. C., Acrivos, A. and Vermeulen, T. (1966). "Pore-and solid-diffusion kinetics in fixed-bed adsorption under constant-pattern conditions." Industrial and Engineering Chemistry Fundamentals, 5(2), $212-223$.

Hambrick III, G. H., DeLaune, R. D. and Patrick, W. H. Jr. (1980). "Effect of estuarine sediment $\mathrm{pH}$ and oxidation-reduction potential on microbial hydrocarbon degradation." Applied and Environmental Microbiology, 40(2), 365 - 369.

Hammer, D. E. and Kadlec, R. H. (1980). "Ortho-phosphate adsorption of peat." Proceedings of 6th International Peat Congress, International Peat Society, Minnesota, U. S. A., 563 - 569 .

Hand, D. W., Crittenden, J. C. and Thacker, W. E. (1983). "User-oriented batch reactor solutions to the homogeneous surface diffusion model." Journal of the Environmental Engineering, 109(1), 82 - 101.

Hand,D.W., Crittenden, J. C. and Thacker, W. E. (1984). "Simplified models for design of fixed-bed adsorption systems." Journal of Environmental the Engineering, $110(2), 440-456$.

Ilanninen, P. (1987). "Comparison between the von Post degree of humification and fiber content method and physical and chemical properties of different grain sizes of peat." Proceedings Symposium '87 Wetlands/Peatlands, C. D. A. Rubec and R. P. Overend, editors, Edmonton, Alberta, Canada, 71 - 75. 
Hazlett, R. N. (1969). "Fibrous bed coalescence of water." Industrial and Engineering Chemistry Fundamentals, 8(4), 625 - 632.

Heidenreich, E., Kicher, F. A. and Davies, G. A. (1982). "Separtion of oil-water mixtures in particulate beds." Harnessing theory for practical application, World Filtration Congress III, $688-695$.

Hertzberg, R. (1986). "New directions in solid waste and recycling." Biocycle, 27(1), $22-28$.

Heukelekian, H., and Balmat, J. L. (1959). "Chemical composition of the particulate fractions of domestic sewage." Sewage and Industrial Waste, 31, (4), $413-423$.

Holmes, P. D. (1980). "Practical experiences of the handling and disposal of waterin-oil emulsions." Disposal of oil and debris resulting from a spill cleanup operation, J. S. Farlow and C. Swanson, editors, ASTM special publication 703, Philadelphia, U. S. A., $98-108$.

Horiba Ltd., (1.983). Bulletin HRE-1849 C, Kyoto, Japan.

Hrudey, S. E., Kok, S. (1987). "Environmentally relevant characteristics of oil-inwater emulsions." Oil in fresh water: Chemistry, biology, counter measure technology, J. H. Vandermeulen and S. E. Hrudey, editors, Pergamon Press, New York, U. S. A., $58-70$.

Hutchins, R. A. (1973). "New method simplifies design of activated carbon systems." Chemical Engineering, 80(8), 133 - 138.

Ivarson, K. C. (1977). "Changes in decomposition rate, microbial population and carbohydrate content of an acid peat bog after liming and reclamation." Canadian Journal of Soil Science, 57, 129 - 137.

Jeffreys, G. V. and Davies, G. A. (1971). "Coalscence of liquid droplets and liquid dispersion." Recent advances in liquid-liquid extractions, C. Hanson, editor, Pergamon Press, New York, U. S. A., 495 - 584. 
Johnson, L. C. (1987). "Macrostructure of Sphagnum peat as an indication of bog processes." Proceedings Symposium' 87 Wetlands/Peatlands, Edmonton, Alberta, Canada, $61-69$.

Johnston, P.R. (1983). "The most probable pore-size distribution in fluid filter media." Journal of Testing and Evaluation, 11(2), 117-125.

Jordon, G. V. Jr., (1955). "Separation of immiscible liquids by means of porous membranes," Transactions American Society of Mechanical Engineering, (4), 393 400 .

Kim, S. H. and Pirbazari, M. (1989). "Bioactive adsorber model for industrial wastewater treatment." Journal of Environmental Engineering , 115(6), 1235 - 1256.

Keinath, T. M. and Weber, W. J. Jr.(1968). "A predictive model for the design of fluid-bed adsorbers." Journal Water Pollution Control Federation, 40(5), 741 - 765.

Kirchman, D. and Mitchell,R. (1982). "Contribution of particle - bound bacteria to total microheterotrophic activity in five ponds and two marshes." Applied Environmental Microbiology, 43, 200 - 209.

Kong, K. Lindsay, J. D. and McGill, W. B. (1980). "Characterization of stored peat in the Alberta oil sands area." Prepared for the Oil Sands Environmental Research Program by Research Council of Alberta, Soils Division and Department of Soil Science, University of Alberta, AOSEP Report 91, Alberta, Canada.

Knowlton, H. E. and Ricker, J. E. (1980). "Refinery oily waste treatment and disposal techniques and their potential application to oil spill debris." Disposal of oil and debris resulting from a spill cleanup operation, J. S. Farlow and C. Swanson, editors, ASTM special publication 703, Philadelphia, U. S. A. 107 - 117.

Korpijaakko, M. and Radforth, N. W. (1974). "Studies on the hydraulic conductivity of peat." Proceedings of the 4th International Peat Congress, International Peat Society, Helsinki, Finland, 323 - 334.

Kuster, E. (1963). "Influence of peat and peat substances on the metabolism of 
fungi." Pure and Applied Chemistry, 7, 611-617.

La Poe, R. G. (1985). Sorption and desorption of volatile chlorinated aliphatic compounds by soils and soil components, Ph.D dissertation, Cornell University, U. S. A.

Leahy, J. G. and Colwell, R. R. (1990). "Microbial degradation of hydrocarbons in the environment." Microbiological Reviews, 54(03), $305-315$.

Lishtvan, I .I., Davidovsky, P. N., Korchunov, S. S., Lytch, A. M. and Terentyev, A. A. (1980). "Physical bases of regulating peat properties to control the quality of peat products." proceedings of the 6th Peat International Congress, International Peat Society, Minnesota, U .S. A., 591 - 596.

Lissant, K. J. (1977). Emulsions and emulsion technology, Part I, Marcel Dekker, Inc., New York, U. S. A.

Loxham, M. (1980). "Theoretical considerations of transport of pollutants in peat." Proceedings of the 6th International Peat Congress, International Peat Socicty, Minnesota, U.S. A., $600-606$.

Liu, K. T., Weber, W. J. ' $\therefore$ (1981). "Characterization of masstransfer parameters for adsorber modeling and design." Journal Water Pollution Control Federation, 53(10), $1541 \cdot 1550$.

Malterer, T. J., Cohen, A. D. and Verry, E. S. (1987). "Comparison of fiber content determintaion by NRCC and proposed ASTM methods." Proceedings, Symposium '87 Wetlunds/Peatlands, C. D. Rubec and R. P. Overend, editors, Edmonton, Alberta, Canada, 7 - 15.

Manning, F. S. and Snider, E. H. (1983). Assessment data base for peiroleum refining wastewater and residues. U.S. Department of Commerce, Washington, U.S. A.

Martin, N. J., Siwasin, J. and Holding, A. J. (1982). "Bacterial population of blanket peat." Journal of Applied Bacterialogy, 53, 35 - 48. 
McLellan, J. K. and Rock, C. A. (1986). "The application of peat in environmental pollution control: A review." International Peat Journal, 1, 1 - 14.

Mensinger, M. C. (1980). "Wet-carbonization of peat: State-of-the-art review." Proceedings of the Symposium on Peat as an Energy Allternative Arlington, Virginia, 249 -280 .

Metcalf and Eddy Inc., (1979). Wastewater enginer,ing treatment, and, disposal, reuse, McGrow Hill Book Company, New York, U. S. A.

Mueller, J. C. (1972). "Peat in pollution abatement." Proceedings of the Symposium on Peat, Sherbrooke, Quebec, Canada, 1-16.

Murkes, J. and Stockholm, S. (1986). "Cross-flow filtration of emulsions combined with coalscing. A new filter-coalscer concept." Proceedings of the 4th World Filtration Congress, Ostend, Belgium, Volume 2, 35 - 41.

Nicholson, J. P. (1984). Peat policies and activities in Canada, II, CNRC Publication, No.24354, Canada.

Ocean Affairs Board (1975).Petroleum in the marine environment, Natural Research Council, National Academy of Sciences, Washington, D. C. , U. S. A., 104- 107.

Oil and Gas Journal, (1990). 89(17).

Olschewsky, D. and Megna, A. (1988). "Hazardous waste regulations summarized for refineries." Oil and Gas Journal, 86(1), 39 - 44.

Owens, W. W. and Archer, D. L. (1971). "The effect of rock wettability on oil-inwater relative permeability relationships." Journal of Petroleum Technology, 23, 873 $-878$.

Paine, P. J. and Blakeman, W. B. (1987). "Environmental summary: Harvesting and use of peat as an energy source." Proceedings of the symponiun' 87 wetlands/ peatlands, Edmonton, Alberta, Canada, 177-187. 
Patterson, J. W. (1975). Wastewater treatment technology, Ann Arbor Science Publishers,Inc., U. S. A., 175 - 189.

Patterson, J. W. (1985). Industrial wastewater treatment technology, Butterworth Publishers, U. S. A., 273 - 302.

Percy, J.A. (1982). Benthic and intertidal organisms oil and dispersants in Canadian seas, Environment Canada Report EPS3-EC-82-2, Ottawa, Canada.

Pereda, P. M. and Gloyna, E. F. (1974). Removal of emusified oils in graphite ore medium, Technical Report EHE-74-05, CRWR-118, Center for Research in Water Resources, University of Texas at Austin, U. S. A.

Polson, A. (1950). "Some aspects of diffusion in solution and a definition of a colloidal particle." Journal of Physical Chemistry, 54(5), 649 - 652.

Poots, V. J. P. McKay, G. and Healy, J. J. (1976). "Basic dye adsorption on peat." Scientific Proceedings, Royal Dublin Society" series A, 6(6), 61 - 76.

Poots, V. J. P. and McKay, G. (1979). "Flow characteristics and parameters relating to the use of peat and wood as cheap adsorbent materials for wastewater purification." Scientific Proceedings, Royal Dublin Society, Series A, 6, 409 - 440.

Pushkarev, V. V. Yuzhaninov, A. G. and Men, S. K. (1983). Treatment of oilcontaining wastewater, Allerton Press, Inc., Nwe York, U. S. A.

Reynolds, T. D. (1982). Unit operations and processes in environmental enginecring, Wadsworth Inc., Belmont, California, U. S. A.

Rhee, C. H., Martyn, P. C. and Kremer, J. G. (1987). "Removal of oil and grease in the hydrocarbon processing industry." Proceedings of the 42 2nd Purdue Industrial Waste Conference, Lewis Publishers, Michigan, U. S. A., 143 - 150.

Richardson, J. G. (1961). "Flow through porous media." Handbook of fluid dynamics, V. L. Streeter, editor, McGraw Hill, New York, U. S. A. 
Riely, J. L. (1986). Laboratory methods for testing peat - Ontario peatland inventory project, Open File Report 5572, Ottawa, Ontaio, Canada.

Rosenfeld, J. I. and Wasan, D. T. (1974). "Coalescence of drops in a liquid- liquid dispersion by passage through a fibrous bed." The Canadian Journal of Chemical Engincering, 52(2), 3 - 10.

Roth, J. A. and Kodavasal, A. S. (1981). "Mass transfer characteristics of activated carbon adsorption." Proceedings of the International Conference on Application of Adsorption to Wastewater Treatment, W.W. Eckenfelder, Jr., editor, Enviro Press, Inc., Nashville, Tennessee, U. S. A., 67 - 94.

Rotman, D. (1988). "Superfund cleanup: the burning question." Industrial Chemist, $9(1), 22-27$.

Rushton, A. and Griffiths, P. V. R. (1977). "Filter media." Filtration principles and practices, Part I, C. Orr, editor, Marcel Dekker, Inc., New York, U. S. A., 251 - 308.

Ruthven, D. M. (1984). Principles of adsorption and adsorption processes, John Wiley and Sons, New York, U. S. A.

Saatci, A. M. (1979). Application of adsorption methods to filtration, $\mathrm{Ph} . \mathrm{D}$ dissertation, lowa State University, lowa, U. S. A.

Saatci, A. M. and Oulman, C.S. (1980). "The bed depth service time design meihod for deep bed filtration." Journal American Water Works Association, (9), 524 - 528.

Sakthivadivel, R., Thanikachalam, V. and Seetharaman, S. (1972). "Head-loss theories in filtration." Journal American Water works Association, 64, 233 - 238.

Sapek, B. and Sapek, A. (1987). "Changes in the properties of humus substances and the sorption complex in reclaimed peat soils." Internationl Peat Journal, 2, $99-117$. 
Sapek, B. Sapek, A. and Stawinnski, J. (1988). "The effect of moorish forming process on the specific surface area and sorption properties of peat-moorish soils." Proceedings of the VIII International Peat Society, Leningrad, U. S. S. R., 288 - 294.

Sareen, S. S., Rose, P. M., Gudesen, R. C. and Kintner, R. C. (1966). "Coalescence in Fibrous beds." American Institute of Chemical Engineers Journal, 12(6), 1045 1050 .

Saskatchewan Energy and Mines (1986). Approval guidelines for the on-lease and off-lease land application of freshwater drilling systems fluids, Information guidelines, GL-86-01, Saskatchewan, Canada.

Saskatchewan Mineral Resources (1981). Buffalo Narrows peat utilization study, Saskmont Engineering, Regina, Saskatchewan, Canada.

Scheidegger, A. E. (1974). The physics of flow through porous media, University of Toronto Press, Toronto, Canada.

Sharp, J. J. (1982). "Treatment of fuel peat to enhance moisture removal." Fuel, 61, $741-744$.

Sherony, D. F. and Kintner, R. C. (1971a). " Coalescence of an emulsion in a fibrous bed: Part I, Theory." The Canadian Journal of Chemical Engineering, 49(6), 314 320.

Sherony, D. F. and Kintner, R. C. (1971b). "Coalescence of an emulsion in a fibrous bed: Part II, Experiment." The Canadian Journal of Chemical Enginecring, 49(6), $321-325$.

Sherony, D. F. Kintner, R. C. and Wasan, D. T. (1978). "Coalescence of secondary emulsions in fibrous bed." In: Surface and Colloid Science, vol. 10, E. Matijevic, editor, Plenum Press, New York, U. S. A.

Simard, R. G., Hasegawa, I., Bandaruk, W. and Hedington, C. E. (1951). "Infrared spectrophotometric determination of oil and phenols in water." Analytical Chemistry, $23,1384-1387$. 
Smith, E. F. (1976a). "The development of chemically modified forms of peat as a cation exchanger and oil coalescer." Ph.D dissertation, University of Cincinati, U. S. A.

Smith, J. W. (1976b). "Oil spills from tankers." Marine ecology and oil Pollution, J. M. Baker, editor, Applied Science Publishers Ltd., England, 473 - 481.

Smith, J. W. (1983). The Control of Oil Pollution, Graham and Trotman Ltd., London.

Smith, E. F., MacCarthy, P. and Mark, H. B. Jr. (1976). "The characterization of phosphoric acid-treated peat as a cation exchanger." Journal of Environmental Science and Health, A1l (2), 179 - 189.

Smith, E. F. and Mark, H. B. Jr. (1976). "The use of modified forms of peat as an oil coalescer." Journal of Environmental Science and Health, A11 (12), 727 - 734.

Smith, E. F., MacCarthy, P., Yu, T. C. and Mark, H. B. Jr. (1977). "Sulfuric acid treatment of peat for cation exchange." Joumal Water Pollution Control Federation, $49(4), 633-638$.

Smith, E. F., Mark, H. B. Jr., and MacCarthy, P. (1980). "Investigation of chemically modified forms of peat as inexpensive means of wastewater treatment." Chemistry of Wastewaler Technology, A. J. Rubin, editor, Ann Arbor Science, Michigan, U. S. A., $349 \cdot 373$.

Soo, H., and Radke, C. J.(1986). "A filtration model for the flow of dilute stable emulsions in porous media - I Theory." Chemical Engineering Science, 41 (2), 263 272.

Soo, H., Williams, M. C. and Radke, C. J.(1986). " A filtration model for the flow of dilute stable emulsions in porous media - II Parameter evaluation and estimation." Chemical Engineering Science, 41 (2), 273 - 281.

Spedding, P. J. (1988). "Peat." Fuel, 67(7), $881 \cdot 899$. 
Speitel, G. E. Jr. and Zhu, X. J. (1990). "Sensitivity analyses of biodegradation/adsorption models." Journal of Environmental Engineering, 116(1), $32-48$.

Spielman, L. A. and Goren, S. L. (1970). "Capture of small particles by London forces from low-speed liquid flows." Environmental Science and Technology , 4(2), 135 -

Spielman, L. A. and Goren, S. L. (1972). "Experiments in coalescence by flow through fibrous mats." Industrial and Engineering Chemistry Fundamenials, 11 (1), 73 - 83.

Sprackers, S. (1985). "Waste recyclers now subject to broader regulation." Nalional Law, 7(47), 18 - 21.

Stanek, W. and Silc, T. (1977). "Comparison of four methods for detcrmination of peat humification (decomposition) with emphasis on the von Post method." Canadian Journal of Soil Science, 48, 323 - 330.

Stanek, W. and Worley, I. A. (1983). "A terminology of vergin p'sat and peatlands." Proceedings of the International Symposium on Peat Utilization, C. II. Fuchsman, ed. itor, Bemidji State University, Center for Environmental Studies, Minnesota, U.S.a., $75-102$.

Stenstrom, K. M., Fam, S. and Silverman, G. S. (1986). "Analytical methods for quantitative and qualitative determination of hydrocarbons and oil and grease in water and wastewater." Environmental Technology Letters, 7, 625 - 636.

Sun, P. T., Price, C. L., Raia, J. C. and Balders, R. A. (1987). "Anomalies in oil and grease analyses of petroleum wastewaters and their implications." Proceedings of the 42nd Annual Purdue Industrial Waste Conference, Lewis Publishers, Michigan, U. S. A., $151-162$.

Tabakin, R. B., Trattner, R. and Cheremisinoff, P. N. (1978a). "Oil/water separations: The options available, Part I." Water and Sewage Works, 125(7), 74.77. 
Tabakin, R. B., Trattner, R. and Cheremisinoff, P. N. (1978b). "Oil/water separations: The options available, Part II." Water and Sewage Works, 125(8), $72-75$.

Tabor, J. J. (1969). "Dynamics of static forces required lo remove a discontinuous oil phase from porous media containg both oil and water." Society of Petroleum Enginecring Journal, 9, 3 - 12.

Tadros, T. F. and Vincent, B. (1983). "Emulsion Stability." Encylopedia of Emulsion Technology, Vol.I, P. Becher, editor, Marcel Dekker Inc., New York, U. S. A., 129 285.

Thomas, H. G. (1948). "Chromatography: A problem in kinetics." Annals New York Academy of Sciences, 49, $161-182$.

'Thun, R. Asplund, D. and Ekman, E. (1983a). The Production of Peat Berthinate and its use for Water Purification. Technical Research Centre of Finland, Fuel and Lubricant Research Laboratory, Otaniemi, Finland, $71-80$.

Thun, R. Fagernas, L. and Brandt, J. (1983b). "Use of thermally treated peat for water purification." Proceedings of the International Symposium on Peat Utilization, C. II. Fuchsman and S. A. Spigarelli, editors, Bemidji State University, Minnesota, U.S. A., $365 \cdot 379$.

Thun, R. and Leena, F. (1982). "Use of surface peat for water purification." Technical Research Centre of England, Fuel and Lubricant Research Laboratory, Finland, 32 34.

Tibbetts, T. E. (1976). Evaluation of peat samples as part of a peat fuel inventory in the province of New Founldland, Canmet Report 76-42, Canada Centre for Mineral and Energy Technology, Ottawa, Canada.

Tinh, V. Q., Leblanc, R., Jannassens, J. M. and Ruel, M. (1971). "Peat moss: A natural adsorbing agent for the treatment of polluted water." Canadian Mining and Melallurgical Bulletin, 64, 99 - 104. 
Transport Canada (1980). Oil Pollution. Minister of Supply and Services, Catalogue No. T 22-49/1980E, Ottawa, Canada.

Treybal, R. E. (1963). Liquid extraction, McGrow-Hill, New-York, U. S. A., 447 450 .

Trunick, P. A. (1987). "Landfilling industrial wastes is not the simple solution it used to be." Recycling Today, 25(4), 60 - 65 .

United States Environmental Protection Agency. (1972). Oily waste disposal by soil cultivation process, Report EPA - R2 - 72 - 110, Washington, D. C., U. S. A.

United States Environmental Protection Agency (1974a). Developmenl document for effluent limitations and guidelines and new source performance standard for the petroleum refining point source category, USEFA Report 440 / 1 - 74-014, Cincinati, Ohio, U. S. A.

United States Environmental Protection Agency (1974b). Waste oil recycling and disposal, Report EPA - 670/2 - 74 -052, Cincinati, Ohio, U. S. A., 328 -

United States Environmental Protection Agency (1977a). Oil spill: decision for debris disposal, volume I, procedure manual, Report EPA-600/2-77-153a, Cincinati, Ohio, U. S. A.

United States Environmental Protection Agency (1977b). Oil spill: decision for debris disposal, volume III, literature review and case study reports, Report EPA. 600/2-77. 153b, Cincinati, Ohio, U. S. A.

United States Environmental Protection Agency (1978). Oil/water separation statcof-the-art, Report EPA-600/2-78-069, Cincinati, Ohio, U. S. A.

United States Environmental Protection Agency (1980). Oil spill debris; Where to put the waste, Report EPA-600/7-80-016, Cincinati, Ohio, U.S. A.

United States Environmental Protection Agency (1982). Development document for 
effluent limitations and guidelines and new source performance standard and pretreatment siandards for the petroleum refining point source category, USEPA - 440 / 1 82 - 04, Washington, D.C. U. S. A.

Universal Oil Products Company (1972). UOP method 720 -772. (Unpubli,hed) U. S. A.

Vinson, C. G. (1965). The Coalscence of micro-size drops in liquid-liquid dispersions in flow past fine mesh screen, Ph. D. Dissertation, University of Michigan, U .S. A.

Vinson, C. G. and Churchill (1970). "Removal of drops from liqiud-liquid dispersions upon flow through screens." The Chemical Engineering Journal, 1, 110 - 119.

Viraraghavan, T. and Ayyaswami, A. (1987). "Use of peat in water pollution control: A Riview." Canadian Journal of Civil Engineering, 14, $230-233$.

Wahbeh, N. (1980). "Disposal of oily waste from oil spills by land forming." Disposal of oil and debris resulting from a spill cleanup operation, J. S. Farlow and C. Swanson, editors, ASTM special publication 703, Philadelphia, U. S. A. 29 - 35.

Waksman, S. A. and Purvis,E. R. (1932). "Microbiological population of peat." Soil Science, 34, 95 - 109.

Wallace, J. T. Jr. and Brown, J. S. (1972). "Deep bed filtration of oil field produced water." Proceedings of the 27th Purdue Industrial waste Conference, Lewis Publishers, Michigan, U. S. A., 151 - 158.

Water Pollution Control Federation (1981). Pretreatment of industrial wastes, Manual of Practice No. FD-3, Lancaster press, Inc., U. S. A., 63 - 72.

Weber, W. J. Jr. (1972) Physicochemical proceses for water quality control,John Wiley \& Sons, New York, U. S. A., 199 - 259.

Weber, T. W. and Chakravorti, R. K. (1974). "Pore and colid diffusion models for fixed-bed adsorbers." American Industrial and Chemical Engineering Journal, 20 (2), 
$228-238$.

Weber, J. W. Jr., and Morris, J. C. (1963). "Kinetics of adsorption on carbon from solution." Journal of the Sanitary Engineering Division, ASCE, 89(2), 31 - 59.

Wheatley, R. E., Greaves, M. P.,and Inkson,R. H. E. (1976). "The aerobic bacterial flora of a raised bog." Soil Biology and Biochemistry, 8, 453 - 460.

Wiggins, E. J., Campbell, W. B. and Maass, O. (1939). "Determination of the specific surface of fibrous materials." Canadian Journal of Research, 17 B, $318-324$.

Williams, R. T. and Crawford, R. L. (1983). "Effects of various physical -chemical factors on microbial activity in peatlands." Aerobic biodegradative processes." Canadian Journal of Microbiology, 29, 1430 - 1437.

Williamson, J. E., Bazaire, K. E. and Geankoplis, C. J. (1963). "Liquid-phase mass transfer at low Reynolds numbers." Industrial and Engineering Chemistry Fundamentals. $126-129$.

Witherspoon, P. D. and Swiss, J. J. (1986). "The use of oil-spill incinerators for the disposal of oil based drilling muds." Proceedings of the 9th Arctic Marine Oil Spill Technical Seminar, Environment Canada, Edmonton, Alberta, Canada.

Wyllie, M. R. J. and Gregory, A. R. (1955). "Fluid flow through unconsolidated porous aggregates." Industrial and Engineering , 47, 1379 - 1388.

Yates, P. B. (1987). "The Good oil on the reuse of waste lubricating oil." Proceedings of the 2nd National Hazardous Waste Management Conference, Australian Water and Wastewater Association, Sydney, Australia.

Ying, W. C. and Weber, W. J. Jr. (1979). "Bio-physicochemical adsorption model systems for wastewater treatment." Journal Water Pollution Control Federation, $51(1), 2661-2677$.

Young, J. C.(1979). "Removal of grease and oil by biological treatment processes." 
Journal Water Pollution Control Federation, 51 (8), 2071 - 2087.

Young, D. M. and Crowell, A. D. (1962). Physical adsorption of gases, Butterworth Publishers Limited, London.

Yves, A. (1982). Treatments of oil - containing wastewater, Chulalongkorn University, Department of Sanitary Engineering, Insa Toulouse, France.

Zytner, R., Biswas, N. and Bewtra, J. K. (1989). "Adsorption and desorption of perchloroethylene in soils, peat moss and granular activated carbon." Canadian Journal of Civil Engineering, 16(6), 798 - 806. 


\section{APPENDIX. A}

\section{CONCENTRATIONS OF OILY MATERIALS IN INDUSTRIAL WASTEWATERS}

Table A.1. Concentrations of oily materials in various industrial wastewaters (Patterson 1985)

\begin{tabular}{||l|c||}
\hline \hline Industrial source & $\begin{array}{c}\text { Oil concentration } \\
(\mathrm{mg} / \mathrm{L})\end{array}$ \\
\hline \hline 1. Petroleum refinery & 20 \\
API effluent & $10-500$ \\
& $10-146$ \\
& $16-3200$ \\
2. Steel rolling mills & $200-1800$ \\
3. Steel mill & $80-7200$ \\
Cold rolling & 700 \\
Cold rolling coolant & $2088-46742$ \\
(Total oil) & \\
4. Continuous iron-casting & $20-22$ \\
plants & $5000-50000$ \\
5. Aluminum rolling & \\
6. Can production & 200000 \\
Forming operations & 819 \\
Washing operations & 3830 \\
7. Food processing & 287 \\
8. Fish processing & $30-546$ \\
9. Sea food processing & \\
\hline \hline
\end{tabular}

Contd... 
Table A1 Contd....

\begin{tabular}{|c|c|}
\hline Industrial source & $\begin{array}{l}\text { Oil concentration } \\
(\mathrm{mg} / \mathrm{L})\end{array}$ \\
\hline 10. Rendering plants & $14-3551$ \\
\hline 11. Edible oil refining & $4000-6000$ \\
\hline Raw wastewater & 4260 \\
\hline $\begin{array}{l}\text { Aerated lagoon } \\
\text { effluent }\end{array}$ & 101 \\
\hline 12. Metal finishing & \\
\hline (soluble oil) & $100-5000$ \\
\hline $\begin{array}{l}\text { 13. Electrolytic } \\
\text { copper industry }\end{array}$ & $0-436$ \\
\hline 14. Secondary copper & \\
\hline industry & $1.8-9.5$ \\
\hline 15. Automotive plating & $33-1123$ \\
\hline $\begin{array}{l}\text { 16. Oil field brine } \\
\text { Produced waters }\end{array}$ & $25-50$ \\
\hline after gravity separation & $50-400$ \\
\hline $\begin{array}{l}\text { 17. Oil drilling and } \\
\text { production waste }\end{array}$ & $7-1300$ \\
\hline tanker ballast & $32-1050$ \\
\hline 19. Crude oil tank ballast & $3-72$ \\
\hline 20. Road tanker washing & $32-91$ \\
\hline 21. Paint manufacture & $9-1900$ \\
\hline 22. Air craft maintenance & $500-1200$ \\
\hline $\begin{array}{l}\text { 23. Transport vehicle } \\
\text { maintenance }\end{array}$ & 490 \\
\hline
\end{tabular}




\section{APPENDIX. B}

\section{PHOTOGRAPHS OF PEAT SAMPLES AND OIL-IN-WATER EMULSIONS}

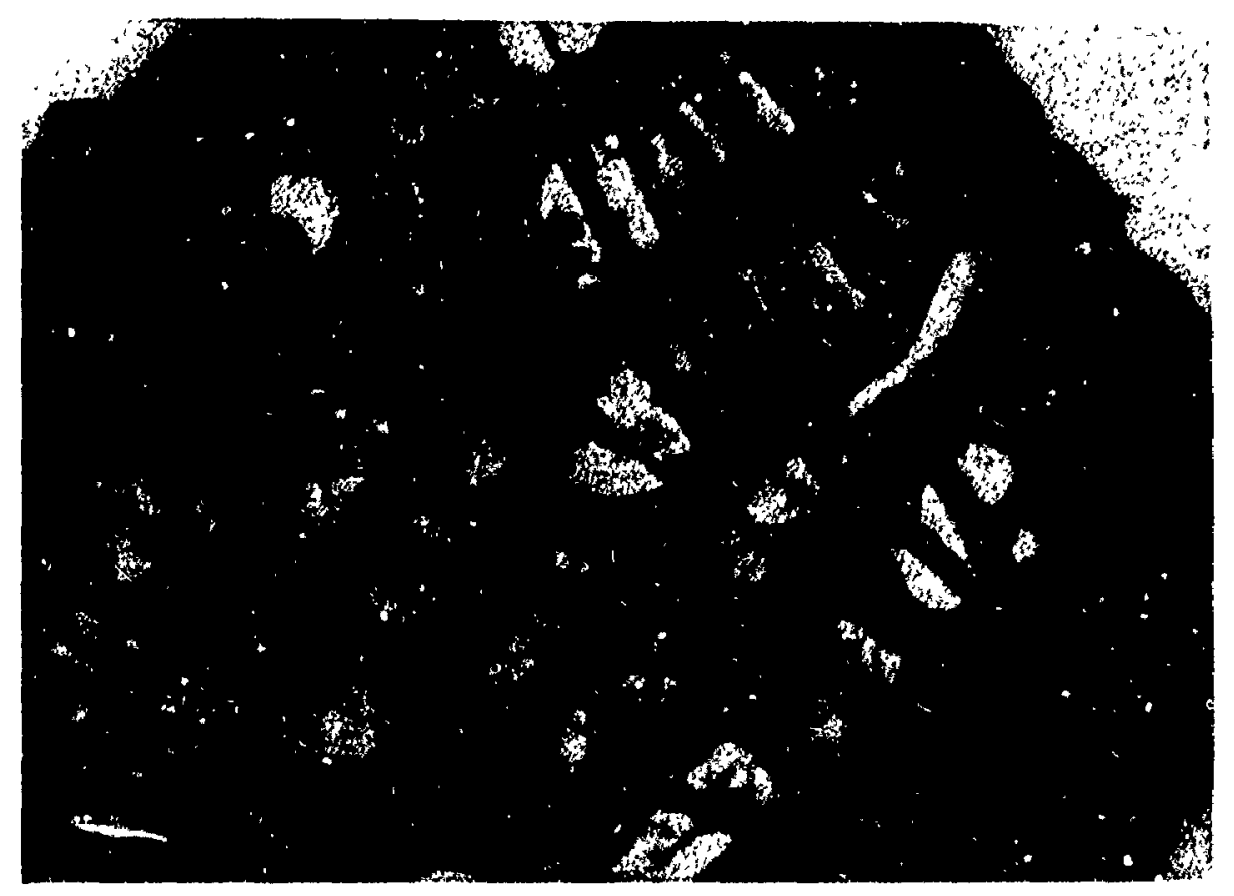

Figure B.1. Typical pore structure of a Sphagnum peat moss 


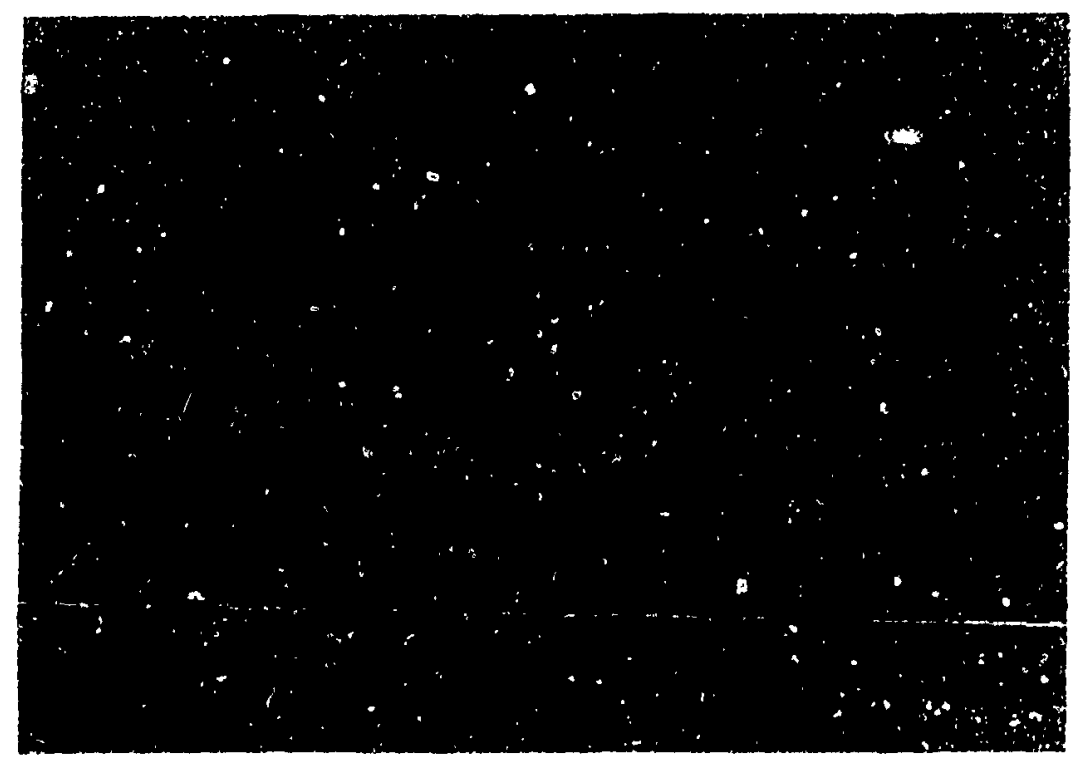

(i) SMO (mean oil droplet size $35.86 \pm 14.21 \mu \mathrm{m}$ )

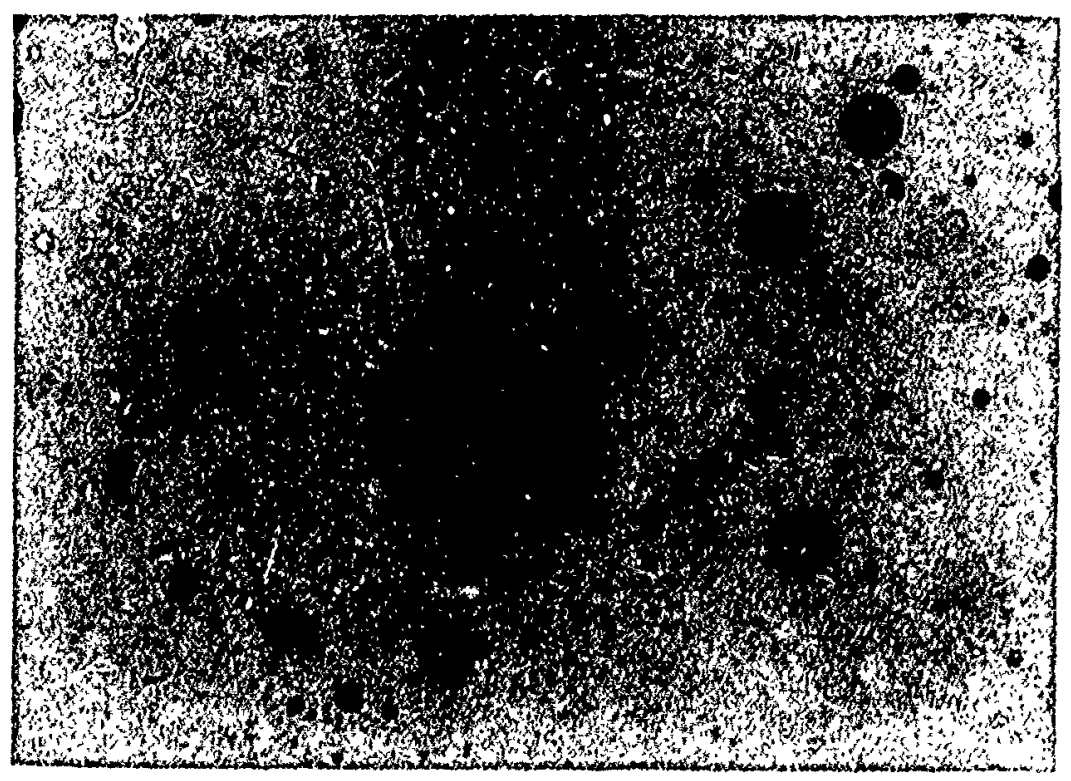

(ii) MCO (mean oil droplet size $35.86 \pm 14.21 \mu \mathrm{m}$ )

Figure B.2. Photographs of oil-in-water emulsions (1) 


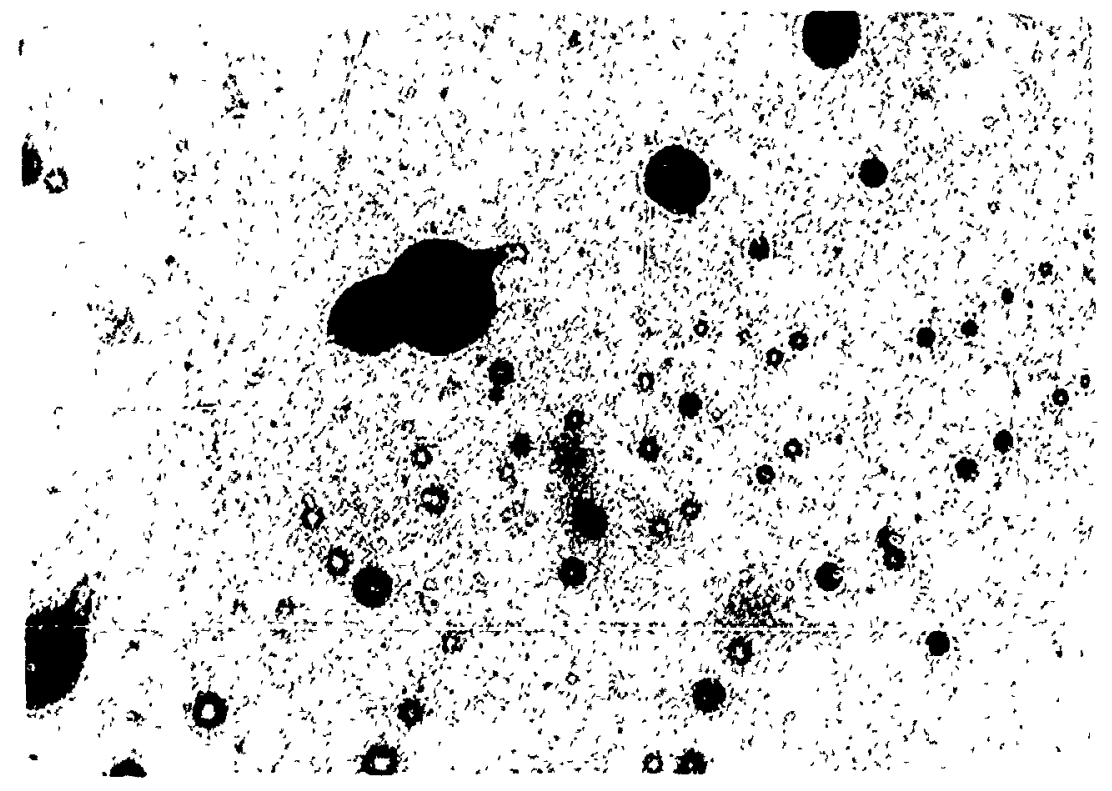

(iii) $\mathrm{CO}$ (mean oil droplet size $9.36 \pm 4.85 \mu \mathrm{m}$ )

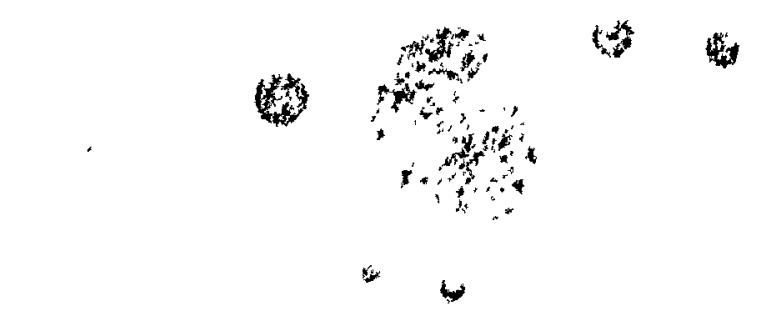

4

(iv) RE (mean oil droplet size $15.85 \pm 11.05 \mu \mathrm{m}$ )

Figure B.3. Photographs of oil-in-water emulsions (2) 


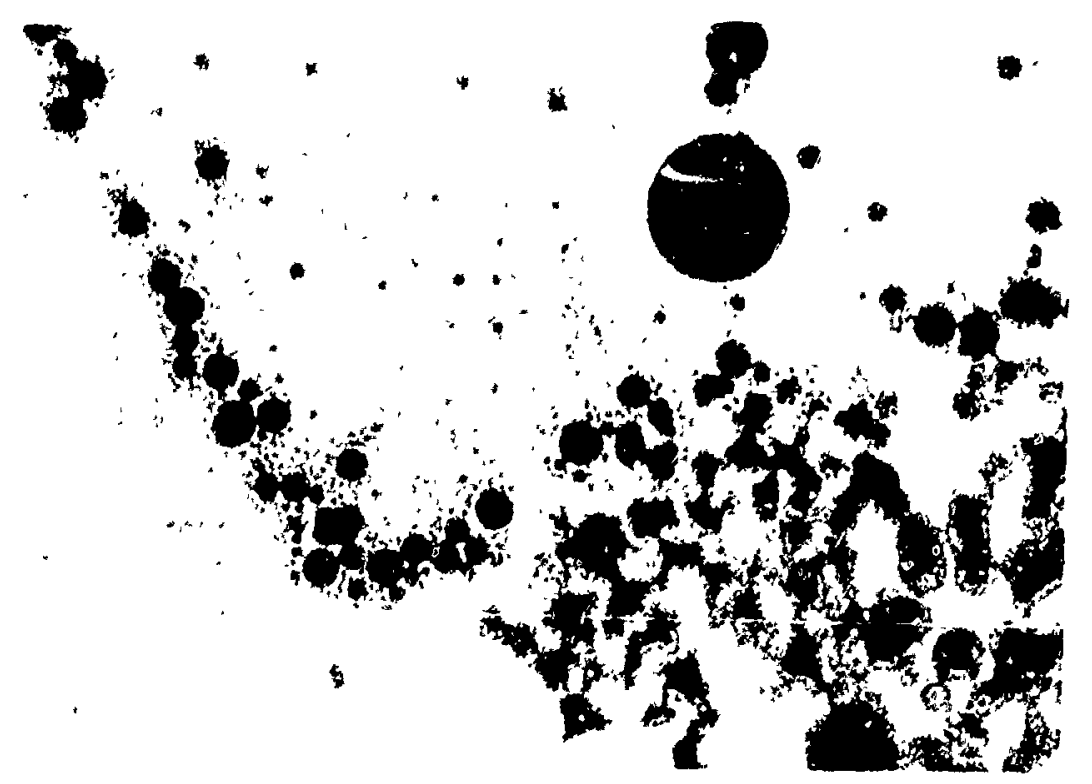

(v) PW (mean oil droplet size $7.31 \pm 5.74 \mu \mathrm{m}$ )

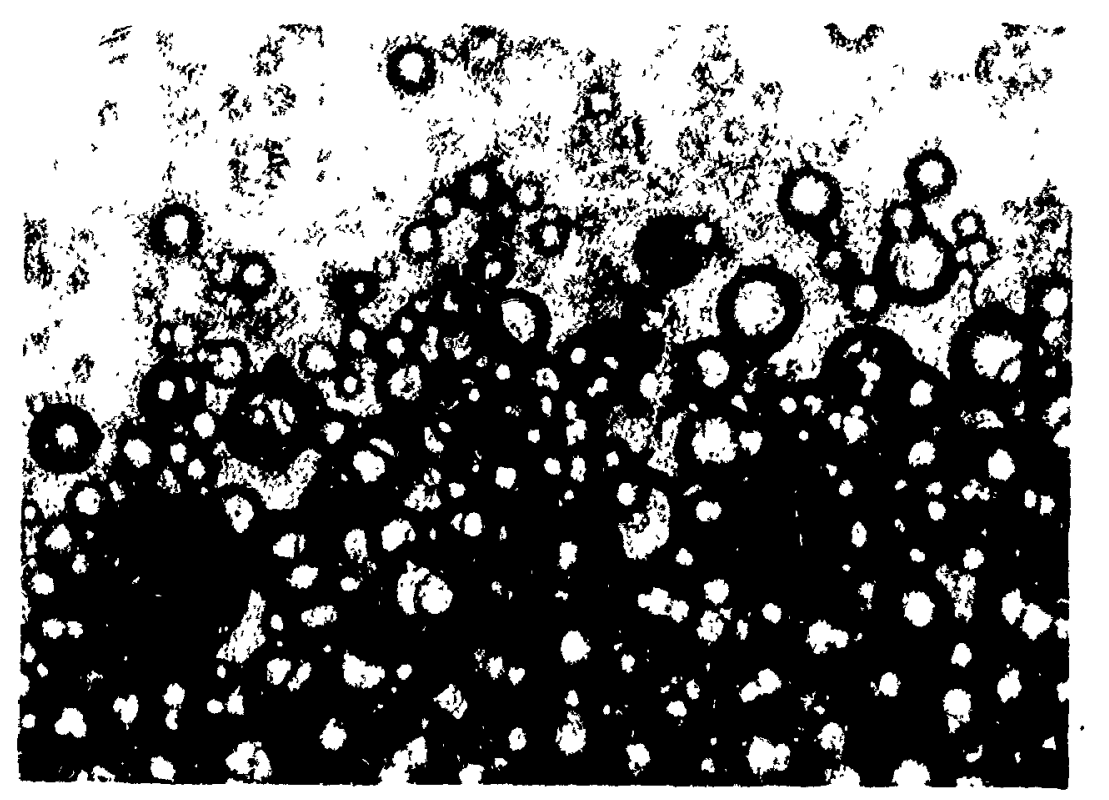

(vi) SMO with chemical emulsifiers (mean oil droplet size $21.60 \pm 10.0 \mu \mathrm{m}$ )

Figure B.4. Photographs of oil-in-water emulsions (3) 


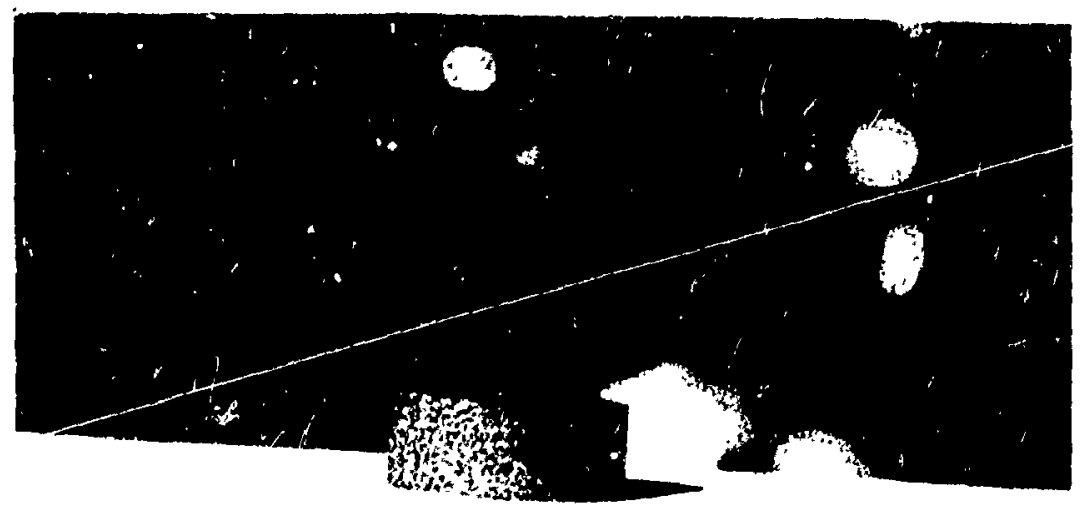

(i) SMO (contact angle with peat $=21^{\circ}$ )

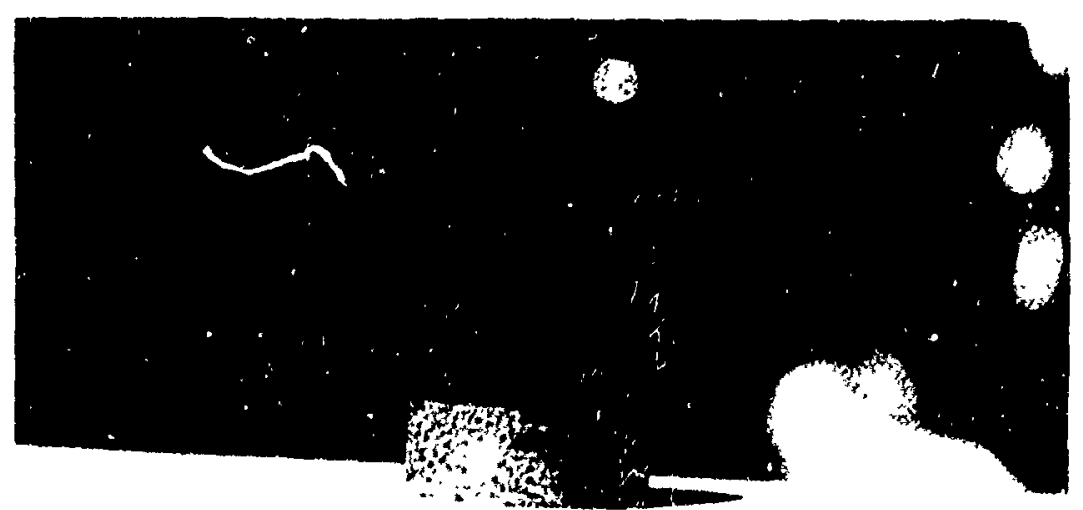

(ii) $\mathrm{MCO}$ (contact angle with peat $=28^{\circ}$ )

Figure B.5. Photographs of contact angle between horticultutal peat and oils 


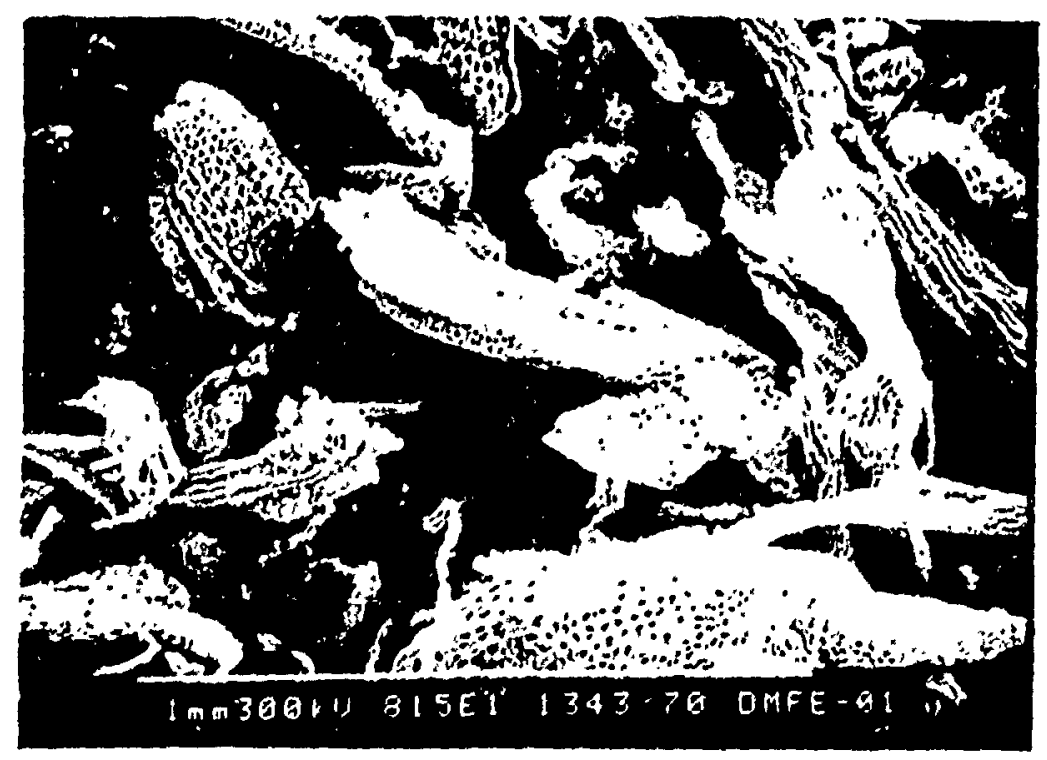

Horticultural peat

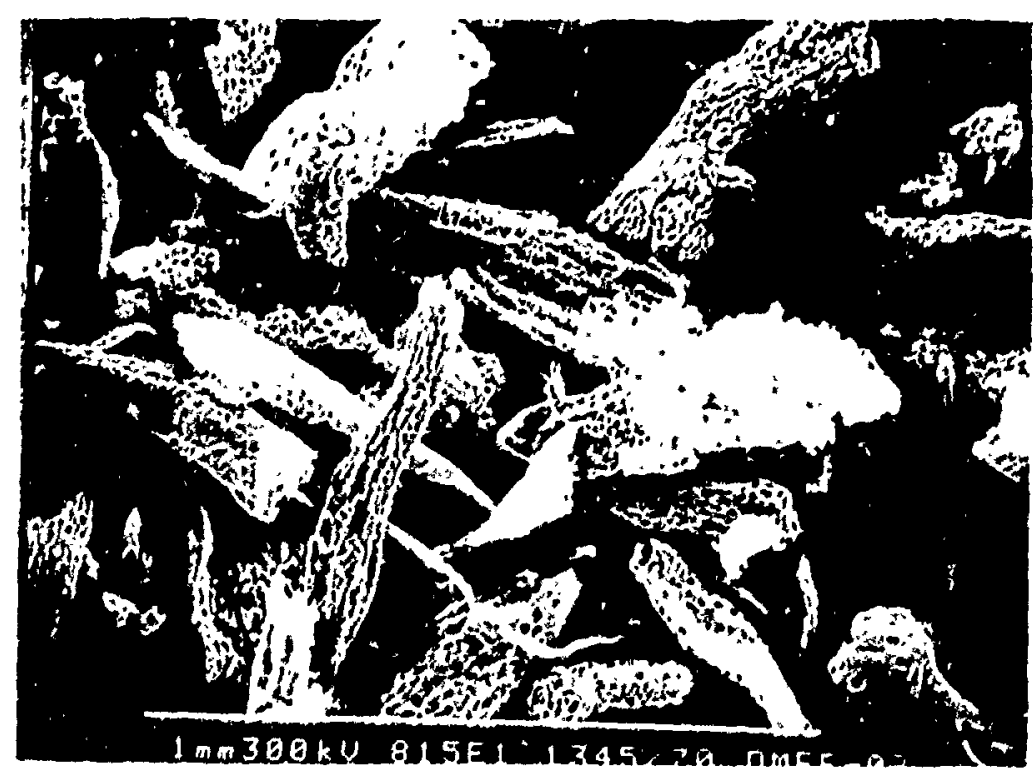

Oven-dried (1day) peat

Figure B.6. Photographs of pretreated peat samples (1) 


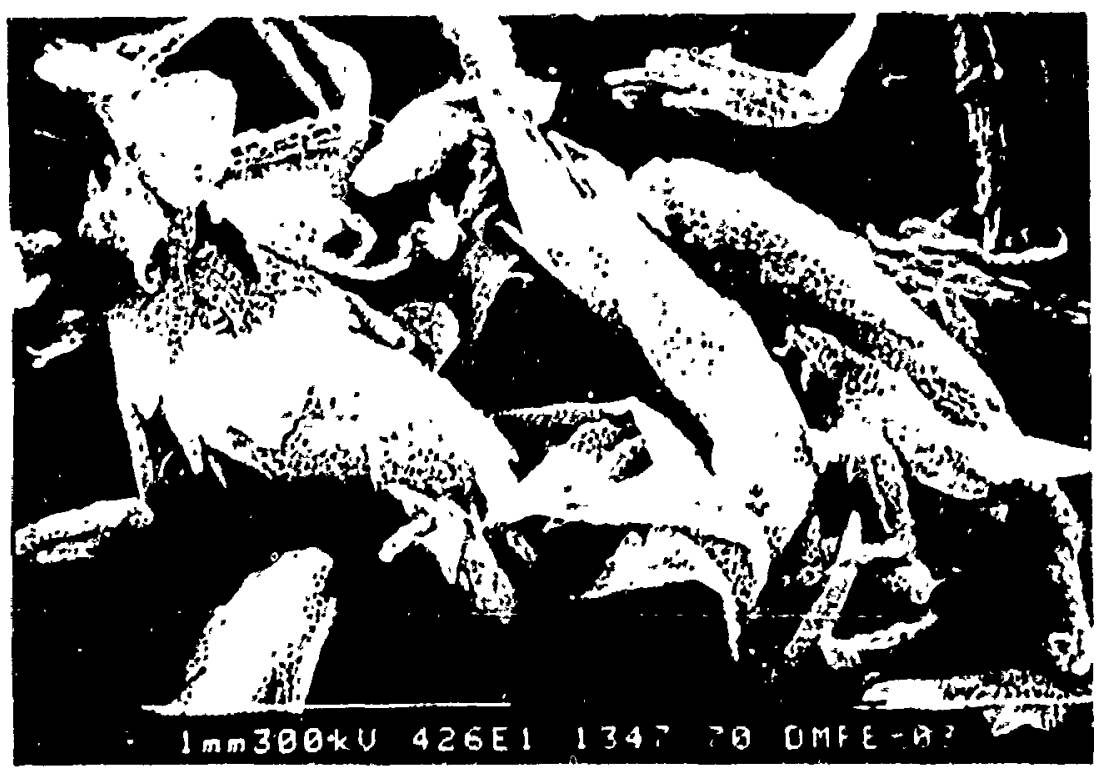

Wet-neated and air-dried peat

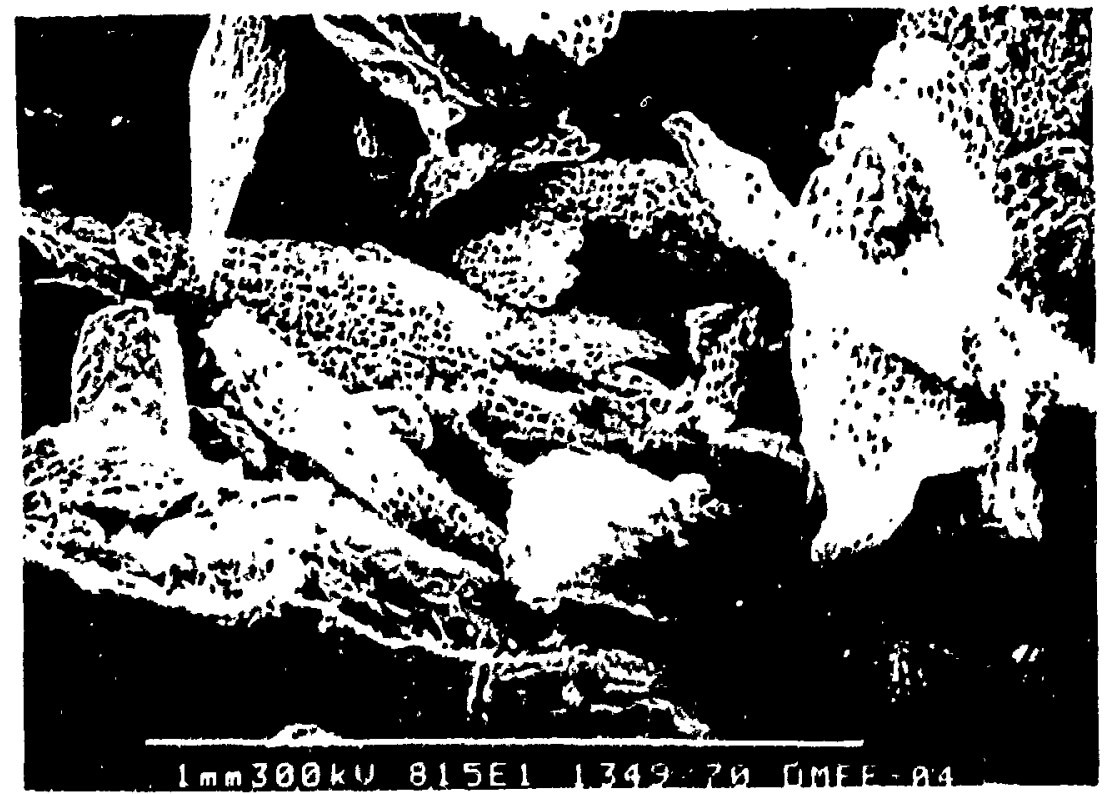

Oven-dried (3day) peat

Figure B.7. Photographs of pretreated peat umples (2) 


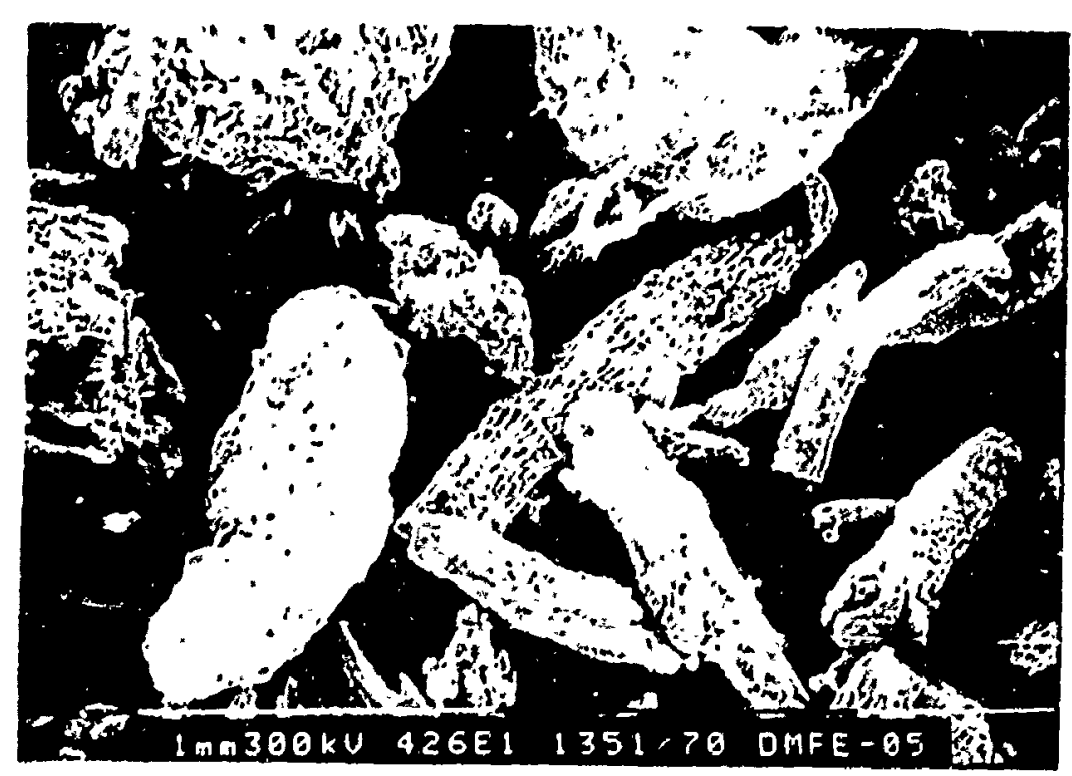

Wet-heated and oven-dried (1day) peat

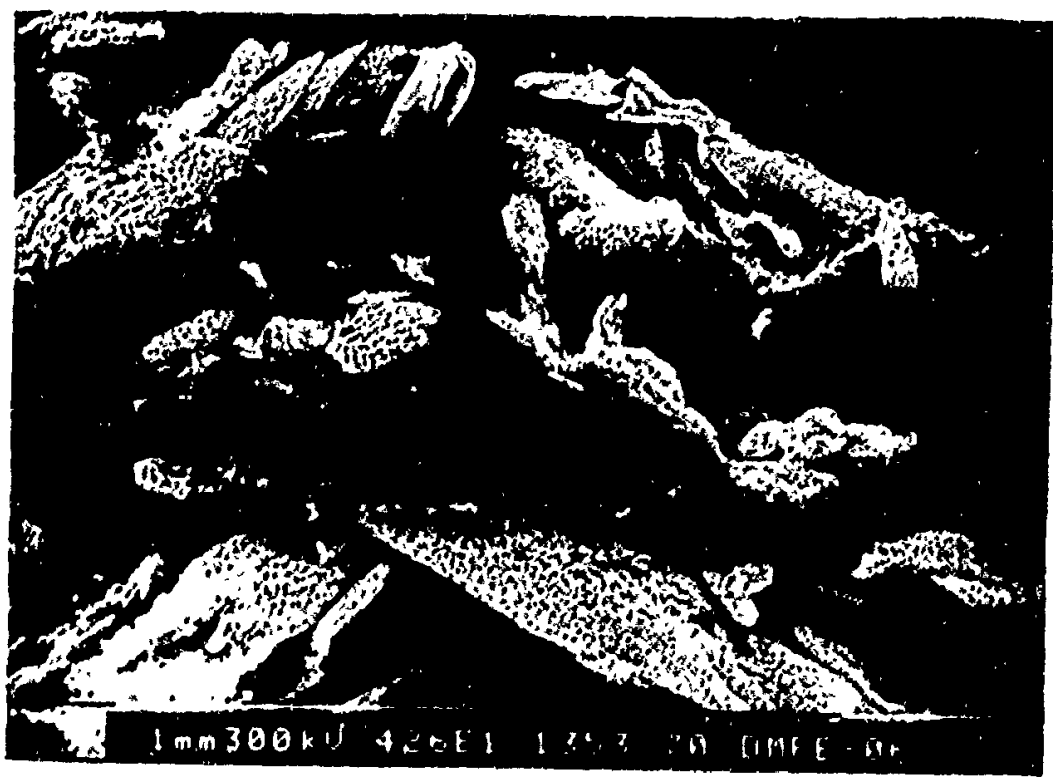

Acid (sulfuric) treated peat

Figure B.8. Photographs of pretreated peat samples (3) 


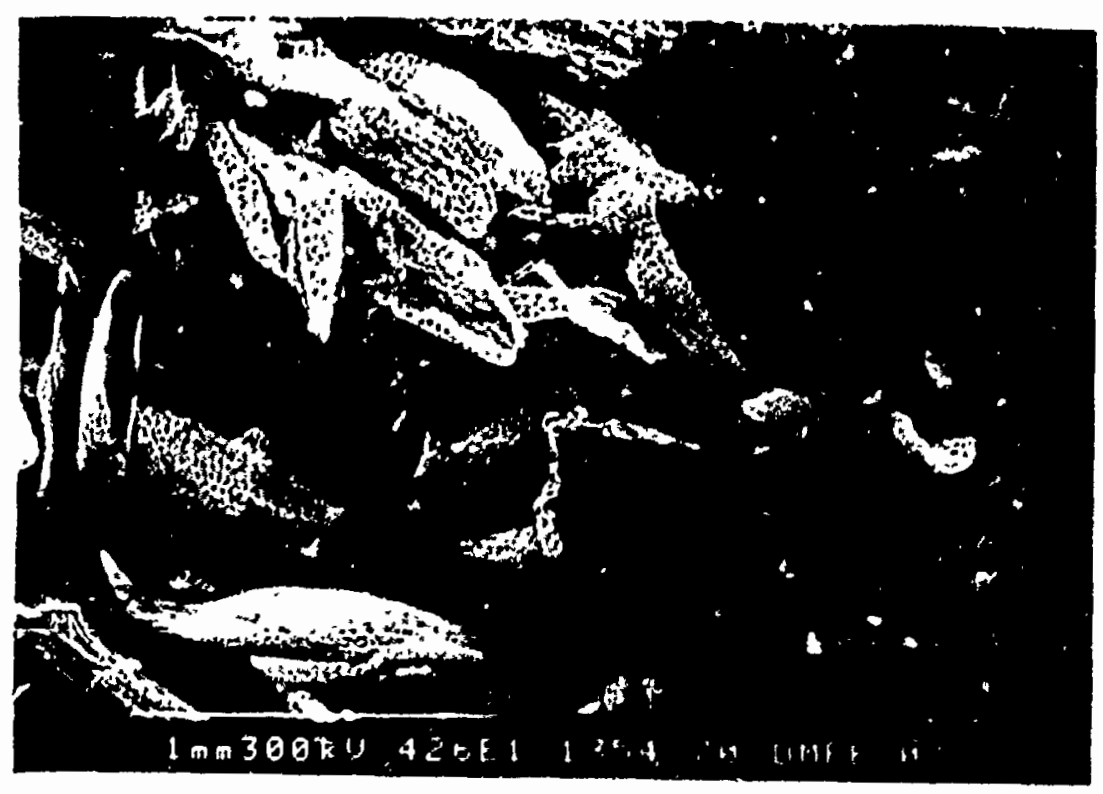

Alkali (sodium hydroxide) peat

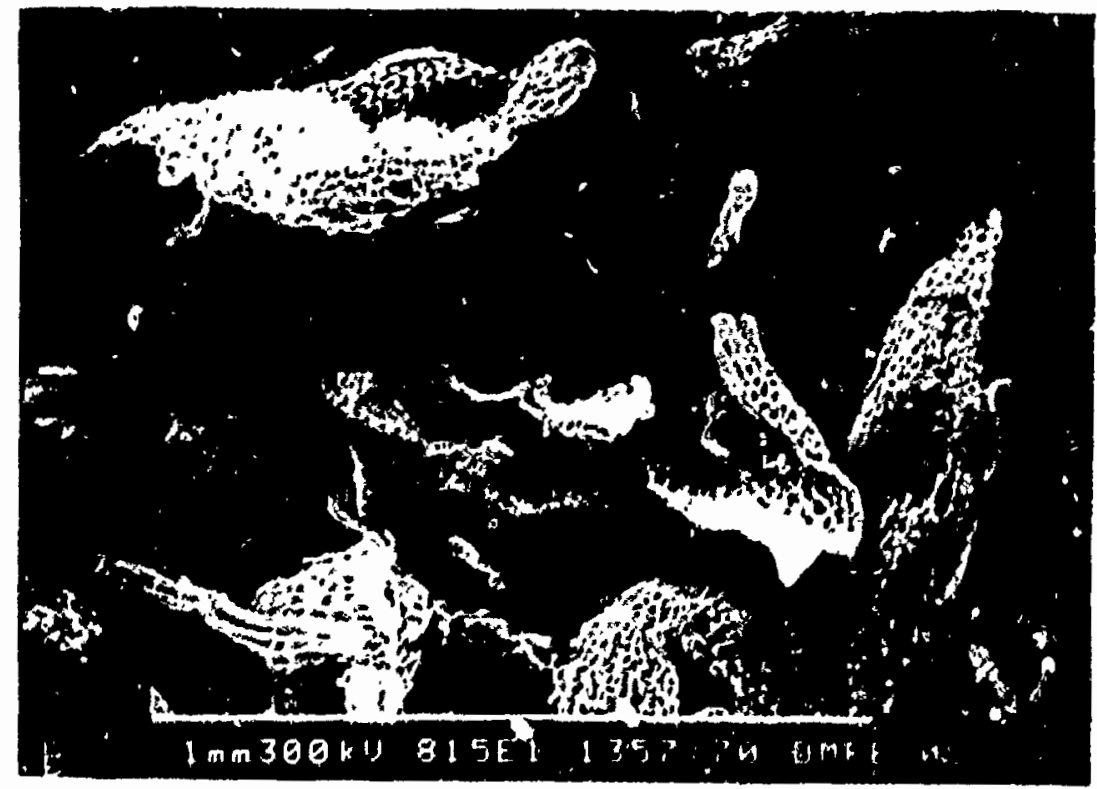

Pyrolyzed at $150^{\circ} \mathrm{C}$

Figure B.9. Photographs of pretreated peat samples (4) 


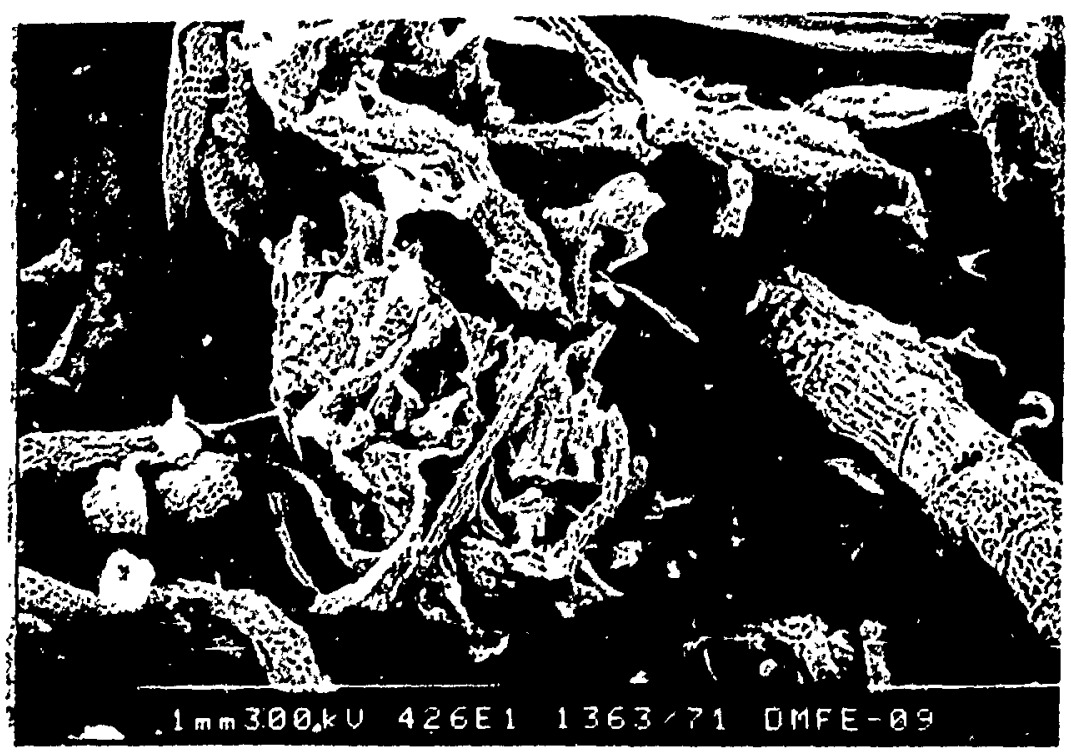

Pyrolyzed at $175^{\circ} \mathrm{C}$

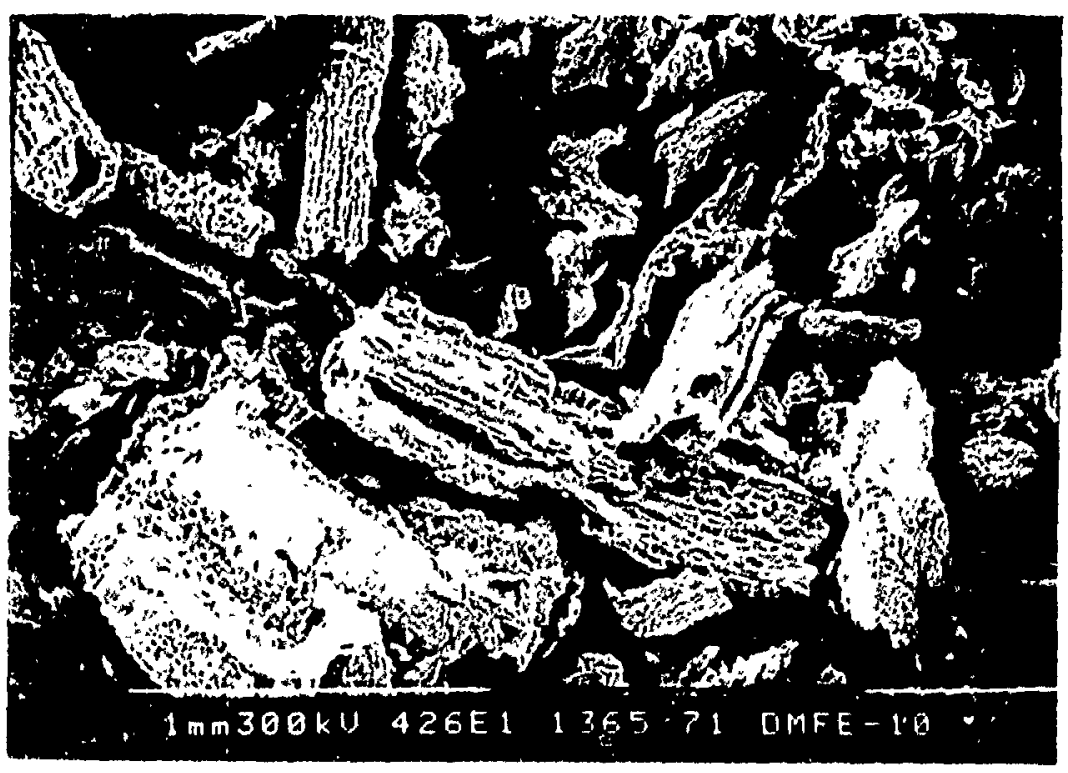

Pyrolyzed at $200^{\circ} \mathrm{C}$

Figure B.10. Photographs of pretreated peat samplcs (5) 


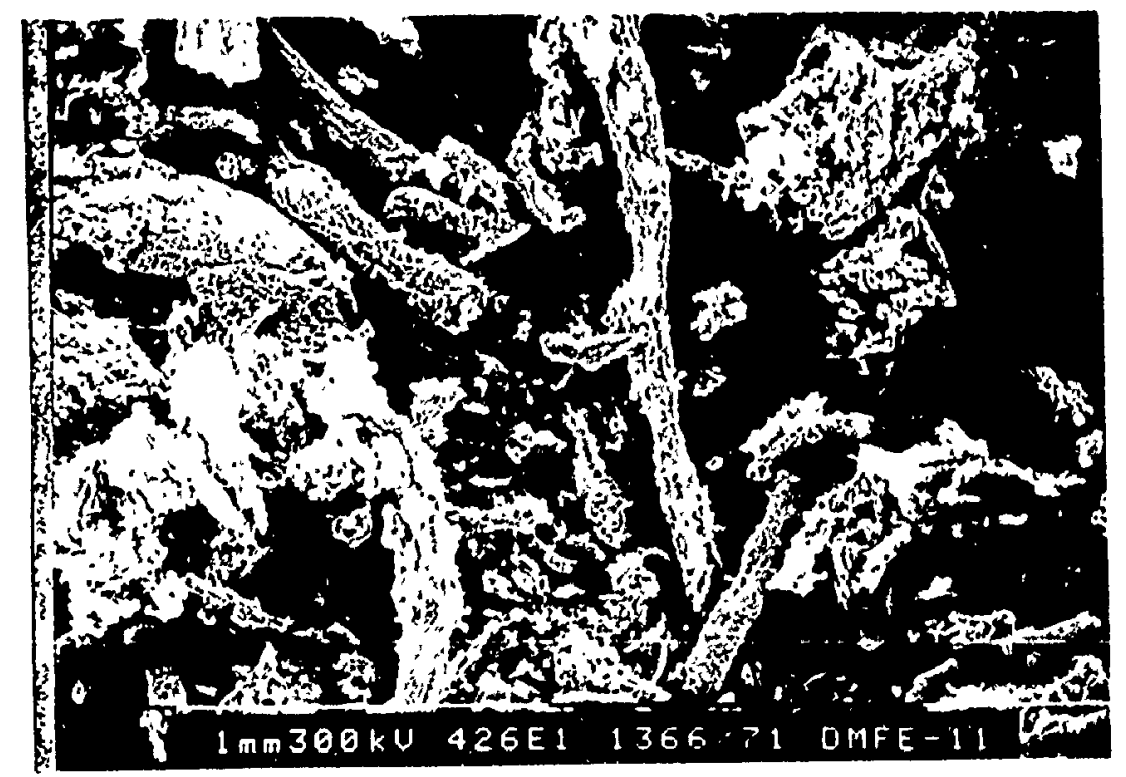

Pyrolyzed at $225^{\circ} \mathrm{C}$

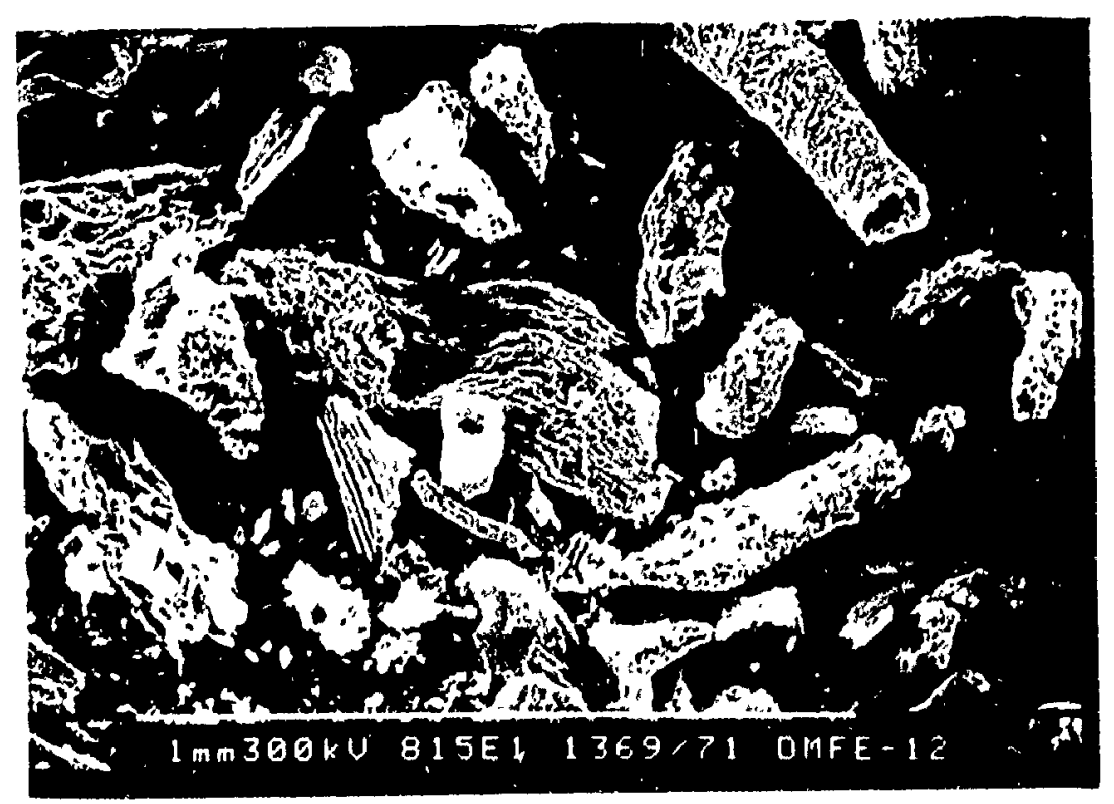

Pyrolyzed at $250^{\circ} \mathrm{C}$

Figure B.11. Photographs of pretreated peat samples (6) 


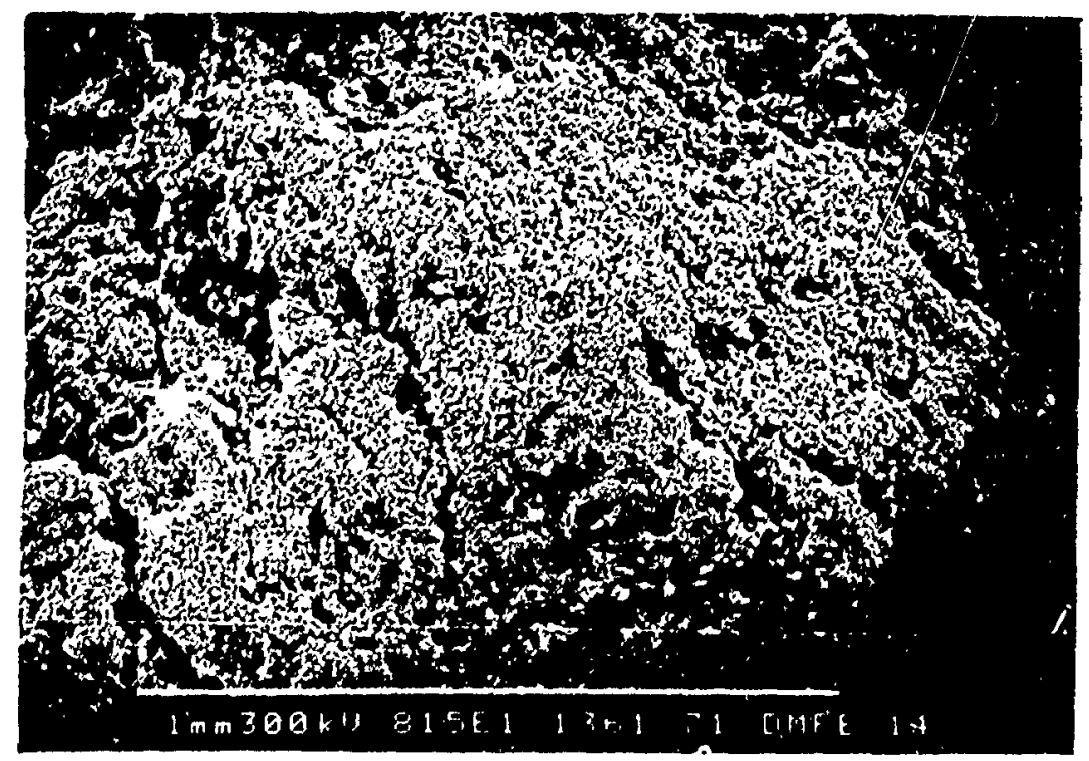

Filtrasorb 400 (activated carbon)

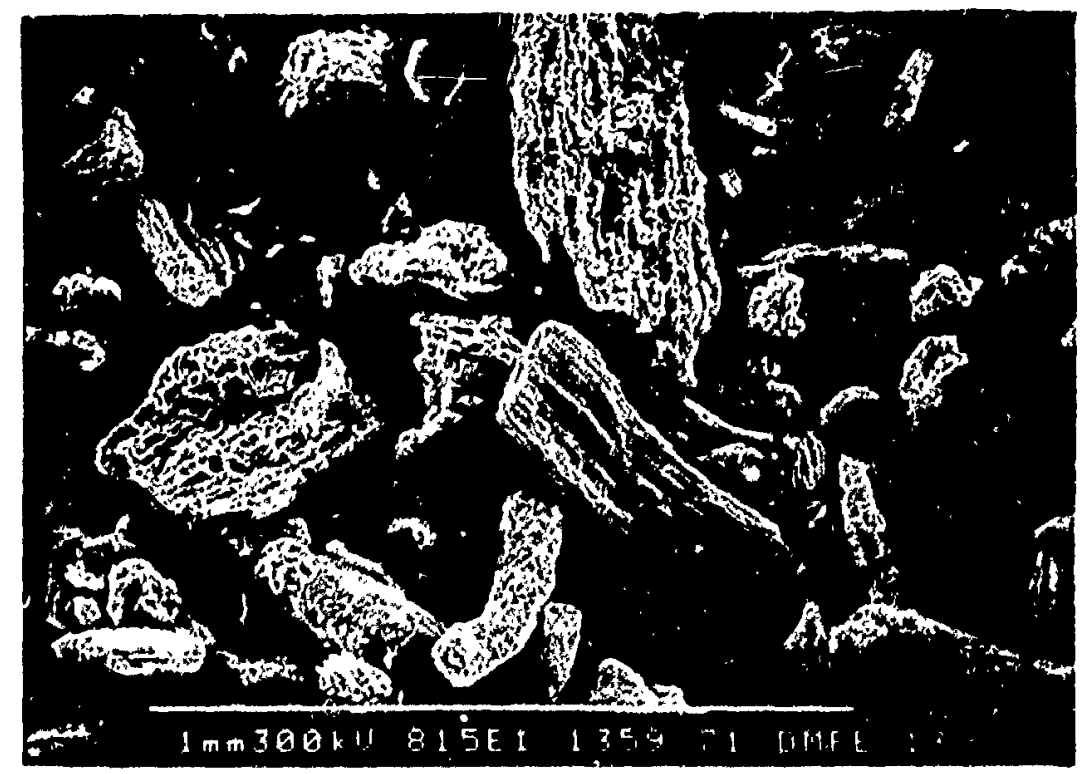

Pyrolyzed at $275^{\circ} \mathrm{C}$

Figure B.12. Photographs of pretreated peat samples (7) 


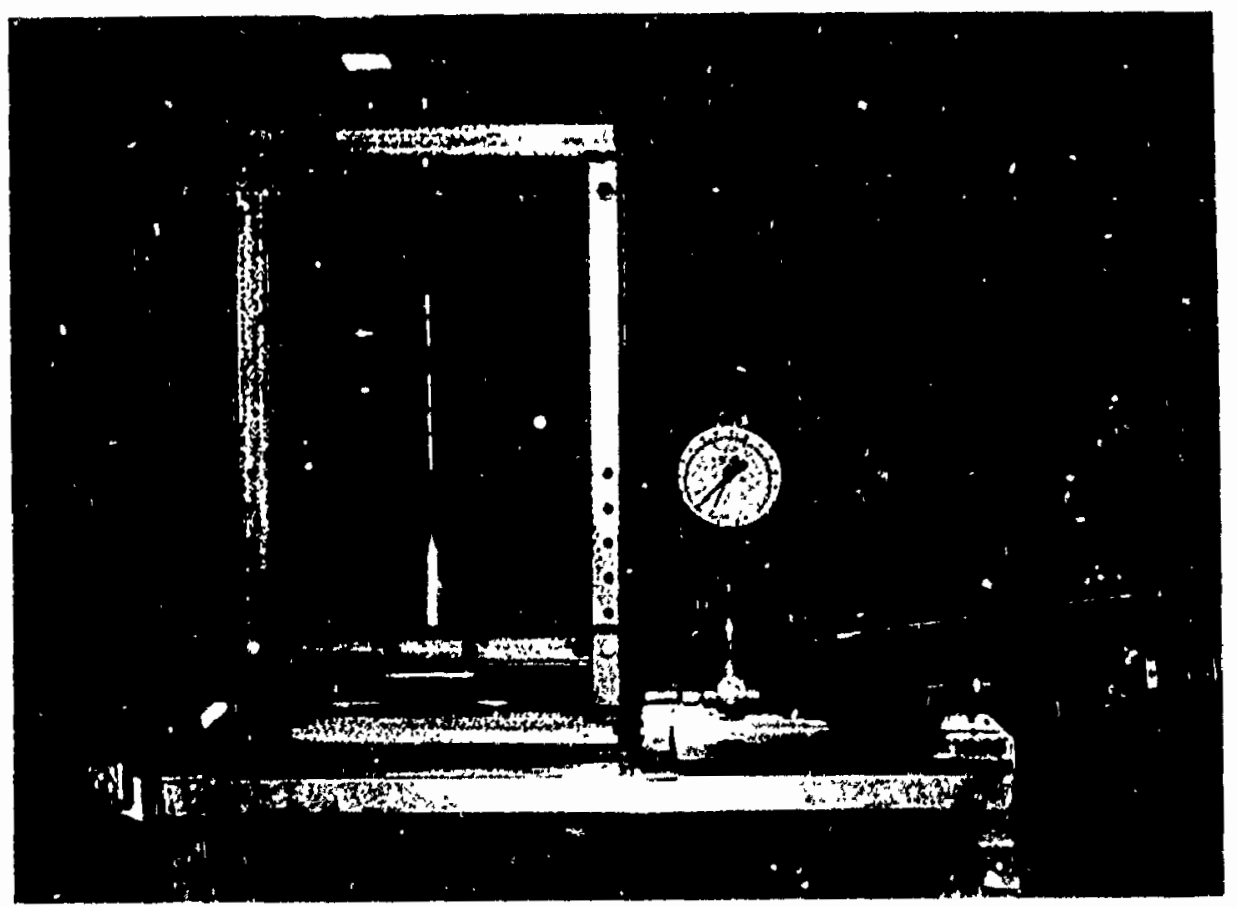

Figure B.13. Photograph of the apparatus used for squeezing oil-sorbed peat 


\section{APPENDIX. C}

\section{DESIGN OF BATCH ADSORBER SYSTEM USING BATCH ADSORPTION DATA}

Dily wastewater to be treated Assumed influent oil concentration Assumed effluent oil concentration.
$=150$ cubic meter/d (39,000 gpd)

$=115 \mathrm{mg} / \mathrm{L}$

$=15 \mathrm{mg} / \mathrm{L}$

1. Design for SMO-in-water emulsion:

For SMO, the BET constants are(Table 4.20):

$$
\begin{aligned}
A & =-12.9752 \\
X_{m} & =0.0479
\end{aligned}
$$

Substituting these values in Equation 2.5, the value of $x / m$ was calculated as: $=0.0551$ Weight of SMO removed/day

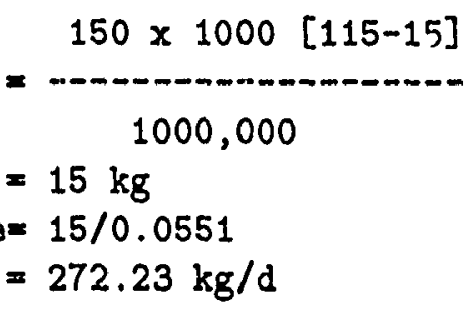

2. Design for MCO-inwater emulsion:

For MCO, the BET constants are(Table 4.20):

$$
\begin{aligned}
A & =-4.5381 \\
X_{m} & =0.0230
\end{aligned}
$$

Substituting these values in Equation 2.5, the value of $x / m$ was calculated as: $\quad=0.0230$ Height of MCU removed/day

$$
\begin{aligned}
& =150 \times 1000[115-15] \\
& =15 \mathrm{~kg}
\end{aligned}
$$

Mass of peat required using the $x / m$ value $=15 / 0.0230$

$$
=652.2 \mathrm{~kg} / \mathrm{d}
$$


3. Design for CO-in-water emulsion:

For $\mathrm{CO}$, the BET constants are(Table 4.20):

$$
\begin{aligned}
A & =-9.6680 \\
X_{m} & =0.2032
\end{aligned}
$$

Substituting these values in Equation 2.5, the value of $x / m$ was calculated as:

$=0.3387$

Weight of MCO removed/day

$$
\begin{aligned}
& =\frac{150 \times 1000[250-100]}{1000,000} \\
& =22.5 \mathrm{~kg}
\end{aligned}
$$

Mass of peat required using the $x / m$ value $22.5 / 0.3387$

$=66.43 \mathrm{~kg} / \mathrm{d}$

4. Design for RE-in-water emulsion:

For RE, the BET constants are(Table 4.20):

$A=-1.0551$

$X_{\mathfrak{m}}=0.00022$

Surstituting these values in Equation 2.5,

the value of $x / m$ was calculated as: $\quad=0.000253$

Initial oil concentrat; $\mathrm{n} \quad=15 \mathrm{mg} / \mathrm{L}$

Final oil concentraticn $\quad=2.1 \mathrm{mg} / \mathrm{L}$

Percentage oil removed $\quad=86$

Weight of RE removed/day

$150 \times 1000[15-2,1]$

1000,000

$=1.97 \mathrm{~kg}$

Mass of peat required using the $x / \mathrm{m}$ value $=1.97 / 0.00022$

$=7766 \mathrm{~kg} / \mathrm{d}$

5. Design for PW-in-water emulsion:

For PW, the Langmuir constants are(Table 4.20):

$$
\begin{aligned}
& a=0.0072 \\
& b=0.2762
\end{aligned}
$$

Substituting these values in Equation $2 \ldots .$. 


$\begin{array}{ll}\text { the value of } x / \mathrm{m} \text { was calculated as: } & =0.0109 \\ \text { Initial oil concentration } & =50 \mathrm{mg} / \mathrm{L} \\ \text { Final oil concentration } & =7.0 \mathrm{mg} / \mathrm{L} \\ \text { Percentage oil removed } & =86 \\ \text { Weight of } \mathrm{PW} \text { removed/day } & \\ & =-150 \times 1000[50-7.0] \\ & =6.45 \mathrm{~kg} \\ \text { Mass of peat required using the } x / \mathrm{m} \text { value } & =6.45 / 0.0109 \\ & =592 \mathrm{~kg} / \mathrm{d}\end{array}$




\section{APPENDIX. D}

\section{DESIGN OF COLUMN ADSORBER SYSTEM USING COLUMN ADSORPTION DATA}

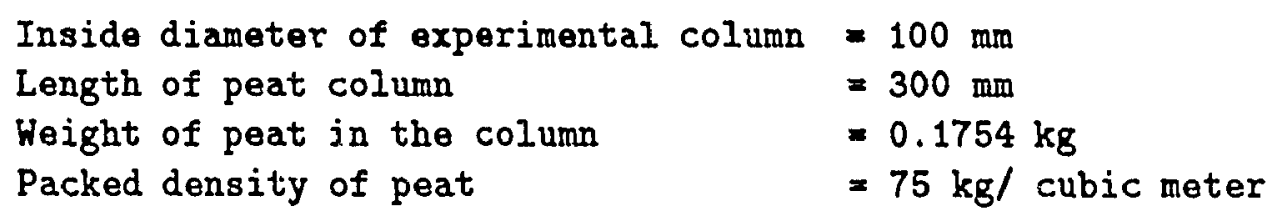

1. For SMO-in-kater emulsions:

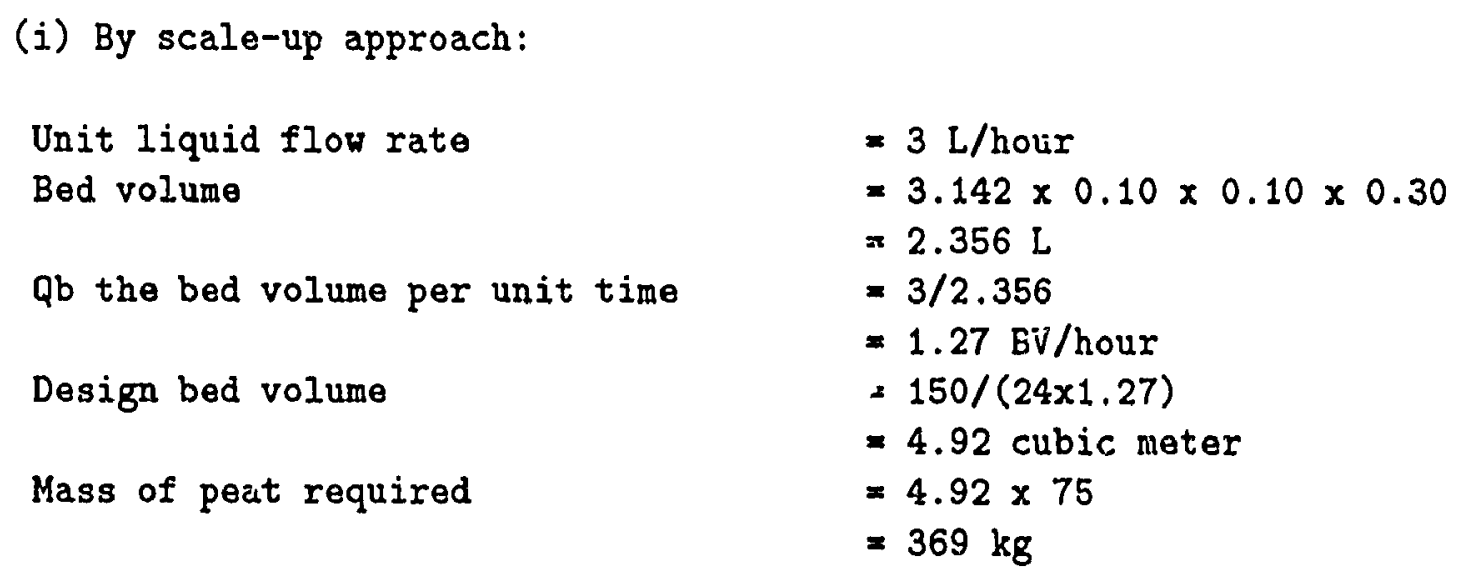

From breakthrough curve (Figure 4.42);

for allowable breakthrough concentration

of $15 \mathrm{mg} / \mathrm{L}$ of oil, the

corresponding volume

Solution treated per $\mathrm{kg}$ of peat

$=678 \mathrm{~L}$

Peat exhausted/hour

$=678 / 0.1754$

$=3874 \mathrm{~L} / \mathrm{kg}$

$=(150 \times 1000) /(24.3874)$

Breakthrough time

$=1.61 \mathrm{~kg} / \mathrm{h}$

. $369 / 1.61$

Breakthrough volume

- 228 hour or 9.53 days

$=150 \times 9.53$

$=1429.6$ cubic meter 
(ii) By kinetic approach:

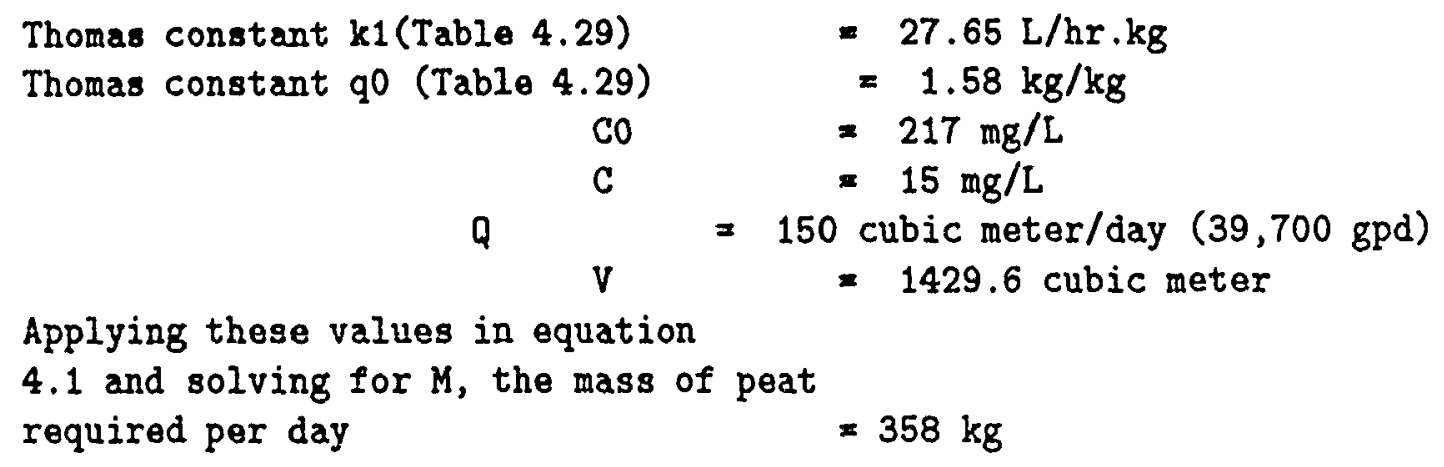

2. For MCO-in-water emulsions:

(i) By scale-up approach:

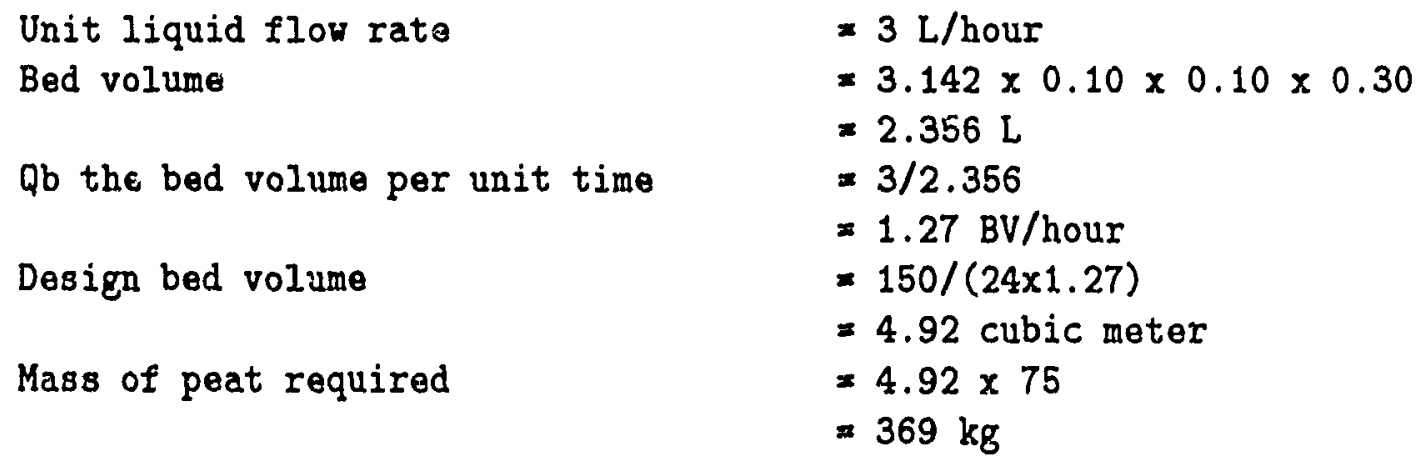

From breakthrough curve (Figure 4.43);

for allowable breakthrough concentration of $15 \mathrm{mg} / \mathrm{L}$ of oil, the

corresponding volume

Solution treated per $\mathrm{kg}$ of peat

Peat exhausted/hour

Breakthrough time

Breakthrough volume
$=641.8 \mathrm{~L}$

$\times 641.8 / 0.1754$

$=3667 \mathrm{~L} / \mathrm{kg}$

$=(150 \times 1000) /(24 \times 3667)$

$=1.71 \mathrm{~kg} / \mathrm{h}$

- 369/1.71

- 216 hour or 9.02 days

- $150 \times 9.02$

= 1353 cubic meter

(ii) By kinetic approach: 
Thomas constant $k 1$ (Table 4.29)

Thomas constant qO (Table 4.29)

C

Q
$=30.22 \mathrm{~L} / \mathrm{hr} . \mathrm{kg}$

$=1.33 \mathrm{~kg} / \mathrm{kg}$

- $210 \mathrm{mg} / \mathrm{L}$

$=15 \mathrm{mg} / \mathrm{L}$

- 150 cubic meter/day $(39,700$ gpd)

- 1353 cubic meter

Applying these values in equation

4.1 and solving for $M$, the mass of peat required per day $=410 \mathrm{~kg}$

3. For CO-in-water emulsions:

(i) By scale-up approach:

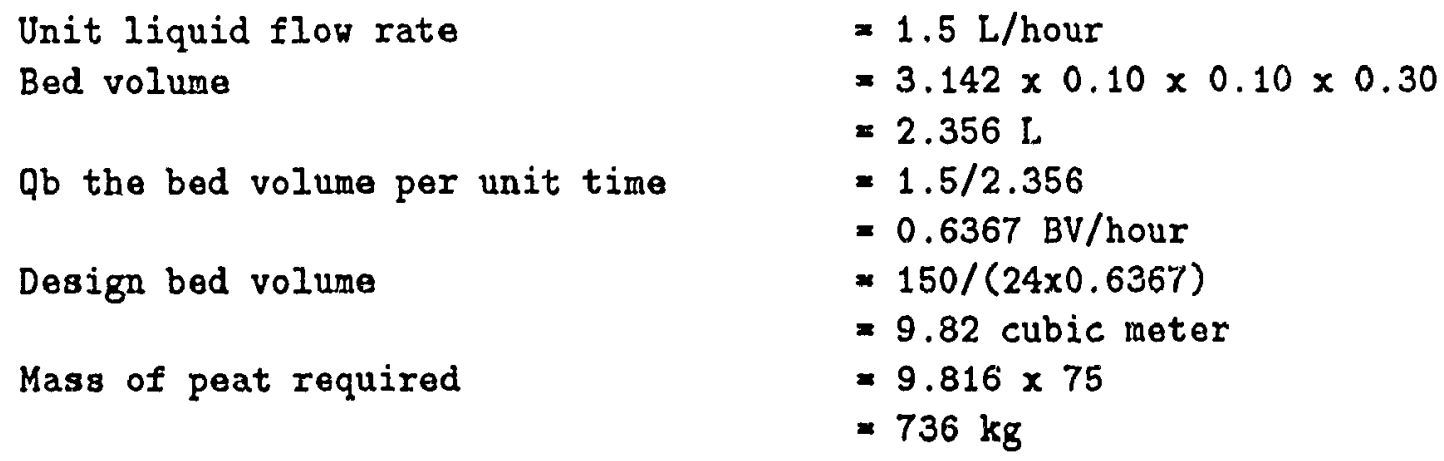

From breakthrough curve (Figure 4.44);

for allowable breakthrough concentration of $100 \mathrm{mg} / \mathrm{L}$ of oil, the

corresponding volume

Solution treated per $\mathrm{kg}$ of peat

Peat exhausted/hour

Breakthrough time

Breakthrough volume

(ii) By kinetic approach: $\times 31.75 \mathrm{~L}$

$=31.75 / 0.1754$

$=181.43 \mathrm{~L} / \mathrm{kg}$

= $(150 \times 1000) /(24 \times 181.4)$

$=34.45 \mathrm{~kg} / \mathrm{h}$

- 736/34.45

- 21.4 hour or 0.9 day

- $150 \times 0.9$

- 135 cubic meter 
Thomas constant $k 1$ (Table 4.29)

Thomas constant q0 (Table 4.29)

CO

C

Q

$\mathrm{V}$
$=32.37 \mathrm{~L} / \mathrm{hr} . \mathrm{kg}$

$=0.140 \mathrm{~kg} / \mathrm{kg}$

$=278 \mathrm{mg} / \mathrm{L}$

$=100 \mathrm{mg} / \mathrm{L}$

= 150 cubic meter/day $(39,700 \mathrm{gpd})$

- 135 cubic meter

Applying these values in equation

4.1 and solving for $M$, the mass of peat required per day

$=617.8 \mathrm{~kg}$

4. For RE-in-water emulsions:

(i) By scale-up approach:

Unit liquid flow rate

Bed volume

Qb the bed volume per unit time

Design bed volume

Mass of peat required
$=1.5 \mathrm{~L} /$ hour

$=3.142 \times 0.10 \times 0.10 \times 0.30$

$=2.356 \mathrm{~L}$

$=1.5 / 2.356$

$=0.6367 \mathrm{BV} / \mathrm{hour}$

$=150 /(24 \times 0.6367)$

- 9.82 cubic meter

$=9.816 \times 75$

$=736 \mathrm{~kg}$

From breakthrough curve (Figure 4.45);

for allowable breakthrough concentration

of $2 \mathrm{mg} / \mathrm{L}$ of oil, the

corresponding volume

$=284.12 \mathrm{~L}$

Solution treated per $\mathrm{kg}$ of peat

$=284.12 / 0.1754$

$=1623.54 \mathrm{~L} / \mathrm{kg}$

Peat exhausted/hour

$=(150 \times 1000) /(24 \times 1623.54)$

$* 3.85 \mathrm{~kg} / \mathrm{h}$

Breakthrough time

$=736 / 3.85$

Breakthrough volume

$=191.23$ hour or 7.96 days

$=150 \times 7.96$

= 1194 cubic meter

(ii) By kinetic approach:

Thomas constant $\mathrm{kl}$ (Table 4.29) $\quad=210.02 \mathrm{~L} / \mathrm{hr} \cdot \mathrm{kg}$ 
Thomas constant q0 (Table 4.29)

$=0.034 \mathrm{~kg} / \mathrm{kg}$

C $\quad=2.0 \mathrm{mg} / \mathrm{L}$
= 150 cubic meter/day $(39,700 \mathrm{gpd})$
V
- 1194 cubic meter

Applying these values in equation

4.1 and solving for $M$, the mass of poat required per day

$=812 \mathrm{~kg}$

5. For PW-in-water emulsions:

(i) By scale-up approach:

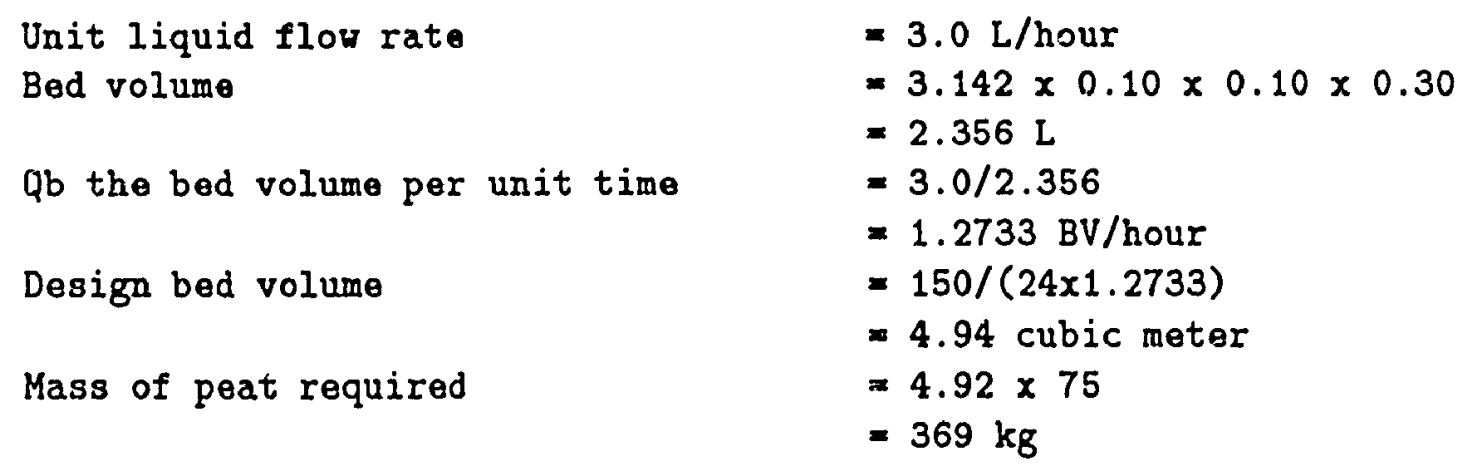

From breakthrough curve (Figure 4.46);

for allowable breakthrough concentration

of $7 \mathrm{mg} / \mathrm{L}$ of oil, the

corresponding volume

Solution treated per $\mathrm{kg}$ of peat

Peat exhausted/hour

Breakthrough time

Breakthrough volume

(ii) By kinetic approach:

Thomas . nnstant $k 1$ (Table 4.29)

Thoma: vastant qo (Table 4.29)
$=516.41 \mathrm{I}$

$=516.41 / 0.1754$

$=2948.6 \mathrm{~L} / \mathrm{kg}$

$=(150 \times 1000) /(24 \times 2948.6)$

$=2.12 \mathrm{~kg} / \mathrm{h}$

$=369 / 2.12$

$=174.1$ hour or 7.25 days

$=150 \times 7.21$

- 1088 cubic meter 


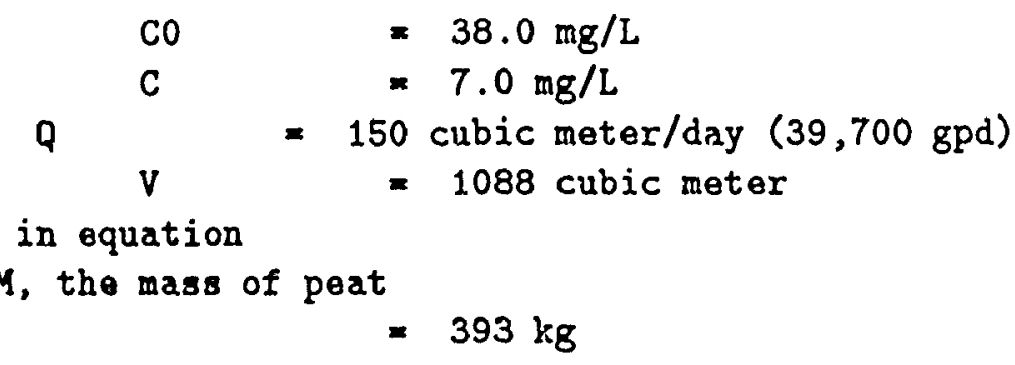




\section{APPENDIX. E}

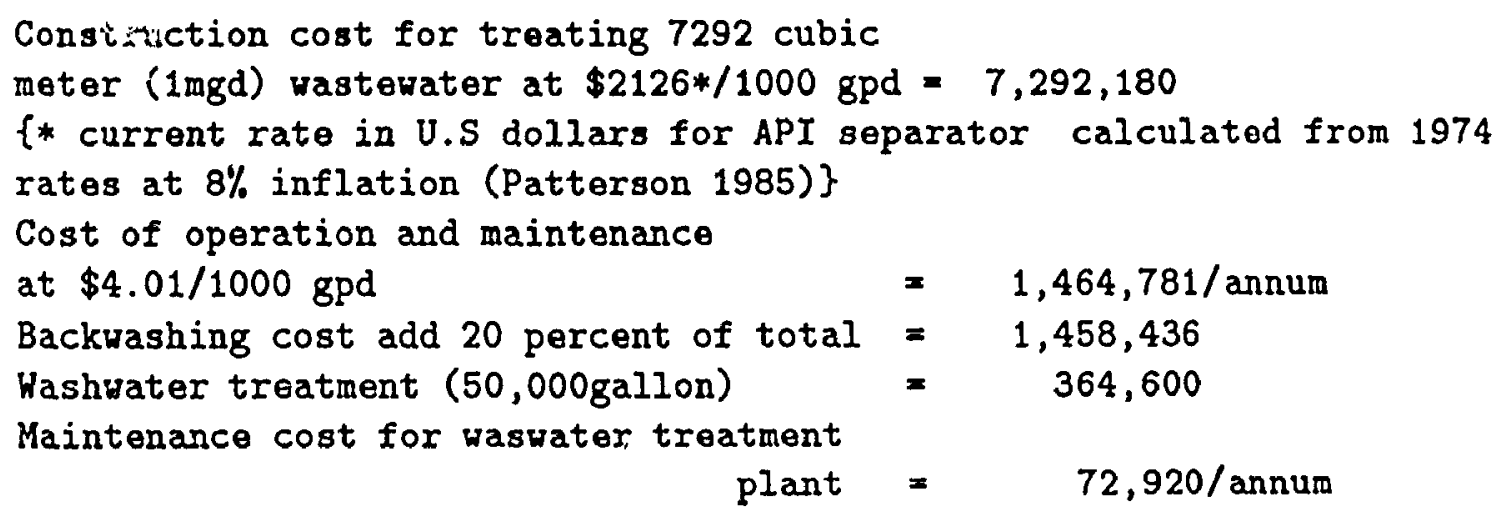

Cost of peat:

Assumed influent oil concentration Assumed effluent oil concentration Assumed type of oil-in-water emulsion

$=150 \mathrm{mg} / \mathrm{L}$

$=15 \mathrm{mg} / \mathrm{L}$

= SMO

By applying the Thomas rate constants for SMO (Table 4.29) and using equation 4.1 , the mass of peat required to treat 3785 (1mgd) wastewater plant Volume of peat

$\times 6860 \mathrm{~kg}$

$=6860 / 75$

- 91.5 cubic meter

Breakthrough time (Figure 4.)

$=9.5$ days

Peat required/annum

$=6860 \times(365 / 9.5)$

$=263.6 \mathrm{MT}$

Assuming 3gpm/sq.ft loading,

Diameter of peat column

$\approx$ 1mgd $\times 4 /(3 \times 24 \times 60 \times 3.142)$

$\approx 5.23 \mathrm{~m}$

Depth of bed

$=91.5 \times 4 /(3.14 \times 5.25 \times 5.25)$

Cost of peat at $\$ 300 / M T$

$=4.25 \mathrm{~m}$

$=263.6 \times 300$

$=79,080$

Cost of hot washwater for backwashing:

To raise water $(55-20)$ by 35 degree heat required

$=35 \mathrm{kCal} / \mathrm{kg}$ 


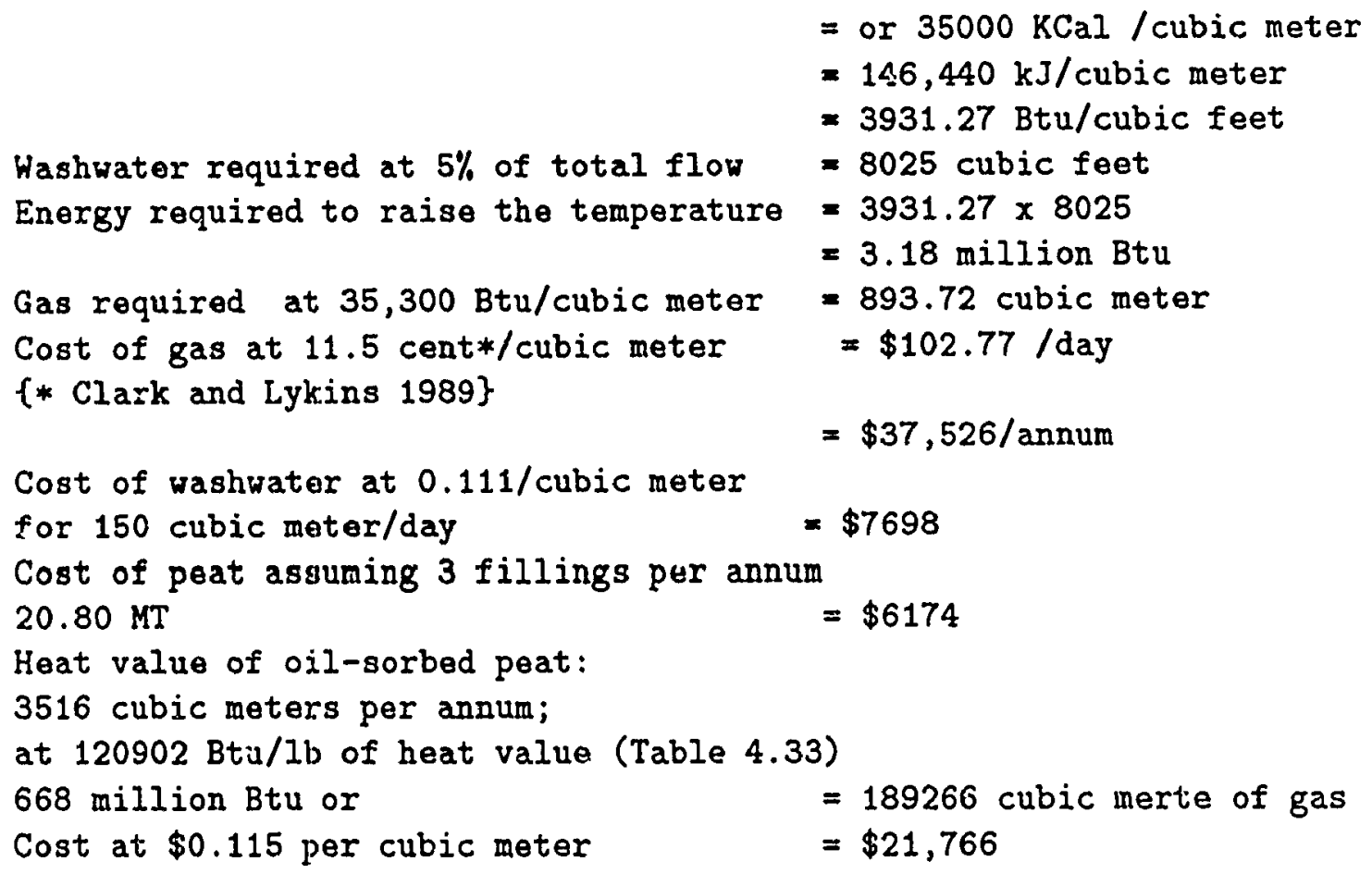

2. CALCULATION FOR BACTERIAL DEGRADATION OF OIL

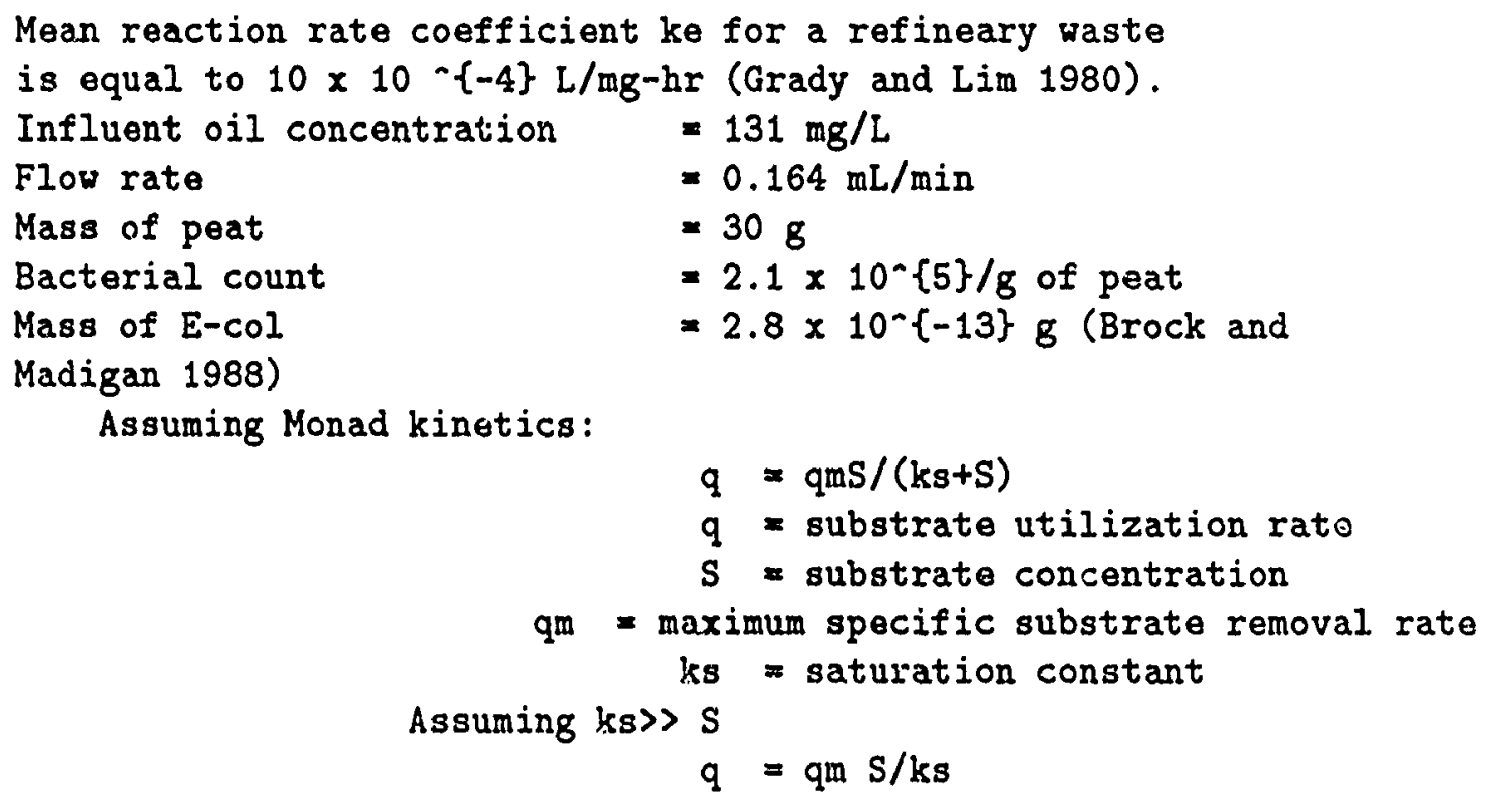




$$
\begin{aligned}
q & =k e S \quad(k e=q m / k s) \\
k e & =m e a n \text { reaction rate coefficient } \\
& =3.5 \text { to } 10 \times 10^{-}\{-10\} \mathrm{L} / \mathrm{mg}-\mathrm{hr} \\
q & =10 \times 10^{-}\{-4\} \times 131 \\
& =0.131 \mathrm{mgoil} / \mathrm{mg} \text { of volatile }
\end{aligned}
$$

suspended solids-hr.

$=0.131 \times 7$ (day) $\times 24$

$=22 \mathrm{mg}$ oil/ $/ \mathrm{mg}$ of VSS

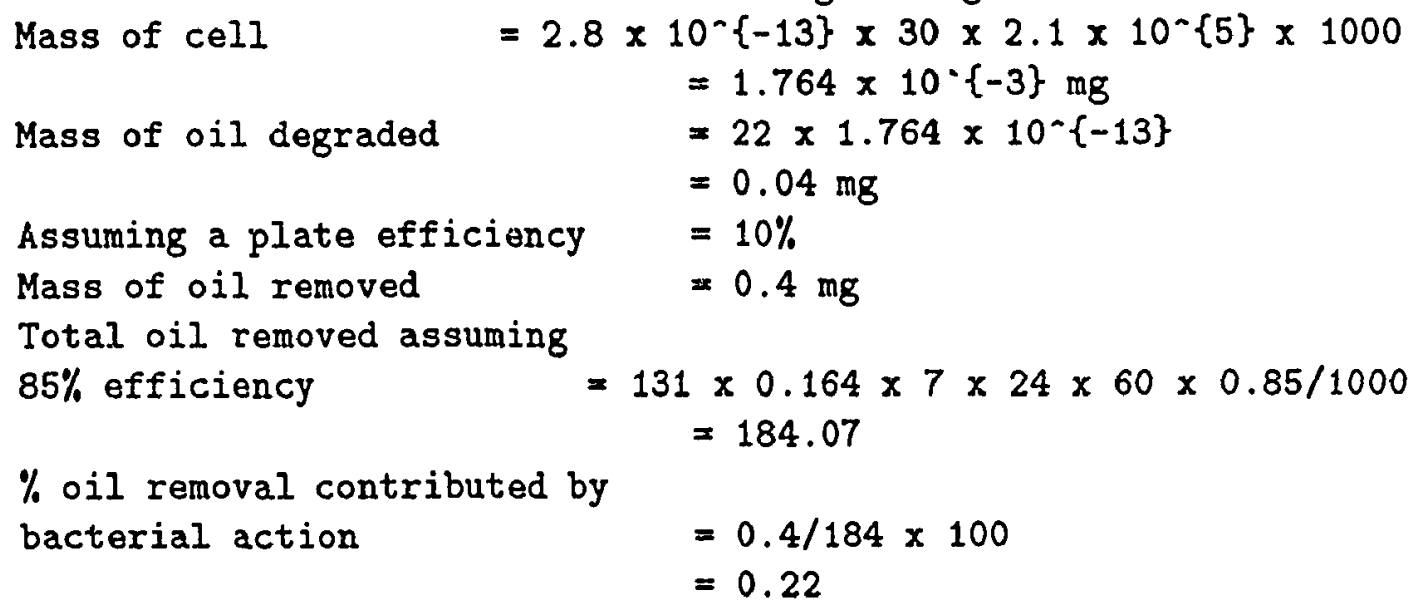




\title{
APPENDIX. F
}

\author{
RAW DATA
}

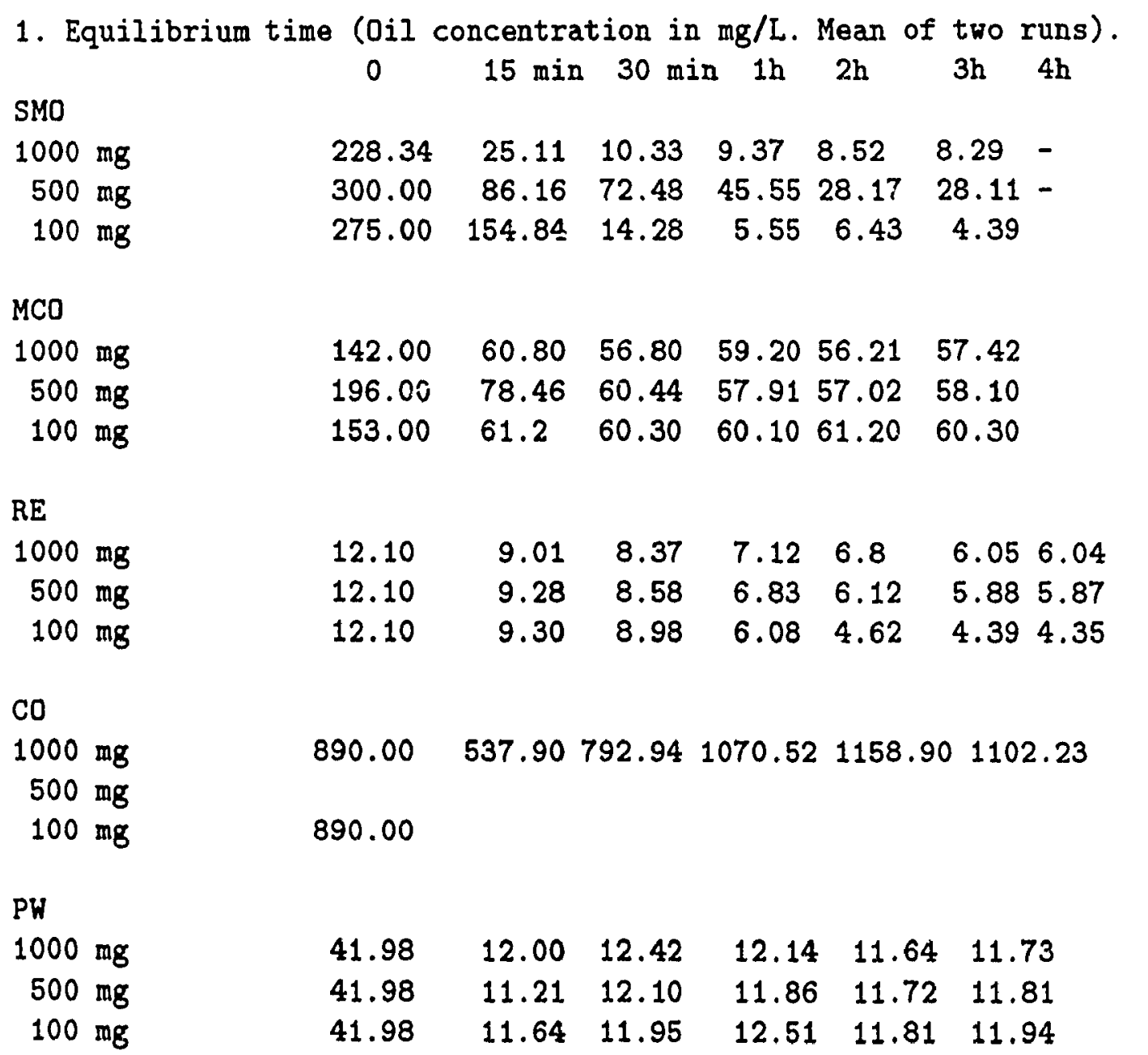

2. Leaching of peat

weight of

peat (mg)

$\begin{array}{cccc}\text { Leaching as } \mathrm{mg} / \mathrm{L} \text { of } & \text { oil } \\ \text { SMO } & M C O & \mathrm{CO} & \mathrm{RE}\end{array}$




$\begin{array}{rrrrrr}50 & 1.23 & 1.98 & 15.12 & 0.27 & 1.38 \\ 100 & 1.70 & 1.62 & 16.56 & 0.94 & 2.44 \\ 200 & 2.11 & 1.89 & 22.12 & 1.04 & 4.19 \\ 300 & 2.43 & 3.95 & 24.43 & 1.35 & 4.58 \\ 400 & 3.61 & 3.92 & 43.69 & 2.05 & 4.59 \\ 500 & 4.01 & 4.71 & 44.71 & 2.21 & 5.30\end{array}$

3. Batch adsorption experiments with horticultural peat:

$$
\text { SMO MCO CO RE PW }
$$

Initial oil concentration

$\begin{array}{rrrrrr}(\mathrm{mg} / \mathrm{L}) & 231.21 & 172.20 & 890.0 & 12.1 & 59.94 \\ 50 \mathrm{mg} & 19.57 & 40.21 & 154.11 & 10.89 & 36.54 \\ 100 \mathrm{mg} & 16.80 & 43.42 & 156.06 & 10.92 & 27.86 \\ 200 \mathrm{mg} & 29.10 & 33.13 & 155.45 & 10.52 & 26.06 \\ 300 \mathrm{mg} & 29.93 & 45.31 & 114.24 & 10.25 & 17.92 \\ 400 \mathrm{mg} & 31.07 & 63.12 & 122.28 & 8.92 & 15.06 \\ 50 \mathrm{rgg} & 29.41 & 39.83 & 135.38 & 6.84 & 9.66\end{array}$

4. Batch adsorption experiments with pretreated peat samples:

(I) With SMO emulsion:

Equilibrium oil concentration at the end of adsorption ( $\mathrm{mg} / \mathrm{L}$ )

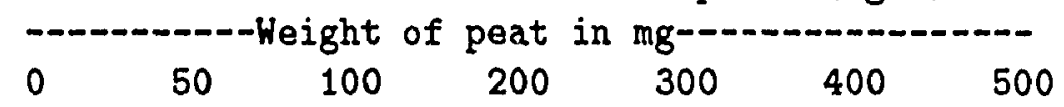

$\begin{array}{llrlrrrrr}\text { (i) } & \text { OD-1 } & 218.10 & 25.33 & 25.28 & 24.51 & 30.45 & 26.16 & 24.10 \\ \text { (ii) } & \text { OD-3 } & 183.26 & 31.96 & 31.91 & 39.46 & 22.23 & 33.52 & 38.17 \\ \text { (ii) } & \text { WH\&A } & 140.60 & 34.84 & 50.57 & 30.65 & 52.23 & 60.57 & 62.00 \\ \text { (iv) } & \text { WH\&O } & 193.29 & 8.64 & 8.34 & 7.13 & 7.07 & 5.82 & 3.35 \\ \text { (v) } & \text { ACID } & 226.45 & 23.48 & 22.75 & 17.90 & 16.83 & 9.22 & 8.48 \\ \text { (vi) } & \text { ALKALI } & 206.20 & 27.90 & 26.20 & 19.10 & 16.30 & 15 .- & 14.90 \\ \text { (vii) P150 } & 168.00 & 18.80 & 17.90 & 16.00 & 15.10 & 12.90 & 9.50 \\ \text { (viii) P200 } & 188.10 & 55.10 & 47.20 & 46.90 & 46.70 & 39.20 & 33.10 \\ \text { (ix) } \text { P225 } & 209.00 & 68.70 & 60.10 & 52.70 & 47.80 & 42.00 & 41.60 \\ \text { (x) } & \text { P250 } & 181.06 & 29.10 & 28.80 & 30.00 & 23.60 & 25.30 & 31.40 \\ \text { (xi) } \text { P275 } & 210.04 & 30.00 & 63.10 & 79.03 & 83.00 & 88.00 & 85.00\end{array}$

(II) With CO emulsion:

Equilibrium oil concentration at the end of adsorption ( $\mathrm{mg} / \mathrm{L}$ )

$\begin{array}{lllllllllll}0 & 50 & 100 & 150 & 200 & 250 & 300 & 350 & 400 & 450 & 500\end{array}$




$\begin{array}{llcrrrrrrrrrr}\text { (i) } & \text { HORT } & 128 & 98 & 67 & 77 & 79 & 40 & 43 & 51 & 66 & 50 & 41 \\ \text { (ii) } & \text { OD-1 } & 128 & 96 & 65 & 78 & 76 & 41 & 41 & 42 & 50 & 64 & 30 \\ \text { (iii) } & \text { OD-3 } & 128 & 97 & 91 & 88 & 79 & 53 & 50 & 51 & 52 & 49 & 47 \\ \text { (iv) } & \text { WH\&A } & 128 & 67 & 60 & 59 & 55 & 58 & 51 & 49 & 50 & 49 & 43 \\ \text { (v) } & \text { HH\&O } & 128 & 65 & 59 & 56 & 54 & 51 & 47 & 48 & 41 & 41 & 40 \\ \text { (vi) } & \text { ACID } & 128 & 86 & 80 & 75 & 59 & 51 & 54 & 56 & 50 & 51 & 43 \\ \text { (vii) } & \text { ALKALI } & 128 & 113 & 106 & 105 & 103 & 99 & 104 & 95 & 101 & 83 & 95 \\ \text { (viii) P150 } & 128 & 76 & 66 & 68 & 70 & 72 & 65 & 63 & 63 & 64 & 61 \\ \text { (ix) } & \text { P175 } & 128 & 78 & 69 & 62 & 75 & 70 & 70 & 69 & 63 & 66 & 63 \\ \text { (x) } & \text { P200 } & 128 & 40.1 & 39.3 & 42.7 & 36.9 & 34.2 & 38.8 & 31.5 & 32.2 & 33.1 & 30.3 \\ \text { (xi) } & \text { P225 } & 128 & 39.3 & 41.2 & 43.5 & 34.7 & 31.6 & 38.2 & 32.8 & 33.8 & 32.6 & 31.9 \\ \text { (xii) } & \text { P250 } & 128 & 44.6 & 43.9 & 43.5 & 45.7 & 42.4 & 39.1 & 33.1 & 32.9 & 34.0 & 30.6 \\ \text { (xiii) P275 } & 128 & 41.3 & 42.8 & 41.9 & 43.9 & 40.8 & 38.1 & 30.0 & 31.3 & 31.2 & 30.1\end{array}$

(III) With CO emulsion

Equilibrium oil concentration at the end of desorption:

\begin{tabular}{|c|c|c|c|c|c|c|c|c|c|c|c|c|}
\hline & & 0 & 50 & 100 & 150 & 200 & 250 & 300 & 350 & 400 & 450 & 500 \\
\hline (i) & HORT & 128 & 1.1 & 1.2 & 2.2 & 2.5 & 1.5 & 2.0 & 2.5 & 3.0 & 3.0 & 3.0 \\
\hline ii) & $O D-1$ & 128 & .9 & 1.1 & 1.8 & 2.2 & 1.0 & 1.8 & 2.0 & 2.8 & 3.1 & 2.9 \\
\hline (iii) & $O D-3$ & 128 & 1.0 & 1.6 & 2.3 & 2.2 & 1.5 & 1.9 & 2.0 & 2.3 & 2.8 & 3.0 \\
\hline (iv) & WH\&A & 28 & 1.7 & 1.7 & 2.8 & 1.8 & 2.9 & 2.4 & 3.0 & 2.7 & 3.8 & 2.9 \\
\hline (v) & WHEO & 28 & 0.9 & 1.7 & 1.9 & 1.9 & 2.1 & 2.4 & 2.3 & 2.6 & 2.9 & 3.2 \\
\hline$(v i)$ & ACID & 128 & 0.7 & 0.8 & 1.0 & 1.6 & 1.6 & 1.9 & 2.1 & 2.9 & 3.0 & 3.9 \\
\hline & ALKALI & 128 & 0.7 & 2.3 & 2.1 & 2.3 & 2.5 & 2.4 & 2.2 & 1.6 & 2.2 & 3.0 \\
\hline & P150 & 128 & 1.2 & 2.2 & 1.8 & 2.6 & 2.6 & 2.7 & 2.7 & 2.5 & 3.0 & 3.1 \\
\hline (xi) & P175 & 128 & 1.8 & 2.5 & 2.6 & 2.1 & 1.0 & 1.9 & 2.2 & 2.3 & 2.4 & 3 \\
\hline$(x)$ & P200 & 128 & 2.8 & 2.6 & 3.0 & 3.0 & 2.4 & 2.0 & 2.5 & 2.2 & 2.5 & 2. \\
\hline$(x i)$ & P225 & 128 & 2.2 & 2.5 & 2.7 & 3.2 & 2.7 & 3.1 & 3.2 & 3.5 & 2.6 & 3. \\
\hline & P250 & 128 & 2.5 & 2.3 & 1.7 & 2.8 & 2.3 & 3.0 & 2.2 & 3.0 & 2.4 & 3. \\
\hline$(x i i i)$ & 75 & 128 & 1.2 & 3.1 & 2.6 & 1.6 & 3.4 & 2.2 & 2.3 & 2.7 & 2.9 & 2.7 \\
\hline
\end{tabular}

5. 8-hour column experiments

I. Effluent oil concentrations with horticultural jeat (mg/L)

TIME (hours)

SMO $M C O \quad$ CO $\quad$ RE $\quad$ PW1 $\quad$ PW2

(i) FLOW $=12 \mathrm{~mL} / \mathrm{min}$ 0 $\begin{array}{lllll}215.39 & 212.18 & 715.25 & 7.18 & 28.19\end{array}$ 


\begin{tabular}{|c|c|c|c|c|c|c|}
\hline 1 & 0.51 & 0.74 & 25.03 & 0.49 & 5.41 & \\
\hline 2 & 1.08 & 0.85 & 27.18 & 0.36 & 5.52 & \\
\hline 3 & 1.49 & 0.67 & 18.60 & 0.42 & 5.65 & \\
\hline 4 & 1.24 & 1.08 & 20.03 & 0.89 & 5.59 & \\
\hline 5 & 0.82 & 0.92 & 13.59 & 0.94 & 6.01 & \\
\hline 6 & 0.82 & 1.94 & 12.87 & 0.92 & 5.55 & \\
\hline 7 & 0.82 & 0.85 & 14.31 & 0.54 & 5.34 & \\
\hline 8 & 0.82 & 1.01 & 19.31 & 0.65 & 5.56 & \\
\hline \multicolumn{7}{|c|}{$(i i) F L O W * 48 \mathrm{~mL} / \mathrm{min}$} \\
\hline 0 & 178.20 & 125.77 & 145.92 & 8.20 & & 537.14 \\
\hline 1 & 1.24 & 0.75 & 6.56 & 0.64 & & 87.65 \\
\hline 2 & 1.36 & 0.87 & 8.95 & 0.51 & & 86.21 \\
\hline 3 & 0.57 & 0.70 & 8.05 & 0.72 & & 94.40 \\
\hline 4 & 0.47 & 0.71 & 7.60 & 1.01 & & 102.37 \\
\hline 5 & 0.83 & 0.89 & 7.50 & 1.08 & & 102.86 \\
\hline 6 & 0.82 & 0.74 & 7.39 & 0.91 & & 102.01 \\
\hline 7 & 0.82 & 0.85 & 22.18 & 1.12 & & 101.95 \\
\hline 8 & 1.18 & 1.20 & 14.45 & 1.32 & & 102.84 \\
\hline \multicolumn{7}{|c|}{ (iii)FLOW $=300 \mathrm{~mL} / \mathrm{min}$} \\
\hline 0 & 178.20 & 142.84 & 164.220 & 5.37 & & 537.14 \\
\hline 1 & 12.12 & 3.21 & 54.23 & 0.91 & & 106.20 \\
\hline 2 & 8.17 & 3.42 & 51.16 & 1.08 & & 123.10 \\
\hline 3 & 5.13 & 5.84 & 47.38 & 2.01 & & 128.30 \\
\hline 4 & 6.72 & 5.48 & 39.29 & 2.82 & & 129.60 \\
\hline 5 & 7.48 & 5.50 & 21.52 & 1.91 & & 131.20 \\
\hline 6 & 2.91 & 4.64 & 19.35 & 1.48 & & 136.10 \\
\hline 7 & 4.61 & 4.20 & 18.88 & 2.32 & & 138.20 \\
\hline 8 & 4.39 & 4.51 & 20.09 & 2.02 & & 139.10 \\
\hline \multicolumn{7}{|c|}{ OFlow $=100 \mathrm{~mL} / \mathrm{min}$} \\
\hline \multicolumn{7}{|c|}{$\begin{array}{l}\text { 5. (a) 8-hour column experiments after backwashing: } \\
\text { Effluent oil concentration in } \mathrm{mg} / \mathrm{L} \\
\text { Flow }=12 \mathrm{~mL} / \mathrm{min}\end{array}$} \\
\hline 0 & 275.89 & 215.04 & 715.25 & 7.18 & & \\
\hline 1 & 0.74 & 0.84 & 22.89 & 0.81 & & \\
\hline 2 & 0.62 & 0.81 & 20.74 & 0.67 & & \\
\hline 3 & 0.68 & 0.97 & 17.88 & 0.62 & & \\
\hline 4 & 0.98 & 1.41 & 20.03 & 0.71 & & \\
\hline 5 & 1.05 & 1.61 & 23.60 & 0.42 & & \\
\hline 6 & 1.01 & 1.48 & 25.03 & 0.36 & & \\
\hline 7 & 0.90 & 1.21 & 26.46 & 0.58 & & \\
\hline
\end{tabular}


5. (b) 8-hour column experiments with other media

Effluent SMO concentration in $\mathrm{mg} / \mathrm{L}$

Diameter of the experimental column $=100 \mathrm{~mm}$

Flow $=2.9 \mathrm{~mL} / \mathrm{min}$

Depth of media $=300 \mathrm{~mm}$

Time(h) HORT COAL SAND XAD-2 AC PP FG WH\&O P150

\begin{tabular}{|c|c|c|c|c|c|c|c|c|c|}
\hline & & & & 66 & & & & & \\
\hline 1 & 4.3 & 82.4 & 5.9 & 1.9 & 1.3 & 6.1 & 6.6 & 20.4 & 7.7 \\
\hline$?$ & 2.1 & 86.7 & 4.2 & 3.7 & 1.5 & 10.7 & 5.2 & 10.7 & 3.2 \\
\hline & 3.7 & 88.2 & 18.7 & 3.4 & 2.0 & 13.1 & 11.5 & 6.2 & 3.8 \\
\hline & 6.1 & 89.1 & 18.7 & 2.3 & 1.1 & 12.7 & 9.1 & 5.2 & 3.3 \\
\hline & 2.1 & 91.2 & 37.2 & 2.9 & 0.9 & 16.2 & 10.5 & 4.1 & 3.5 \\
\hline & 1.9 & 88.6 & 36.8 & 3.6 & 1.2 & 12.8 & 10.6 & 4.3 & 3.5 \\
\hline & 3.6 & 91.2 & 38.1 & 3.5 & 1.6 & 15.6 & 10.9 & 4.5 & 3.1 \\
\hline & 3.1 & 90.1 & 37.5 & 3.3 & 1.4 & 14.2 & 11.4 & 4.7 & 3.3 \\
\hline
\end{tabular}

5. (c) 8-hour column experiments with other media

Effluent $\mathrm{CO}$ concentrtaion in $\mathrm{mg} / \mathrm{L}$

Diameter of experimental column $=100 \mathrm{~mm}$

Flow $=2.9 \mathrm{~mL} / \mathrm{min}$

Depth of media $=300 \mathrm{~mm}$

$\begin{array}{cccccccccc}\text { Time }(\mathrm{h}) & \text { HORT } & \text { COAL } & \text { SAND } & \text { XAD-2 } & \text { AC } & \text { PP } & \text { FG } & \text { WH\&O } & \text { P150 } \\ 0 & -120 & 120 & 128 & 67 & 44 & 100 & 135 & 97 & 92 \\ 1 & 101 & 118 & 129 & 67 & 45 & 94 & 126 & 98 & 87 \\ 2 & 106 & 118 & 128 & 68 & 47 & 99 & 130 & 94 & 92 \\ 3 & 108 & 122 & 128 & 130 & 101 & 97 \\ 4 & 107 & 121 & 130 & 70 & 48 & 103 & 139 & 101 \\ 5 & 111 & 125 & 132 & 68 & 50 & 108 & 129 & 103 & 99 \\ 6 & 110 & 123 & 135 & 65 & 53 & 106 & 141 & 107 & 103 \\ 7 & 114 & 126 & 137 & 49 & 51 & 107 & 143 & 111 & 101 \\ 8 & 118 & 127 & 139 & 47 & 52 & 112 & 144 & 115 & 105\end{array}$

6. Continuous column experiments (Breakthrough).

Flow rate $=50 \mathrm{~mL} / \mathrm{min}$ for $\mathrm{SMO}, \mathrm{MCO}$ and $\mathrm{PW}$

Flow rate $=25 \mathrm{~mL} / \mathrm{min}$ for $\mathrm{CO}$ and $\mathrm{RE}$

Mean of two readings

Peat depth $=300 \mathrm{~mm}$ 


\section{Time (hours)}

0

8

16

24

32

40

48

56

64

72

80

88

96

104

112

120

128

136

144

152

160

168

176

184

192

200

208

216

224

232

240

248

256

264

272

280

288

296 $\begin{array}{llll}- & & & \\ \text { SMO } & \text { MCO } & \text { CO } & \text { RE }\end{array}$

$\begin{array}{lllll}193.26 & 201.32 & 278.20 & 8.91 & 38.40\end{array}$

1.89

$1.25 \quad 72.24$

1. 28

3.41

0.82

1.14

81.65

1.26

4.01

0.93

1.04

110.09

1.33

1.38

1.59

2.15

114.54

114.21

1.83

1.64

1.72

1.54

1.74

1.85

1.62

1.91

1.85

1.76

1.72

1.76

1.84

1.81

1.76

1.95

1.96

1.98

2.01

1.97

2.05

2.10

2.15

2.61

3.55

3.85

3.94

4.81

5.26

5.41

5.34

6.71

4.10

4.90

3. 28

3.41

3.62

3.94

4.08

5.21

3.96

4.15

5.34

5.61

5.42

5.62

5,94

6.21

5.84

6.01

6.10

8.21

3.01

10.10

12.95

14.05

15.15

19.25

19.76

19.85

54.24

30.06

24.62

83.92

39.24

44.90

50.20

28.75

51.41

30.21

52.21

37.28

312 


$\begin{array}{lrl}304 & 54.28 & 6.75 \\ 312 & 68.96 & 7.10 \\ 320 & 75.21 & 8.26 \\ 328 & 96.42 & \\ 336 & 98.21 & \\ 344 & 142.24 & \\ 352 & 161.21 & \\ 360 & 186.98 & \end{array}$

7. Breakdown mechanism

(a)Filtration experiments (single-phase flow)

Mean of two readings

Horticultural peat with emulsified SMO-in-water emulsion

\begin{tabular}{|c|c|c|c|c|c|c|}
\hline \multirow[t]{2}{*}{ Flow (mL/min) } & \multicolumn{6}{|c|}{ - Pressure drop in $m$ head of water } \\
\hline & 200 & 300 & $4.00^{2}$ & 600 & 800 & 1000 \\
\hline 165 & 0.006 & 0.0105 & 0.02 & 0.0547 & 0.096 & 0.11 \\
\hline 198 & 0.018 & 0.03 & 0.044 & 0.108 & 0.20 & 0.25 \\
\hline 231 & 0.038 & 0.060 & 0.112 & 0.18 & 0.282 & 0.35 \\
\hline 264 & 0.042 & 0.084 & 0.162 & 0.252 & 0.384 & 0.55 \\
\hline 297 & 0.0505 & 0.123 & 0.241 & 0.342 & 0.480 & 0.689 \\
\hline 331 & 0.1194 & 0.20 & 0.35 & 0.51 & 0.7599 & 1.050 \\
\hline
\end{tabular}

(b) For two-phase flow

llean of two readings

Emulsified SMO concentration $=1.31 .00 \mathrm{mg} / \mathrm{L}$

Flow (mL/min)

----pressure drop in $m$ head of water-.-.--

$\begin{array}{llllll}200 & 300 & 400 & 600 & 800 & 1000 \\ 0.007 & 0.0195 & 0.0480 & 0.1224 & 0.1942 & 0.3142 \\ 0.0205 & 0.04101 & 0.0620 & 0.195 & 0.3710 & 0.5061 \\ 0.047 & 0.0810 & 0.150 & 0.3270 & 0.520 & 0.700 \\ 0.048 & 0.1089 & 0.2190 & 0.4609 & 0.644 & 1.010 \\ 0.0595 & 0.1809 & 0.333 & 0.5405 & 0.8818 & 1.3311 \\ 0.1200 & 0.29497 & 0.4359 & 0.8701 & 1.3598 & 2.0502\end{array}$

(c) Coalescence (Mean of two readings)

Flow (mL/min)

Time

$200 \quad 300 \quad 400 \quad 600 \quad 800 \quad 1000$

313 
(i) Effluent oil concentration ( $\mathrm{mg} / \mathrm{L}$ )

165

\begin{tabular}{|c|c|c|c|c|c|c|}
\hline & & & & & & \\
\hline 1 & 1.7 & 1.5 & 1.2 & 1.8 & 1.9 & 1.6 \\
\hline 2 & 1.9 & 1.8 & 1.6 & 1.9 & 2.1 & 1.8 \\
\hline 3 & 2.5 & 2.1 & 2.3 & 1.7 & 3.2 & 1.9 \\
\hline 4 & 3.4 & 3.1 & 2.6 & 1.8 & 3.6 & 2.6 \\
\hline 5 & 3.5 & 3.3 & 2.4 & 2.6 & 2.1 & 2.1 \\
\hline 6 & 4.4 & 3.6 & 2.9 & 3.1 & 3.7 & 2.5 \\
\hline 7 & 4.7 & 3.3 & 3.1 & 3.1 & 2.8 & 2.7 \\
\hline 8 & 4.9 & 3.2 & 2.7 & 4.1 & 3.4 & 2.5 \\
\hline 9 & 4.8 & 3.6 & 2.6 & 3.7 & 2.4 & 3.3 \\
\hline 10 & 4.8 & 3.5 & 2.7 & 3.3 & 2.6 & 3.1 \\
\hline 11 & 4.7 & 3.7 & 3.1 & 2.8 & 2.6 & 3.1 \\
\hline 12 & 4.6 & 4.1 & 3.6 & 1.9 & 3.5 & 3.1 \\
\hline 13 & 5.3 & 4.2 & 3.1 & 2.7 & 3.1 & 3.7 \\
\hline 14 & 5.4 & 3.3 & 4.1 & 2.3 & 3.3 & 3.5 \\
\hline 15 & 5.0 & 4.3 & 3.8 & 2.5 & 3.8 & 3.7 \\
\hline 16 & 5.6 & 4.2 & 4.5 & 2.4 & 3.6 & 3.7 \\
\hline
\end{tabular}

(ii) Diameter of the oil droplets (micro meter)

$\begin{array}{rrrrrrr}1 & 9.4 & 9.4 & 10.9 & 9.5 & 9.4 & 8.1 \\ 2 & 9.6 & 10.2 & 9.6 & 9.4 & 9.1 & 8.5 \\ 3 & 10.2 & 8.8 & 9.1 & 8.6 & 8.3 & 9.9 \\ 4 & 9.6 & 7.4 & 7.9 & 7.1 & 7.9 & 7.8 \\ 5 & 13.6 & 8.9 & 7.8 & 7.2 & 8.1 & 7.5 \\ 6 & 8.1 & 7.7 & 7.3 & 6.2 & 6.1 & 7.1 \\ 7 & 9.0 & 8.7 & 6.7 & 6.9 & 7.8 & 6.3 \\ 8 & 11.9 & 11.1 & 8.1 & 5.1 & 6.2 & 6.2 \\ 9 & 9.9 & 8.6 & 6.5 & 5.5 & 7.5 & 6.0 \\ 10 & 10.3 & 8.1 & 6.1 & 6.7 & 7.1 & 5.5 \\ 11 & 9.5 & 7.9 & 5.9 & 6.5 & 15.8 & 6.1 \\ 12 & 10.9 & 7.8 & 5.2 & 5.8 & 7.2 & 5.9 \\ 13 & 11.6 & 6.1 & 6.3 & 6.8 & 6.8 & 6.1 \\ 14 & 9.4 & 7.6 & 5.9 & 6.8 & 7.5 & 6.4 \\ 15 & 10.1 & 7.3 & 6.8 & 7.1 & 8.2 & 7.1 \\ 16 & 10.3 & 6.6 & 5.1 & 7.9 & 6.5 & 8.1\end{array}$

(iii) Drop density (Nos./cubic centimeter)

$$
\begin{array}{rrrrrrr}
1 & 120.5 & 103.1 & 107.8 & 105.9 & 101.1 & 99.3 \\
2 & 102.1 & 111.1 & 103.1 & 100.6 & 99.8 & 94.4
\end{array}
$$




$\begin{array}{rrrrrrr}3 & 110.6 & 105.9 & 110.6 & 90.7 & 95.6 & 91.3 \\ 4 & 100.7 & 110.7 & 100.9 & 92.9 & 89.5 & 94.3 \\ 5 & 117.9 & 110.6 & 99.4 & 96.5 & 97.5 & 90.7 \\ 6 & 120.9 & 110.6 & 98.5 & 93.3 & 83.7 & 89.6 \\ 7 & 115.0 & 100.9 & 94.7 & 91.9 & 90.5 & 87.7 \\ 8 & 100.0 & 101.2 & 98.6 & 90.6 & 99.8 & 85.4 \\ 9 & 119.1 & 109.4 & 92.1 & 94.7 & 96.8 & 87.3 \\ 10 & 116.9 & 110.4 & 93.7 & 92.8 & 99.2 & 101.0 \\ 11 & 106.7 & 109.7 & 90.7 & 90.9 & 100.9 & 96.1 \\ 12 & 101.7 & 102.6 & 89.5 & 90.9 & 101.7 & 91.2 \\ 13 & 112.3 & 105.7 & 85.7 & 91.0 & 99.3 & 91.6 \\ 14 & 109.2 & 100.3 & 84.8 & 92.8 & 91.7 & 93.8 \\ 15 & 106.9 & 99.1 & 84.9 & 84.6 & 90.7 & 90.6 \\ 16 & 102.9 & 110.1 & 80.9 & 90.6 & 101.7 & 89.66 \\ 16 & 102.9 & 110.1 & 80.9 & 90.6 & 101.7 & 89.6\end{array}$

Flow (mL/min) $200 \quad 300 \quad 400 \quad 600 \quad 800 \quad 1000$

(i) Effluent o.il concentration (mg/L) 198

$\begin{array}{rrrrrrr}0 & 1.9 & 1.5 & 1.7 & 1.1 & 1.0 & 0.9 \\ 2 & 1.9 & & & & & \\ 3 & 1.8 & 1.9 & 1.6 & 0.9 & 0.9 & 1.3 \\ 4 & 1.4 & 2.1 & 1.4 & 0.8 & 1.1 & 1.1 \\ 4 & 3.2 & 2.8 & 1.9 & 0.9 & 1.5 & 1.2 \\ 5 & 3.6 & 3.3 & 1.2 & 0.8 & 0.8 & 1.7 \\ 6 & 3.1 & 2.8 & 1.6 & 1.1 & 1.3 & 0.9 \\ 7 & 4.1 & 3.7 & 1.5 & 1.4 & 1.2 & 1.4 \\ 8 & 4.2 & 2.8 & 1.0 & 1.7 & 1.7 & 1.7 \\ 9 & 4.3 & 2.6 & 1.9 & 1.8 & 1.2 & 1.7 \\ 10 & 3.4 & 3.3 & 1.8 & 2.0 & 0.9 & 1.8 \\ 11 & 3.3 & 4.5 & 1.2 & 1.9 & 1.1 & 1.3 \\ 12 & 3.4 & 4.1 & 1.8 & 2.1 & 1.6 & 1.2\end{array}$

(ii) Diameter of the oil droplets (micro meter) 198

$\begin{array}{rrrrrrr}1 & 7.3 & 5.0 & 4.6 & 4.3 & 5.1 & 4.7 \\ 2 & 6.6 & 6.1 & 4.9 & 3.1 & 4.1 & 4.9 \\ 3 & 7.4 & 5.4 & 4.5 & 4.6 & 4.6 & 5.1 \\ 4 & 10.3 & 7.1 & 5.0 & 4.3 & 5.5 & 4.1 \\ 5 & 6.9 & 4.7 & 5.1 & 5.3 & 5.8 & 5.3\end{array}$




$\begin{array}{rrrrrrr}6 & 7.4 & 5.3 & 5.4 & 5.1 & 5.9 & 5.2 \\ 7 & 8.4 & 5.5 & 4.9 & 5.7 & 4.9 & 6.0 \\ 8 & 7.1 & 5.1 & 4.1 & 5.0 & 4.9 & 6.0 \\ 9 & 8.1 & 6.3 & 6.1 & 5.9 & 4.6 & 4.9 \\ 10 & 10.1 & 7.1 & 4.9 & 5.2 & 5.7 & 5.1 \\ 11 & 8.4 & 7.0 & 6.9 & 6.1 & 3.9 & 5.3 \\ 12 & 8.7 & 7.9 & 5.4 & 7.8 & 4.8 & 5.0\end{array}$

(iii) Drop density (Nos./cubic centineter) 198

$\begin{array}{rrrrrrr}1 & 110.1 & 90.8 & 90.0 & 89.0 & 76.9 & 77.9 \\ 2 & 109.5 & 95.9 & 99.9 & 88.1 & 79.9 & 76.9 \\ 3 & 106.9 & 98.7 & 89.5 & 98.8 & 78.9 & 76.8 \\ 4 & 108.5 & 99.4 & 87.8 & 89.9 & 80.8 & 75.4 \\ 5 & 102.9 & 98.3 & 86.5 & 89.6 & 79.4 & 80.5 \\ 6 & 112.8 & 89.9 & 89.9 & 83.8 & 78.8 & 81.8 \\ 7 & 113.9 & 98.4 & 88.3 & 86.6 & 78.2 & 85.7 \\ 8 & 100.7 & 87.2 & 89.7 & 90.9 & 80.0 & 74.8 \\ 9 & 101.8 & 97.6 & 83.6 & 83.2 & 79.9 & 88.1 \\ 10 & 102.8 & 99.8 & 87.1 & 84.3 & 81.8 & 75.8 \\ 11 & 104.6 & 94.1 & 89.5 & 91.6 & 87.8 & 77.2 \\ 12 & 100.1 & 100.1 & 90.8 & 98.6 & 78.8 & 72.1\end{array}$

Flow (mL/min) Time -.-1-n---- Peat depth in $\mathrm{mm}-100$ (i) Effluent oil concentration (mg/L) 231

\begin{tabular}{|c|c|c|c|c|c|}
\hline 1 & 1.1 & 0.9 & 1.7 & 1.0 & 0.9 \\
\hline 2 & 2.8 & 0.8 & 1.9 & 1.1 & 0.9 \\
\hline 3 & 1.2 & 1.0 & 1.7 & 2.9 & 0.7 \\
\hline 4 & 4.1 & 1.1 & 1.1 & 2.6 & 1.1 \\
\hline 5 & 2.7 & 2.1 & 1.8 & 3.6 & 1.7 \\
\hline 6 & 3.3 & 0.6 & 1.9 & 3.9 & 1.1 \\
\hline 7 & 4.2 & 1.1 & 1.5 & 4.1 & 1.4 \\
\hline 8 & 3.4 & 0.7 & 1.8 & 4.8 & 2.1 \\
\hline 9 & 4.3 & 1.1 & 2.1 & 3.8 & 1.2 \\
\hline 10 & 4.1 & 1.0 & 3.1 & 2.9 & 0.9 \\
\hline
\end{tabular}

(ii) Diameter of oil droplets (micro meter) 231

$\begin{array}{lllllll}1 & 6.8 & 6.0 & 5.0 & 5.4 & 6.0 & 4.2 \\ 2 & 7.8 & 6.0 & 6.8 & 4.8 & 5.2 & 5.7\end{array}$




$\begin{array}{rrrrrrr}3 & 6.9 & 5.3 & 7.1 & 4.5 & 5.3 & 5.0 \\ 4 & 6.2 & 7.0 & 7.0 & 5.5 & 5.1 & 4.0 \\ 5 & 9.8 & 5.7 & 5.8 & 5.1 & 4.1 & 5.1 \\ 6 & 10.1 & 6.2 & 5.1 & 6.6 & 5.5 & 4.9 \\ 7 & 6.8 & 5.1 & 6.1 & 5.8 & 5.1 & 6.1 \\ 8 & 7.7 & 6.3 & 6.2 & 5.9 & 6.2 & 5.8 \\ 9 & 6.3 & 6.3 & 6.1 & 6.1 & 6.1 & 5.8 \\ 10 & 6.1 & 6.9 & 5.2 & 6.2 & 5.1 & 5.4\end{array}$

(iii) Drop density (Nos./cubic centimeter)

231

$\begin{array}{rrrrrrr}1 & 100.8 & 91.8 & 89.2 & 88.7 & 88.9 & 71.8 \\ 2 & 98.5 & 98.1 & 88.8 & 99.4 & 87.9 & 79.9 \\ 3 & 102.7 & 88.6 & 82.9 & 98.8 & 85.9 & 76.4 \\ 4 & 94.7 & 89.9 & 102.9 & 81.6 & 93.1 & 79.5 \\ 5 & 94.8 & 93.7 & 101.7 & 85.8 & 79.6 & 85.6 \\ 6 & 110.8 & 94.7 & 100.9 & 86.1 & 81.9 & 88.6 \\ 7 & 92.8 & 81.1 & 88.8 & 95.8 & 92.9 & 78.7 \\ 8 & 99.9 & 94.1 & 89.9 & 79.3 & 86.1 & 87.8 \\ 9 & 105.1 & 95.7 & 98.7 & 87.6 & 97.6 & 83.9 \\ 10 & 101.8 & 102.9 & 78.6 & 89.1 & 91.9 & 80.9\end{array}$

Flow (mL/min) Time -Peat depth

(i) Effluent oil concentration (mg/L) 264

$\begin{array}{lllllll}0 & -1.5 & 2.1 & 1.1 & 1.0 & 0.9 \\ 2 & 2.1 & 2.5 & 1.9 & 1.7 & 0.9 & 1.2 \\ 3 & 5.1 & 2.8 & 2.4 & 1.8 & 1.7 & 0.8 \\ 4 & 6.8 & 3.7 & 3.1 & 2.5 & 2.0 & 0.9 \\ 5 & 4.7 & 1.9 & 3.6 & 2.9 & 1.4 & 1.1 \\ 6 & 5.1 & 2.4 & 4.0 & 1.8 & 1.2 & 1.0 \\ 7 & 6.8 & 4.0 & 3.6 & 1.9 & 1.9 & 0.9 \\ 8 & 6.3 & 5.1 & 3.1 & 2.7 & 0.7 & 1.4\end{array}$

(ii) Diameter of ol droplets (micro meter)

$\begin{array}{rrrrrrrr}264 & 1 & 12.8 & 7.5 & 8.8 & 5.1 & 6.0 & 6.3 \\ & 2 & 11.5 & 7.8 & 6.8 & 4.9 & 6.8 & 5.6 \\ 3 & 10.6 & 7.1 & 7.7 & 5.1 & 5.0 & 5.1 \\ & 4 & 9.5 & 5.8 & 7.5 & 5.7 & 6.1 & 6.0 \\ & 5 & 12.1 & 4.6 & 5.1 & 7.8 & 4.1 & 4.4\end{array}$




$\begin{array}{rrrrrrr}6 & 11.3 & 5.8 & 6.3 & 6.5 & 5.5 & 5.3 \\ 7 & 12.0 & 6.1 & 8.0 & 7.1 & 5.1 & 4.8 \\ 8 & 9.9 & 6.7 & 7.5 & 6.9 & 6.2 & 4.1\end{array}$

(iii) Drop density (Nos./Cubic centimeter) 264

$\begin{array}{rrrrrrr}1 & 200.8 & 95.8 & 100.6 & 87.6 & 76.5 & 72.8 \\ 2 & 201.0 & 90.4 & 98.4 & 78.9 & 78.4 & 75.7 \\ 3 & 197.2 & 100.5 & 91.2 & 97.6 & 69.7 & 73.7 \\ 4 & 165.3 & 94.8 & 102.7 & 80.3 & 61.4 & 65.6 \\ 5 & 150.1 & 82.8 & 96.5 & 86.5 & 62.6 & 66.8 \\ 6 & 200.0 & 98.9 & 97.1 & 78.6 & 66.1 & 69.9 \\ 7 & 160.7 & 89.7 & 78.4 & 85.1 & 77.6 & 70.5 \\ 8 & 176.1 & 87.8 & 80.6 & 80.1 & 77.1 & 67.8\end{array}$

Flow (mL/min) Time -1.-1-neat depth in $\begin{array}{llllll}200 & 300 & 400 & 600 & 800 & 1000\end{array}$

(i) Effluent oil concentration ( $\mathrm{mg} / \mathrm{L}$ ) 297

$\begin{array}{lllllll}0 & -1.5 & 2.0 & 1.0 & 0.9 & 0.9 \\ 1 & 1.9 & 1.5 & 1.5 & 0.9 & 1.0 \\ 2 & 4.2 & 2.7 & 2.1 & 1.5 & 1.9 & 0.8 \\ 3 & 4.7 & 3.5 & 1.5 & 1.9 & 1.0 & 0.8 \\ 4 & 6.3 & 4.6 & 2.1 & 2.9 & 1.2 & 0.0 \\ 5 & 6.6 & 3.2 & 2.2 & 2.5 & 1.0 & 1.0 \\ 6 & 6.8 & 3.3 & 3.0 & 2.8 & 1.2 & 1.0\end{array}$

(ii) Diameter of oil droplets (micro meter)

297

$\begin{array}{rrrrrrr}1 & 11.9 & 6.7 & 5.5 & 5.0 & 6.1 & 6.8 \\ 2 & 8.8 & 6.9 & 4.9 & 5.9 & 5.9 & 5.3 \\ 3 & 11.8 & 7.1 & 6.3 & 6.0 & 5.1 & 5.9 \\ 4 & 9.7 & 7.8 & 6.9 & 6.8 & 5 & 5.0 \\ 5 & 8.3 & 6.9 & 6.1 & 4.9 & 6.4 & 4.9 \\ 6 & 10.1 & 7.8 & 7.5 & 6.1 & 5.4 & 4.3\end{array}$

(iii) Drop density (Nos./cubic centimeter) 297

$\begin{array}{lllllll}1 & 187.5 & 95.4 & 88.7 & 80.2 & 71.3 & 74.4 \\ 2 & 190.6 & 91.9 & 83.5 & 78.8 & 71.3 & 71.6 \\ 3 & 165.8 & 90.1 & 80.1 & 78.8 & 72.8 & 70.6 \\ 4 & 178.8 & 82.2 & 77.1 & 80.7 & 71.8 & 65.3 \\ 5 & 165.6 & 91.1 & 83.4 & 75.8 & 69.6 & 69.3 \\ 6 & 181.1 & 90.0 & 81.2 & 74.6 & 71.4 & 70.7\end{array}$

318 


\begin{tabular}{|c|c|c|c|c|c|c|c|}
\hline \multicolumn{2}{|c|}{ Flow (mL/min) } & \multicolumn{6}{|c|}{ - Peat depth in $\mathrm{mm}$} \\
\hline \multicolumn{2}{|c|}{ Time } & 200 & 300 & $400^{-}$ & 600 & 800 & 1000 \\
\hline \multicolumn{8}{|c|}{ (i) Iffluent oil concentration (mg/L) } \\
\hline \multirow[t]{6}{*}{331} & 0 & & & ---13 & $0--\infty$ & --- & $--\infty$ \\
\hline & 1 & 3.1 & 2.9 & 1.5 & 1.6 & 1.0 & 1.5 \\
\hline & 2 & 4.8 & 3.8 & 2.7 & 2.0 & 1.8 & 2.0 \\
\hline & 3 & 5.9 & 4.0 & 1.9 & 2.6 & 2.9 & 2.2 \\
\hline & 4 & 6.2 & 5.1 & 3.8 & 3.1 & 4.4 & 3.2 \\
\hline & 5 & 7.9 & 5.6 & 3.7 & 3.6 & 4.8 & 4.1 \\
\hline
\end{tabular}

(ii) Diameter of oil droplets (micron)

\begin{tabular}{|c|c|c|c|c|c|c|c|}
\hline \multirow[t]{5}{*}{331} & 1 & 10.6 & 12.1 & 10.7 & 11.5 & 6.0 & 6.2 \\
\hline & 2 & 11.9 & 10.7 & 10.1 & 11.1 & 6.5 & 5.7 \\
\hline & 3 & 10.8 & 12.7 & 8.4 & 10.7 & 5.7 & 5.8 \\
\hline & 4 & 9.9 & 10.2 & 9.2 & 9.8 & 4.7 & 4.8 \\
\hline & 5 & 9.1 & 9.6 & 9.4 & 9.7 & 6.5 & 5.0 \\
\hline
\end{tabular}

(iii) Drop density (Nos./cubic centimeter) 331

$\begin{array}{rrrrrrr}1 & 300.8 & 158.3 & 95.5 & 110.0 & 106.8 & 93.9 \\ 2 & 270.6 & 143.1 & 94.6 & 92.2 & 100.0 & 92.1 \\ 3 & 230.8 & 131.1 & 91.2 & 80.1 & 97.4 & 90.3 \\ 4 & 234.8 & 148.2 & 90.8 & 80.6 & 99.2 & 85.5 \\ 5 & 221.8 & 135.2 & 88.7 & 78.3 & 103.2 & 82.7\end{array}$

(i) Batch adsorption experiments

$\begin{array}{cc}\text { Weight of peat (mg) } & \begin{array}{c}\text { Effluent oil concentration at the end of } \\ \text { equilibrium time in nig/L }\end{array} \\ 0 & 131 \\ 50 & 98 \\ 100 & 67 \\ 150 & 77 \\ 200 & 79 \\ 250 & 40 \\ 300 & 43 \\ 350 & 51\end{array}$




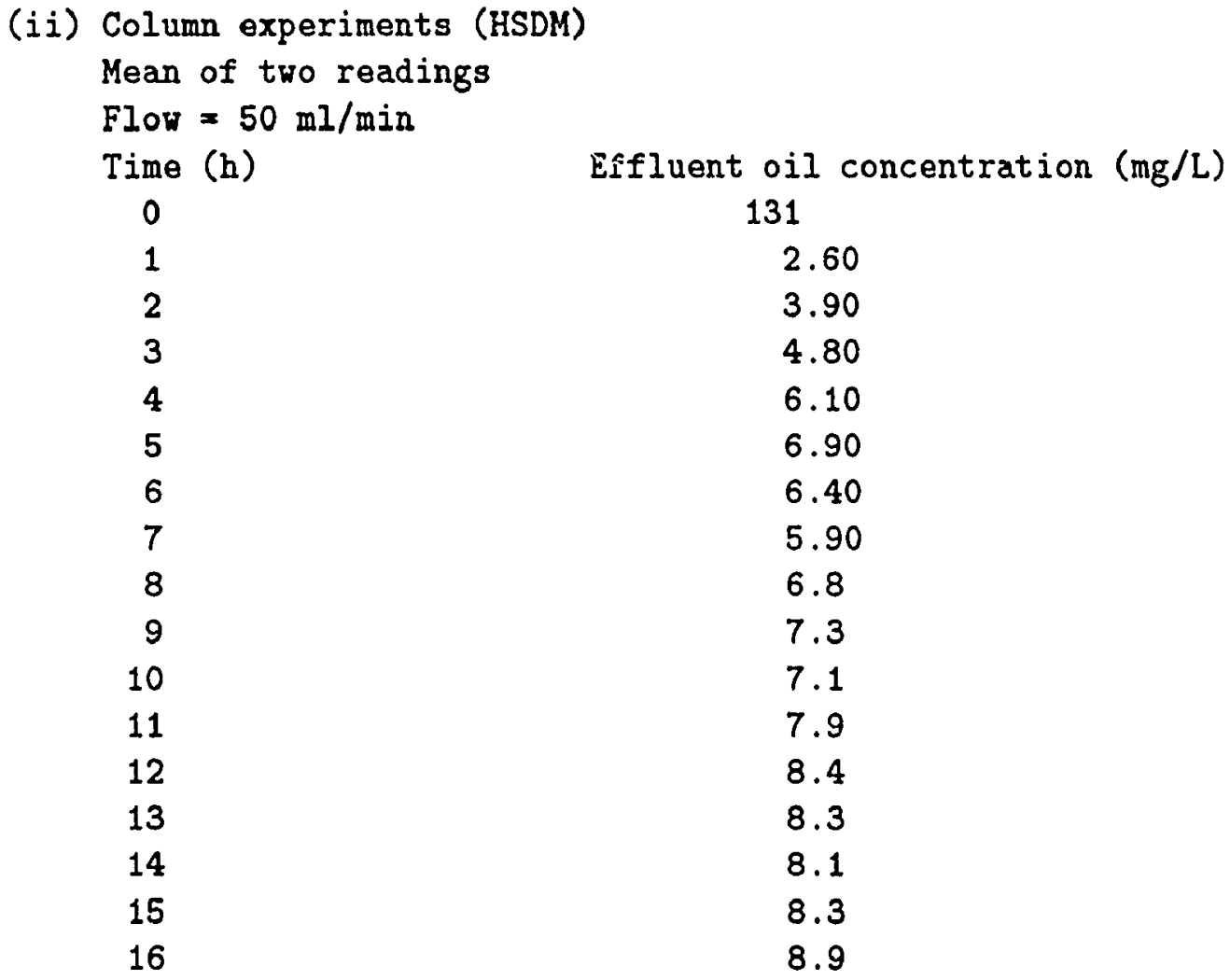

